\title{
Aggression and Impulsitivity: Two of a kind ?
}

Citation for published version (APA):

Tonnaer, F. M. C. L. (2018). Aggression and Impulsitivity: Two of a kind ? Theory, provocation paradigms and neurocorrelates of aggression and impulsitivity in a forensic population. [Doctoral Thesis, Maastricht University]. Maastricht University. https://doi.org/10.26481/dis.20181220ft

Document status and date:

Published: 01/01/2018

DOI:

10.26481/dis.20181220ft

Document Version:

Publisher's PDF, also known as Version of record

\section{Please check the document version of this publication:}

- A submitted manuscript is the version of the article upon submission and before peer-review. There can be important differences between the submitted version and the official published version of record.

People interested in the research are advised to contact the author for the final version of the publication, or visit the DOI to the publisher's website.

- The final author version and the galley proof are versions of the publication after peer review.

- The final published version features the final layout of the paper including the volume, issue and page numbers.

Link to publication

\footnotetext{
General rights rights.

- You may freely distribute the URL identifying the publication in the public portal. please follow below link for the End User Agreement:

www.umlib.nl/taverne-license

Take down policy

If you believe that this document breaches copyright please contact us at:

repository@maastrichtuniversity.nl

providing details and we will investigate your claim.
}

Copyright and moral rights for the publications made accessible in the public portal are retained by the authors and/or other copyright owners and it is a condition of accessing publications that users recognise and abide by the legal requirements associated with these

- Users may download and print one copy of any publication from the public portal for the purpose of private study or research.

- You may not further distribute the material or use it for any profit-making activity or commercial gain

If the publication is distributed under the terms of Article $25 \mathrm{fa}$ of the Dutch Copyright Act, indicated by the "Taverne" license above, 


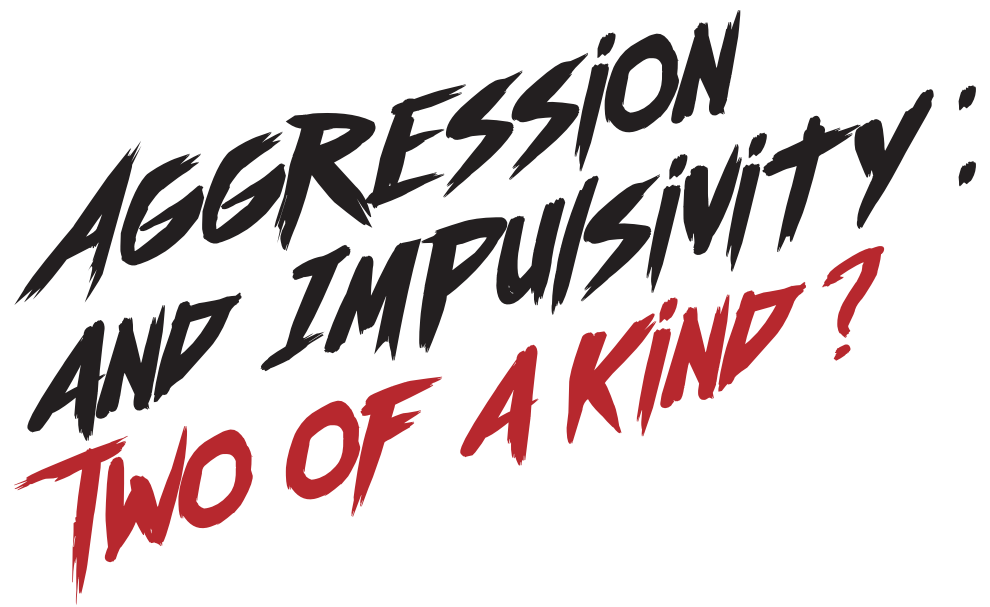

Theory, provocation paradigms and neurocorrelates of aggression and impulsivity in a forensic population

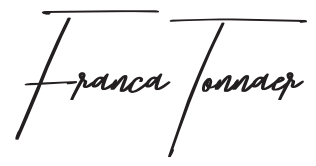


"Anybody can become angry - that is easy,

but to be angry with the right person and to the right degree and at the right time and for the right purpose, and in the right way

- that is not within everybody's power and is not easy."

Aristotle

Cover design Hoenenenvandooren, creatieve communicatie. Inspired by the Bad Brains.

Printing Hoenenenvandooren, creatieve communicatie ISBN 978-90-90312446-0

(C) Franca Tonnaer, Maastricht, 2018

No parts of this thesis may be reproduced, stored in a retrieval system, or transmitted, in any forms or by any means, electronically, mechanically, by photocopying, recording or otherwise, without prior written permission of the author. 


\title{
Aggression and Impulsivity: Two of a kind?
}

\author{
Theory, provocation paradigms and neurocorrelates of \\ aggression and impulsivity in a forensic population
}

Proefschrift

ter verkrijging van de graad van doctor aan de Universiteit Maastricht op gezag van de rector magnificus, Prof. dr. Rianne M. Letschert volgens het besluit van het college van Decanen, in het openbaar te verdedigen op donderdag 20 december 2018 om 14.00 uur door Franca Maria Catharina Leonie Tonnaer 


\section{Promotores}

Prof. dr. A. R. Arntz (Universiteit van Amsterdam)

Prof. dr. M. J. Cima (Radboud Universiteit, Nijmegen)

\section{Beoordelingscommissie}

Prof. dr. M. Jelicic (voorzitter)

Prof. dr. P. J. van Koppen (Vrije Universiteit, Universiteit Maastricht)

Dr. J. Lobbestael

Prof. dr. H. L. I. Nijman (Radboud Universiteit)

Dr. S. Verwaaijen (Conrisq Groep) 


\section{Contents}

General Introduction

\section{Part II - Neurocognitive vulnerability factors of provoked reactive aggression}

Chapter 3 Explosive matters: does venting anger reduce or increase aggression?

Differences in anger venting effects in violent offenders

Chapter 4 Executive (dys)functioning and impulsivity as possible vulnerability factors for aggression in forensic patients

Chapter 5 Anger provocation increases limbic and decreases medial prefrontal cortex connectivity with the left amygdala in reactive aggressive violent offenders..

Chapter 6 Anger provocation in violent offenders leads to emotion dysregulation

Valorization Addendum 


\section{General Introduction}

Human aggression is not only a great cost for society, but also has great consequences for general health as it is among the world's foremost cause of premature death (Krug, Dahlberg, Mercy, Zwi, \& Lozano, 2002). In the Netherlands, as in the rest of Europe, 3\% of all cause-specific mortality is a result of injury by violence or aggression (Wang et al., 2016). The cost of injury due to aggression has been estimated up to $€ 30$ million yearly in medical costs and $€ 66$ million in absenteeism costs (Snijders et al., 2016). In the literature, different terms such as aggression, reactive (impulsive) aggression, and impulsivity are frequently used interchangeably (García-Forero, Gallardo-Pujol, Maydeu-Olivares, \& Andrés-Pueyo, 2009), although they actually differ in meaning. Aggression can be defined as 'hostile, injurious or destructive behavior' (Siever, 2008 p. 429) and can be distinguished in reactive and proactive aggression. Reactive aggression indicates spontaneous and emotion-driven responses to perceived threats (Cima \& Raine, 2009), and is also referred to as hostile, impulsive, or angry aggression (Anderson \& Bushman, 2002). Proactive aggression refers to forethought and planned, instrumental, goal directed aggression (Berkowitz, 1993; Raine et al., 2006).

Impulsivity is defined as 'behavior without adequate thought, the tendency to act with less forethought than do most individuals of equal ability and knowledge, or a predisposition toward rapid, unplanned reactions to internal or external stimuli without regard to the negative consequences of these reactions' (The International Society for Research on Impulsivity, ISRI). Although prevalence of pathological impulsivity is reported to be extremely high in forensic (incarcerated) samples (up to 88\%; Bjørkly, 2006), impulsivity not only signals dysfunctional behavior, but may also be functional (Dickman, 1990). Functional impulsivity is characterized by fast, high speed of information processing when a quick response style is beneficial (Dickman, 1990, Troche \& Rammsayer, 2013). For example, functional impulsivity is the ability to rapidly implement an effective conflict resolution strategy in a situation of disagreement, preventing escalation (Pitts \& Leventhal, 2012).

Clinical practice has shown that (reactive) aggression is closely related to (dysfunctional) impulsivity (Swann \& Hollander, 2002). And risk assessment in forensic clinical practice includes impulsivity as a core and predictive risk factor for violent recidivism (Webster, Douglas, Eaves, \& Hart, 1997). Therefore, the work in this current dissertation aims to confirm the predictive value of impulsivity for (reactive) aggression in a forensic population. However, impulsivity as a construct has many facets, hence there is no commonly accepted unitary definition of impulsivity. To illustrate the minimal consensus regarding the definition of impulsivity, Evenden (1999) introduced 28 terms to describe impulsivity. Additionally, different types of impulsivity relevant as risk factors for recidivism might be quite diverse (Douglas et al., 2014; Howard, 2017). At the very least, the types of aggressive acts that are assumed to be related to impulsivity vary greatly. For instance, 
impulsivity might be involved in acting out sexual drive (in various sexual disorders), compulsive drive (e.g., in kleptomania, compulsive shopping, internet addiction), or explosive anger outbursts (in intermittent explosive disorder; American Psychiatric Association, 2013). Furthermore, it is questionable whether all variances of impulsive behavior require the same risk management strategy in preventing violent recidivism (Byrne \& Roberts, 2007; Douglas et al., 2014).

In essence, in order to get a better understanding about the concepts of aggression and impulsivity, it is essential to disentangle the different concepts and definitions (García-Forero et al., 2009). This is especially important in relation to forensic offender populations, since these different facets of impulsivity all relate to various forms of psychopathology (Fields et al., 2015) and (violent) recidivism risk, but not necessarily through the same process. Moreover, they might have a different cause. And the prevalence of maladaptive aggression tends to be specifically high in mental health treatment populations (Connor, 2002), as is the proneness towards aggression (Smith \& Waterman, 2003). Subsequently, more insight in possible vulnerability factors for reactive aggression is of particular interest for forensic offender samples.

The aim of the current dissertation research is twofold. First, we believe that a conceptual clarification is needed about the main concepts of interest, namely aggression and impulsivity. Therefore, in the first part of the dissertation research we aim to address the concepts controversy and provides definitions, models and theories of both aggression and impulsivity. Second, the dissertation research aims to unravel the neurocognitive and vulnerability factors of (impulsive) reactive aggression in a forensic population. Therefore, in the second part of the dissertation we describe the neurocognitive findings following neurological, behavioral and brain imaging tests of provoked reactive aggression.

Consequently, we start the dissertation with disentangling the definitions of reactive aggression and impulsivity (Chapter $\mathbf{1}$ ). Within the first chapter of this dissertation we focus on aggression in general, and its relation to impulsivity is explained in the context of forensic risk assessment. Since research indicates that impulsivity is a key risk factor for (reactive) aggressive behavior (Pratt \& Cullen, 2000; Vazsonyi \& Belliston, 2007) and violent crime (Scarpa \& Raine, 2000), several theories (e.g., social learning, biological and emotional) regarding the development of aggression are exemplified. Finally, in the first chapter an overview of neurobiological (the frontal lobe, autonomic reactivity, hormones and neurochemical functioning) abnormalities predisposing individuals towards aggressive responses is given as well as a short overview of effective treatment programs for aggression.

Given the importance of impulsivity in forensic practice as a risk factor for aggressive behavior and violence (American Psychiatric Association, 2013; Douglas et al., 2014; Webster et al., 1997), along with a high prevalence of pathological impulsivity in forensic populations (Haden, \& Shiva, 2008), we focus in the second chapter on the concept of impulsivity and possible predictive validity of impulsivity dimensions for psychopathology (Chapter 2 ). More specifically, in chapter two a multidimensional model of impulsivity based on both self-reports and behavioral instruments in a forensic sample is presented. 
In order to enable venting anger in a controlled manner, participants participated in two different anger provocation paradigms described in Chapter 3. The effects of the anger provocation paradigms within different violent offender populations were measured by aggression indices taken before and afterwards. Violent offenders are characterized by extreme aggressive behaviour (Grochowska \& Kossowska), with past aggression as a risk factor for violent recidivism (Mooney \& Daffern, 2011; Mooney \& Daffern, 2015). Therefore, we aimed to investigate a paradigm that is able to provoke anger, resulting in reactive aggression (Blair, 2012). We focus on anger, because anger is the emotional drive or motive behind reactive aggression (Averill, 1983). Besides, using anger provocation paradigms enables us investigate if venting anger is an effective management strategy, or it rather increases aggression. In the current dissertation two different anger provocation paradigms were used; namely Articulated Thoughts during Simulated Situations (ATSS; Davison, Robins, \& Johnson, 1983) containing anger stories, and Reactive Aggressive Behavior (RAB) response using a harassing body opponent punching bag in a violent (penitentiary and forensic psychiatric) offender population. Further, the relationships between the provocation paradigm responses on the one hand, and reactive as well as proactive trait aggression and psychopathy on the other hand is reported in this chapter.

Next, empirical evidence indicates that not only impulsivity as a risk factor for reactive aggressive behavior (Chan \& Chui, 2012), but also pinpoints to problems in executive functioning as a possible vulnerability factor for reactive aggression (Baker \& Ireland, 2007). Although both impulsivity and executive (dys)functioning relate to reactive aggression, the possible interrelation between both indicators of reactive aggression remains unclear. Therefore, in Chapter $\mathbf{4}$ we investigate whether aspects of executive dysfunction (i.e., working memory, flexibility and divided attention) and impulsivity (i.e., sensation Seeking, impulsive decision making, and (inadequate) response inhibition) are both vulnerability factors for reactive aggression after anger provocation.

In the following two chapters we focus on possible neurobiological brain abnormalities related to anger and anger regulation problems that result in reactive aggression. Neurobiological research results indicate that reactive aggression is the consequence of dysfunctional emotion regulation, caused by an imbalance between prefrontal cortical control and excessive affect response of limbic regions (incl. amygdala, Blair, 2004; Davidson, Putnam, \& Larson, 2000; Raine \& Yang, 2006), but the exact nature of this imbalance remains unknown (Chapter 5). Therefore, in the fifth chapter we focus on amygdala resting-state functional connectivity before and after an emotion (anger and happiness) provocation and regulation task in violent offenders and non-offender controls. While previous cognitive research focused on frustration as a trigger of anger or aggression (Blair, 2012), emotion research has focused solely on the recognition of anger as an indicator for dysfunctions in anger experience and perception (Lindquist, Wager, Kober, Bliss-Moreau, \& Barrett, 2012; Kret \& de Gelder, 2013), with deficits in emotion recognition ultimately leading to aggressive and violent behaviour (Hubble, Bowen, Moore, \& Van Goozen, 2015). We investigated neurobiological differences in brain responses 
during emotion (anger and happiness) provocation and regulation between violent offenders and non-offender controls, to help understanding the brain mechanisms associated with provocation as well as regulation of anger in violent offenders (Chapter 6).

Finally, all findings within the current dissertation research will be summarized and discussed with attention to methodological issues and suggestions for future research as well as clinical practice (Summary and General Discussion). Moreover, the value, social and economic relevance and implications resulting from the current thesis will be discussed in a valorization addendum. 


\section{References}

American Psychiatric Association (APA). (2013). Diagnostic and statistical manual of mental disorders (5th ed.). Arlington, VA: American Psychiatric Publishing. doi:10.1176/appi.books.9780890423349

Anderson, C. A., \& Bushman, B. J. (2002). Human Aggression. The Annual Review of Psychology, 53, 27-51. doi: 10.1146/annurev.psych.53.100901.135231

Averill, J. R. (1983). Studies on anger and aggression: Implications for theories of emotion. American Psychologist, 38, 1145-1160. doi: 10.1037/0003-066X.38.11.1145

Baker, S. F., \& Ireland, J. L. (2007). The link between dyslexic traits, executive functioning, impulsivity and social self-esteem among an offender and non-offender sample. International Journal of Law and Psychiatry, 30, 492-503. doi: 10.1016/j.ijlp.2007.09.010

Berkowitz, L. (1993). Pain and aggression: some findings and implications. Motivation and Emotion, 17, 277-293.

Bjørkly, S. (2006). Empirical evidence of a relationship between insight and risk of violence in the mentally ill - A review of the literature. Aggression and Violent Behavior, 11, 414-423. doi:10.1016/j.avb.2006.01. 006

Blair, R. J. R. (2012). Considering anger from a cognitive neuroscience perspective. Wiley Interdisciplinary Reviews: Cognitive Science, 3, 65-74. doi:10.1002/wcs.154

Blair, R. J. R. (2004). The roles of orbital frontal cortex in the modulation of antisocial behavior. Brain and Cognition, 55, 198-208. doi: 10.1016/S0278-2626(03)00276-8.

Byrne, J. M., \& Roberts, A. R. (2007). New directions in offender typology design, development, and implementation: Can we balance risk, treatment and control? Aggression and Violent Behavior, 12, 483-492. doi: 10.1016/j.avb.2007.02.009

Chan, H. C., \& Chui, W. H. (2012). Psychological correlates of violent an non-violent Hong Kong juvenile probationers. Behavioral Sciences \& the Law, 30, 103-120. doi: 10.1002/bsl.2003

Cima, M., \& Raine, A. (2009). Distinct characteristics of psychopathy relate to different subtypes of aggression. Personality and Individual Differences, 47, 835-840. doi: 10.1016/j.paid.2009.06.031

Connor, D. F. (2002). Aggression and Antisocial Behavior in Children and Adolescents. New York: The Guilford Press.

Davidson, R. J., Putnam, K. M., \& Larson, C. L. (2000). Dysfunction in the neural circuitry of emotion regulation-a possible prelude to violence. Science, 289, 591-594. doi: 10.1126/science.289.5479.591

Dickman, S. J. (1990). Functional and dysfunctional impulsivity: personality and cognitive correlates. Journal of Personality and Social Psychology, 58, 95. doi: 10.1037/0022-3514.58.1.95

Douglas, K., S., Hart, S. D., Webster, C. D., Belfrage, H., Guy, L. S., \& Wilson, C. M. (2014). Historical-Clinical-Risk Management-20, Version 3 (HCR-20V3): Development and Overview, International Journal of Forensic Mental Health, 13, 93-108. doi: 10.1080/14999013.2014.906519

Evenden, J. L. (1999). Varieties of impulsivity. Psychopharmacology, 146, 348-361.

Fields, S., Edens, J. F., Smith, S. T., Rulseh, A., Donnellan, M. B., Ruiz, M. A., McDermott, B. E., \& Douglas, K. S. (2015). Examining the psychometric properties of the Barratt Impulsiveness Scale-Brief Form in justice-involved samples. Psychological Assessment, 27, 1211-1218. doi: 10.1037/a0039109

García-Forero, C., Gallardo-Pujol, D., Maydeu-Olivares, A., \& Andrés-Pueyo, A. (2009). Disentangling impulsiveness, aggressiveness and impulsive aggression: an empirical approach using self-report 
measures. Psychiatry Research, 168, 40-49. doi: 10.1016/j.psychres.2008.04.002

Grochowska, K. \& Kossowska, M. (2012). Fact sheet violent offenders. European Association of Psychology and Law - Student Society Publishing House, Poland, EAPL-s. https://www.eaplstudent.com/component/ content/article/193-fact-sheet-violent-offenders

Haden, S. C., \& Shiva, A. (2008). Trait impulsivity in a forensic inpatient sample: An evaluation of the Barratt Impulsiveness Scale. Behavioral Sciences \& the Law, 26, 675-690. doi: 10.1002/bsl.820

Howard, R. C. (2017). Psychopathy, Impulsiveness and Violence: How are they linked? Journal of Behavior, 2, 100. https://www.jscimedcentral.com/Behavior/Articles/behavior-2-1004.pdf

Hubble, K., Bowen, K. L., Moore, S. C., \& Van Goozen, S. H. (2015). Improving negative emotion recognition in young offenders reduces subsequent crime. PloS One, 10, e0132035. doi:10.1371/journal.pone.0132035

Kret, M. E., \& de Gelder, B. (2013). When a smile becomes a fist: the perception of facial and bodily expressions of emotion in violent offenders. Experimental Brain Research, 228, 399-410. doi: 10.1007/s00221-013-3557-6

Krug, E. G., Dahlberg, L. L. Mercy, J. A., Zwi, A. B., \& Lozano, R. (2002). World report on violence and health. Geneve: World Health Organization. http://apps.who.int/iris/bitstream/10665/42495/1/9241545615_eng.pdf

Lindquist, K. A., Wager, T. D., Kober, H., Bliss-Moreau, E., \& Barrett, L. F. (2012). The brain basis of emotion: a meta-analytic review. Behavioral and Brain Sciences, 35, 121-202. doi: 10.1017/S0140525X11000446

Mooney, J. L., \& Daffern, M. (2015). The relationship between aggressive behaviour in prison and violent offending following release. Psychology, Crime \& Law, 21, 314-329. doi: 10.1080/1068316X.2014.989163

Mooney, J. L., \& Daffern, M. (2011). Institutional Aggression as a Predictor of Violent Recidivism: Implications for Parole Decision Making. International Journal of Forensic Mental Health, 10, 52-63. doi: 10.1080/14999013.2010.550984

Pitts, S. R., \& Leventhal, A. M. (2012). Associations of functional and dysfunctional impulsivity to smoking characteristics. Journal of Addiction Medicine, 6, 226. doi: 10.1097/ADM.0b013e31825e2a67

Pratt, T. C., \& Cullen, F. T. (2000). The empirical status of Gottfredsons and Hirschi's General Theory of Crime: A meta analysis. Criminology, 38, 931-964. doi: 10.1111/j.1745-9125.2000.tb00911.x

Raine, A., Dodge, K., Loeber, R., Gatzke-Kopp, L., Lynam, D., Reynolds, C., Stouthamer-Loeber, M., \& Liu, J. (2006). The Reactive-Proactive Aggression Questionnaire: Differential correlates of reactive and proactive aggression in adolescent boys. Aggressive Behavior, 32, 159-171. doi: 10.1002/ab.20115

Raine, A., \& Yang, Y. (2006). Neural foundations to moral reasoning and antisocial behavior. Social Cognitive and Affective Neuroscience, 1, 203-213. doi: 10.1093/scan/nsI033

Scarpa, A., \& Raine, A. (2000). Violence associated with anger and impulsivity. In J. C. Borod (Eds.), The neuropsychology of emotion: series in affective science (pp. 320-339). New York: Oxford University Press.

Siever, L. J. (2008). Neurobiology of Aggression and Violence. American Journal of Psychiatry, 165 , 429-442. doi: 10.1176/appi.ajp.2008.07111774

Smith, P., \& Waterman, M. (2003.) Processing bias for aggression words in forensic and non-forensic samples. Cognition and Emotion, 17, 681-701. doi: 10.1080/02699930302281

Snijders, B. E. P., Gommer, A. M., Haagsma, J. A., Panneman, M. J., Polinder, S., van Beeck, M-C. E. F. (2016). Ziektelast en kosten van letsel door geweld. RIVM Rapport 2015-0179, Rijksinstituut voor Volksgezondheid en Milieu (RIVM): Bilthoven. http://www.rivm.nl/bibliotheek/rapporten/2015-0179.pdf 
Swann, A. C. \& Hollander, E. (2002). Impulsivity and Aggression: Diagnostic Challenges for the Clinician. A Monograph for Continuing Medical Education Credit. Illinois: ACCESS Medical Group.

Troche, S.J. \& Rammsayer, T.H. (2013). Attentional blink and impulsiveness: evidence for higher functional impulsivity in non-blinkers compared to blinkers. Cognitive Processing, 14, 273-281. doi: 10.1007/s10339-013-0553-5

Værøy, H., Western, E. \& Andersson, S. (2016). The Link between Facets of Impulsivity and Aggression in Extremely Violent Prisoners. Open Journal of Psychiatry, 6, 86-94. doi: 10.4236/ojpsych.2016.61010 Vazsonyi, A. T. \& Belliston, L. M. (2007). The family> low self-control > deviance: A Cross-Cultural and Cross-National Test of Self-Control Theory. Criminal Justice and Behavior, 34, 505-530. doi: 10.1177/0093854806292299

Wang, H., Naghavi, M., Allen, C. ... et al. (2016). Global, regional, and national life expectancy, all-cause mortality, and cause-specific mortality for 249 causes of death, 1980-2015: a systematic analysis for the Global Burden of Disease Study 2015. The Lancet, 388, No. 10053. doi: 10.1016/S0140-6736(16)31012-1

Webster, C. D., Douglas, K. S., Eaves, D., \& Hart, S. D. (1997). HCR-20: Assessing risk for violence, version 2. Burnaby, BC, Canada: Simon Fraser University. 


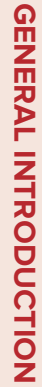




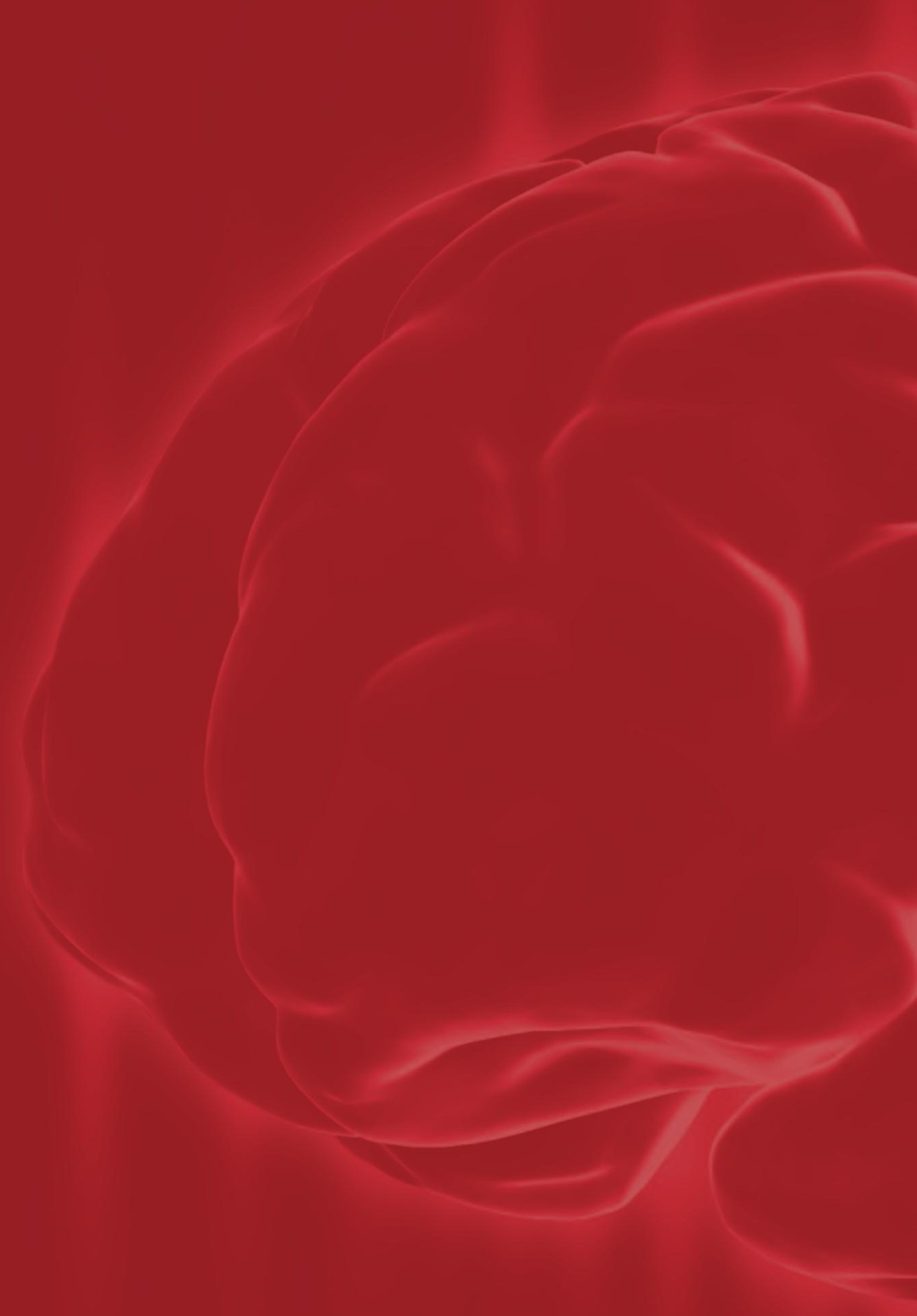




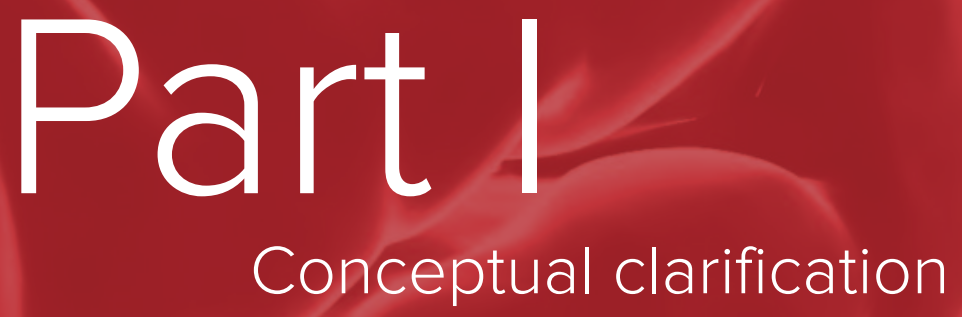




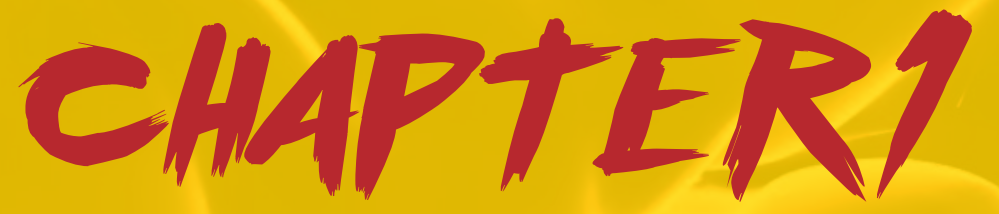

Aggression

This chapter has been published as Tonnaer, F., Cima, M., \& Arntz, A. (2016). Aggression. In M. Cima (Eds.), The Handbook of Forensic Psychopathology and Treatment (pp. 270 - 312). London: Routledge Mental Health. 


\section{Abstract}

Aggression, violence and deviant behavior are terms frequently used interchangeable, but relate to different theoretical concepts. Therefore, we start this chapter with a definition of aggression. Furthermore, several theories regarding the development of aggression will be presented. According to some theories, aggression is biologically or emotionally driven and innate, while other theories state that aggression is the result of a (social) learning process, susceptible to change. In this chapter we present a discussion of various etiological models of aggression. As research indicates that a lack of self-control and impulsivity is a key risk factor for aggressive behavior, models regarding impulsivity and scientific studies of the relationship between impulsivity and aggression will be outlined. In relation to risk assessment within the forensic field, various risk factors relate to aggression and various abnormalities in neurobiology (the frontal lobe, autonomic reactivity, hormones and neurochemical functioning) seem to predispose individuals towards aggressive responses. Therefore, we also give an overview of these risk factors, with a special emphasize on the role of impulsivity. Finally, we end this chapter with a short overview of effective treatment programs for aggression.

Keywords aggression, violence, deviant behavior, impulsivity, risk assessment 


\section{Introduction}

Human aggression, violence, and deviant behavior are not only a great cost for society - up to $\$ 40.2$ billion yearly only for England and Wales and 3.3\% of the gross domestic product in America (Waters et al., 2004) -, but have also great consequences for general health as it is among the world's foremost causes of premature death (Krug, Dahlberg, Mercy, Zwi, \& Lozano, 2002). Moreover, violence is often stated as a preventable public health problem (Gilligan, 1997). A search for literature on human aggression learns that different terms, such as aggression and violence, are frequently used interchangeably (Perry, 2001), although they actually differ in meaning. Therefore, we start the current by defining the different concepts. Furthermore, in the current chapter we will further outline several subtypes of aggression and explain the concept of impulsivity in the context of aggression and forensic risk assessment. Thereby, we present several developmental theories of aggression. More specifically, theories emphasizing biological, psychological and social origins of aggression will be reported. We will end this chapter describing some interventions for aggressive problem behavior.

\section{Concept}

Violence is defined by the World Health Organization as the 'intentional use of physical force or power, threatened or actual, against a person, or against a group or community, that either results in or has a high likelihood of resulting in injury, death, psychological harm, maldevelopment or deprivation' (Krug et al., 2002, p. 4).

Aggression can be defined as 'hostile, injurious or destructive behavior' (Siever, 2008 p. 429). While violence and aggression are both defined as behavior, violence explicitly includes the use of physical force or power towards someone or a group. Aggression is a broader concept also comprising verbal aggression, non-directed behavioral acts out of frustration and threat. Thus, violence includes aggression, but not all aggression results in violence. Another important qualification for behavior to be perceived as aggressive or violent is the violation of normative believes and shared rules of society (Tedeschi, Gaes, \& Rivera, 1977). Behavior that is prohibited, criminal, and in violation of normative believes and social rules, is defined as deviant behavior (Perry, 2001).

Aggression can be described referring to its style or response modulation including e.g. verbal aggression, physical aggression and sexual aggression; its immediacy with direct versus indirect aggression; its instigation as unprovoked versus retaliate aggression; the duration of consequences as transient or long-term; its type of harm as physical versus psychological; its visibility as overt and covert aggression; its response quality as action versus failure to act aggressive and the target of the aggression, self-directed or other directed (Siever, 2008; Krahé, 2001). 


\section{Subtypes of aggression}

Within the concept of aggression, different subtypes exist. The most frequently stated subtypes are those defined by its goal direction, reactive vs. proactive (Babcock, Sharp, Tharp, Hepner, \& Stanford, 2014). Reactive aggression indicates spontaneous and emotion-driven responses to perceived threats (Cima \& Raine, 2009), and proactive aggression refers to forethought and planned, goal directed aggression (Raine et al., 2006). Reactive aggression is also called hostile, impulsive, injurious, destructive, instinct or angry aggression (Anderson \& Bushman, 2002), in which there is a lack of regulating anger (Cima \& Siep, 2015), while proactive aggression is often called instrumental aggression as it is utilized to obtain some goal other than harming the victim perse (Berkowitz, 1993). In this type of aggression anger is often overregulated in the presence of lacking empathy. This distinction between reactive and proactive aggression is not only present in psychology, but also in law settings where it refers to 'one single act (e.g., murder) which can either be reactive (e.g. manslaughter) or proactive (e.g., first degree murder, Cima \& Raine, 2009, p. 383).

Although reactive and proactive aggression refer to underlying motives of behavior (driven by defense or driven by deliberate purpose) in which certain individuals tend to display primarily reactive or primarily proactive aggression, in practice they often overlap (an aggressive act can have aspects of both types) and tend to co-occur in individuals (Hubbard, Morrow, Romano, Meghan, \& McAuliffe, 2010). Distinguishing subtypes of aggression is nevertheless useful (Cima \& Raine, 2009), since they indicate certain episodes of aggression instead of fixed traits (Hubbard et al., 2010), which might be useful in directing treatment choice (Barker, Vitaro, Lacourse, Fontaine, Carbonneau, \& Tremblay, 2010). A process that plays an important role in reactive aggression is impulsivity.

\section{Aggression and impulsivity}

In the self-control theory of crime or the general theory of crime, Gottfredson and Hirschi (1990) relate aggression to impulsivity and thereby focuses on reactive, impulsive aggression. More specifically, they state that crime is a result of a lack of self-control, by an impulsive personality and in criminal opportunities. Moreover, research shows that a lack of self-control (impulsivity) indeed is a core factor in predicting crime (Pratt \& Cullen, 2000; Vazsonyi \& Belliston, 2007). Furthermore, research has demonstrated a relation between impulsivity and aggression or violent crime (Lane \& Cherek, 2000; Scarpa \& Raine, 2000; Swann \& Hollander, 2002). There is, however, little consensus regarding the definition of impulsivity. For example, Evenden (1999) introduced 28 terms to describe impulsivity. The International Society for Research on Impulsivity (ISRI) defines impulsivity as: "behavior without adequate thought, the tendency to act with less forethought than do most individuals of equal ability and knowledge, or a predisposition toward rapid, unplanned reactions to internal or external stimuli without regard to the negative consequences of these reactions.' Recently an impulsivity model is presented, including three distinctive impulsivity dimensions capturing 
various impulsive behavior ranging from sensation seeking to impulsive decision making and response (dis)inhibition (Tonnaer, Cima, \& Arntz, 2016a). In fact, research on this three-dimensional impulsivity model showed that the impulsivity dimension '(inadequate) Response Inhibition' was the essential predictor for reactive aggressive behavior (Tonnaer, Cima, \& Arntz, 2016b), again, showing that a lack of impulse control is associated with aggressive actions (Gottfredson \& Hirschi, 1990).

Clinical practice also shows a clear link between impulse control problems and aggressive behavior (Swann \& Hollander, 2002). For example, in the Diagnostic and Statistical Manual of mental disorders (DSM-V, American Psychiatric Association, APA, 2013) a category of impulsive control disorders as pyromania, pathological gambling and also the intermitted explosive disorder (IED, APA, 2013) is included. The IED is characterized by frequent episodes of extreme anger or physical outburst leading to destructiveness or violence. Importantly, the reactive impulsive aggression in the intermitted explosive disorder is defined as a disproportionate reaction to provocation.

Impulsive reactive aggression is driven by lack of anger regulation. Several studies have shown neurocognitive correlates of underlying anger (e.g., Denson, Perderson, Ronquillo, \& Nandy, 2009; Fabiansson, Denson, Moulds, Grisham, \& Schira, 2012; Lindquist et al., 2012). Until recently, neurocognitive studies regarding impulsivity and reactive aggression, reported an imbalance between prefrontal cortical control and excessive bottom-up signals of negative affect by limbic regions (Raine et al., 1998). In a study of Dambacher et al., (2014) examining neural mechanisms underlying lack of self-control, an overlap of neural correlates for failed motor response inhibition and reactive aggression in healthy subjects was located the anterior insula, indicating that this brain area is involved in both motor impulsivity and reactive aggression. A recent functional imaging study regarding resting-state within aggressive violent offenders focusing on reactive aggression, showed that an anger provocation significantly increased amygdala connectivity with (para)limbic regions in a violent offender group and decreased connectivity in a non-violent control group (Siep, Tonnaer, Ven, Arnzt, Raine, \& Cima, 2018). Prior to the provocation, connectivity within the violent offender group was stronger, while after provocation, results showed a significant decrease in amygdala - medial prefrontal functional connectivity in the violent group but an increase in the control group. These results point to a dominance of emotion processes in reactive aggression, in which the emotional processes seem to have the potential to grow out of control (especially when provoked), as indicated by the lack a of medial prefrontal cortex regulation (Siep et al., 2015). These types of studies, in which violent subjects are provoked into an anger state to elicit aggressive behavior while examining neurocognitive correlates, are important in order to understand the biological underlying mechanisms of reactive aggression. 


\section{Theories regarding the Development of Aggression Short Historical Overview.}

\section{Instinct}

In 1920 Freud described the dual instinct theory in his book named 'Beyond the pleasure principle' (Freud, 1955). In his view behavior is driven by instincts. Based on biological processes ("drives"), energy builds up and has to be released. Aggression was viewed by Freud as a primary reactive drive (Thompson, Arora, \& Sharp, 2002). Acting out aggressively is a way to release, but as it is often forbidden people usually develop other ways to deal with it - these ways are called 'defense mechanisms'. An individual acts aggressively in order to obtain intra psychic stability. However, his theory has been criticized because its lack of operational definitions, and empirical evidence largely builds on case studies without stringent operationalization. Nevertheless, the Freudian approach was a source of inspiration for the frustration aggression hypothesis (Krahé, 2001).

The frustration-aggression hypothesis as proposed by Dollard, Doob, Miller, Mowrer, and Sears (1939) describes aggression as a result of frustration. In the view of Dollard and colleagues frustration - as an emotional experience - is created when an external trigger interferes with goal directed behavior. Frustration subsequently activates the desire to act aggressively, leading to reactive aggressive behavior against the source of frustration (Vitaro \& Brendgen, 2005). Research has indeed demonstrated a relationship between frustration and aggression, with frustration leading to more reactive aggressive behavior (Berkowitz \& LePage, 1967). However, this theory is quite stringent stating that "aggression always presupposes the existence of frustration" and "contrawise, that the existence of frustration always leads to some form of aggression" (Dollard et al., 1939, p1.). Not surprisingly, in 1994, the founders of the frustration-aggression hypothesis - driven by Miller -, nuance the original statement in two ways; firstly, they state that frustration can initiate aggression, but not automatically results in aggressive behavior. For instance, aggressive behavior can be inhibited by the notion of punishment. Secondly, they modified the statement that frustration always causes aggression, now claiming that frustration can cause a number of different reactions in which aggression is one, but not the only (Miller, Sears, Mowrer, Doob, \& Dollard, 1941). Even so, either version of the frustration-aggression hypotheses did not receive consistent empirical support (Baron, 1977). Lorenz (1974) was the first to offer an etiological model of aggression. His model - sometimes described as a hydraulic model of emotional or instinctive pressures - described how a constant input of aggressive energy within an individual leads to aggressive behavior based on the intensity of the trigger and the quantity of aggression. Although Lorenz believed that aggression was innate, originating from the failure of a certain instinct but not necessary reactive, current literature classifies his theory as theory of reactive aggression (Dodge, 2006). However, Lorenz theory has been criticized because the lack of operational definitions. Lorenz did not define aggressive energy, neither did he present a way of measuring the amount of energy presented in an individual, making it impossible to test his theory. 
In 1989 Berkowitz reformulated the frustration-aggression hypotheses to the cognitive neoassociation theory (CNT), a new aggression theory based the relation between frustration and aggression. Although Berkowitz proposed his theory explaining merely hostile aggression, it is also relevant to other types of aggression. Berkowitz states that all aversive events frustration, but also provocations, pain, loud noises, uncomfortable temperature - empower negative affect, which is a powerful instigator of anger and aggression (Berkowitz 1989, 1990, 1993). In his view, negative affect automatically triggers diverse thoughts, memories, expressive motor reactions and physiological responses associated with both fight and flight reactions. The fight reactions do have an aggressive nature, where the flight reactions have a nature of fear. In memory, concepts with related connotations or concepts triggered together, automatically form an associative network and become stronger associated. Aversive primes triggered during fight reactions, as well as the actual responses become associated with an event, linking aggressive thoughts, emotions, and behavioral tendencies to each other in memory (Collins \& Loftus, 1975). For example, in memory a link between angry feelings and approach motivation more specifically the motivation to approach the source of anger is formed, leading to stronger memory associations for approach in case of aversive events. Berkowitz incorporates higher order cognitive processes such as appraisal (e.g. considering the consequences of an aggressive act) and causal attributions (e.g. explore the cause of negative affect) in the CNT, but refers to aggressive behavior as an automatic, uncontrolled reaction to an aversive event (Anderson, Bushman, 2002). So, in the CNT is not only the frustration aggression hypothesis (Dollard et al., 1939) included, but Berkowitz broadens it to aversive experiences in general, and provides a broadly applicable cognitive concept on the cause of reactive aggression. Berkowitz thus gives an explanatory framework for aggressive preference in specific individuals in the CNT (Berkowitz, 1989).

\section{Social theories}

The social learning theory (Bandura, 1983; Mischel, 1973) states that individuals learn aggressive behavior in the same way as they learn other complex forms of social behavior, either by direct experience or by observing others. In the learning theory, Bandura offers useful concepts explaining aggression by describing the beliefs and expectations driving social behavior (Anderson \& Bushman, 2002). For instance, Bandura did not believe that individuals have an aggressive nature, but believes both reactive and proactive aggression is learned by instrumental conditioning in which behavior is influenced by its consequences and reinforcement, and modeled by the observation of aggressive models (Bandura \& Ribes-Inesta, 1976).

A related social theory attributing behavior to the social habitat is the differential association theory, developed by Sutherland (1939). Sutherland believed that criminal 'definitions' or associations are learned by interaction with other deviant individuals, causing an over exposure to rationale, motives etc. favoring crime related 'definitions' above pro social 
ones. His theory is most useful in explaining deviance, and both reactive and proactive aggression in adolescent and youth groups due to peer influence and exposure to criminal behavior. However, there is al lot of comments on the theory of Sutherland with the lack of defining the core concept 'definitions' and the mechanisms involved in learning criminal behavior as main critique along with the lack of empirical support (Akers \& Lee, 1996; Pfohl, 1994). Moreover, Sutherlands' theory lacks an explanation on origin of criminal behavior (Warr \& Stafford, 1991).

Another theory focusing on the labeling of information as the former described excitation transfer theory is the labeling theory. In this theory the focus is shifted from the individual to its social environment, stating that deviance is not intrinsic but socially determined behavior. Becker (1963) described this by stating that: "Social groups create deviance by making the rules whose infraction constitutes deviance, and by applying those rules to particular people and labeling them as outsiders. From his point of view, deviance is not a quality of the act the person commits, but rather a consequence of the application by others of rules and sanctions to an 'offender.' The deviant is one to whom that label has successfully been applied; deviant behavior is behavior that people so label" (Becker, 1963, p.9). Thus, Becker believes that individuals are labeled by groups and behavior is judged in accordance to the stereotypes of this group. In other words, aggressive behavior either reactive or proactive is defined by the norms of the group, and not by some forces inside the individual. The most prominent critique to the labeling theory is given by Sagarin (1975), stating that an individual is more then only a label. Furthermore, this labeling theory ignores the process of becoming deviant. Still another theory explaining aggression as a social learning process is the social interaction theory (of coercive action) introduced by Tedeschi and Felson in 1994 which focuses on proactive, instrumental aggression. They describe proactive aggression as aggression used to protect someone's positive self-identity as toughness by means of threat, punishment, or bodily force. The type of response is a decision making process based on past learning experiences, weight the costs of aggressive behavior (Anderson \& Bushman, 2002).

Lastly, according to the script theory (Tomkins, 1954) reactive as well as proactive aggression can be learned by the acquisition of scripts. Tomkins proposes that behavior is based on scripts, representing specific behavioral patterns. Scripts are described as sets of repeatedly associated concepts in memory, used to guide our behavior (Anderson \& Bushman, 2002; Schank \& Abelson, 1997). The more specific sets are associated, the stronger the connection between the concepts, possibly forming a unitary concept. Even few repetitions might change individual expectations and behavioral intentions (Marsh, Hicks, \& Bink, 1998). Huessmann (1988) states that when youngsters are presented with aggressive scripts e.g. in video games of the mass media, they learn aggressive scripts, ultimately believing that aggressive behavior is a normal response. 


\section{Biological theories}

On a neurobiological level, a prominent theory concerning the etiological and biological origin of aggression is the frontal lobe dysfunction theory (e.g. Hawkins \& Trobst, 2000; Séguin, 2013; Swann \& Hollander, 2002), which proposes a relation between dysfunctional abnormalities in the frontal brain regions related to reactive aggression and increased aggressive antisocial behavior (Blair, 2004; Brower \& Price, 2001). More specifically, in the frontal lobe dysfunction theory deficits in frontal lobe functioning may lead to inhibition problems and therefore to increased aggression (Barratt, 1994; Blair, 2004; Raine, Lencz, Bihrle, Lacasse, \& Colletti, 2000). Indeed, a series of brain imaging studies have supported the notion of reduced cortical inhibition in violent offenders (Raine, Buchsbaum, \& Lacasse, 1997; Raine et al., 2000). In particular, research has focused on the role of the medial prefrontal cortex (mPFC) and reactive aggression, which is strongly associated with impulse control and self-regulation (Bobadilla, Wampler \& Taylor, 2012). The frontal lobe dysfunction theory is supported by brain imaging studies showing abnormalities in the frontal lobe in persons displaying reactive aggression (Brower \& Price, 2001). However, not all persons with prefrontal lesions show aggressive behavior (Raine et al., 2000). Often these studies do not distinguish between different forms of frontal lobe dysfunctions like encoding of emotional material (e.g. happy vs. angry, Guastella, Kenyon, Alvares, Carson, \& Hickie, 2010) or emotion recognition (e.g. stressors, Raine et al., 2000). Up to now, no study has reliably demonstrated a characteristic pattern of frontal network dysfunction predictive of violent crime in offenders (Brower \& Price, 2001). However, literature reviews of functional and structural neuroimaging studies show distinct functional pathways for anger experience and anger perception (Lindquist, Wager, Kober, Bliss-Moreau, \& Barrett, 2012) and support the frontal lobe dysfunction theory implying that a combination of decreased medial prefrontal activity (the orbitorfontal, the anterior medial, medial frontal and superior frontal cortex) along with increased subcortical activity (the medial-temporal lobe, including the amygdala, hippocampus, and basal ganglia) is related to antisocial behavior and reactive aggression (see also below: 'aggression and impulsivity', Bufkin \& Luttrell, 2005; Fabian, 2010).

Research on autonomic reactivity and psychophysiology suggests a link between under arousal - e.g. low resting heart rate and skin conductance - and aggressive behavior (Glenn, Raine, Venables \& Mednick, 2007; King, 2012). This is in accordance with the earlier mentioned excitation transfer theory (Zillmann, 1983) giving a central role for arousal and the cognitive judgment of the experienced arousal leading to aggressive behavior. It is believed that individual variability in arousal levels influence their behavior to maintain an optimal arousal level (Kohn, Cowles, \& Lafreniere, 1987).

Also, a hormonal influence on aggressive behavior is suggested (King, 2012). Most research focuses on testosterone and cortisol. Testosterone is one of the steroid male hormones from the androgen group. Research on sex differences in aggressive behavior during adolescence, suggest a strong role for testosterone (Archer, 2009; Terburg, Morgan, 
\& van Honk, 2009; Terburg, Peper, Morgan, van Honk, 2009). Higher levels of testosterone have been associated with higher dominance behavior, aggression in response to provocation, as well as sexual and violent offending (Englander, 2003; Mehta \& Beer, 2009). More specific, research suggests a link between testosterone and the control of aggressive responding, with administering testosterone resulting in more aggressive responses (Archer, 2009; Kouri, Lukas, Pope, \& Olivia, 1995; Mehta \& Beer, 2009). Testosterone is positively associated with the tendency of a person to respond aggressively, due to reduced activation of the neural circuitry of impulse control and self-regulation located in the medial orbitofrontal cortex (Mehta $\&$ Beer, 2009). A recent study focusing on reactive aggression showed a mediating effect for testosterone, with reduced testosterone levels mediating positive intervention program effects in social provocations (Carré, Iselin, Welker, Hariri, \& Dodge, 2014). In contrast, low cortisol levels have been linked to general aggressive behavior, especially in males (Cima, Smeets, \& Jelicic, 2008; Cima, Nicolson, de Lijster, \& Popma, 2015; Feilhauer, Cima, Korebrits, \& Nicolson, 2013; King, 2012; Poustka et al., 2010). Cortisol hormone levels reflect the stress reactivity in the hypothalamic- pituitary-adrenal (HPA) axis of the individual (Poustka et al., 2010). Apparently, low stress responses are associated with aggressive behavior, which is apparently at odds with theories stating that high arousal fuels aggression. Moreover, research reveals an intertwined relationship between aggressive behavior, reactive as well as proactive and both testosterone and cortisol levels (Terburg, Morgan et al, 2009). For instance, Popma and colleagues (2007) found that cortisol moderates the relationship between testosterone and aggression in male delinquent adolescents. They found that only individuals with low cortisol levels showed a relation between testosterone and aggression (Popma et al., 2007). Another example is given by Pavlov, Chistiakov and Chekhonin (2012), who found that an imbalance in the testosterone and cortisol ratios in the sense of increased testosterone levels and reduced cortisol levels, enhance the tendency towards reactive aggressive behavior, due to a reduced activation of the neural circuitry of impulse control. These findings led to a testosterone-cortisol hypothesis of reactive aggression (Van Honk, Harmon-Jones, Morgan, \& Schutter, 2010) in which the combination of high levels of testosterone and low levels of cortisol predispose one to aggression by means of threat perception, biases towards punishment or reward, and an increase or decrease in neuronal control over subcortical structures (Montaya, Terburg, Bos, \& van Honk, 2012). Moreover testosterone mediates aggression by increasing the vasopressin gene expression at the amygdala, which is hypothesized to facilitate aggressive approach behavior (Schulkin, 2003).

Turning to the neurotransmitters, recently, serotonin (5-hydroxytryptamine, 5-HT, Bevilacque et al., 2010; Montaya et al., 2012; Van Honk et al., 2010) but also dopamine and serotonin have been related to especially reactive aggression (King, 2012). Dopamine has a function in the neural reward system, and high dopamine levels reduce the threshold to respond to a perceived threat, increasing the readiness for reactive aggressive response (Pavlov et al., 2012). However, serotonin facilitates prefrontal inhibition, and as a result, 
increased serotonin activity inhibits aggression. Lowered serotonin activity can enhance aggressive responses (Summers et al., 2005), especially in those individuals prone to reactive aggression due to a high testosterone-cortisol ratio (Montaoya et al., 2011; van Honk et al., 2010). Serotonin seems especially relevant in relation to self-control. In a study of Seo, Patrick, and Kennealy (2008) it was demonstrated that low serotonin might be a vulnerability factor for impulsive aggression, in which high levels of dopamine contribute additionally to this serotonergic insufficiency.

Returning to biological factors, twin and adoptive studies (Miles \& Carey, 1997) have indicated that heritable factors influence a person's tendency to behave aggressively. These types of studies for instance showed genetic components as shared genes better explained (up to 50\%) aggressive behavior as family and other environmental factors could (Crowe, 1975; Miles \& Carey, 1997). For instance, adult criminal adoptees whose biological as well as adoptive parents were criminal had the highest likehood of becoming criminal themselves, followed by criminal adoptees whose biological parents, but not adoptive parents had criminal records (Cloninger, Sigvardsson, Bohman, \& von Knorring, 1982). Further, the influence of genetic and family environment varied with age, with genetic factors become increasingly important with age (Miles \& Carey, 1997). These results differ from reviews of adoption studies and the intergeneration transmission of violent behavior (Mednick, Brennan, \& Kandel, 1988), but they are broadly consistent with more recent studies on a genetic component in antisocial behavior. These studies show relationships between delinquency, criminality and antisocial personality in the sense that adopted children whose biological parents were diagnosed with antisocial personality disorder tend to have higher rates of antisocial behavior themselves (Kline, 2004; Taylor, Loney, Bobadilla, lacono, \& McGue, 2003). On the other hand, the failure to detect specific genes that explain the heritability suggested by these studies, despite the enormous amounts of money and effort put in human genome research, has created a crisis in the field. As yet, it is unclear what explains the heritability findings from twin and adoption studies.

\section{Integrative theories}

In contrast to the learning theories on the origins of aggression, the excitation transfer theory (Zillmann, 1983), originating from Schachter and Singers' (1962) two-factor theory of emotion, is a biological oriented theory stating that emotion is a function of both cognitive factors and physiological arousal. According to Schachter and Singers, reactive aggression is the experiencing of physiological arousal including the transfer of arousal with environmental emotional cues. Likewise, Zillmann (1983) argued that a combination of physiological arousal and cognitive judgment shape the emotional experience of anger. The level of arousal determines the intensity of the emotional response while the labeling of arousal is essentially determining the kind of emotion. Interestingly, mislabeling by transferring arousal from a neutral or even irrelevant source to the arousal elicited by an aversive stimulation can cause a longer and stronger experience of anger (Anderson \& Bushman, 2002). This may extend over long 
periods of time if the heightened arousal is labeled consciously to anger, making an individual ready to aggress even when the source of anger is gone.

A related theory searching for etiologically determined reactive aggression and the central role of self-control is the self-control theory of crime, or often referred as the general theory of crime. The theory developed by Gottfredson and Hirschi (1990) proposes crime to be a result of a lack of self-control, an impulsive personality and criminal opportunities. Most crime has an impulsive, opportunistic nature, showing a lack of control. In the quest for the origin of crime, Gottfredson and Hirschi (1990) pointed to the strong relationship between criminal behavior and age, with self-control improving with age due to several components as hormonal development and socialization (Hirschi \& Gottfredson, 1983). Empirical evidence has suggested that a lack of self-control (impulsivity) indeed is a core factor in predicting crime (Baumeister \& Vohs, 2007; Pratt \& Cullen, 2000; Vazsonyi \& Belliston, 2007). The prefrontal cortex enables self-control in humans. As mentioned above, aggressive behavior is also associated with deficits in the basal-orbital prefrontal cortex (Damasio, Grabowski, Frank, Galaburda, \& Damasio, 1994). This brain area involves a dopaminergic neuronal circuit, which underlies reactivity, arousal modulation, and attention modulation. In children prenatally exposed to cocaine, this pathway seems disrupted related to a general aggressive behavioral tendency later in life (Mayes, 1999; Bendersky, Bennett, \& Lewis, 2006). Other prenatal factors related to the development of aggression and antisocial behavior, include prenatal depression (Hay, Pawlby, Waters, Perra, \& Sharp, 2010), alcohol (Streissguth, Barr, Bookstein, Sampson, \& Olson, 1999), smoking (Huijbregts, Seguin, Zoccolillo, Boivin, \& Tremblay, 2008) and stress (Zohsel et al., 2013). Such biological-environmental factors influence brain make-up of the child, and constitute one group of factors that result in individual child differences regarding the degree in which they are vulnerable to their environment. For instance, maltreatment in children has been related to aggressive antisocial behavior in some, but not all cases (see box 1 for an example of gen $X$ environment interaction example).

As to the different etiological theories regarding aggression, the differential susceptibility theory may best explain way some individuals develop reactive and/or proactive aggressive response tendencies while others do not. According to this theory individuals with a biological predisposition are sensitive to both negative as well as positive environmental influences. For instance, similarly as the study of Caspi et al., (2002, see box 1), in a study of Bakermans-Kranenburg and ljzendoorn (2006) the effect of genes (Dopaminereceptor D4 7-repeat polymorphisme, DRD4-7R) in combination with the sensitivity of the mother was examined in relation to externalizing behavior including aggression. Authors reported that children with the DRD4-7R allele in combination with an insensitive mother demonstrated more externalized behavior as compared to children with the same allele but sensitive mothers. Children with the DRD4-7R allele and sensitive mothers showed the least externalized disorders, while sensitivity of the mother had no effect on children without this DRD4-7R allele.

Many hypotheses about what genetic and other biological factors determine children's 
vulnerability have been proposed, but after promising results the initial enthusiasm has been damped due to failure to replicate early findings (Duncan \& Keller, 2011; Duncan, Pollastri, \& Smoller, 2014). At the present moment, despite the attractiveness of the theory, it is not clear what biological factors exactly influence the child's vulnerability to environmental influences.

Box 1

Maltreated children with low MAO-A levels, were more likely to develop antisocial behavior later on in life, as compared to children who were also maltreated, but had high MAO-A levels. These results suggest that traumatized stressful experiences may be a risk factor in some but not all cases of victims, and that the persons' sensitivity to negative environmental factors seems moderated by their genetic makeup (Caspi et al., 2002).

This also accords with a more recent study of Obradovic, Bush, Stamperdahl, Adler, and Boyce's (2010) in which 5-year-old children with elevated levels of cortisol reactivity were identified by their teachers as less prosocial in case the children were raised under adverse conditions. When these children were raised under better circumstances, they displayed the most prosocial behavior even in comparison with children with low cortisol reactivity. These findings indicate that more vulnerable individuals are more sensitive to environmental influences, both associated with negative as well aspositive surroundings.

In 2002, Anderson and Bushman integrated some of the above mentioned theories (as the cognitive neoassociation theory, the social learning theory, the script theory, the social interaction theory and the excitation transfer theory) on aggression into one social cognitive model named the General Aggression Model (GAM, Anderson \& Bushman, 2002), as a framework for understanding reactive as well as proactive aggression and violence. According to Anderson and Bushman aggression can be learned either by instrumental conditioning (Bandura, \& Ribes-Inesta, 1976), by learning to label information (Becker, 1963), by attributing behavior to asocial habitat (Sutherland, 1939), by social interaction (Tedeschi \& Felson, 1994), or by frequent confrontation with aggressive scripts (Huessmann, 1988).

In the GAM three different learning structures are distinguished. First, perceptual schemata are used to identify everyday psychical objects; second, person schemata consist of beliefs of individuals and stereotypes; third, behavioral scripts contain behavioral guides. Furthermore, in the GAM four different processing stages are described to explain aggressive behavior (see Figure 1: The General Aggression Model, re-used from Krahé, 2013, with permission), namely 1) input variables coming from a) the individual ('person'); b) input from the environment ('situation'); 2) cognitive, affective and arousal information processing routes; 3) several complex decision processes and (re)appraisal from relative automatic processes as immediate appraisal to more controlled cognitive processes as reappraisal (Anderson \& Bushman, 2002) determining response expression leading to 4) either thoughtful, proactive 
or impulsive, reactive action outcomes. It is important to note that the focus of the model is aggression, and all elements described in the GAM are denoted towards aggressive behavior, but the opposite perspective like anti-aggressive beliefs and attitudes is evenly important (Anderson \& Carnagey, 2004). The idea is that because Anderson and Bushman integrated various theories that each focus on a different aspect of aggression, the GAM is more inclusive and capable to explain aggressive acts based on multiple motives. Likewise, its integrated view on aggression demands for comprehensive interventions targeting the multiple influential factors and developmental trajectories responsible for aggressive behavior (Anderson \& Bushman, 2002).

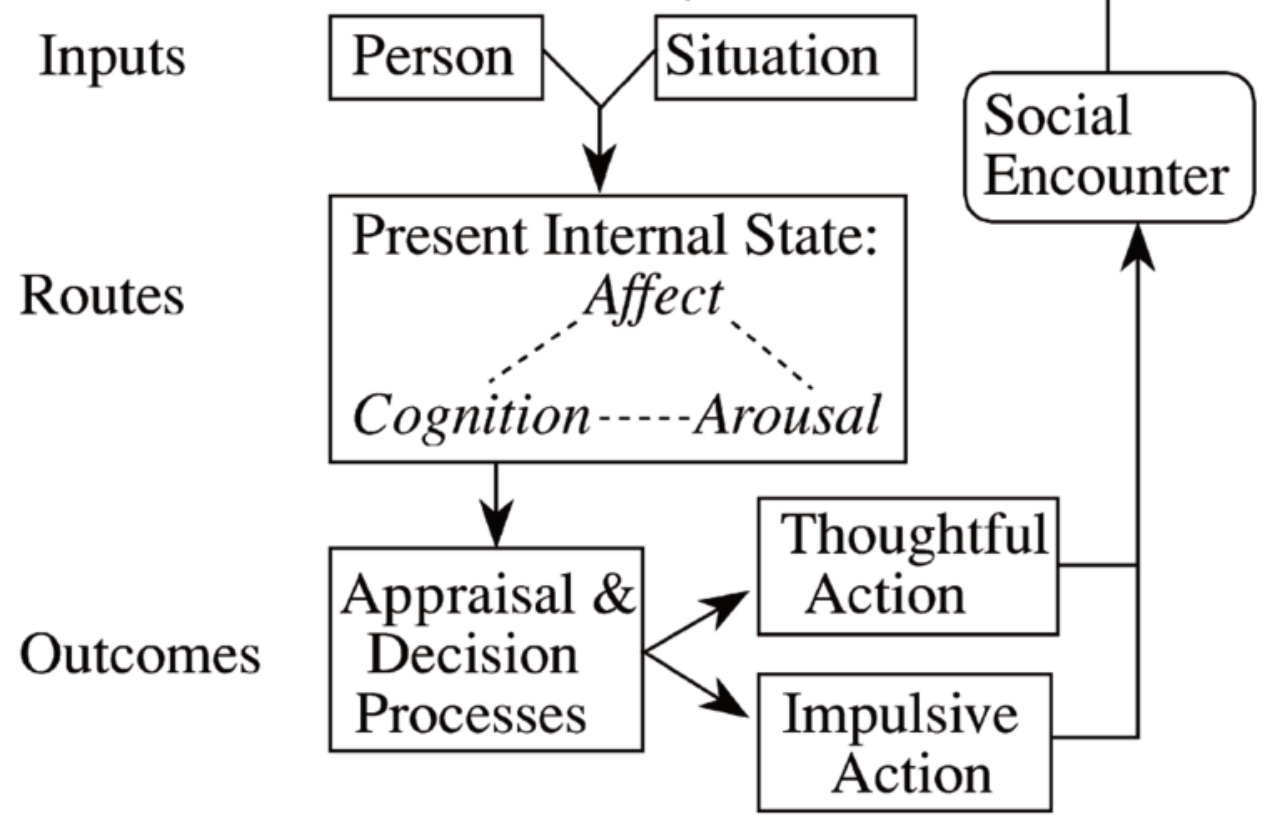

Figure 1. The General Aggression Model (Krahé, 2013).

\section{Interventions}

Most interventions focus on reactive aggression (Buchmann, Hohmann, Brandeis, Banaschewski, \& Poustka, 2014), while prevention primary focus on proactive aggression (Henggeler, Cunningham, Pickrel, Schoenwald, \& Brondino, 1996). However, interventions based on cognitive behavioral approaches and aimed to alter cognitions like Aggression Replacement Training (ART, Goldstein, 1996) and Stress Inoculation Treatment (SIT, Novaco, 
1975) are promising in reducing reactive as well as proactive aggressive behavior (de Ruiter, \& Hildebrand, 1999). ART is a program original targeting juvenile delinquents in penitentiary institutions by improving their anger management by anger-control training, social skills training and moral reasoning training (Goldstein, 1996; National Center, 2007). ART is a multimodal treatment empowering the adolescent using aspects of the learning theory as observations. Another multi modal treatment combining cognitive and affective coping strategies is the SIT for anger management in stressful events (Novaco, 1975). In the SIT individuals ar empowered by training coping techniques such as cognitive restructuring, relaxation training, interpersonal communication skills training and training in utilizing social support systems (Meichenbaum, 1996). A recent meta-analysis showed that such cognitive behavioral treatment techniques are effective in decreasing aggression (Smeets et al., 2014), reactive as well as proactive (Down, Willner, Watts, \& Griffiths, 2011). Smeets and colleagues (2014) also examined possible moderators in predicting treatment response. Although no significant predictors were identified, better standardization of predictors and outcome measures across studies is required to be able to reliable recognize responders and non-responders to aggression reduction treatment.

Interventions not only focusing on the individual but also on its interactions with others like MultiSystemic Therapy (MST, Borduin, 1999; Henggeler, Schoenwald, Borduin, Rowland \& Cunningham, 1998) seem to present encouraging results. MST is home based family therapy based on Bronfenbrenner (1979) theory of social ecology combined with interventions on empirical known risk factors (such as criminal environment, low intelligence, school dropout etc.) for antisocial behavior in youth (Henggeler, Cunningham, Pickrel, Schoenwald, \& Brondino, 1996; Lahey, Moffitt, \& Caspi, 2002, see also chapter 5). In MST the focus is concentrated on the family, school, community and peers as a system and not solely on the adolescent with antisocial behavioral problems. Therefore, the parents are coached in interventions as showing more warmth and learning how to more effectively discipline their children (Curtis, Ronan, \& Borduin, 2004; Henggeler et al., 1996). Results on a meta-analysis on the effectiveness of MST did show that MST is indeed effective, with families that received MST versus alternatives, functioning up to $70 \%$ better (Curtis et al., 2004). Even more promising, earlier research demonstrated long-term reductions in criminal activity and general aggression after MST (Henggeler et al., 1996, p.1). Additionally, results did also show that MST is most effective in targeting family relations more that in individual adjustment or peer relations (Curtis et al., 2004).

Interventions tapping into a neurological level involve pharmacotherapy interventions. Various pharmacotherapies are available aiming to reduce (mostly reactive) aggressive behavior (Swann \& Hollander, 2002). Historically, most acute care settings utilized a combination of antipsychotic medication and benzodiazepines. However, the results show only a modestly effect for antipsychotic medication in reducing reactive aggressive behavior and other non-cognitive behavioral symptoms (Antonius et al., 2013; Schneider, Pollock, \& Lyness, 1990) and mostly in patients with acute psychotic symptoms (Swanson, Swartz, et al., 
2008). But atypical antipsychotics tend to show positive effects in anger management (Buckley, 1999). For example, a study showed a reduction in interpersonal sensitivity, impuslsivity and anger in borderline personality disordered individuals using olanzapine (Schulz, Camlin, Berry, \& Jesberger, 1999). Benzodiazepines are prescribed to reduce symptoms of hyper activity and attention, insomnia and panic related to anxiety problems (Swann \& Hollander, 2002). Research shows that benzodiazepines are not advised for long-term use, but only in case of acute reactive aggressive outburst in which they seem effective (Citrome \& Volavka, 1997). However, over the last years, more is known about the mechanism underlying aggression (and impulsivity) and possible positive effects of different pharmacotherapy as mood stabilizers, monoamine-oxidase inhibitors (MAOIs), antidepressants, anticonvulsants, and beta-blockers (Swann \& Hollander, 2002). A mood stabilizer commonly used is Valproate (e.g. available as divalproex sodium), originally developed for treatment of mania and epilepsy, but now applied in a variety of psychiatric disorders as panic disorders, borderline personality disorder as well as drug withdraw, and successful in the reduction of reactive aggression and impulsivity (Huband, Ferriter, Nathan, \& Jones, 2010) by e.g. the reduction in patients irritability in personality disordered individuals (Hollander et al., 2001; Kavoussi \& Coccaro, 1998). Another commonly used mood stabilizer in individuals with depression symptoms is Lithium, which aims to increase the serotonin function leading to less reactive aggression (Sheard, Marini, Bridges, \& Wagner, 1976). Monoamine-oxidase inhibitors (MAOIs) mostly prescribed in case of depression symptoms seem to be successful in anger management reducing anger and hostility in borderline personality disordered individuals (Soloff et al., 1993). In addition, antidepressants and more specific selective serotonin reuptake inhibitors (SSRIS) seem to be effective in reducing reactive aggressive behavior by increasing serotonin levels (Conacher, 1997; Phan, Lee, \& Coccaro, 2011). Anticonvulsants are mostly prescribed in case of epilepsy and seizures, but seem to show a reduction of aggressive behavior (Young \& Hillbrand, 1994). However, not much research is done on the anti-aggressive effects of anticonvulsants as e.g. carbarnazepine on reactive aggression and persistent aggression (Huband, Ferriter, Nathan, \& Jones, 2010; Young \& Hillbrand, 1994), but the number of reports is growing (Eatmon \& Daniel, 2014; Stanford, Anderson, Lake \& Baldridge, 2009). Beta-blockers have been introduced targeting situational anxiety (Conacher, 1997). However, caution towards the use of beta-blockers in reactive aggressive individuals is needed because studies only show positive results on agitation and aggression in demented geriatric facilities (Shankle, Nielson, \& Cotman, 1995) and in reactive aggressive patients with brain damage (Kavoussi, \& Coccaro, 1998). Moreover, in several studies, Beta-blockers were subscripted in addition to other (e.g. antipsychotic) medication (Conacher, 1997; Silver, Yudofsky, Kogan, \& Katz, 1986).

Improving anger behavioral control in order to decrease aggression, treatment focusing on up-regulating prefrontal-cortex functions supporting enhanced ability to reappraisal of negative emotions, may also be fruitful. In this regard, research showed that reappraisal is the most affective anger regulation strategy (Denson, Moulds, \& Grisham, 2012; 
Fabiansson et al., 2012) and may lead to less negative interpretational biases, consequently altering behavioral response to perceived threat in reactive impulsive aggression (Siep et al., 2015). Supportive recent studies demonstrated neurobiological changes after behavioral interventions (see for review Cornet, De Kogel, Nijman, Raine, \& de Laan, 2014; Vaske, Galyean, \& Cullen, 2011). Moreover, some studies documented predictive value of neurobiological factors in behavioral treatment success (see for review Cornet, De Kogel, Nijman, Raine, \& de Laan, 2013). These types of studies give important insight in variability of treatment response.

An upcoming development in examining interventions and treatment of aggression and hostility, are studies focusing on nutrition, especially Omega 3 fatty acids (Hibbeln, Ferguson, \& Blasbalg, 2006). In a well-designed placebo-controlled study, a reduction of $26 \%$ incidents was reported within 231 young adult offenders (Gesch et al., 2002). In a recent study this relationship between nutrition supplements and aggressive incidents was repeated in adult male prisoners in The Netherlands, demonstrating again a reduction of $34 \%$ in the experimental group as compared to $14 \%$ increase in the control group. Although there was a relationship between supplements and reported incidents (observed behavior) there was no association between supplements and other measures of aggression (Zaalberg, Nijman, Bulten, Stroosma, \& van der Staak, 2010). Research regarding aggression reduction and nutrition is still premature, but so far seems a promising avenue for future research, in which underlying mechanisms may be further examined.

\section{Concluding remarks}

As earlier theories explain aggression as an instinctive, innate system, in more recent theories aggression is described as a learning process in which some individuals may have a biological predisposition, making them more vulnerable to react aggressively in certain circumstances. Environmental influences regarding the development of aggression are based on social learning and labeling models. Although several types of aggression have been identified (i.e., reactive versus proactive; direct versus indirect; verbal versus physical; hostile versus instrumental), little attention so far has been given to the influence of these different subtypes of aggression in their possible moderating role in treatment response. There is however, some evidence that these subtypes of aggression benefit from distinct treatment components. Reactive aggressors seem to have more profit from psychosocial interventions based on anger control (Barker, et al., 2010; Vitaro, Brendgen, \& Barker, 2006), while children and adolescents with severe problems of Conduct Disorder and proactive aggression in general are often more unwilling and unaffected by treatment resulting in less clinical improvement (Barker et al., 2010; Haas, Waschbusch, Pelham, King, Andrade, \& Carrey, 2011; Masi, Manfredi, Milone, Muatori, Polidori, Ruglioni, Muratori, 2011). Interventions for proactive aggression should possibly better focus on teaching the individual alternative strategies in achieving instrumental goals, such as negotiation and compromising (Hubbard et al., 2010). Additionally, interventions including an emotional component targeting callous unemotional 
traits often related to this subtype of aggression (Frick \& White, 2008, see also chapter 3) seem important. Cognitive Behavioral Therapy focusing on cognitions (cognitive distortions) and emotion (anger reappraisal), but also pharmacology and nutrition treatment all seem promising opportunities in reducing reactive as well as proactive aggression. However more research on predictors and possible moderators of treatment response in decreasing aggression is needed. Deficits in emotion regulation (see also introductory chapter), either a lack of regulating anger (reactive aggression) or overregulating anger emotions in the presence of lacking empathy (instrumental goal directed aggression) seem essential in understanding treatment aimed at helping individuals to control their aggressive behavior more effectively. 


\section{References}

Akers, R., \& Lee, G. (1996). A longitudinal test of social learning theory: adolescent smoking. Journal of Drug Issues, 26, 317- 343. doi: 10.1177/002204269602600203

American Psychiatric Association. (2013). Diagnostic and statistical manual of mental disorders (5th ed.). Arlington, VA: American Psychiatric Publishing.

Anderson, C. A., \& Bushman, B. J. (2002). Human aggression. The Annual Review of Psychology, 53, 27-51. doi: 10.1146/annurev.psych.53.100901.135231

Anderson, C. A., \& Carnagey, N. L. (2004). Violent evil and the general aggression model. In A. Miller (Ed.), The Social Psychology of Good and Evil (pp. 168-192). New York: Guilford Publications.

Antonius, D., Sinclair, S. J., Shiva, A., Messinger, J. W., Maile, J., Siefert, C. J., Belfi, B., Malaspina, D., \& Blais, M. A. (2013). Assessing the heterogeneity of aggressive behavior traits: exploratory and confirmatory analyses of the reactive and instrumental aggression Personality Assessment Inventory (PAl) scales. Violence and Victims, 28, 587-601. doi: 10.1891/0886-6708.VV-D-12-00032

Archer, J. (2009). Does sexual selection explain human sex differences in aggression? Behavioural and Brain Sciences, 32, 249-311. doi: 10.1017/S0140525X09990951

Babcock, J. C., Sharp, C., Tharp, A., Hepner, W., \& Stanford, M. A. (2014). Similarities and differences in impulsive/premeditated and reactive/proactive bimodal classifications of aggression. Aggression and Violent Behavior, 19, 251-262. doi: 10.1016/j.avb.2014.04.002

Bandura, A. (1983). Psychological mechanism of aggression. In R. G. Geen, \& E. I. Donnerstein (Eds.), Aggression: Theoretical and empirical reviews (pp. 1-40). New York: Academic Press.

Bandura, A., \& Ribes-Inesta, E. (1976). Analysis of Delinquency and Aggression. New Jersey: Lawrence Erlbaum Associates.

Barker, E. D., Vitaro, F., Lacourse, E., Fontaine, N. M. G., Carbonneau, R., \& Tremblay, R.E. (2010). Testing the developmental distinctiveness of male proactive and reactive aggression with a nested longitudinal experimental intervention. Aggressive Behavior, 36, 127-140. doi: 10.1002/ab.20337

Baron, R. (1977). Human Aggression. New York: Plenum.

Barratt, E. S. (1994). Impulsiveness and aggression. In J. S., Monahan, \& H. J., Steadman (Eds.), Violence and mental disorder: developments in risk assessment (pp. 61-79). Chicago: University of Chicago Press.

Baumeister, R. F., Smart, L., \& Boden, J. M. (1996). Relation of threatened egotism to violence and aggression: the dark side of high self-esteem. Psychological Review, 103, 5-33. doi: 10.1037/0033-295X.103.1.5

Baumeister, R. F., \& Vohs, K. D. (2007). Self-regulation, ego-depletion, and motivation. Social and Personality Psychology Compass, 1, 115-128. doi: 10.1111/j.1751-9004.2007.00001.x

Bakermans-Kranenburg, M. J., \& ljzendoorn, M. H. (2006). Gene-environment interaction of the dopamine D4 receptor (DRD4) and observed maternal insensitivity predicting externalizing behavior in pre-schoolers. Developmental Psychobiology, 48, 406-409. doi: 10.1002/dev.20152

Becker, H. S. (1963). Outsider: Studies in the sociology of deviance. New York: The Free Press.

Bendersky, M., Bennett, D., \& Lewis, M. (2006). Aggression at age 5 as a function of prenatal exposure to cocaine, gender, and environmental risk. Journal of Pediatric Psychology, 31, 71-84. doi: 10.1093/jpepsy/jsj025 
Berkowitz, L. (1989). Frustration-aggression hypothesis: examination and reformulation. Psychological Bulletin, 106, 59-73.

Berkowitz, L. (1990). On the formation and regulation of anger and aggression: a cognitive neoassociationistic analysis. American Psychologist, 45, 494-503. doi: 10.1037/0003-066X.45.4.494

Berkowitz, L. (1993). Pain and aggression: some findings and implications. Motivation and Emotion, 17, 277-293. doi: 10.1007/BF00992223

Berkowitz, L, \& LePage, A. (1967). Weapons as aggression-eliciting stimuli. Journal of Personality and Social Psychology, 7, 202-207. doi: 10.1037/h0025008

Bevilacque, L., Doly, S., Kaprio, J., Yuan, Q., Tikkanen, R., \& Paunio, T (2010). A population specific HTR2B stop codon predisposes to severe impulsivity. Nature, 468, 1061-1066. doi: 10.1038/nature09629

Blair, R. J. R. (2004). The roles of the orbital frontal cortex in the modulation of antisocial behaviour. Brain and Cognition, 55, 198-208. doi: 10.1016/S0278-2626(03)00276-8

Bobadilla, L., Wampler, M., \& Taylor, J. (2012). Proactive and reactive aggression are associated with different physiological and personality profiles. Journal of Social and Clinical Psychology, 31, 458-487. doi: 10.1521/jscp.2012.31.5.458

Borduin, C. M. (1999). Multisystemic treatment of criminality and violence in adolescents. Journal of the American Academy of Child \& Adolescent Psychiatry, 38, 242-49. doi: 10.1097/00004583-199903000-00009

Brower, M. C., \& Price, B. H. (2001). Neuropsychiatry of frontal lobe dysfunction in violent and criminal behaviour: a critical review. Journal of Neurology, Neurosurgery \& Psychiatry, 71, 720-726. doi: 10.1136/jnnp.71.6.720

Buchmann, A., Hohmann, S., Brandeis, D., Banaschewski, T., \& Poustka, L., (2014). Aggression in children and adolescents. In Miczek, K. A., Meyer-Lindenberg, A. (Eds.), Neuroscience of Aggression. New York: Springer.

Buckley, P. F. (1999). The role of typical and atypical antipsychotic medications in the management of agitation and aggression. Journal of Clinical Psychiatry, 60, 52-60.

Bufkin, J. L., \& Luttrell, V. (2005). Neuroimaging studies of aggressive and violent behavior. Current findings and implications for criminology and criminal justice. Trauma, Violence, \& Abuse, 6, 176-191. doi: $10.1177 / 1524838005275089$

Carré, J. M., Iselin, A-M. R., Welker, K. M., Hariri, A. R., \& Dodge, K A. (2014). Testosterone reactivity to provocation mediates the effect of early intervention on aggressive behavior. Psychological Science, 25, 1140-1146. doi: 10.1177/0956797614525642

Caspi, A., McClay, J., Moffitt, T.E., Mill, J., Martin, J., Craig, I.W., Taylor, A., \& Poulton, R. (2002). Role of genotype in the cycle of violence in maltreated children. Science, 297, 851-854. doi: 10.1126/science.1072290

Cima, M., \& Raine, A. (2009). Distinct characteristics of psychopathy relate to different subtypes of aggression. Personality and Individual Differences, 47, 835-840. doi: 10.1016/j.paid.2009.06.031

Cima, M., Nicolson, N., de Lijster, J., \& Popma, A. (2015). Salivary cortisol reactivity patterns in psychopathic and non-psychopathic offenders. Manuscript submitted for publication.

Cima, M., \& Siep, N. (2015). Neurobiologische benaderingen van psychopathologie. In Molen, H.T. van der, Simon, E., Lankveld, J. van (ed.), Klinische psychologie: Theorieën en psychopathologie (pp.3 - 54). Noordhoff Uitgevers: Groningen/Houten. 
Cima, M., Smeets, T., \& Jelicic, M. (2008). Self-reported trauma, cortisol levels, and aggression in psychopathic and non-psychopathic prison inmates. Biological Psychology, 78, 75-86. doi: 10.1016/j.biopsycho.2007.12.011

Cima M., Tonnaer, F., \& Lobbestael, J. (2007). Moral emotions in predatory and impulsive offenders using implicit measures. Netherlands Journal of Psychology, 4, 144-155. doi: 10.1007/BF03061076

Citrome, L., \& Volavka, J. (1997). Psychopharmacology of violence. Part I: assessment and acute treatment. Psychiatric Annals, 27, 691-695. doi: 10.3928/0048-5713-19971001-10

Cloninger, C. R., Sigvardsson, S., Bohman, M., \& von Knorring, A. L. (1982). Predisposition to petty criminality in Swedish adoptees, II. Cross-fostering analysis of gene-environment interaction. Archives of General Psychiatry, 39, 1242-1249. doi: 10.1001/archpsyc.1982.04290110010002

Collins, A. M., \& Loftus, E. F. (1975). A spreading activation of semantic processing. Psychological Review, 82, 407-428. doi: 10.1037/0033-295X.82.6.407

Conacher, G. N. (1997). Pharmacological approaches to impulsive and aggressive behavior. In C. D. Webster, \& M. A. Jackson (Eds.), Impulsivity: Theory, Assessment, and Treatment (pp. 394-408). New York: Guilford Press.

Cornet, L., De Kogel, C., Nijman, H., Raine, A., \& van der Laan, P. (2013). Neurobiological factors as predictors of cognitive-behavioral therapy outcome in individuals with antisocial behavior: a review of the literature. International Journal of Offender Therapy and Comparative Criminology, 9, 1-18. doi: $10.1177 / 0306624 \times 13494694$

Cornet, L., De Kogel, C., Nijman, H., Raine, A., \& van der Laan, P. (2015). Neurobiological changes after intervention in individuals with anti-social behaviour: a literature review. Criminal Behavior and Mental Health, 25, 10-27. doi: 10.1002/cbm.1915

Crick, N. R, \& Dodge, K. A. (1994). A review and reformulation of social information processing mechanisms in children's adjustment. Psychological Bulletin, 115, 74-101. doi: 10.1037/0033-2909.115.1.74

Crowe, R. R. (1975). An adoptive study of psychopathology: Preliminary results from arrest records and psychiatric hospital records. In R. R. Fieve, D. Rosenthal, \& H. Brill (Eds.), Genetic research in psychiatry (pp. 95-103). Baltimore: Johns Hopkins University Press.

Curtis, N. M., Ronan, K. R., \& Borduin, C. M. (2004). Multisystemic treatment: A meta-analysis of outcome studies. Journal of Family Psychology, 18, 411-419. doi: 10.1037/0893-3200.18.3.411

Damasio, H., Grabowski, T., Frank, R., Galaburda, A. M., \& Damasio, A. R. (1994). The return of Phineas Gage: clues about the brain from the skull of a famous patient. Science, 264, 1102-1105. doi: 10.1126/science.8178168

Dambacher, F., Sack, A. T., Lobbestael, J., Arnts, A., Brugman, S., \& Schuhman, T. (2014). Out of control: evidence for anterior insula involvement in motor impulsivity and reactive aggression. Social Cognitive and Affective Neuroscience, 17, 1-9. doi: 10.1093/scan/nsu077

Denson, T. F., Moulds, M. L., \& Grisham, J. R. (2012). The effects of rumination, reappraisal, and distraction on anger experience. Behavior Therapy, 43, 355-364. doi: 10.1016/j.beth.2011.08.001

Denson, T. F., Pederson, W. C., Ronquillo, J., \& Nandy, A. S. (2009). The angry brain: neural correlates of anger, angry rumination, and aggressive personality. Journal of Cognitive Neuroscience, 21, 734-744. doi: 10.1162/jocn.2009.21051 
Dodge, K. A. (2006). Translational science in action: hostile attributional style and the development of aggressive behavior problems. Development and Psychopathology, 18, 791-814. doi: 10.1017/S0954579406060391

Dodge, K. A., \& Coie, J. D. (1987). Social information processing factors in reactive and proactive aggression in children's peer groups. Journal of Personality and Social Psychology, 53, 1146-1158. doi: $10.1037 / 0022-3514.53 .6 .1146$

Dollard, J., Doob, L. W., Miller, N. E., Mowrer, O. H., \& Sears, R. R. (1939). Frustration and aggression. New Haven: Yale University Press.

Down, R., Willner, P., Watts, L., \& Griffiths, J. (2011). Anger management groups for adolescents: a mixed-methods study of efficacy and treatment preferences. Clinical Child Psychology \& Psychiatry, 16, 33-52. doi: 10.1177/1359104509341448

Duncan, L.E., \& Keller, M.C. (2011). A critical review of the first 10 years of candidate gene-by-environment interaction research in psychiatry. American Journal of Psychiatry, 168, 1041-1049. doi: 10.1176/appi.ajp.2011.11020191

Duncan, L.E., Pollastri, A.R., \& Smoller, J.W. (2014). Mind the gap: why many geneticists and psychological scientists have discrepant views about gene-environment interaction (GXE) research. American Psychologist, 69, 249-268. doi: 10.1037/a0036320

Eatmon, C. V., \& Daniel, J. S. (2014). Should you use an anticonvulsant to treat impulsivity and aggression? Current Psychiatry, 13, 49-51. www.mdedge.com/currentpsychiatry/article/81206/neurology/shouldyou-use-anticonvulsant-treat-impulsivity-and/pdf

Englander, E. K. (2003). Understanding violence (2nd ed.). Mahwah: Lawrence Erlbaum Associates.

Evenden, J. L. (1999). Varieties of impulsivity. Psychopharmacology, 146, 348-361. doi: 1 0.1007/PL00005481

Fabian, J. M. (2010). Neuropsychological and neurological correlates in violent and homicidal offenders: a legal and neuroscience perspective. Aggression and Violent Behavior, 15, 209-223. doi: 10.1016/j.avb.2009.12.004

Fabiansson, E. C., Denson, T. F., Moulds, M.L., Grisham, J.R., \& Schira, M.M. (2012). Don’t look back in anger: neural correlates of reappraisal, analytical rumination, and angry rumination during recall of an anger-inducing autobiographical memory. Neurlmage, 59, 2974-2981. doi: 10.1016/j.neuroimage.2011.09.078

Feilhauer, J., Cima, M., Korebrits, A., \& Nicolson, N. (2013). Salivary cortisol and psychopathy dimensions in detained antisocial adolescents. Psychoneuroendocrinology, 38, 1586-1595. doi: 10.1016/j.psyneuen.2013.01.005

Frick, P.J., \& White, S.F. (2008). Research review: the importance of callous unemotional traits for developmental models of aggressive and antisocial behavior. Journal of Child Psychology and Psychiatry, 49, 359-375. doi: 10.1111/j.1469-7610.2007.01862.x

Freud, S. (1955). Beyond the pleasure principle. (J. Strachey, Trans.). London: Hogaths Press (Original work published in 1920).

Gesch, C. B, Hammond, S. M., Hampson, S. E., Eves, A., \& Crowder, M. J. (2002). Influence of supplementary vitamins, minerals and essential fatty acids on the antisocial behavior of young adult prisoners. Randomised, placebo-controlled trial. British Journal of Psychiatry, 181, 22-28. doi: 10.1192/bjp.181.1.22

Glenn, A. L., Raine, A., Venables, P. \& Mednick, S.A. (2007). Early temperamental and psychophysiological precursors of adult psychopathic personality. Journal of Abnormal Psychology, 116, 508-518. doi: 10.1037/0021-843X.116.3.508 
Gilligan, J. (1997). Violence: Reflections on a national epidemic. New York, NY: Vintage Books.

Goldstein, A. P. (1996). Aggression Replacement Training: teaching prosocial behaviors to antisocial youth. In R. Ross, D. H. Antonowicz, \& K. Dhuluval (eds.), Effective Delinquency Prevention and Offender Rehabilitation. Ottawa: AIR Training and Publications.

Gottfredson, M. R., \& Hirschi, T. (1990). General theory of crime. Stanford: Stanford University Press.

Guastella, A. J., Kenyon, A. R., Alvares, G. A., Carson, D. S., \& Hickie, I. B. (2010). Intranasal arginine vasopressin enhances the encoding of happy and angry faces in humans. Biological Psychiatry, 67, 1220-1222. doi: 10.1016/j.biopsych.2010.03.014

Haas, S. M., Waschbusch, D. A., Pelham, W. E. Jr, King, S., Andrade, B. F., \& Carrey, N. J. (2011). Treatment response in CP/ADHD children with callous/unemotional traits. Journal of Abnormal Child Psychology, 39, 541-552. doi: 10.1007/s10802-010-9480-4

Hawkins, K. A., \& Trobst, K. K. (2000). Frontal lobe dysfunction and aggression: conceptual issues and research findings. Aggression and Violent Behaviour, 5, 147-157. doi: 10.1016/S1359-1789(98)00033-0

Hay, D. F., Pawlby, S., Waters, C. S., Perra, O. \& Sharp, D. (2010). Mothers' antenatal depression and their children's antisocial outcomes. Child Development, 81, 149-165. doi: 10.1111/j1467-8624.2009.01386.x

Henggeler, S. W., Cunningham, P. B., Pickrel, S. G., Schoenwald, S. K., \& Brondino, M. J. (1996). Multisystemic therapy: an effective violence prevention approach for serious juvenile offenders. Journal of Adolescence, 19, 47-61. doi: 10.1006/jado.1996.0005

Henggeler, S. W., Schoenwald, S. K., Borduin, C. M., Rowland, M. D., \& Cunningham, P. B. (1998). Multisystemic treatment of antisocial behavior in children and adolescents. New York: Guilford.

Hibbeln, J. R., Ferguson, T. A., \& Blasbalg, T. L. (2006). Omega-3 fatty acid deficiencies in neurodevelopment, aggression and autonomic dysregulation: Opportunities for intervention. International Review of Psychiatry, 18, 107-118. doi: 10.1080/09540260600582967

Huesmann, L. R. (1988). An information processing model for the development of aggression. Aggressive Behavior, 14, 13-24. doi: 10.1002/1098-2337(1988)14:1<13::AID-AB2480140104>3.0.CO;2-J

Hirschi, T., \& Gottfredson, M. R. (1983). Age and the explanation of crime. American Journal of Sociology, 89, 552-584. doi: 10.1086/227905

Hollander, E., Allen, A., Lopez, R. P., Bienstock, C. A., Grossman, R., Siever, L. J., Merkatz, L., \& Stein, D. J. A. (2001). A preliminary double-blind, placebo-controlled trial of divalproex sodium in borderline personality disorder. Journal of Clinical Psychiatry, 62, 199-203. https://www.psychiatrist.com/JCP/ article/Pages/2001/v62n03/v62n0311.aspx

Huband, N., Ferriter, M., Nathan, R., \& Jones, H. (2010). Antiepileptics for aggression and associated impulsivity. Cochrane Database of Systematic Reviews, Issue 2, Art. No.: CD003499. doi: 10.1002/14651858.CD003499.pub3

Hubbard, J. A., Morrow, M. T., Romano, L. J., \& McAuliffe, M. D. (2010). The role of anger in children's reactive versus proactive aggression: review of findings, issues of measurement, and implications for intervention. In W. F. Arsenio, E. A. Lemerise (Eds.), Emotions, aggression, and morality in children: bridging development and psychopathology. Washington DC: American Psychological Association. 
Huijbregts, S., Seguin J., Zoccolillo, M., Boivin, M., \& Tremblay, R. E. (2008). Maternal prenatal smoking, parental antisocial behavior, and early childhood physical aggression. Development and Psychopathology, 20, 437-453. doi: 10.1017/S0954579408000217

Kavoussi, R. J., \& Coccaro, E. F. (1998). Divalproex sodium for impulsive aggressive behavior in patients with personality disorder. Journal of Clinical Psychiatry, 59, 676-680. http://www.psychiatrist.com/jcp/ article/Pages/1998/v59n12/v59n1206.aspx

King, B. (2012). Psychological theories of violence, Journal of Human Behavior in the Social Environment, 22, 553-571. doi: 10.1080/10911359.2011.598742

Kline, K. (2004). Conduct Disorder, Antisocial Personality Disorder, and Psychopathy. Unpublished presentation, Florida State University at Panama.

Kohn, P. M., Cowles, M. P., \& Lafreniere, K. (1987). Relationships between psychometric and experimental measures of arousability. Personality and Individual Differences, 8, 225-31. doi: 10.1016/0191-8869(87)90178-4

Kouri, E. M. Lukas, S. E., Pope, H. G., \& Olivia, P. S. (1995). Increased aggressive responding in male volunteers following the administration of gradually increasing doses of testosterone cypionate. Drug and Alcohol Dependence, 40, 73-79. doi: 10.1016/0376-8716(95)01192-7

Krahé, B. (2001). The social psychology of aggression. Philadelphia: Psychology Press.

Krug, E. G., Dahlberg, L. L. Mercy, J. A., Zwi, A. B., \& Lozano, R. (2002). World report on violence and health. Geneve: World Health Organization.

Lahey, B., Moffitt, T. E., \& Caspi, A. (2003). The causes of conduct disorder and serious juvenile delinquency. New York: Guilford Press.

Lane, S. D., \& Cherek, D. R. (2000). Analysis of risk taking in adults with a history of high risk behavior. Drug and Alcohol Dependence, 60, 179-187. doi: 10.1016/S0376-8716(99)00155-6

Lindquist, K. A., Wager, T. D., Kober, H., Bliss-Moreau, E., \& Barrett, L. F. (2012). The brain basis of emotion: a meta-analytic review. Behavioral and Brain Sciences, 35, 121-202. doi: 10.1017/ S0140525X11000446

Lorenz, K. (1974). On aggression. New York: Harcourt Brace Jovanovich.

Masi, G., Manfredi, A., Milone, A., Muatori, P., Polidori, L., Ruglioni, L., \&Muratori, F. (2011). Predictors of nonresponse to psychosocial treatment in children and adolescents with disruptive behaviour disorders. Journal Child Adolescent Psychopharmacology, 21, 51-55. doi: 10.1089/cap.2010.0039

Marsh, R. L., Hicks, J. L., \& Bink, M. L. (1998). Activation of completed, uncompleted and partial completed intentions. Journal of Experimental Psychology: Learning, Memory and Cognition, 24, 350-361. doi: 10.1037/0278-7393.24.2.350

Mednick, S. A., Brennan, P, \& Kandel, E. (1988). Predisposition to violence. Aggressive Behavior, 14, 25-33. doi: 10.1002/1098-2337(1988)14:1<25::AID-AB2480140105>3.0.CO;2-9

Mehta, P. H. \& Beer, J. (2009). Neural mechanisms of the testosterone-aggression relation: the role of orbitofrontal cortex. Journal of Cognitive Neuroscience, 22, 2357-2368. doi: 10.1162/jocn.2009.21389 Meichenbaum, D. (1996). Stress inoculation training for coping with stressors. The Clinical Psychologist, 49, 4-7. http://www.apa.org/divisions/div12/rev_est/sit_stress.html 
Mellow, A. M., Solano-Lopez, C., \& Davis, S. (1993). Sodium valproate in the treatment of behavioral disturbance in dementia. Journal of Geriatric Psychiatry and Neurology, 6, 205-209. doi: $10.1177 / 089198879300600404$

Miles, D. R., \& Carey, G. (1997). Genetic and environmental architecture of human aggression. Journal of Personality and Social Psychology, 72, 207-217. doi: 10.1037/0022-3514.72.1.207

Miller, N. E., Sears, R. R., Mowrer, O. H., Doob, L. W., \& Dollard, J., (1941). The frustration-aggression hypothesis. Psychological Review, 48, 337-342. doi: 10.1037/h0055861

Mischel, W. (1973). Toward a cognitive social learning reconceptualization of personality. Psychological Review, 80, 252-283. doi: 10.1037/h0035002

Montaya, E. R., terburg, D., Bos, P.A., \& van Honk, J. (2012). Testosterone, cortisol, and serotonin as key regulators of social aggression: a review and theoretical perspective. Motivation and Emotion, 36, 65-73. doi: 10.1007/s11031-011-9264-3

National Center. (2007). Aggression Replacement Training ${ }^{\circledR}$ (ART $\left.{ }^{\circledR}\right)$ : Fractsheet. Waltham: The National Center for Mental Health Promotion and Youth Violence Prevention.

Novaco, R. W. (1975). Anger control: the development and evaluation of an experimental treatment. Lexington: Heath.

Nyth, A. L., \& Gottfries, C. G. (1990). The clinical efficacy of citalopram in treatment of emotional disturbances in dementia disorders. A Nordic multicentre study. British Journal of Psychiatry, 157, 894-901. doi: 10.1192/bjp.157.6.894

Obradovic, J., Bush, N. R., Stamperdahl, J., Adler, N. E., \& Boyce's, W. T. (2010). Biological sensitivity to context: the interactive effects of stress reactivity and family adversity on socioemotional behavior and school readiness. Child Development, 81, 270-289. doi: 10.1111/j.1467-8624.2009.01394.x

Pavlov, K. A., Chistiakov, D. A., \& Chekhonin, V. P. (2012). Genetic determinants of aggression and impulsivity in humans. Journal of Applied Genetics, 53, 61-82. doi: 10.1007/s13353-011-0069-6

Perry, B. D. (2001). The neurodevelopmental impact of violence in childhood. In D. Schetky \& E. P. Benedek (Eds.), Textbook of child an adolescent forensic psychiatry (pp. 221-238). Washington: American Psychiatric Press.

Pfohl, S. (1994). Images of deviance and social control: a sociological history, 2nd Ed., New York: McGraw-Hill.

Phan, K. L., Lee, R., \& Coccaro, E. F. (2011). Personality predictors of anti-aggressive response to fluoxetine: inverse association with neuroticism and harm avoidance. International Clinical Psychopharmacology, 26, 278-283. doi: 10.1097/YIC.0b013e32834978ac

Pokhrel, P., Sussman, S., Sun, P., Kniazer, V., \& Masagutov, R. (2010). Social self-control, sensation seeking, and substance use in samples of US and Russian adolescents. American Journal of Health Behavior, 34, 374-384. doi: 10.5993/AJHB.34.3.12

Popma, A., Vermeiren, R., Geluk, C. A. M. L., Rinne, T., van den Brink, W., Knol, D. L., Jansen, L. M.C., van Engeland, H., \& Doreleijers, T. A. H. (2007). Cortisol moderates the relationship between testosterone and aggression in delinquent male adolescents. Biological Psychiatry, 61, 405-411. doi: 10.1016/j.biopsych.2006.06.006

Poustka, L., Maras, A., Hohm, E., Fellinger, J., Holtmann, M., Banaschewski, T., Lewicka, S., Schmidt, M. H., Esser, G., \& Laucht, M. (2010). Negative association between plasma cortisol levels and aggression 
in a high-risk community sample of adolescents. Journal of Neural Transmission, 117, 621-627. doi: 10.1007/s00702-010-0386-7

Pratt, T. C., \& Cullen, F. T. (2000). The empirical status of Gottfredsons and Hirschi's general theory of crime: a meta analysis. Criminology, 38, 931-964. doi: 10.1111/j.1745-9125.2000.tb00911.x

Raine, A., Buchsbaum, M. S., \& La Casse, L. (1997). Brain abnormalities in murderers indicated by positron emission tomography. Biological Psychiatry, 42, 495-508. doi: 10.1016/S0006-3223(96)00362-9

Raine, A., Dodge, K., Loeber, R., Gatzke-Kopp, L., Lynam, D., Reynolds, C., Stouthamer-Loeber, M., \& Liu, J. (2006). The Reactive-Proactive Aggression Questionnaire: differential correlates of reactive and proactive aggression in adolescent boys. Aggressive Behavior, 32, 159-171. doi: 10.1002/ab.20115

Raine, A., Lencz, T., Bihrle, S., Lacasse, L., \& Colletti, P. (2000). Reduced prefrontal gray matter volume and reduced autonomic activity in antisocial personality disorder. Archives of General Psychiatry, 57, 119-127. doi: 10.1001/archpsyc.57.2.119

Raine, A., Meloy, J.R., Bihrle, S., Stoddard, J., Lacasse, L., \& Buchsbaum, M.S. (1998). Reduced prefrontal and increased subcortical brain functioning assessed using positron emission tomography in predatory and affective murderers. Behavioral Sciences and the Law, 16, 319-332. doi: 10.1002/(SICI)10990798(199822)16:3<319::AID-BSL311>3.0.CO;2-G

de Ruiter, C., \& Hildebrand, M. (1999). Behandelingsstrategieën bij forensich-psychiatrische patiënten. [Treatment strategies with forensic psychiatric patients]. Bohn Stafleu van Loghum: Houten.

Sagarin, E. (1975). Deviants and deviance. New York: Praeger.

Scarpa, A., \& Raine, A. (2000). Violence associated with anger and impulsivity. In J. C. Borod (Eds.), The neuropsychology of emotion: series in affective science (pp. 320-339). New York: Oxford University Press.

Schachter, S., \& Singer, J. (1962). Cognitive, social, and physiological determinants of emotional state. Psychological Review, 69, 379-399. doi: 10.1037/h0046234

Schank, R. C., \& Abelson, R. P. (1977). Scripts, plans, goals and understanding: an inquiry into human knowledge structures. Hillsdale: Erlbaum.

Schulkin, J. (2003). Rethinking homeostasis: allostatic regulation in physiology and pathophysiology. Cambridge, MA: MIT Press.

Schneider, L. S., Pollock, V. E., \& Lyness, S. A. A. (1990). Metaanalysis of controlled trials of neuroleptic treatment in dementia. Journal of the American Geriatrics Society, 38, 553-563. doi: 10.1111/j.15325415.1990.tb02407.x

Schulz, S. C., Camlin, K. L, Berry, S. A., \& Jesberger, J. A. (1999). Olanzapine safety and efficacy in patients with borderline personality disorder and comorbid dysthymia. Biological Psychiatry, 46, 1429-1435. doi: 10.1016/S0006-3223(99)00128-6

Séguin, J. R. (2013). The frontal lobe and aggression. European Journal of Developmental Psychology, 6 , 100-119. doi: 10.1080/17405620701669871

Seo, D., Patrick, C. J., \& Kennealy, P. J. (2008). Role of serotonin and dopamine system interactions in the neurobiology of impulsive aggression and its comorbidity with other clinical disorders. Aggression and Violent Behavior, 13, 383-395. doi: 10.1016/j.avb.2008.06.003 
Shankle, W. R., Nielson, K. A., \& Cotman, C. W. (1995). Low-dose propranolol reduces aggression and agitation resembling that associated with orbitofrontal dysfunction in elderly demented patients. Alzheimer Disease \& Associated Disorders, 9, 233-237. doi: 10.1097/00002093-199500940-00010

Sheard, M. H., Marini, J. L., Bridges, C. I., \& Wagner, E. (1976). The effect of lithium on impulsive aggressive behavior in man. American Journal of Psychiatry, 133, 1409-1413. doi: 10.1176/ajp.133.12.1409

Siep, N., Tonnaer, F., Ven, V., van de, Arntz, A., Raine, A., \& Cima, M. (2018). Anger provocation increases limbic and decreases medial prefrontal cortex connectivity with the left amygdala in reactive aggressive violent offenders. Brain Imaging and Behavior, doi: 10.1007/s11682-018-9945-6

Siever, L. J. (2008). Neurobiology of aggression and violence. American Journal of Psychiatry, 165, 429-442. doi: 10.1176/appi.ajp.2008.07111774

Silver, J. M., Yudofsky, S. C., Kogan, M. \& Katz, B. L. (1986). Elevation of thioridazine plasma levels by propanolol. American Journal of Psychiatry, 143, 1290-1292. doi: 10.1176/ajp.143.10.1290

Smeets., K. C., Leeijen, A. A. M., van der Molen, M. J., Scheepers, F. E., Buitelaar, J. K., \& Rommelse, N. N. J. (2015). Treatment moderators of cognitive behavior therapy to reduce aggressive behavior: a meta-analysis. European Child and Adolescent Psychiatry, 24, 255-264. doi: 10.1007/s00787-014-0592-1

Soloff, P. H., Cornelius, J., George, A., Nathan, S., Perel, J. M., \& Ulrich, R. F. (1993). Efficacy of phenelzine and haloperidol in borderline personality disorder. Archives of General Psychiatry, 50, 377-385. doi: 10.1001/archpsyc.1993.01820170055007

Stanford, M. S., Anderson, N. E., Lake, S. L., \& Baldridge, R. M. (2009). Pharmacologic treatment of impulsive aggression with antiepileptic drugs. Current Treatment Options in Neurology, 11, 383-390. doi: 10.1007/s11940-009-0043-3

Streissguth, A. P., Barr, H. M., Bookstein, F. L., Sampson, P. D., \& Olson, H. C. (1999). The Iong-term neurocognitive consequences of prenatal alcohol: a 14-year study. Psychological Science, 10, 186-190. doi: 10.1111/1467-9280.00131

Summers, C. H., Korzan, W. J., Lukkes, J. L., Watt, M. J., Forster, G. L., Øverli, Ø., Höglund, E., Larson, E. T., Ronan, P. J., Matter, J. M., Summers, T. R., Renner, K. J., \& Greenberg, N. (2005) Does serotonin influence aggression? Comparing regional activity before and during social interaction. Physiological and Biochemical Zoology, 78, 679-694. doi: 10.1086/432139

Sutherland, E. H. (1939). Principles of criminology, 3rd Ed., Philadelphia: J.B. Lippincott.

Swann, A. C. \& Hollander, E. (2002). Impulsivity and aggression: diagnostic challenges for the clinician. A monograph for continuing medical education credit. Illinois: ACCESS Medical Group.

Swanson, J. W., Swartz, M. S., Van Dorn, R. A., Volavka, J., Monahan, J., Stroup, T. S., \& Lieberman, J. A. (2008). Comparison of antipsychotic medication effects on reducing violence in people with schizophrenia. British Journal of Psychiatry, 193, 37-43. doi: 10.1192/bjp.bp.107.042630

Taylor, J., Loney, B. R., Bobadilla, L., Iacono, W. G., \& McGue, M. (2003). Genetic and environmental influence on psychopathy: findings from an adolescent male twin cohort. Journal of Abnormal Child Psychology, 31, 633-645. doi: 10.1023/A:1026262207449

Tedeschi, J. T., Gaes, G. G., \& Rivera, A. N. (1977). Aggression and the use of coercive power. Journal of Social Issues, 33, 101-125. doi: 10.1111/j.1540-4560.1977.tb01871.x 
Tedeschi, J. T., \& Felson, R. B. (1994.) Violence, aggression, \& coercive actions. Washington: APA.

Terburg, D., Morgan, B. \& van Honk, J. (2009). The testosterone-cortisol ratio: a hormonal marker for proneness to social aggression. International Journal of Law and Psychiatry, 32, 216-223. doi: 10.1016/j.jijp.2009.04.008

Terburg, D., Peper, J. S., Morgan, B., \& van Honk, J. (2009). Sex differences in human aggression: The interaction between early developmental and later activational testosterone. Behavioral and Brain Sciences, 32, 290-290. doi: 10.1017/S0140525X09990367

Thompson, D. A., Arora, T., \& Sharp, S. (2002). Bullying-effective strategies for long term improvement. London: Routledge/Falmer.

Tomkins, S. S. (1954). Script theory: differential magnification of affects. Fourteenth International Congress of Psychology. Montreal: Canada.

Tonnaer, F. \& Chakhssi, F. (2007). Incident profiling on patients characteristics. 5th EU-Violence in Clinical Psychiatry: Amsterdam.

Tonnaer, F., Cima, M., \& Arntz, A. Explosive matters: does venting anger reduce or increase aggression? Differences in anger provocation responses in violent offenders. Manuscript submitted.

Tonnaer, F., Cima, M., \& Arntz, A. (2016a). Modeling impulsivity in forensic patients: a three-dimensional model of impulsivity. American Journal of Psychology, 129, 429-441. doi:10.5406/amerjpsyc.129.4.0429

Tonnaer, F., Cima, M., \& Arntz, A. (2016b). Executive (dys)functioning and impulsivity as possible vulnerability factors for aggression in forensic patients. Journal of Mental and Nervous Disease, 204, 280-286. doi: 10.1097/NMD.0000000000000485

Van Honk, J., Harmon-Jones, E., Morgan, B.A., \& Schutter, D.L.G. (2010). Socially explosive minds: the triple imbalance hypothesis of reactive aggression. Journal of Personality, 78, 67-94. doi: 10.1111/j.1467-6494.2009.00609.x

Vaske, J., Galyean, K., \& Cullen, F. T. (2011). Toward a biosocial theory of offender rehabilitation: why does cognitive-behavioral therapy work? Journal of Criminal Justice, 39, 90-102. doi: 10.1016/j.jcrimjus.2010.12.006

Vazsonyi, A. T. \& Belliston, L. M. (2007). The family> low self-control > deviance: a cross-cultural and cross-national test of self-control theory. Criminal Justice and Behavior, 34, 505-530. doi: 10.1177/0093854806292299

Vitaro, F., \& Brendgen, M. (2005). Proactive and reactive aggression: a developmental perspective. In R. E. Tremblay, W. M. Hartup, \& J. Archer (Eds.), The developmental origins of aggression (pp. 178 -201). New York: Guilford Press.

Vitaro, F., Brendgen, M., \& Barker, E. D. (2006). Subtypes of aggressive behaviors: a developmental perspective. International Journal of Behavioural Development, 30, 12-19. doi: 10.1177/0165025406059968

Warr, M., \& Stafford, M. (1991). The influence of delinquent peers: what they think or what they do? Criminology, 29, 851-866. doi: 10.1111/j.1745-9125.1991.tb01090.x

Waters, H., Hyder, A., Rajkotia, Y., Basu, S., Rehwinkel, J. A., \& Butchart, A. (2004). The economic dimensions of interpersonal violence. Geneva: World Health Organization. 
Young, J. L., \& Hillbrand, M. (1994). Carbamazepine lowers aggression: a review. Bulletin of the American Academy of Psychiatry and the Law, 22, 53-61. http://jaapl.org/content/jaapl/22/1/53.full.pdf

Zaalberg, A., Nijman, H., Bulten, E., Stroosma, L., \& van der Staak, C. (2010). Effects of nutritional supplements on aggression, rule-breaking, and psychopathology among young adult prisoners. Aggressive Behavior, 36, 117-126. doi: 10.1002/ab.20335

Zillmann, D. (1983). Arousal and aggression. In R. G. Geen \& E. I. Donnerstein (Eds.), Aggression: Theoretical and empirical reviews (pp. 75-102). New York: Academic Press.

Zohsel, K., Buchmann, A. F., Blomeyer, D., Hohm, E., Schmidt, M. H., Esser, G., Brandeis, D., Banaschewski, T., \& Lauch, M. (2013). Mothers' prenatal stress and their children's antisocial outcomes - a moderating role for the dopamine D4 receptor (DRD4) gene. Journal of Child Psychology and Psychiatry, 55, 69-76. doi: $10.1111 /$ jcpp.12138 


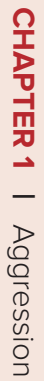




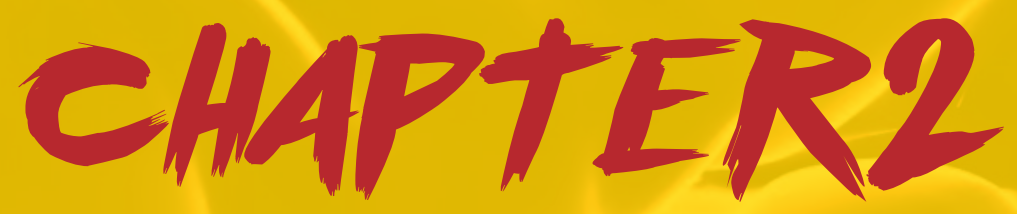

\section{Modeling impulsivity in forensic patients: a three-dimensional model of impulsivity}

This chapter has been published as Tonnaer, F., Cima, M., \& Arntz, A. (2016). Modeling Impulsivity in Forensic Patients: A Three-Dimensional Model of Impulsivity. American Journal of Psychology, 129, 429-441. doi: 10.5406/amerjpsyc.129.4.0429 


\section{Abstract}

In the current study we investigated whether a multidimensional model could underlie impulsivity and its associations with various disorders in a forensic sample. Data was available from self-report and behavioral impulsivity instruments of 87 forensic patients. Principal component analysis (PCA) was used to derive a dimensional impulsivity model, and the relationship between and possible predictive validity of impulsivity dimensions for psychopathology was investigated using product moment correlations and regression analysis. A 3-dimensional model of impulsivity was derived, with factors labeled impulsive decision making, sensation seeking, and response inhibition. Impulsive decision making was a predictor for a history of drug dependence, the impulsive lifestyle facet of psychopathy, and antisocial personality disorder. Sensation seeking was not related to any psychopathology. Inadequate response inhibition was a predictor for drug dependence, psychopathy, and antisocial personality disorder. Given the importance of the concept impulsivity with regard to forensic risk assessment, the current results replicated earlier impulsivity models and imply that impulsivity is a crucial target for diagnosis and interventions and underlines the importance to consider impulsivity as a multidimensional construct.

Keywords principal component analysis (PCA), sensation seeking, decision making, response inhibition, psychopathology, forensic patients, impulsivity 


\section{Introduction}

Impulsivity plays a key role in problematic human behavior and mental disorders (American Psychiatric Association, APA, 2013). Despite its importance, there is little consensus regarding the concept of impulsivity (Gay, Rochat, Billieux, D’Acremont, \& Van der Linden, 2008). Impulsivity is defined by the International Society for Research on Impulsivity as "behavior without adequate thought, the tendency to act with less forethought than do most individuals of equal ability and knowledge, or a predisposition toward rapid, unplanned reactions to internal or external stimuli without regard to the negative consequences of these reactions" (http://impulsivity.org/). More consensus is rising that impulsivity is a multifaceted construct, and different dimensional models have been proposed (Coskunpinar, Dir, \& Cyders, 2013; Dalley, Everitt, \& Robins, 2011). For instance, Reynolds, Ortengren, Richards, and de Wit (2006) and Trent and Davies (2012) described a cognitive, two-dimensional model including impulsive decision making, referring to delay discounting and risk taking, and impulsive disinhibition, referring to inhibitory control. In addition, Harden and Tucker-Drob (2011) described a developmental dual system with impulsivity, defined as the tendency to act immediately on behavioral impulse, and sensation seeking, defined as the tendency to seek novel, exciting situations.

In more recent research Reynolds and colleagues added a third dimension to the two original impulsivity dimensions (impulsive decision making and impulsive disinhibition), which they named impulsive inattention, referring to deficits in sustained attention (Harris et al., 2014). This addition is in line with an earlier three-dimensional model presented by Patton, Stanford, and Barratt (1995) incorporating the behavioral, psychological, social, and medical perspective into motor impulsiveness, referring to perseverance and acting without thinking; nonplanning, covering self-control and cognitive complexity; and attentional impulsiveness, referring to cognitive instability (Barratt, 1993).

Whiteside and Lynam (2001) presented a four-factor model, based on the Five-Factor Model of personality (McCrae \& Costa, 1990) and commonly used impulsivity questionnaires resulting in the UPPS model, with urgency, defined as a tendency of sudden response to negative affect $(U)$; premeditation, defined as the tendency to think before acting $(P)$; perseverance, defined as the ability of sustained attention (P); and sensation seeking, defined as the tendency to pursue excitement (S). Another personality-based, four-factor model was introduced earlier by Eysenck and Eysenck (1985), containing the dimensions narrow impulsiveness, reflecting acting without thinking; risk taking, indicating taking a dare; nonplanning, reflecting a failure to plan ahead; and liveliness, reflecting rapid decision making.

All these models support the growing consensus that impulsivity is a multidimensional construct. However, there is still a great discrepancy in assessment related to the theoretical origins of the proposed models (Nigg, 2000). These discrepancies in results may have to do with two important aspects.

First, personality research focuses on measuring impulsivity with self-report, whereas cognitive research focuses on measuring impulsivity with behavioral measurements (Roberts, 
Fillmore, \& Milich, 2011). It seems that self-report and behavioral measurements assess different forms of impulsivity that do not always overlap (Cyders \& Coskunpinar, 2011; Reynolds et al., 2006) and therefore show low (Heyman \& Gibb, 2006; Vonmoos et al., 2013) or even no correlations (Reynolds, Penfold, \& Patak, 2008). Surprisingly, only a few studies examined the relationship between self-report and behavioral tasks (Cyders \& Coskunpinar, 2011; Vonmoos et al., 2013). However, these studies focused on particular impulsivity dimensions in a specific population (recreational and dependent cocaine users) or on the strength of the relationship between different assessments of impulsivity. Accordingly, the present study examines different impulsivity dimensions using both self-report and behavioral measurements, reflecting the total concept of impulsivity.

Second, the earlier proposed models have been examined only in nonpatients. Research in forensic samples investigating impulsivity merely self-report a specific unidimensional behavioral task. However, in forensic (incarcerated) samples, prevalence of pathological impulsivity is reported to be extremely high (up to $88 \%$, Bjørkly, 2006). Moreover, impulsivity is indicated as an important component of various forms of psychopathology (Fields et al., 2015, p. 1). How different impulsivity dimensions relate to various psychopathology problems in forensic populations is not clear and needs more attention (Fields et al., 2015). Therefore, a clarification of the relationship and possible predictive validity between different impulsivity dimensions and psychopathology most commonly present in forensic populations is needed. Given that a forensic sample shows extreme impulsiveness (Haden, \& Shiva, 2008; Værøy, Western, \& Andersson, 2016), the present study is unique in examining a multidimensional impulsivity model using various assessment methods in a forensic sample. By doing so, the current study contributes to the external validity of earlier proposed impulsivity models.

\section{Aims of the study}

The aims of the present study are twofold. First, we investigate a dimensional structure of impulsivity based on multiple assessments (both self-report and behavioral instruments) related to earlier presented models. Second, we examine the predictive validity of distinct impulsivity dimensions for psychopathology in a forensic incarcerated sample. Given the extremely high prevalence of pathological impulsivity in forensic populations (Haden, \& Shiva, 2008), the resulting dimensional model in the current study might be different from other proposed and tested models using samples in a nonpatient population. Moreover, we believe that the resulting impulsivity dimensions should be targets for interventions and risk management specifically in forensic (inpatient) populations.

\section{Methods}

\section{Participants}

In the present study, we examined 87 male incarcerated psychiatric patients undergoing mandatory treatment at Forensic Psychiatric Centre de Rooyse Wissel. The Ethical Committee 
of Maastricht University and the research committee of FPC de Rooyse Wissel approved the research protocol. All participants cooperated on a voluntary basis and were free to withdraw from the study at any time. They received written and oral instruction emphasizing that participation was not related to treatment or prospects for release. Participants ranged in age from 22 to 61 years $(M=37.9, S D=8.9)$.

The Psychopathy Checklist-Revised (PCL-R, Hare, 1991, 2003) from a subsample of 75 forensic offenders was available $(M=23.1$, range $=10-36, S D=6.5)$. All interviews were scored for diagnostic purposes by a separate interview and discussed by two trained forensic professionals resulting in a consensus score. In the sample, $43 \%$ were psychopathic $(N=32$ scoring $\geq 26$, indicating psychopathy).

Regarding the type of offenses, 38\% of participants had been convicted for (attempted) manslaughter or murder, $19 \%$ for sexual offenses such as rape, $14 \%$ for sexual offenses with minors, $11 \%$ for property crime with violence, $9 \%$ for bodily harm, $7 \%$ for arson, and 3\% for property crime without violence. Regarding the type of psychopathology, $67 \%$ of participants met the diagnostic criteria for substance dependency (in full remission), 64\% for antisocial personality disorder (PD), 31\% for intermittent explosive disorder, 25\% for major depressive disorder (single episode, in full remission), 22\% for posttraumatic stress disorder, $18 \%$ for paranoid PD, 16\% for borderline PD and autism spectrum disorder, and 7\% for passive-aggressive PD, obsessive-compulsive PD, narcissistic PD, and pathological gambling, with a comorbidity rate of $58 \%$.

\section{Measures}

\section{Explicit measures of impulsivity.}

The Barratt Impulsiveness Scale-11 (BIS-11, Patton et al., 1995). The BIS-11 is a 30-item self-report questionnaire measuring impulsivity. The items are rated on a 4-point Likert scale (1 = seldom or never, 4 = almost always or always). The BIS-11 contains three subscales: Attention Impulsiveness (Al), measuring quick cognitive decisions and restlessness in items such as "I am restless at the theatre or lectures"; Motor Impulsivity (MI), measuring acting without thinking in items such as "I do things without thinking"; and Non Planning Impulsivity (NPI), measuring willingness to plan the future in items such as "I plan for job security". Research showed good intrascale reliability ( $\alpha=$.82), (Spinella, 2007). Following the George and Mallery (2003) rule for interpreting the Cronbach's alpha reliability, $\alpha$ in the current sample was questionable to good (.80 BIS-11 total, $\alpha \mathrm{Al}=.62, \alpha \mathrm{MI}=.68$, and $\alpha \mathrm{NPI}=.64$ ).

The Sensation Seeking Scale (SSS, Zuckerman, Kolin, Price \& Zoos, 1964). The SSS is a 51-item sensation-seeking questionnaire. Items are rated on a 7-point Likert scale (1 = totally disagree, 7 = totally agree). The SSS contains four subscales: Thrill-and-Adventure Seeking (SSS-TAS), measuring the desire for activities involving physical danger in items such as "I sometimes like to do things that are a little frightening"; Experience-Seeking (SSS-ES), showing the desire for new experiences in items such as "People should dress in individual 
ways even if the effects are sometimes strange"; Disinhibition (SSS-DIS), assessing disinhibited social behavior in items such as "I like wild 'uninhibited' parties"; and Boredom-Susceptibility (SSS-BS), demonstrating an aversion for routine in items such as "I have no patience with dull or boring persons". The SSS has good internal reliability (.85) and excellent test-retest reliability (.94), (Feij, Zuilen, \& Gazendam, 1982). Cronbach's $\alpha$ in the current sample for the SSS-DIS scale was good (.81).

The Impulsiveness-Venturesomeness-Empathy Questionnaire (I7, Eysenck, Pearson,

Easting, \& Allsopp, 1985). The 17 is a 54-item self-report to assess impulsivity via dichotomous ("true" or "false") answer options. The 17 contains three scales: Impulsiveness (I), indicating acting without thinking in items such as "Do you often long for excitement?"; Venturesomeness $(V)$, indicating welcomeness to new experiences in items such as "Do you quite enjoy taking risks?"; and Empathy (E), containing items such as "Do you often get emotionally involved with your friends' problems?". The 17 has proven good reliability $(\alpha=.67-.81$, Lijfijt, Caci, \& Kenemans, 2005). Cronbach's $\alpha$ in the current sample was acceptable, with $\alpha=.77$ for the I scale and $\alpha=.78$ for the $V$ scale.

\section{Implicit measures of impulsivity.}

The GoStop Impulsivity Paradigm (GoStop, Dougherty, Mathias, Marsh, \& Jagar, 2005).

The GoStop is a computer task designed to measure response inhibition (Logan, 1983). Participants are presented a series of five-digit numbers in a prompt sequence $(600 \mathrm{~ms}$ ) and must either respond (while the number is still on the computer screen) by pushing a button to a "go" signal (two following identical numbers in black) or withhold a response when a "stop" signal appears (a following identical number changing to red, $250 \mathrm{~ms}$ after the go signal). In the current version, a block of 40 no-stop trials, 25 stop trials, and 65 filler trials with nonmatching numbers is used, with an interstimulus interval time of 1,500 ms (default). Moreover, the stop signal onset-delay time was adjusted with steps of $50 \mathrm{~ms}$ based on successful or failed inhibition (e.g., a delayed stop signal after a successful trial), resulting in an adjusted optimum stopping rate of $50 \%$. The primary response of interest is the failure to inhibit responding when a go signal is accompanied by a stop signal. The GoStop Latency specifies the time interval between the onset of the stop signal and the response (Figure 1), the GoStop Stop Latency represents the time interval between stimulus onset and response with the stop signal timing altered to a successful withholding at $50 \%$ of the response, and the GoStop Inhibition indicates the proportion of trials in which the participant withheld response. The GoStop has proven good criterion and concurrent validity (Dougherty et al., 2005). 

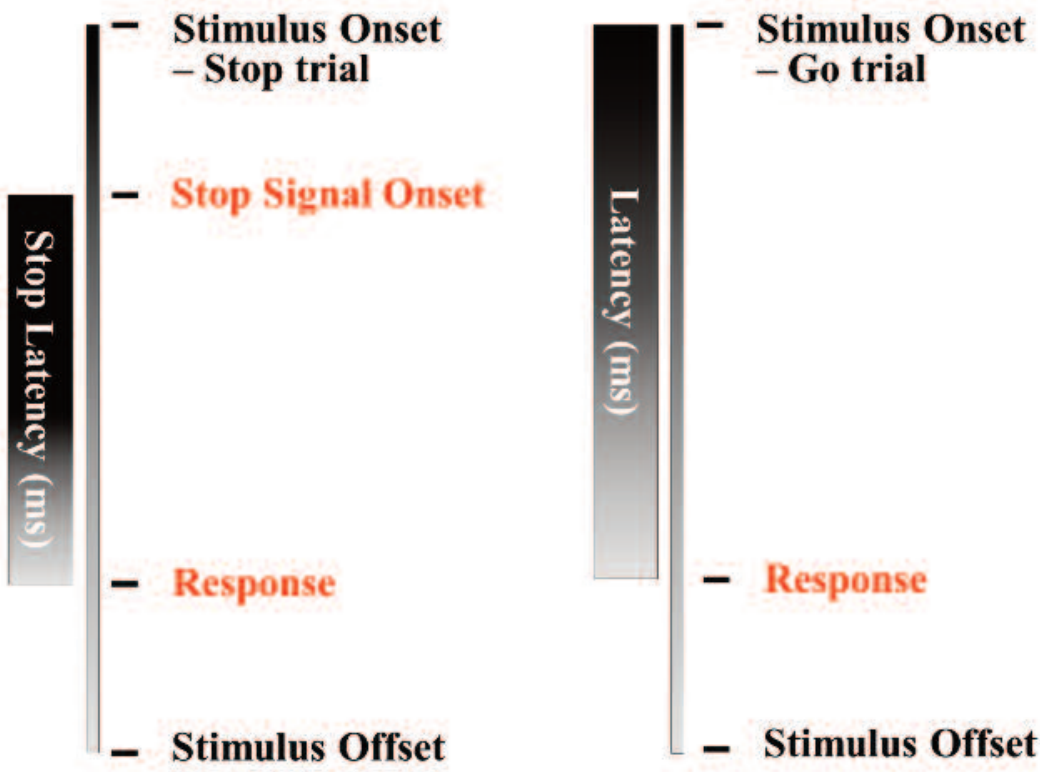

Figure 1. GoStop latency and Stop latency of the GoStop Impulsivity Paradigm.

The Balloon Analogue Risk Task (BART, Lejuez et al., 2002). The BART is a computer task designed to measure risk taking behavior. The task's objective is to collect the largest amount of points by pumping 30 balloons up by clicking on a button. Each pump inflates the balloon until a random threshold at which the balloon is overinflated and explodes. Thus the more pumps, the larger the balloon and the greater the reward, but likewise the bigger the risk that the balloon explodes and consequently no reward is given. In the current study, participants could earn a small amount of cash related to the resulting task price (small price $=€, 50$ - bonus prize $=€ 2,50$ ). The BART Explosions represents the number of exploded balloons indicating risk taking; the BART Pumps shows the total amount of pumps, demonstrating risk appetite. Research has shown the validity of the BART demonstrating a relation with real-life risk taking (Lejuez, Aklin, Zvolensky, \& Pedulla, 2003).

\section{Measures of psychopathology.}

The Structured Clinical Interview for DSM-IV Axis I Disorders (SCID-I, First, Spitzer, Gibbon, \& Williams, 1995). The SCID-I is a semistructured interview based on the fourth edition text revision of the Diagnostic and Statistical Manual of mental disorders (DSM-IV-TR, APA, 2000). All interviews were scored and discussed by two master's students and a forensic professional trained to administer the interview, resulting in a consensus score arrived at by discussion. Several studies demonstrated superior validity of the SCID-I over standard clinical interviews (Basco et al., 2000). 


\section{The Structured Clinical Interview for DSM-IV Axis II Disorders (SCID-II, Weertman,}

Arntz \& Kerkhofs, 2003). The SCID-II, like the SCID-I, is a semistructured personality interview based on the DSM-IV-TR (APA, 2000). As already mentioned, all interviews were discussed by two master's students and a forensic professional, resulting in a consensus score. Research demonstrates good validity (Dreessen \& Arntz, 1998) and reliability (Lobbestael, Leurgans, \& Arntz, 2011).

Psychopathy Checklist-Revised (PCL-R, Hare, 1991, 2003). The PCL-R is a 20-item assessment for psychopathy based on an interview and collateral file records. Each item was evaluated on a 3-point Likert scale ( 0 = does not apply, 2 = does definitely apply). The PCL-R contains four facets: an interpersonal facet indicating glibness and grandiose self-worth, an affective facet reflecting a lack of remorse, a behavioral lifestyle facet indicating impulsivity and a lack of long-term goals, and an antisocial facet reflecting poor behavioral control and multifarious criminality. Research has shown good reliability and validity (Cronbach's $\alpha=.83-.87$ and mean interitem correlation of .25, Hildebrand, 2008).

\section{Data Reduction and Analysis}

Normality of the raw data was checked by means of skewness, kurtosis, and visual inspection of the distributions. If necessary, outliers were corrected by setting the maximum value in to $2 S D$ plus 1 scale point (or 2 scale points in case of 2 outliers for the more extreme). The dimensional structure of impulsivity was investigated with a second order principal component analysis (PCA) followed by oblimin rotation. Adequate sample size for PCA was evaluated with the Kaiser-Meyer-Olkin index and Bartlett's Test of Sphericity and analyzed based on the method presented by Winter, Dodou, and Wieringa (2009). Number of factors to be extracted was based on examination of the scree plot and interpretability of the rotated factors. The relationship between psychopathology and impulsivity was investigated with Pearson correlations. An additional Pearson correlation analysis was performed with impulsivity items of certain diagnosis removed (e.g., the item "impulsivity or failure to plan ahead" of antisocial PD) to check for possible tautology. Also, for all significant correlations of psychopathology and impulsivity, the specific predictive value of each impulsivity dimension was investigated by means of a forward regression analysis (logistic or linear depending on the nominal or orthogonal scoring method of the dependent variable).

\section{Results}

Normality

Frequency analysis of the distribution of the impulsivity data revealed a normal distribution (skewness $=.08-.55$, kurtosis $=.01-1.0$ ). See Table 1 for impulsivity scores in the current sample and a variety of nonpatient comparison samples (with no norm scores presented). 
Table 1. Group Differences for all Impulsivity scores between the current forensic sample $(N=87)$ and nonpatient comparison samples; Means and Standard Deviations, Independent-Samples t-Tests, and Effect Size (d).

\begin{tabular}{|c|c|c|c|c|c|c|}
\hline \multirow[t]{2}{*}{ Measurement } & \multicolumn{2}{|c|}{ Current Sample } & \multicolumn{2}{|c|}{ Control Sample } & \multirow[b]{2}{*}{$t$} & \multirow[b]{2}{*}{$d$} \\
\hline & $M$ & $S D$ & $M$ & $S D$ & & \\
\hline \multicolumn{7}{|l|}{ Impulsive Decision Making } \\
\hline BIS-11 Motor Impulsiveness' & 21.1 & (4.4) & 22.1 & (4.4) & $2.00^{\circ}$ & .23 \\
\hline 17 Impulsiveness ${ }^{2}$ & 7.8 & (3.5) & 7.8 & (4.7) & .00 & .00 \\
\hline BIS-11 Non Planning Impulsivity' & 24.1 & $(4.5)$ & 24.9 & (5.1) & 1.40 & .17 \\
\hline BIS-11 Attention Impulsiveness' & 16.5 & (3.4) & 17.2 & (3.9) & 1.60 & .19 \\
\hline \multicolumn{7}{|l|}{ Sensation Seeking } \\
\hline BART Explosions ${ }^{3}$ & 8.8 & (3.7) & 9.1 & $(4.5)$ & .40 & .07 \\
\hline BART Pumps ${ }^{4}$ & 904.4 & (306.8) & 1102 & (337) & $3.92^{\cdots *}$ & .61 \\
\hline 17 Venturesomeness ${ }^{5}$ & 11.4 & (3.3) & 11.6 & (3.3) & .47 & .06 \\
\hline \multicolumn{7}{|l|}{ Inadequate Response Inhibition } \\
\hline GoStop Stop Latency $(\mathrm{ms})^{6}$ & 179.5 & $(66.0)$ & 172.7 & (94.8) & .38 & .08 \\
\hline GoStop Inhibition (\%) & 69.8 & $(14.8)$ & 57.0 & (21.4) & $4.38^{* \cdots}$ & .69 \\
\hline SSS- Disinhibition 8 & 4.3 & (1.3) & 4.0 & (2.4) & 1.13 & .16 \\
\hline GoStop Latency $(\mathrm{ms})^{9}$ & 393.1 & (94.1) & 449.5 & (91.7) & $3.30 \cdots$ & .61 \\
\hline
\end{tabular}

Note. "p<.05, "p<.01,"** $p<.001$

${ }^{1} M$ and $S D$ of a control sample ( $n=700$, Spinella, 2007).

${ }^{2} M$ and $S D$ of a control sample ( $n=151$, Nagoshi, Wood, Cote \& Abbit, 1994).

${ }^{3} M$ and $S D$ of a control sample ( $n=43$, Lejuez, et al., 2002).

${ }^{4} \mathrm{M}$ and $S D$ of a control sample ( $n=77$, Dimitrova et al., 2011).

${ }^{5} M$ and SD of a control sample ( $n=193$, Lijfijt, Caci, \& Kenemans, 2005).

${ }^{6} M$ and $S D$ of a control sample ( $n=22$, Bunch, 2009).

${ }^{7} M$ and SD of a control sample ( $n=80$, Morgan, Gray \& Snowden, 2011).

${ }^{8} M$ and $S D$ of a control sample ( $n=397$, Herrero \& Colom, 2008).

${ }^{9} M$ and $S D$ of a control sample ( $n=50$, Billieux et al., 2010).

\section{Validity Impulsivity Model}

A PCA was performed to reveal the dimensions underlying the impulsivity tests (Table 2). Although the sample size was above the minimum sample size of $N=60$ for factor recovery (MacCallum, Widaman, Preacher, \& Hong, 2001), within the range of $N=-100$ stated as adequate in determining psychometric properties by means of PCA (Sapnas \& Zeller, 2002), and in accordance with the rule of number variables per factor of 1:5 (Ford, MacCallum, \& Tait, 1986), adequacy of the sample was examined. Results based on the data characteristics of the current sample show that the minimal sample size should be $N=71$ (results can be obtained on request from the first author) and so the current sample size $(N=87)$ was large enough. Moreover, the Kaiser-Meyer-Olkin $(K M O)$ 
measure of sampling adequacy was above the acceptable level of .50 (KMO =.60), and Bartlett's Test of Sphericity was significant ( $p=.000$, Tabacknick \& Fidell, 2007). Three factors met Kaiser's criteria with an eigenvalue above 1, which was in line with the scree plot test and was further supported by Monte Carlo parallel analysis. The initial eigenvalues showed that the first factor explained $27 \%$, the second $17 \%$, the third $14 \%$, and the three factors cumulatively $57 \%$ of the variance, which is within the common range (Pett, Lackey, \& Sullivan, 2003). The factor labels were based on the item content of the primary loadings on each factor.

The first factor was labeled impulsive decision making and was loaded by the BIS-11 Motor Impulsiveness scale, the 17 Impulsiveness scale, the BIS-11 Non Planning Impulsivity scale, and the BIS-11 Attention Impulsiveness scale. The second factor was labeled sensation seeking and was determined by high loadings of the BART Explosions, the BART Pumps, and the I7 Venturesomeness scale. The third factor was called response inhibition and was defined by high loadings of the GoStop Latency, the GoStop Inhibition, the SSS-Disinhibition scale, and the GoStop Stop Latency, with long reaction times indicating inadequate response inhibition and rapid results indicating adequate response inhibition.

\section{Correlations between the Impulsivity factors.}

Pearson's correlation between the factor scores of the three impulsivity factors showed no significant relations (all $r$ 's $<.15$, all $p$ 's $>$.21), indicating distinct impulsivity components.

Table 2. Factor loadings based on a principal component analysis with oblimin rotation of impulsivity assessments $(N=87)$.

\begin{tabular}{llll}
\hline Measures & $\begin{array}{l}\text { Impulsive } \\
\text { Decision Making }\end{array}$ & $\begin{array}{l}\text { Sensation } \\
\text { Seeking }\end{array}$ & $\begin{array}{l}\text { Response } \\
\text { Inhibition }\end{array}$ \\
\hline BIS-11 Motor Impulsiveness & .76 & & \\
I7 Impulsiveness & .71 & & \\
BIS-11 Non Planning Impulsivity & .69 & & \\
BIS-11 Attention Impulsiveness & .67 & .93 & \\
BART Explosions & & .93 & .75 \\
BART Pumps & .32 & .49 & .65 \\
I7 Venturesomeness & & & -.52 \\
GoStop Stop Latency & & & .51 \\
GoStop Inhibition & .45 & .39 & 1.52 \\
SSS- Disinhibition & & 1.82 & 13.79 \\
GoStop Latency & 2.96 & 16.57 & \\
\hline Eigenvalue & 26.90 & & \\
\% of variance & & & \\
\hline
\end{tabular}

Note. Factor loadings $<.29$ are suppressed 


\section{Correlations with disorders.}

To prevent tautology in the correlation of psychopathology with different impulsivity dimensions, all significant correlated psychopathology was screened on specific impulsivity items. The three authors independently noted the impulsivity items within substance dependency, antisocial personality disorder, and psychopathy. Results led to a consensus of the following impulsivity items to be deleted: In antisocial PD the item signifying impulsivity or the failure to plan ahead (criteria 3), and in psychopathy the items showing the need for stimulation and proneness to boredom (item 3), poor behavioral control (item 10) and impulsivity (item 14). In substance dependency, no specific item was deleted. Then, the numbers of items of the significant related disorders were summed without these impulsivity items (Impulsivity item-corrected results were comparable to the reported results. Both results can be obtained on request from the first author).

Pearson's correlation between the impulsivity dimensions and substance dependency was significant, showing an inverse correlation between response inhibition and substance dependency (Table 3). Separate results for alcohol and drug dependency revealed a significant correlation between impulsive decision making and drug dependence, and again an inverse correlation between response inhibition and drug dependency (Table 3). No significant relations with alcohol dependency were found.

Table 3. Correlations of psychopathology indicators and the factor scores of impulsivity $(\mathrm{N}=87)$.

\begin{tabular}{clll}
\hline Measures & $\begin{array}{l}\text { Impulsive } \\
\text { Decision Making }\end{array}$ & $\begin{array}{l}\text { Sensation } \\
\text { Seeking }\end{array}$ & $\begin{array}{l}\text { Response } \\
\text { Inhibition }\end{array}$ \\
\hline Substance Dependence & .22 & .08 & $-.25^{*}$ \\
Alcohol dependence & .01 & -.01 & -.16 \\
Drug dependence & $.43^{* *}$ & .14 & $-.32^{* *}$ \\
PCL-R Psychopathy & .23 & -.07 & $-.26^{*}$ \\
Interpersonal Facet & -.12 & -.16 & -.20 \\
Affective Facet & -.06 & -.22 & -.22 \\
Impulsive Lifestyle Facet & .40 & -.08 & $-.28^{*}$ \\
Antisocial Facet & .26 & .05 & -.13 \\
Antisocial PD & .24 & .20 & -.27 \\
Borderline PD & .19 & .12 & -.13 \\
\hline
\end{tabular}

Note. " $p<.05, " p<.01 ;{ }^{1} \mathrm{PD}=$ Personality Disorder

Moreover, Pearson's correlations showed a significant inverse correlation between response inhibition and psychopathy (see Table 3). Results on the various psychopathy facets showed a significant inverse correlation between response inhibition and the impulsive lifestyle facet of psychopathy. Also, a significant correlation between impulsive decision making and the impulsive lifestyle facet was found. Furthermore, no correlation between any impulsivity dimension and borderline PD was found. 


\begin{tabular}{|c|c|c|c|c|c|c|c|}
\hline \multicolumn{2}{|c|}{ Logistic regression } & B & SEB & OR & $p$ & Model R* & $p$ \\
\hline \multicolumn{8}{|c|}{ Drug dependence } \\
\hline \multirow[t]{2}{*}{ Model 1} & Constant & .25 & .27 & 1.29 & .34 & .25 & .00 \\
\hline & Impulsive Decision Making & 1.09 & .33 & 2.98 & .00 & & \\
\hline \multirow[t]{3}{*}{ Model 2} & Constant & .29 & .29 & 1.34 & .31 & .36 & .00 \\
\hline & Impulsive Decision Making & 1.19 & .36 & 3.28 & .00 & & \\
\hline & Response Inhibition & -.80 & .31 & .45 & .01 & & \\
\hline \multicolumn{8}{|c|}{ Antisocial PD } \\
\hline \multirow[t]{2}{*}{ Model 1} & Constant & .55 & .26 & 1.73 & .03 & .10 & .02 \\
\hline & Response Inhibition & -.60 & .27 & .55 & .03 & & \\
\hline \multirow[t]{3}{*}{ Model 2} & Constant & .59 & .27 & 1.81 & .03 & .18 & .01 \\
\hline & Response Inhibition & -.63 & .28 & .54 & .03 & & \\
\hline & Impulsive Decision Making & .59 & .30 & 1.81 & .05 & & \\
\hline \multicolumn{2}{|c|}{ Linear regression } & B & SEB & $\boldsymbol{\beta}$ & $p$ & Model R ( $\left.\mathbf{R}^{2}\right)$ & $p$ \\
\hline \multicolumn{8}{|c|}{ PCL-R Impulsive Lifestyle Facet } \\
\hline \multirow[t]{2}{*}{ Model 1} & Constant & 5.81 & .30 & & .00 & $.40(.16)$ & .00 \\
\hline & Impulsive Decision Making & 1.04 & .33 & .40 & .00 & & \\
\hline \multirow[t]{3}{*}{ Model 2} & Constant & 5.82 & .28 & .00 & .00 & $.50(.25)$ & .00 \\
\hline & Impulsive Decision Making & 1.07 & .32 & .42 & .00 & & \\
\hline & Response Inhibition & -.69 & .28 & -.30 & .02 & & \\
\hline
\end{tabular}

Note: "Nagelkerke R

\section{Predictive validity of impulsivity dimensions for psychopathology.}

Results of the forward likelihood ratio logistic with all impulsivity dimensions as predictors and drug dependency as target variable show that impulsive decision making and response inhibition predict drug dependency, with both predictors adding a significant value to the prediction model (Table 4).

Results of the forward likelihood ratio logistic regression with all impulsivity dimensions as predictors and antisocial PD as target variable again show that both impulsive decision making and response inhibition predict antisocial PD, with both predictors adding a significant value to the prediction model (see Table 4).

Results of the forward linear regression with all impulsivity dimensions as predictors and the impulsive lifestyle facet of the PCL-R as target variable show that both impulsive 
decision making and response inhibition predict the PCL-R impulsive lifestyle facet, with both predictors adding a significant value to the prediction model (see Table 4).

\section{Discussion}

We firstly aimed to derive a dimensional impulsivity model based on a broad spectrum of impulsivity tests (self-report and behavioral tasks) completed by a forensic sample. Results show three distinctive impulsivity dimensions: impulsive decision making (reflecting acting without thinking and nonplanning), sensation seeking (reflecting a risk appetite and venturesomeness), and inadequate response inhibition (reflecting response inhibition dysfunction and disinhibited social behavior). Although some evidence suggests low replication results in psychology research (Baker, 2015), these three dimensions replicate the two-dimensional cognitive behavioral models of Reynolds and colleagues $(2006,2008)$ and Harden and Tucker-Drob (2011). However, sustained attention, a third dimension added by Reynolds and colleagues in their updated model of impulsivity and incorporated in the three-dimensional model of Patton, Stanford, and Barratt (1995), was not present in our results. Conversely, these three-dimensional cognitive models seem to lack the sensation seeking component.

Furthermore, Eysenck and Eysenck (1985), who presented the personality-based four-dimensional impulsivity model, later developed an assessment for impulsivity as a personality component, splitting impulsivity from sensation seeking (Eysenck et al., 1985), indicating different personality characteristics instead of different dimensions of a common concept. Still, the current results also fit into the earlier described personality-based four-dimensional model of Whiteside and Lynam (2001), as their urgency facet equals our response inhibition' dimension, their premeditation facet equals our impulsive decision making' dimension, and both models include a sensation seeking' dimension. Moreover, the current results might point to different multidimensional models stemming from specific assessment methods with personality research mainly using only self-report and cognitive research focusing mainly on behavioral measurements (Roberts et al., 2011), whereas the current study combines both assessment methods within the multidimensional impulsivity model. In addition, research has suggested a different manifestation of (self-reported) impulsivity and aggression in severe violent offenders opposed to nonpatients (Værøy et al., 2016). Second, we intend to examine the predictive validity of distinct impulsivity dimensions for psychopathology, which may reflect a multidimensional model unique for a male forensic population.

In conclusion, a combination of past and present results led to the preference of a fourdimensional model of impulsivity resulting in the following dimensions: impulsive decision making (reflecting acting without thinking and nonplanning), sensation seeking (reflecting a risk appetite and venturesomeness), (inadequate) response inhibition (reflecting response inhibition dysfunction), and sustained attention (reflecting perseverance).

As to the second aim, we found several meaningful relationships between impulsivity dimensions and psychopathology. First, a correlation between substance dependence and 
inadequate response inhibition was found. Although this correlation was found only in drug dependence and absent for alcohol, these results correspond with research showing a relationship between disruption of inhibition and drugs (Douma, Kolarz, Postma, Olivier, \& Groenink, 2011; Halberstadt \& Geyer, 2010). Moreover, a relationship between drug dependence and impulsive decision making was found, which is in line with research showing a relationship between impulsive decision making and drug use (Cadet, Bisagno, \& Milroy, 2014). As to the predictive value of impulsivity dimensions for drug dependency, we found that a combination of both impulsive decision making and inadequate response inhibition shows a significant predictive value for drug dependency. No relationship between or predictive value for drug dependence and sensation seeking was found. However, this is in line with previous research into developmental vulnerability components of (drug) dependency, showing that sensation seeking indicates the tendency to experiment with drugs but not necessary frequent use leading to dependency, whereas impulsive decision making (referred to as general impulsivity) indicates an addictive lifestyle, and inadequate response inhibition (referred to as compulsivity) indicates a tendency toward continued use (Ersche, 2013; Ersche et al., 2013). Also, no relationship between alcohol and any impulsivity dimension was found, which could indicate that the mechanisms underlying alcohol dependency may not be associated predominantly with impulsivity. Alternatively, we might have overlooked impulsivity dimensions that are relevant in relation to alcoholism.

Second, a significant correlation between inadequate response inhibition and psychopathy was found. Results on the specific psychopathy facets showed a significant correlation between inadequate response inhibition and the impulsive lifestyle facet of psychopathy. This is in line with research showing poor response inhibition in psychopathy (Kiehl, Smith, Hare, \& Liddle, 2000; Masui \& Nomura, 2010). Additionally, in line with a study by Miranda, Mackillop, Meyerson, Justus, and Lovallo (2009) showing decision-making problems in impulsive antisocial psychopathic people, we found a significant correlation between impulsive decision making and the impulsive lifestyle facet of psychopathy. As to the predictive value of impulsivity dimensions for the impulsive lifestyle facet of psychopathy, it can be concluded that a combination of impulsive decision making and inadequate response inhibition showed a significant predictive value for the impulsive facet of psychopathy.

Third, we found a significant correlation between inadequate response inhibition and antisocial PD, which is in line with research showing antisocial PD is characterized by "increased rapid-response impulsivity" (Swann, Lijfijt, Lane, Steinberg, \& Moeller, 2009, p. 1) and recent research showing a relationship between PD severity and Whiteside and Lynam's (2001) urgency facet, which equals our response inhibition dimension (Howard \& Khalifa, 2016). In addition, a significant correlation between impulsive decision making and antisocial PD was found, indicating more acting without thinking in antisocial PD. This is in correspondence with research showing decision-making deficits in antisocial PD (Coccaro, Sripada, Yanowitch, \& Phan, 2011). Again, as to the predictive value of impulsivity dimensions for antisocial PD, a 
combination of inadequate response inhibition and impulsive decision making have significant predictive value for antisocial PD. The current finding that both impulsive decision making and inadequate response inhibition show a predictive value for specific pathology might indicate shared risk factors in drug dependency, antisocial PD, and secondary psychopathy (Cadoret, Yates, Woodworth, \& Stewart, 1995; Skeem, Johansson, Andershed, Kerr, \& Louden, 2007).

Fourth, no correlation between or predictive value for any impulsivity dimension and borderline PD was found. This could be due to comorbid patient characteristics. All participants meeting the criteria for borderline PD also showed a history of substance dependence. Earlier research on attention and decision-making deficits controlling for a past history of substance abuse in borderline PD showed impairments only in patients with borderline PD without past history of substance abuse (Feliu-Soler et al., 2013).

In sum, the first dimension, impulsive decision making, showed a predictive value for drug dependence, the impulsive lifestyle facet of psychopathy, and antisocial personality disorder. The second dimension, sensation seeking, was not related to any psychopathology. The third dimension, (inadequate) response inhibition, showed a predictive value for drug dependence, psychopathy, and antisocial personality disorder. These findings indicate a relationship between all impulsivity dimensions but sensation seeking in psychopathology and prompting allocations of these impulsivity dimensions as a target component for interventions toward pathology. This is in line with research in a nonpatient population showing a relationship between all (UPPS) impulsivity dimensions but sensation seeking and increased troublesome behavior (Sperry, Lynam, Walsh, Horton, \& Kwapil, 2016). Moreover, sensation seeking assessment by means of the BART pumps (Lejuez et al., 2002) is the only dimension showing significantly lower scores for the forensic sample in comparison with nonpatient control samples from the literature indicating less extreme risk appetite in the current sample (see Table 1). Furthermore, the aforementioned research showed a unique manifestation of (self-reported) impulsivity in extremely violent offenders (Værøy et al., 2016), indicating a central role for inadequate response inhibition (UPPS urgency) driving impulsive behavior. The current findings show significant response inhibition difficulties in the current forensic sample in comparison with nonpatient control samples (see Table 1) and suggest that both impulsive decision making and inadequate response inhibition are specific impulsivity risk factors in a male forensic population.

In line with research in clinical populations, implementing research in response to clinical needs and scientific demands (Rubin, Lazar, Gaich, \& Haray, 2008), the following limitations to the present study should be mentioned. First, not all psychopathology was prevalent enough, so many DSM categories were excluded from analysis. Second, because the focus of the current study was the forensic field, in which prevalence of pathological dysfunctional impulsivity is very high, no control groups were included. We recommend that future research include nonpatient and nonforensic clinical control groups. Third, unfortunately only the dimensions sensation seeking and inadequate response inhibition included a combination 
of self-report and behavioral measurements. It cannot be excluded that rather than content, method variance influenced the formation of the other factor. Fourth, from the current study nothing can be concluded about the causal status of the reported relationships. However, other research found that not only does chronic drug exposure cause impulsivity, but impulsivity also represents a vulnerability factor for substance dependency (Cadet et al., 2014). Thus, impulsivity could be a crucial target in drug interventions.

Impulsivity is an important risk factor in different forensic risk assessments (Hare, 2003). Future research should focus on possible relations between impulsivity dimensions and risk for criminal behavior, because impulsivity is linked to high and stable levels of offending (Higgings, Kirchner, Ricketts, \& Marcum, 2013). For practical purposes, individual risk profiles could be generated for risk management. After all, Einstein's remark that "all primary impulses, not easily described in words, are the springs of man's actions" also holds for forensic patients (Einstein, 1950, p. 15). 


\section{References}

American Psychiatric Association (APA). (2013). Diagnostic and statistical manual of mental disorders (5th ed.). Arlington, VA: American Psychiatric Publishing. doi: 10.1176/appi.books.9780890423349

American Psychiatric Association (APA). (2000). Diagnostic and Statistical Manual of Mental Disorders, 4th edition, Text Revision (DSM-IV-TR). Washington, DC: American Psychiatric Association.

Baker, M. (2015). Over half of psychology studies fail reproducibility test. Nature News, 27 august 2015. doi:10.1038/nature.2015.18248

Barratt, E. S. (1993). Impulsivity: integrating cognitive, behavioral, biological and environmental data. In W. McGowan, J. Johnson, \& M. Shure, The impulsive client: theory, research, and treatment (pp. 39-56). Washington, DC: American Psychological Association.

Basco, M. R., Bostic, J. Q., Davies, D., Rush, A. J., Witte, B., Hendrickse, W., \& Barnett, V. (2000). Methods to improve diagnostic accuracy in a community mental health setting. American Journal of Psychiatry, 157, 1599-1605. doi: 10.1176/appi.ajp.157.10.1599

Billieux, J., Gay, P., Rochat, L., Khazaal, Y., Zullino, D., \& Van der Linden, M. (2010). Lack of inhibitory control predicts cigarette smoking dependence: evidence from a non-deprived sample of light to moderate smokers. Drug and Alcohol Dependence, 112, 164-167. doi: 10.1016/j.drugalcdep.2010.06.006

Bjørkly, S. (2006). Empirical evidence of a relationship between insight and risk of violence in the mentally ill - A review of the literature. Aggression and Violent Behavior, 11, 414-423. doi:10.1016/j.avb.2006.01. 006

Bunch, K. (2009). Risk taking behavior in bipolar affective disorder. Leeds: University of Leeds. URL: http://etheses.whiterose.ac.uk/1176/1/bunchthesis_final.pdf

Cadet, J. L., Bisagno, V., \& Milroy, C. M. (2014). Neuropathology of substance use disorders. Acta Neuropathologica, 127, 91-107. doi: 10.1007/s00401-013-1221-7

Cadoret, R. J., Yates, W. R., Woodworth, G., \& Stewart, M. A. (1995). Genetic-environmental interaction in the genesis of aggressivity and conduct disorders. Archives of General Psychiatry, 52, 916-924

Coccaro, E. F., Sripada, C.S., Yanowitch, R. N., \& Phan, K.L. (2011). Corticolimbic function in impulsive aggressive behavior. Biological Psychiatry, 69, 1153-1159. doi:10.1016/j.biopsych.2011.02.032

Coskunpinar, A., Dir, A. L., \& Cyders, M. A. (2013). Multidimensionality in impulsivity and alcohol use: A meta-analysis using the UPPS model of impulsivity. Alcoholism: Clinical and Experimental Research, 37, 1441-1450. doi: 10.1111/acer.12131

Cyders, M. A., \& Coskunpinar, A. (2011). Measurement of constructs using self-report and behavioral lab tasks: Is there overlap in homothetic span and construct representation for impulsivity? Clinical Psychology Review, 31, 965-982. doi: 10.1016/j.cpr.2011.06.001

Dalley, J. W., Everitt, B. J., \& Robbins, T. W. (2011). Impulsivity, compulsivity, and top-down cognitive control. Neuron, 69, 680-694. doi:10.1016/j.neuron.2011.01.020

Dimitrova, A., Fronczek, R., Van der Ploeg, J., Scammell, T., Gautam, S., Pascual-Leone, A., \& Lemmens, G. J. (2011). Reward-seeking behavior in human narcolepsy. Journal of Clinical Sleep Medicine, 7 , 293-300. doi: 10.5664/JCSM.1076

Dougherty, D. M., Mathias, C. W., Marsh, D. M., \& Jagar, A. A. (2005). Laboratory behavioral measures of impulsivity. Behavior Research Methods, 37, 82-90. doi: 10.4135/9781412952644 
Douma, T. N., Kolarz, A. Postma, Y., Olivier, B., \& Groenink, L. (2011). The amphetamine-chlordiazepoxide mixture, a pharmacological screen for mood stabilizers, does not enhance amphetamine-induced disruption of repulse inhibition. Behavioral Brain Research, 225, 377-381. doi: 10.1016/j.bbr.2011.07.032

Dreessen, L., \& Arntz, A. (1998). Short-interval test-retest interrater reliability of the Structured Clinical Interview for DSM-III-R personality disorders (SCID-II) in outpatients. Journal of Personality Disorders, 12, 138-148. doi: 10.1521/pedi.1998

Einstein, A. (1950). Out of My Later Years. New York: Philosophical Library.

Ersche, K. D. (2013). Neurobiological correlates of the familial risk for stimulant drug dependence. Neuropsychopharmacology Reviews, 38, 238-239.

Ersche, K. D., Jones, S. P., Williams, G. B., Smith D. G., Bullmore, E. T., \& Robbins, T. W. (2013). Distinctive personality traits and neural correlates associated with stimulant drug use versus familial risk of stimulant dependence. Biological Psychiatry, 74, 137-144.

Eysenck, H. J., \& Eysenck, M. W. (1985). Personality and individual differences: a natural science approach. New York: Plenum Press.

Eysenck, S. B. G., Pearson, P. R., Easting, G., \& Allsopp, J. F. (1985). Age norms for impulsiveness, venturesomeness, and empathy in adults. Personality and Individual Differences, 6, 613-619. doi: 10.1016/0191-8869(85)90011-X

Feij, J. A., Zuilen, R. W. van, \& Gazendam, A. (1982). De ontwikkeling van een Nederlandse vragenlijst voor sensation seeking: de Spanningsbehoeftelijst (SBL). (The development of a Dutch questionnaire for sensation seeking.) Gedrag, 10, 364-383. URL: http://www.loa-cnr.it/Papers/ISIB-CNR-TR-18-02.pdf

Feliu-Soler, A., Soler, J., Elices, M., Pascual, J. C., Pérez, J., Martín-Blanco, A., ... \& Portella, M. J. (2013). Differences in attention and impulsivity between borderline personality disorder and bipolar disorder. Psychiatry Research, 210, 1307-1309. doi: 10.1016/j.psychres.2013.09.011

Fields, S., Edens, J. F., Smith, S. T., Rulseh, A., Donnellan, M. B., Ruiz, M. A., McDermott, B. E., \& Douglas, K. S. (2015). Examining the psychometric properties of the Barratt Impulsiveness Scale-Brief Form in justice-involved samples. Psychological Assessment, 27, 1211-1218. doi: 10.1037/a0039109

First, M. B., Spitzer, R. L, Gibbon, M., Williams, J. B. W. (1995). Structured clinical interview for DSM-IV axis I disorders (SCID-I). New York: Biometric Research Department.

Ford, J. K., MacCallum, R. C., \& Tait, M. (1986). The application of exploratory factor analysis in applied psychology: a critical review and analysis. Personnel Psychology, 39, 291-314.

Gay, P., Rochat, L., Billieux, J., D’Acremont, M. \& Van der Linden, M. (2008). Heterogeneous inhibition processes involved in different facets of self-reported impulsivity: evidence from a community sample. Acta Psychologica, 129, 332-339. doi: 10.1016/j.actpsy.2008.08.010.

George, D., \& Mallery, P. (2003). SPSS for Windows step by step: A simple guide and reference11.0 update (4th ed.). Boston: Allyn \& Bacon.

Haden, S. C., \& Shiva, A. (2008). Trait impulsivity in a forensic inpatient sample: An evaluation of the Barratt Impulsiveness Scale. Behavioral Sciences \& the Law, 26, 675-690. doi: 10.1002/bsl.820

Halberstadt, A. L., \& Geyer, M. A. (2010). LSD not lisuride disrupts repulse inhibition in rats by activating the 5-HT2A receptor. Psychopharmacology, 208, 179-189. doi: 10.1007/s00213-009-1718-x 
Harden, K. P., \& Tucker-Drob, E. M., (2011). Individual differences in the development of sensation seeking and impulsivity during adolescence: further evidence of a dual systems model. Developmental Psychology, 47, 739-746. doi: 10.1037/a0023279.

Hare, R. D. (1991). Manual of the Psychopathic Checklist-Revised (PCL-R). North Tonawanda, NW: Multi-Health Systems.

Hare, R. D. (2003). Manual for the Hare psychopathy Checklist-Revises, 2nd ed. Toronto: Multi-Health Systems.

Harris, M., Penfold, R. B., Hawkins, A., Maccomb, J., Wallace, B., \& Reynolds, B. (2014). Dimensions of impulsive behavior and treatment outcomes for adolescent smokers. Experimental and Clinical Psychopharmacology, 22, 57-64. doi: 10.1037/a0034403

Herrero, O., \& Colom, R. (2008). Distinguishing impulsive, unsocialized sensation seeking. A comparison between criminal offenders and the general population. Journal of Individual Differences, 29, 199-204. doi: 10.1027/1614-0001.29. 4.199

Heyman, G. M., \& Gibb, S. P. (2006). Delay discounting in college cigarette chippers. Behavioral Pharmacology, 17, 669-679.

Higgins, G. E., Kirchner, E. E., Ricketts, M. L., \& Marcum, C. D. (2013). Impulsivity and offending from childhood to young adulthood in the United States: a developmental trajectory analysis. International Journal of Criminal Justice Sciences, 8, 182.

Hildebrand, M. (2008). Psychopathy Checklist-Revised en Psychopathy Checklist: Youth Version. In: T. Giesbrecht, C. de Ruiter, \& M. Jelicic, (Eds). Forensisch psychodiagnostisch gereedschap: malingering, psychopathie en andere persoonlijkheidstrekken (Forensic psychological assessment tools: malingering , psychopathy and other personality traits) (pp. 107-125). Amsterdam: Harcourt.

Howard, R., \& Khalifa, N. (2016). Is emotional impulsiveness (Urgency) a core feature of severe personality disorder? Personality and Individual Differences, 92, 29-32. doi: 10.1016/j.paid.2015.12.017

Kiehl, K. A., Smith, A. M., Hare, R. D., \& Liddle, P. F. (2000). An event-related potential investigation of response inhibition in schizophrenia and psychopathy. Biological Psychiatry, 483, 210-221.

Lejuez, C. W., Aklin, W. M., Zvolensky, M. J., \& Pedulla, C. M. (2003). Evaluation of the Balloon Analogue Risk Task (BART) as a predictor of adolescent real-world risk-taking behaviors. Journal of Adolescence, 26, 475-479. doi: 10.1016/S0140-1971(03)00036-8

Lejuez, C. W., Read, J. P., Kahler, C. W., Richards, J. B., Ramsey, S. E., Stuart, G. L., Strong, D. R., \& Brown, R. A. (2002). Evaluation of a behavioral measure of risk taking: the Balloon Analogue Risk Task (BART). Journal of Experimental Psychology, 8, 75-84. doi: 10.1037//1076-898X.8.2.75

Lobbestael, J., Leurgans, M., \& Arntz A. (2011). Inter-rater reliability of the Structured Clinical Interview for DSM-IV Axis I Disorders (SCID I) and Axis II Disorders (SCID II). Clinical Psychology and Psychotherapy, 18,75-79. doi: 10.1002/cpp.693.

Logan, G. D. (1983). On the ability to inhibit simple thoughts and actions: I. Stop-signal studies of decision and memory. Journal of Experimental Psychology: Learning, Memory, And Cognition, 9, 585-606.

Lijffijt, M., Caci, H., \& Kenemans, J. L. (2005). Validation of the Dutch translation of the 17 questionnaire. Personality and Individual Differences, 38, 1123-1133. doi: 10.1016/j.paid.2004.07.010 
Morgan. J. E., Gray, N. S., \& Snowden, R. J. (2011. The relationship between psychopathy and impulsivity: a multi-impulsivity measurement approach. Personality and Individual Differences, 51, 429-434. doi: 10.1016/j.paid.2011.03.043

MacCallum, R. C., Widaman, K. F., Preacher, K. J., \& Hong, S. (2001). Sample size in factor analysis: the role of model error. Multivariate Behavioral Research, 36, 611-637. doi: 10.1207/S15327906MBR3604_06

Masui, K., \& Nomura, M. (2010). The effects of reward and punishment on response inhibition in non-clinical psychopathy. Personality and Individual Differences, 50, 69-73. doi: 10.1016/j.paid.2010.08.024

McCrae, R. R., \& Costa, P. T. (1990). Personality in adulthood. New York: Guilford.

Miranda, R., MacKillop, J., Meyerson, L. A., Justus, A., \& Lovallo, W. R. (2009). Influence of antisocial and psychopathic traits on decision-making biases in alcoholics. Alcoholism, Clinical and Experimental Research, 33, 817-825. doi: 10.1111/j.1530-0277.2009.00901.x

Nagoshi, C. T., Wood, M., Cote, C. C., \& Abbit, S. M. (1994). College drinking game participation within the context of other predictors of alcohol use and problems. Psychology of Addictive Behaviors, 8 , 203-213. doi: 10.1037/0893-164X.8.4.203

Nigg, J. T. (2000). On inhibition/disinhibition in developmental psychopathology: view from cognitive and personality psychology and a working inhibition taxonomy. Psychological Bulletin, 126, 220-246. doi: 10.1037/0033-2909.126.2.220

Patton, J. H., Stanford, M. S., \& Barratt, E. S. (1995). Factor structure of the Barratt Impulsiveness Scale. Journal of Clinical Psychology, 51, 768-774. doi: 10.1002/1097-4679(199511)

Pett, M. A., Lackey, N. R., \& Sullivan, J. J. (2003). Making sense of factory analysis : the use of factor analysis for instrument development in health care research. California: Sage Publications Inc.

Reynolds, B., Ortengren, A., Richards, J. B., \& de Wit, H. (2006). Dimension of impulsive behior: personality and behavioral measures. Personality and Individual differences, 40, 305-315. doi: 10.1016/j.paid.2005.03.024

Reynolds, B., Penfold, R. B., \& Patak, M. (2008). Dimensions of impulsive behavior in adolescents: laboratory behavioral assessments. Experimental and Clinical Psychopharmacology, 16, 124-131. doi: 10.1037/1064-1297.16.2.124

Roberts, W., Fillmore, M. T., \& Milich, R. (2011). Linking impulsivity and inhibitory control using manual and oculomotor response inhibitory tasks. Acta Psychologica, 138, 419-428. doi: 10.1016/j.actpsy.2011.09.002.

Rubin, E., Lazar, D., Gaich, N., \& Haray, D. (2008). The clinical trials landscape: limitations, strengths, and promise. Washington, DC: Association of Academic Health Centres.

Sapnas, K. G., \& Zeller, R. A. (2002). Minimizing sample size when using exploratory factor analysis for measurement. Journal of Nursing Measurement, 10, 135-153. doi: http://dx.doi.org/10.1891/jnum.10.2.135.52552

Sperry, S. H., Lynam, D. R., Walsh, M. A., Horton, L. E., \& Kwapil, T. R. (2016). Examining the multidimensional structure of impulsivity in daily life. Personality and Individual Differences, 94, 153-158.

Spinella, M. (2007). Normative data and a short form of the barratt impulsiveness scale. International Journal of Neuroscience, 117, 359-368. doi: 10.1080/00207450600588881

Skeem, J., Johansson, P., Andershed, H., Kerr, M., \& Louden, J. E. (2007). Two subtypes of psychopathic violent offenders that parallel primary and secondary variants. Journal of Abnormal Psychology, 116, 395-409. doi: 10.1037/0021-843X.116.2.395 
Swann, A. C., Lijffijt, M., Lane, S. D., Steinberg, J. L., \& Moeller, F. G. (2009). Trait impulsivity and response inhibition in antisocial personality disorder. Journal of Psychiatric Research, 43, 1057-1063. doi: 10.1016/j.jpsychires.2009.03.003

Tabacknick, B. G., \& Fidell, L. S. (2007). Using Multivariate Statistics. Boston: Pearson Education Inc.

Trent, S., \& Davies, W. (2012). The influence of sex-linked genetic mechanisms on attention and impulsivity. Biological Psychology, 89, 1-13. doi: 10.1016/j.biopsycho.2011.09.011

Værøy, H., Western, E. \& Andersson, S. (2016). The link between facets of impulsivity and aggression in extremely violent prisoners. Open Journal of Psychiatry, 6, 86-94. doi: 10.4236/ojpsych.2016.61010 Vonmoos, M., Hulka, L. M., Preller, K. H., Jenni, D., Schulz, C., Baumgartner, M. R., \& Quednow, B. B. (2013). Differences in self-reported and behavioral measures of impulsivity in recreational and dependent cocaine users. Drug and Alcohol Dependence, 133, 61-70. doi: 10.1016/j.drugalcdep.2013.05.032

Weertman, A., Arntz, A., \& Kerkhofs., M. L. M. (2003). Gestructeerd klinisch interview voor de vaststelling van DSM-IV As II stoornissen [Structural and Clinical Interview for DSM-IV personality disorders (SCID II)]. Lisse: Swets Test Publishers.

Whiteside, S. P., \& Lynam, D. R. (2001). The five factor model and impulsivity: using a structural model of personality to understand impulsivity. Personality and Individual Differences, 30, 669-689.

Winter, J. C. F., de, Dodou, D., \& Wieringa, P. A. (2009). Exploratory factor analysis with small sample sizes. Multivariate Behavioral Research, 44, 147-181. doi: 10.1080/00273170902794206

Zuckerman, M. Kolin, E. A., Price, L., \& Zoos, I. (1964). Development of a Sensation-Seeking Scale. Journal of Consulting Psychology, 28, 477-482. doi: 10.1037/h0040995 


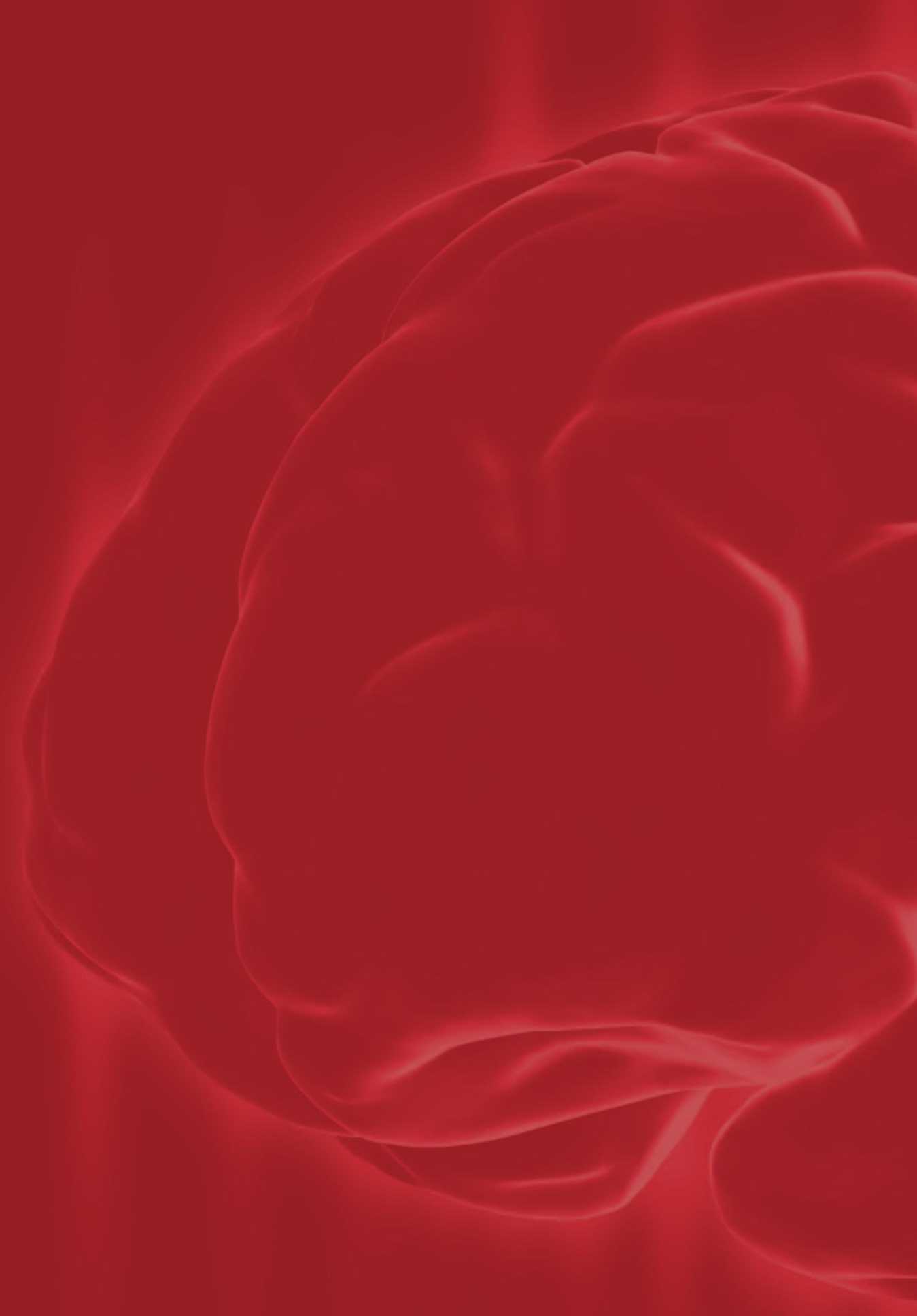




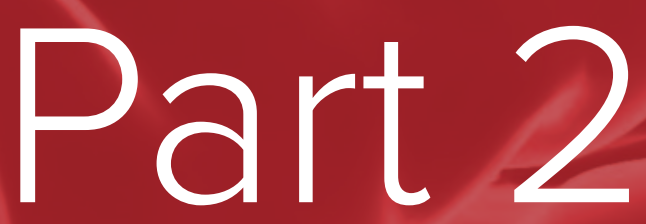

Neurocognitive vulnerability factors of provoked reactive aggression 


\section{CHAPTER3}

\section{Explosive matters: does}

venting anger reduce or increase aggression? Differences in anger venting effects in violent offenders

This chapter has been submitted as Tonnaer, F., Cima, M., \& Arntz, A. Explosive matters: does venting anger reduce or increase aggression? Differences in anger venting effects in violent offenders. Submitted 


\section{Abstract}

In the current study we aim to investigate if venting anger reduces, or rather increases aggression. Therefore, we allowed venting anger and measured its effect on aggression indices after two different anger provocation paradigms in a population of forensic psychiatric offenders ( $\mathrm{FPO}, \mathrm{N}=45$ ) and penitentiary care offenders (PO, $N=22$ ). These provocation paradigms included an Articulated Thoughts during Simulated Situations (ATSS) comprising anger stories, and a harassing body opponent bag (BOB) measuring punching force. To determine the aggression index pre and post provocation, implicit anger and self-reported aggression was assessed. Further, the relation between provocation paradigm response, aggression and psychopathy was evaluated. Results indicate that venting anger is effective in reducing aggression in FPO, but not in PO, where following ATSS even evidence for increase in one aggression index was found. Furthermore, groups differed in immediate responses during provocation, with FPO showing significantly more verbal aggressive responses during ATSS but less physically aggressive responses during BOB than PO. Moreover, results show a correlation between automatic cognitive anger biases during provocation and psychopathy in FPO. In PO, aggressive behavioral intentions and anger control problems during provocation were both related to self-reported aggression. For clinical practice, ATSS could be utilized as a paradigm exploring the actual state of specific cognitive biases towards anger.

Keywords Anger, Aggression, Provocation, Violent Offenders, Forensic, Penitentiary. 


\section{Introduction}

Aggression can be defined as 'hostile, injurious or destructive behavior' (Siever, 2008 p. 429). Often two dimensions of aggression are described, namely 'cold-blooded' referring to instrumental, proactive aggression to obtain a favored outcome (like power) or to coerce others (Raine et al., 2006), and 'hot-headed' referring to responsive, reactive aggression triggered by provocation (Blair, 2012). Both dimensions of aggression are mostly described in terms of problematic and destructive conduct (Howells et al., 2002). Additionally, the current study included the assessment of anger, because anger is the emotional drive or motive behind reactive aggression (Averill, 1983; Blair, 2012). Anger is defined as an emotion 'characterized by antagonism toward someone or something you feel has deliberately done you wrong' (American Psychiatric Association, APA). Anger can be beneficial, for example in defining personal and professional boundaries (Lown, 2007) and in motivating improvement. In fact, in the literature anger is reported to be associated with approach motivation (Harmon-Jones, Peterson, \& Harmon-Jones, 2010; He et al., 2010), or 'the impulse to go toward' (Harmon-Jones, Harmon-Jones, \& Price, 2013, p. 1). But elevated anger and the inability to regulate anger are related to problematic and destructive conduct, including aggressive and violent behaviour (Blair, 2012; Howells \& Howells, 2002). Consequently, anger has been defined as a mental health issue by policy makers, with anger regulation as a crucial target in the prevention of violent crime related to reactive aggression (Howells et al., 2002). It remains, however, elusive what exactly effective anger regulation means. According to the catharsis theory, venting emotions, specifically anger helps reducing angry feelings and consequently aggressive behavior. The catharsis theory has been the fundament of different therapies (Freud \& Brill, 1995; Scheff, 2001). The idea that venting anger is effective in reducing aggressive behavior has been widely supported by educators (Bennett, 1991) and the common public opinion (Gentile, 2013; Leslie, 2008), without any empirical support (Gentile, 2013).

On the contrary, some studies showed that venting anger might be ineffective and could even increase aggression (Bushman, 2002). The ineffectiveness of venting anger is in line with the excitation transfer theory (Zillmann, 1983). The excitation transfer theory (Zillmann, 1983) focuses on the link between arousal and cognitive judgment. Zillmann states that physical activity during a provocation can increase anger. More specific, it is believed that 'residual excitation enhances emotional responses to unrelated, immediately present stimuli only when the prevailing arousal cannot be attributed to its actual source' (Cantor, Zillmann, \& Bryant, 1975, p.1). The excitation transfer theory implies that individuals link arousal (residual excitation) caused by physical activity (like boxing) to the emotional state caused by the harassment (an excitation-transfer towards anger), thereby increasing anger and consequently reactive aggressive behavior.

Accordingly, we aimed to test if venting anger reduces, or rather increases aggression in offenders (forensic psychiatric offenders (FPO) and penitentiary care offenders (PO)). In order to enable venting anger in a controlled manner, participants participated in two different 
anger provocation paradigms. The effects of the provocation paradigms were measured by aggression indices taken before and afterwards. These provocation paradigms included articulated thoughts during simulated situations (ATSS) comprising anger stories, and a Body Opponent Bag (BOB) with harassing feedback. The effects of provocation were analyzed by measuring the number of cognitive anger statements during ATSS and mean force as Reactive Aggressive Behavior (RAB) response during BOB with harassing feedback. To determine the aggression indices pre and post the provocation, implicit anger and self-reported aggression were assessed (see Figure 1). Further, the relationships between the provocation paradigm responses on the one hand, and reactive as well as proactive trait aggression and psychopathy on the other hand were assessed. Given extreme anger expression in violent offender populations (Grochowska \& Kossowska, 2012), and anger being a risk factor for violent recidivism (Loza \& Loza-Fanous, 1999), the present study is unique in investigating anger and aggression response to provocation within violent offenders. By doing so, the current study will contribute to the documentation of the external validity of earlier proposed anger provocation and reactive aggression paradigms.

\section{Method}

\section{Participants}

A total of 67 male, incarcerated offenders participated in the current study. The offenders were recruited from a forensic high security psychiatric hospital Forensic Psychiatric Centre (FPC) de Rooyse Wissel ( $N=45)$, and a care unit of Penitentiary Psychiatric Centre (PPC) Overmaze $(\mathrm{N}=22)$. Offenders in the forensic high security psychiatric hospital received mandatory treatment under 'Ter beschikking stelling' (Tbs, placement under a hospital) order. Tbs serves as an obligatory penal measure for mentally disordered offenders who have committed severe, usually violent, crime (Kogel \& Hartogh, 2005). Offenders serving Tbs are incarcerated because court perceives them as a risk to society concerning their recidivism risk without treatment (de Ruiter, \& Hildebrand, 2007). Offenders in the penitentiary care unit have been replaced in this unit by local penitentiaries because of unmanageable (mostly aggressive) behavior, a need for extra care, or the need of extra diagnostic information. Participants were excluded if they were $<18$ years, reported psychotic symptoms, had an IQ $<80$, or had insufficient comprehension of the Dutch language. All participants were male and ranged in age from 19-66 years $(M=39.1, S D=10.3$; with $M=38.1, S D=8.6$ for the FPO, and $M=41.4, S D=13.2$ for the PO). As to their highest level of educational attainment, $6 \%$ had attended elementary school, $80 \%$ secondary school and $14 \%$ had attended college. In the FPO, 4\% had attended elementary school, $80 \%$ secondary school and 16\% had attended college, while in the PO 17\% had attended elementary school and $83 \%$ secondary school. The differences in age and education between the FPO and the PO was nonsignificant (see Results). Regarding the type of offences, $81 \%$ of all offenders, with $84 \%$ of the FPO, and $73 \%$ of the PO, were convicted for a violent crime (e.g. (attempted) manslaughter or murder, 
property crime with violence). More specific, within the FPO $35.6 \%$ of participants had been convicted for (attempted) manslaughter or murder, 20.0\% for sexual offenses such as rape, $17.8 \%$ for sexual offenses with minors, $6.7 \%$ for property crime with violence, $11.1 \%$ for bodily harm, $8.9 \%$ for arson. Within the penitentiary group, 31.8\% of participants had been convicted for (attempted) manslaughter or murder, 18.2\% for sexual offenses with minors, $13.6 \%$ for property crime with violence, and for bodily harm, $9.1 \%$ for property crime without violence, $4.5 \%$ for sexual offenses such as rape, for arson, and for deprivation of freedom.

Again, no significant group differences were found concerning the type of offence (see Results, section Group Differences). Psychopathy Checklist-Revised (PCL-R, Hare, 1991, 2003) data was collected only for the FPO of which the PCL-R was available ( $N=43,96 \%$ of the FPO). Since PCL-R data of the PO was available for just a vast minority ( $N=4,18 \%$ ), we included PCL-R data from the FPO only. Total PCL-R scores ranged from 10 to $36(M=23.5$, $S D=7.0$ ). All PCL-R interviews were scored and discussed by diagnostic forensic professionals resulting in a consensus score.

The Ethical Committee of Maastricht University and the Research Committee of FPC de Rooyse Wissel approved the methods and procedures described in the research protocol, all of which were performed in accordance with the Declaration of Helsinki. All participants participated on a voluntary basis. They received written and oral instruction emphasizing that participation was not related to treatment or prospects for release, and that participants were free to withdraw from the study at any time. After description of the study, written informed consent was obtained from each subject in accordance with FPC de Rooyse Wissel, PPC Overmaze and Maastricht University. Participants received a financial compensation for their participation.

\section{Procedure}

Participants first completed the Reactive-Proactive Questionnaire (RPQ, Raine et al., 2006) and the aggression indices: the Aggression Questionnaire (AQ, Buss \& Perrry, 1992) Anger-Single Target Implicit Association Test (Anger-STIAT, Lobbestael, Arntz, Cima, \& Chakhssi, 2009) in randomized order to determine the general anger level and possible preference towards specific types of aggression (see Figure 1). In order to provoke anger, the Articulated Thoughts in Simulated Situations paradigm (ATSS, Davison, Robins, \& Johnson, 1983) and the Body Opponent Bag (BOB) were used. Provocation was investigated in two identical sessions with a week in between. The order of the provocation was randomly assigned. In one session ATSS anger stories were used as provocation, while in another session the Reactive Aggressive Behavior (RAB) response to BOB with harassing feedback as provocation paradigm was used (see Measures). After each provocation, participants again completed the aggression indices (Anger-STIAT and AQ) to determine the post anger and aggression level, followed by a debriefing with good care for anger reduction (Kuin, 2000; Kuin, 1996). 


\section{Session 1}

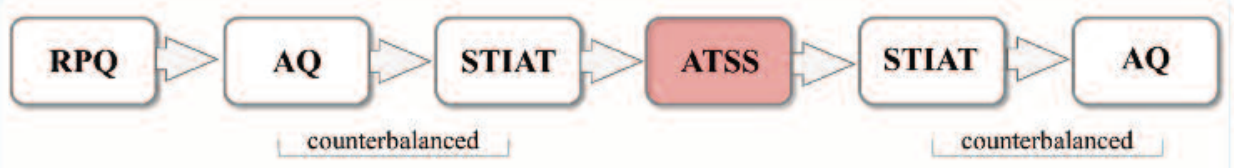

\section{Session 2}

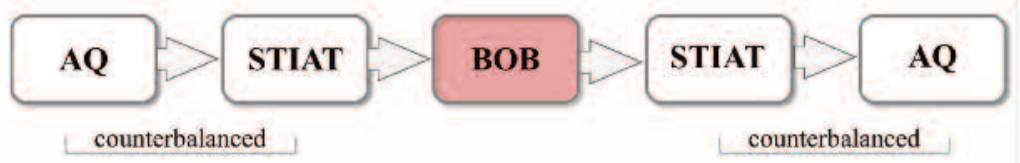

Figure 1. Procedure

\section{Measures}

\section{Anger Provocation Paradigms.}

Articulated Thoughts during Simulated Situations (ATSS, Davison et al., 1983).

ATSS is a cognitive assessment of thoughts and beliefs, in which subjects were asked to imagine one is in that particular situation and react to audiotape presented situations. In the current study, happy, neutral and anger situations were presented. Each situation was divided into seven segments of 15-20s. At the end of each segment there was a tone, followed by a silence interval of 30s. Participants were instructed to reflect on both their thoughts and their feelings on that particular situation within the silence interval. Only when no response was given after 10s, response was prompted asking: 1) "What would you do, or think being in that situation?", and 2) "How would you feel if it was you?". All response statements were transcribed, double scored following the ATSS scoring manual (Eckhardt \& Jamison, 2002) and discussed by two trained forensic professionals resulting in a consensus score. Statements were scored on six dimensions; 1) Articulated Anger Statements, covering signs of anger and other negative emotions; 2) Aggressive Behavioral Intentions reflecting the desire to harm someone/something; 3) Anger Control Strategies indicating prosocial interventions; 4) Irrational Beliefs, referring to low frustration tolerance; 5) Automatic Cognitive Biases as dichotomous thinking; and 6) Hostile Attributions towards someone. Dimensions were scored on a 5-point scale $(0=$ absent and $4=$ extremely present), with the exception of the hostile attributions subscale. Since only the anger stories displayed anger, we only scored the anger stories. Scores were calculated by summing the statement values within the dimension category for all anger segments. Research shows the ATSS is able to trigger anger (Tonnaer, Siep, van Zutphen, Arntz, \& Cima, 2017) and aggression related cognitions (Barbour, Eckhardt, Davison, \& Kassinove, 1998; Eckhardt, Barbour, \& Davison, 1998). For the current study, the anger dimension category scores were used to assess ATSS provocation (Tonnaer et al., 2017). 
Body Opponent Bag with harassing feedback (BOB). BOB with harassing feedback was developed as behavioral assessment of reactive aggression in response to provocation. $\mathrm{BOB}$ includes an in height adjustable full size lifelike mannequin opponent bag with a water filled base, and weighs about $150 \mathrm{~kg} / 330 \mathrm{lbs}$. Four Flexiforce (A201 type) pressure sensors with a force range of $0-445 \mathrm{~N}$ were constructed on Lonsdale training gloves recording the force associated with punch impact in a frequency of 1 ms (Büscher, Kõiva, Schürmann, Haschke, \& Ritter, 2015). At Maastricht University a software program has been developed to record the force of each punch in newton $(N)$. In order to maximize the force sensitivity, mean force of all four force sensors was registered (Falco et al., 2009). Before testing, weight was registered. Participants were instructed to 'punch BOB', knowing that the beginning and end of the recording is indicated with a loud auditory start and stop signal. However, participants did not know that $15 \mathrm{~s}$ after start, harassing feedback was triggered by punching. Hereafter, a total of six auditory feedback fragments were triggered in set order by a punch, each starting related to a punch and minimum $7 \mathrm{~s}$ after last feedback: 1) 'You have to do better, this is nothing!'; 2) 'Can’t you hit harder? We cannot measure anything!'; 3) 'Even my sister hits harder than you!'; 4) 'I don't feel anything yet!'; 5) 'The other participants hit much harder than you!'; 6) 'Are you a man?'. Recording stops $15 \mathrm{~s}$ after the last feedback. For the current study, the mean force after the last harassing feedback from BOB corrected for the time interval (Mean Force/time interval duration) was used to assess reactive aggressive behavior, referred to as Reactive Aggressive Behavior (RAB) response ( $M=4.29$ N.s, $S D=6.75)$.

\section{Implicit anger measure.}

Anger Single Target Implicit Association Test (Anger-STIAT, Lobbestael et al., 2009). The STIAT is a single target variant of the IAT (Greenwald, McGhee, and Schwartz, 1998). It measures the extent to which a target concept is associated with two attributes. When highly associated categories share the same response key, performance is fast and accurate. Conversely, when negative associated categories share a response key, performance is slow and errors increase. For this Anger-STIAT, self-concept was the target category stated as 'l', with the attribute categories 'anger' and 'peaceful'. The congruent condition the target and peaceful words share the same response key, while in the incongruent condition the target and anger words share the same response key. Anger-STIAT effect was calculated subtracting reaction time of the incongruent from the congruent condition (Karpinski \& Hilton, 2001; De Houwer, 2003). Participants were required to respond as quickly as possible. The current Anger-STIAT has proven its validity in earlier research on anger and the self-concept (Lobbestael et al., 2009). In the current sample, $\alpha$ was good to excellent (George \& Mallery, 2003, Anger-STIAT $\alpha=.85$ for the pre ATSS provocation assessment; Anger-STIAT $\alpha=.82$ post ATSS provocation; STIAT $\alpha=.85$ for the pre BOB provocation assessment; Anger-STIAT $\alpha=.92$ post BOB provocation). For the current study, Anger-STIAT score pre and post provocation was used to determine the implicit anger level. 


\section{Aggression measures.}

Reactive-Proactive Questionnaire (RPQ, Raine et al., 2006). The RPQ was used as a self-report of aggression during life time and consists of 23 items, rated on a 3-point Likert scale $(0=$ never and 2 = always). The questionnaire includes two subscales of trait aggression: the proactive subscale, which measures proactive aggression in items such as 'How often have you used force to get others so what you want?', and the reactive subscale measuring reactive aggression in items such as 'How often have you got angry or mad or hit others when teased?'. Scores of the subscales are calculated by summing the values for the items. Research has shown good internal reliability (Cima, Raine, Meesters, \& Popma, 2013), and discriminant validity (Raine et al., 2006). In the current sample, $\alpha$ was excellent (George $\&$ Mallery, 2003) with RPQ Total $\alpha=.92$, and good for the subscales (RPQ Reactive scale $\alpha=.85$ and RPQ Proactive scale $\alpha=.89$ ).

Aggression Questionnaire (AQ, Buss \& Perry, 1992). The $A Q$ is a self-report of 29 items, evaluated on a 5 -point Likert scale $(0$ = definitely disagree and $4=$ definitely agree). The $A Q$ has a four factor structure, represented in equivalent subscales denoting; 1) Physical Aggression (9 items such as 'Given enough provocation, I may hit another person.'), 2) Verbal Aggression (5 items such as 'I can't help getting into arguments when people disagree with me.'), 3) Hostility (8 items such as 'I am sometimes eaten up with jealousy.') and 4) Anger (7 items such as 'Sometimes I fly off the handle for no good reason.'). The AQ has shown good test-retest reliability and construct validity (Buss \& Perry, 1992). Following the George and Mallery (2003, p. 231) rule for interpreting the Cronbach's alpha reliability, $\alpha$ in the current sample was good (AQ Total $\alpha=.86$ for the pre ATSS provocation assessment; AQ Total $\alpha=.88$ post ATSS provocation; $A Q$ Total $\alpha=.84$ for the pre BOB provocation assessment; AQ Total $\alpha=.88$ post BOB provocation). For the current study, AQ Total score pre and post provocation was used to assess the pre and post-self-reported aggression.

\section{Data Reduction and Analysis}

Participants scoring higher or lower than three standard deviations from the mean were considered outliers (Tush et al., 2008). The following outliers were identified prior to the analysis and these value were set in to a maximum (or minimum) of 3 SD plus (or minus) 1 scale point from the mean: for Anger-STIAT 4 outliers were corrected; for the four RAB response during harassing BOB 2 outliers were corrected.

Independent-Samples $t$-Tests were performed in order to check for possible group differences concerning age, education, type of offence. Possible group differences for the index offence were tested using chi-square statistics. Response differences between FPO and $\mathrm{PO}$ in aggression indices (pre and post self-reported aggression as well as implicit anger) were tested by means of a repeated measures ANOVA analysis with group (FPO vs. PO) as a between subject factor and time (pre/post) as a within-subject factor. Group differences between forensic psychiatric offenders (FPO) and penitentiary offenders (PO) in responses 
during the anger provocation paradigms (ATSS and BOB) were tested by means of an Independent-Samples $t$-Test on the number of cognitive anger statements during the ATSS and a Mann-Whitney $U$ Test on mean force in RAB during BOB with harassing feedback. The relationship between the provocation paradigm responses, reactive as well as proactive aggression and psychopathy was assessed with correlational analyses.

\section{Results}

\section{Group differences}

No group differences were found concerning age $(t(67)=-1.07, p=.29)$, education $(t(67)=$ $1.47, p=.15)$, type of offence $(t(67)=.755, p=.45)$.

\section{Pre and Post aggression indices differences}

ATSS. Results on the repeated measures ANOVA with group (FPO vs. PO) as a between subject factor and time (pre/post) indicated a significant interaction of group (FPO vs. PO) * time on self-reported aggression (AQ) (Wilks' Lambda $=.86, F(1,64)=10.24, p=.002$ ) signaling different reaction patterns between the forensic psychiatric offenders and the penitentiary care offenders on the ATSS provocation. The repeated measures ANOVA on the Anger STIAT did not yield any significant result.

ВОВ. The repeated measures ANOVA on self-reported aggression indicated a significant interaction effect of group * time (Wilks' Lambda $=.94, F(1,64)=4.23, p=.04$ ) signaling different reaction patterns between the forensic psychiatric offenders and the penitentiary care offenders on the BOB provocation. The repeated measures ANOVA on the Anger-STIAT showed no significant results.

Table 1. Results Independent-Samples t-Tests investigating group difference in anger provocation response.

\begin{tabular}{|c|c|c|c|c|c|}
\hline \multirow[t]{2}{*}{ Measurement } & \multicolumn{2}{|c|}{$\begin{array}{l}\text { Forensic psychiatric } \\
\text { offenders (FPO) }\end{array}$} & \multicolumn{2}{|c|}{$\begin{array}{l}\text { Penitentiary } \\
\text { offenders (PO) }\end{array}$} & \multirow[t]{2}{*}{$t / z$} \\
\hline & Mean & SD & Mean & SD & \\
\hline ATSS Total & 18.46 & 8.39 & 13.64 & 6.67 & $2.35^{*}$ \\
\hline Anger statements & 6.53 & 4.09 & 5.32 & 3.36 & 1.20 \\
\hline Aggressive behaviour intentions & 5.60 & 3.51 & 4.23 & 2.93 & 1.58 \\
\hline Irrational beliefs & 2.90 & 2.62 & 1.32 & 1.99 & $-2.92^{* 0}$ \\
\hline Automatic cognitive biases & .28 & .57 & .41 & .59 & $-1.15^{\circ}$ \\
\hline Anger Control & 5.04 & 2.80 & 6.18 & 3.65 & .23 \\
\hline BOB RAB Total & 1.88 & 3.99 & 9.25 & 8.48 & $-4.27^{* 0}$ \\
\hline
\end{tabular}

Note. $" p<.05, " p<.01 ;{ }^{\circ}$ value based on Mann-Whitney 


\section{Provocation Paradigms differences}

The anger provocation paradigm (ATSS and BOB) responses between FPO and PO were tested by means of an Independent-Samples $t$-Test on the number of cognitive anger statements during the ATSS and a Mann-Whitney $U$ Test on mean force in RAB during BOB. Results showed significantly more anger response statements in the FPO while provoked by means of ATSS, while the PO showed significantly more reactive aggression behavior responses provoked by BOB (see Table 1). The group differences in ATSS total responses, were due to significant differences between the groups regarding the anger response statement dimension reflecting irrational beliefs (low frustration tolerance) and automatic cognitive biases (e.g., dichotomous thinking). Because of the significant group effect in the anger provocation paradigms, all following tests were performed for the groups separately.

\section{Results for the forensic sample (FPO)}

ATSS. Paired-Samples $t$-Tests of self-reported aggression (AQ, Buss \& Perrry, 1992) and implicit anger (Anger-STIAT, Lobbestael et al., 2009) pre and post the anger provocation using ATSS showed a significant decrease in aggression after the provocation and no significant difference in implicit anger (see Table 2).

Table 2. Results Paired-Samples t-Tests on assessment of anger and aggression pre and post the anger provocation.

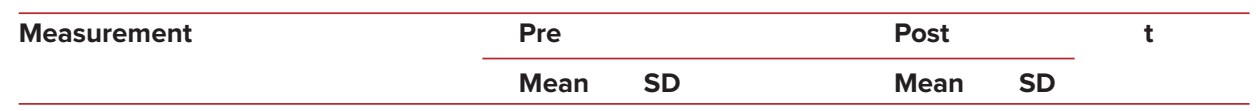

\section{Forensic psychiatric offenders (FPO)}

ATSS

$\begin{array}{llllll}\text { AQ Total } & 39.25 & 13.10 & 37.39 & 13.81 & -2.07^{*} \\ \text { Anger-STIAT } & -40.9 & 173.39 & -7.41 & 180.83 & 1.16\end{array}$

BOB RAB Response

$\begin{array}{llllll}\text { AQ Total } & 39.57 & 13.66 & 37.34 & 14.24 & -2.12^{*} \\ \text { Anger-STIAT } & -48.25 & 155.98 & -12.32 & 133.46 & 1.21\end{array}$

\section{Penitentiary offenders (PO)}

ATSS

$\begin{array}{llllll}\text { AQ Total } & 49.31 & 19.12 & 52.86 & 18.86 & 2.24^{\circ} \\ \text { Anger-STIAT } & -63.08 & 128.12 & -48.32 & 158.04 & .41\end{array}$

BOB RAB Response

\begin{tabular}{llllll} 
AQ Total & 52.23 & 16.07 & 53.77 & 18.22 & 1.01 \\
Anger-STIAT & -106.99 & 185.34 & -116.29 & 214.56 & -1.31 \\
\hline
\end{tabular}

Note. $" p<.05$ 
Moreover, correlational analysis between ATSS responses, reactive as well as proactive aggression (RPQ, Raine et al., 2006) and psychopathy (PCL-R, Hare, 1991, 2003), showed no significant correlation. But, a significant correlation was found between the ATSS dimension Automatic Cognitive Biases and psychopathy (see Table 3).

BOB. Paired-Samples t-Tests of self-reported aggression and implicit anger pre and post the anger provocation using $\mathrm{BOB}$, showed again a significant decrease in aggression after the provocation and no significant difference in implicit anger (see Table 2).

Moreover, correlational analysis between the RAB response during $\mathrm{BOB}$, reactive as well as proactive aggression and psychopathy, showed no significant correlations with the RAB response during $\mathrm{BOB}$ (see Table 3).

Table 3. Correlations of reactive as well as proactive aggression, psychopathy and the provocation paradigm responses.

\begin{tabular}{|c|c|c|c|c|c|}
\hline \multirow[t]{2}{*}{ Measure } & \multicolumn{2}{|c|}{$\begin{array}{l}\text { RPQ Reactive } \\
\text { Aggression }\end{array}$} & \multicolumn{2}{|c|}{$\begin{array}{l}\text { RPQ Proactive } \\
\text { Aggression }\end{array}$} & \multirow{2}{*}{$\begin{array}{l}\text { PCL-R } \\
\text { Psychopathy } \\
\text { FPO }\end{array}$} \\
\hline & FPO & PO & FPO & PO & \\
\hline ATSS Total & -.11 & $.53^{*}$ & -.13 & .32 & -.16 \\
\hline Anger statements & -.06 & .22 & -.09 & .08 & -.16 \\
\hline Aggressive behaviour intentions & -.07 & $.48^{*}$ & .01 & .33 & .06 \\
\hline Irrational beliefs & -.11 & .23 & -.18 & .15 & -.21 \\
\hline Automatic cognitive biases & .09 & .08 & .14 & -.22 & $.35^{\circ}$ \\
\hline Anger Control & .03 & $-.71^{* *}$ & -.01 & $-.59 "$ & -.03 \\
\hline BOB RAB Total & -.11 & -.01 & -.18 & -.04 & -.11 \\
\hline
\end{tabular}

Note. $" p<.05, " p<.01$

\section{Results for the penitentiary sample (PO)}

ATSS. Paired-Samples $t$-Tests of self-reported aggression and implicit anger pre and post the ATSS anger provocation, showed a significant increase in aggression after the provocation and no significant difference in implicit anger (see Table 2).

Furthermore, correlational analysis between the ATSS anger provocation responses and reactive as well as proactive aggression showed a significant correlation between ATSS responses and RPQ reactive aggression (see Table 3). More specific, a significant correlation between the ATSS dimension Aggressive behavioral intentions and RPQ reactive aggression was found (see Table 3). Furthermore, there was a significant negative correlation between the ATSS dimension Anger control and RPQ reactive aggression, as well as RPQ proactive aggression (see Table 3).

BOB. Paired-Samples $t$-Tests of self-reported aggression and implicit anger pre and post 
the anger provocation during BOB, showed no significant effects (see Table 2).

Moreover, correlational analysis between the $\mathrm{RAB}$ response during $\mathrm{BOB}$ and reactive as well as proactive aggression showed no significant correlations (see Table 3).

\section{Discussion}

In the current study we aimed to investigate whether venting anger reduces or increases aggression in two violent offender samples (forensic psychiatric offender (FPO) and penitentiary offenders (PO). We aimed to test the effect of venting anger on aggression in a lab controlled manner. Therefore we confronted all participants with two different provocation paradigms provoking anger and allowed venting anger. These provocation paradigms included articulated thoughts during simulated situations (ATSS) containing anger stories, and a body opponent bag (BOB) with harassing feedback eliciting a Reactive Aggressive Behavior (RAB) response. The provocation paradigm responses were analyzed measuring the number of cognitive anger statements in ATSS and mean force in RAB during BOB. Further, to determine the aggression indices (pre- and post-provocation), implicit anger and self-reported aggression was assessed. The relation between the provocation paradigms responses, reactive as well as proactive trait aggression (RPQ) and psychopathy (PCL-R) was assessed.

Regarding the aim of the study, the current results support the catharsis theory indicating that venting anger is effective in reducing aggression, in FPO. FPO showed a decrease in self-reported aggression propensity after both anger provocation paradigms. Although the FPO showed significantly more anger response statements compared to the PO while provoked by means of ATSS, only the PO group demonstrated an actual increase in self-reported aggression propensity after the ATSS provocation. As the ATSS is a cognitive provocation paradigm assessing thoughts and beliefs related to anger, this finding of an increase in self-reported aggression propensity only in the PO group is actually in line with the observation of very high rates of anger rumination in prison population (Bullock, 2010; Wener, 2012) that result in intensified anger, but not necessarily to less inhibitory control (Lievaart, Huijding, van der Veen, Hovens, \& Franken, 2017). Regarding BOB, a more behavioral provocation paradigm assessing physical anger venting, no increase nor decrease in anger was found in the PO.

The finding that the FPO group showed significantly more anger response statements in ATSS, while the PO group showed significantly more physically reactive aggression in response to a harassing $\mathrm{BOB}$, might indicate criminogenic, diagnostic, or context differences between both groups of violent offenders. An Independent Samples $t$-Test investigation on differences concerning the type of offence showed no significant group differences. Unfortunately, we only had access to criminogenic information concerning the $\mathrm{PO}$, leaving possible diagnostic differences (e.g. confounding addiction problems in the PO group or cognitive distortions in the FPO group) speculative. A majority of offenders within the PO were assigned to the special care unit because of a need for extra care, for extra diagnostic information (frequently personality disorder or addiction problems in the current population), or because of 
unmanageable (mostly aggressive) behavior. As one of the assignment criteria for this penitentiary care unit is the unmanageable of aggressive behavior, it might not be surprising that the PO group is more likely to show physical aggression (in the RAB response using $B O B$ ).

A possible implication of the sensitivity for sample type of BOB provocation paradigm is that its validity depends on population. Alternatively, it is also possible that the FPO serving a penal treatment measure because of mental problems exhibits more cognitive distortions related to mental illness, resulting in more anger statements on ATSS containing anger stories. This was supported by the finding that the ATSS differences were mainly due to the dimension cognitive biases. However, these group differences might also reflect a context effect like residence regime, length of stay and level of therapeutic interventions. As to possible residence regime differences, the FPO is sanctioned for physical aggression within the clinical setting, while the PO group is admitted within the special care unit because of unmanageable behavior elsewhere in the penitentiary (Wesselius, 2013). Regarding the length of stay, the PO had a mean length of stay of 3-5 months in a PPC facility (DJI, 2012), whereas the FPO has a mean length of stay of 62 months (DRW, 2012). Moreover, 82\% of the FPO receives a combined verdict with penitentiary facility placement preceding the forensic setting acceptance (Nagtegaal, van der Horst, \& Schönberger, 2011). One could speculate that especially the FPO is more hospitalized and used to be 'tested' on their response to provocation by daily interaction of other psychiatric patients at their ward for quite a long time. Furthermore, as to differences in the level of therapeutic interventions, FPO has a considerable history of therapy aiming to prevent violent outburst. They might therefore, be trained to actual reflect on their feelings - resulting in more anger statements on (ATSS) - and not acting out on anger.

For the FPO, self-reported aggression showed a significant decrease after both provocations. Although very speculative, one could argue that the effects of anger venting in the FPO group supports the catharsis theory. Recent fMRI research on anger provocation and regulation showed regulation difficulties in violent (forensic psychiatric) offenders, with an increased initiation to (implicitly) regulate during anger provocation (Tonnaer et al, 2017). The constant effort required for violent offenders to regulate anger might exhaust the necessary cognitive resources, resulting in a risk for self-control failure. Therefore, venting anger in a controlled setting like for instance during psychomotor therapy could be helpful for the FPO group reducing anger feelings and aggressive behaviors, preventing cognitive exhaustion when provoked.

Results concerning the relationship between provocation, reactive as well as proactive aggression and psychopathy showed a relationship between the ATSS dimension automatic cognitive biases towards anger and psychopathy in the FPO. Since both automatic cognitive biases towards anger and psychopathy are strongly associated with violent recidivism (Dolan \& Doyle, 2000; Douglas et al., 2014), the presence of these automatic cognitive biases towards anger could be identified using the ATSS paradigm in FPO, and in individuals with psychopathic characteristics in particular. 
In the PO, a relationship between the ATSS dimension aggressive behavioral intentions and self-reported (reactive) aggression was found. Also, in line with the general theory of crime (Gottfredson \& Hirschi, 1990), a significant negative relationship between the ATSS dimension anger control and self-reported aggression in the ATSS provocation was found. Gottfredson and Hirschi (1990) propose crime to be a result of a lack of self-control, an impulsive personality and criminal opportunities. The current results seem to support an important role for the lack of self-control resulting in reactive aggression, specifically in the PO group. For this reason, special care to anger regulation when provoked is necessary as empirical evidence suggested that a lack of self-control is a core factor in predicting crime (Baumeister \& Vohs, 2007; Vazsonyi \& Belliston, 2007).

The strengths of the current study are the naturalistic but very different anger provocation paradigms, and the use of different violent offender samples. However, a number of limitations should also be acknowledged. First, as previously described we only tested men, which limits the generalizability of our results. No healthy control groups and no female participants were included. We recommend that further research include non-patient as well as non-violent clinical control groups including women. Second, the generalizability of our study might be limited due to the context of a high security hospital. Perhaps, a less restricted setting is more suitable to provoke anger. Third, no diagnostic information was available for the PO group, leaving possible diagnostic differences speculative. Fourth, for future research it is recommended to combine implicit as well as explicit measurements of both anger and aggression and measures assessing state aggression, sensitive for measuring change in relative small time intervals like the Anger-STIAT is (Bluemke, Friedrich, \& Zumbach, 2010; Bluemke, \& Friese, 2008).

Concluding the current results, venting anger is effective in reducing aggression, at least in the FPO. Additionally, results show group differences in provocation sensitivity with the FPO group showing significant more anger response statements in ATSS provocation, whereas the $\mathrm{PO}$ showed significantly more reactive aggression behavior during $\mathrm{BOB}$. Within the FPO, a relation between automatic cognitive biases towards anger and psychopathy was found. In the PO group, a relationship between aggressive behavioral intentions and self-reported (reactive) aggression was found along with a significant negative relationship between anger control and self-reported aggression. For future research, it would be informative to investigate which automatic cognitive biases towards anger within forensic individuals with psychopathic characteristics relate to a higher recidivism risk. Additionally, in order to provide effective treatment, ATSS could be utilized as a supplemented paradigm exploring specific cognitive biases towards anger. 


\section{References}

Averill, J. R. (1983). Studies on anger and aggression: Implications for theories of emotion. American Psychologist, 38, 1145-1160. doi: 10.1037/0003-066X.38.11.1145

Barbour, K. A., Eckhardt, C. I., Davison, G. C., \& Kassinove, H. (1998). The experience and expression of anger in martially violent and martially discordant-nonviolent men. Behavior Therapy, 29, 173-191.

Bennett, J. C. (1991). The irrationality of the catharsis theory of aggression as justification for educators' support of interscholastic football. Perceptual and Motor Skills, 72, 415-418. doi: https://doi.org/10.2466/pms.1991.72.2.415

Blair, R. J. R. (2012). Considering anger from a cognitive neuroscience perspective. Wiley Interdisciplinary Reviews: Cognitive Science, 3, 65-74. doi: 10.1002/wcs.154

Bluemke, M., Friedrich, M., \& Zumbach, J. (2010). The influence of violent and nonviolent computer games on implicit measures of aggressiveness. Aggressive Behavior, 36, 1-13. doi: 10.1002/ab.20329

Bluemke, M., \& Friese, M. (2008). Reliability and validity of the Single[Target IAT (ST[IAT): assessing automatic affect towards multiple attitude objects. European Journal of Social Psychology, 38, 977-997. doi: 10.1002/ejsp.487

Bullock, J. S. (2010). The relation between anger rumination, provocation, and aggressive behavior. Tallahassee, Florida: Florida State University.

Bushman, B. J. (2002). Does Venting Anger Feed or Extinguish the Flame? Catharsis, Rumination, Distraction, Anger, and Aggressive Responding. Personality and Social Psychology Bulletin, 28, 724-731. doi: 10.1177/0146167202289002

Cantor, J. R., Zillmann, D., \& Bryant, J. (1975). Enhancement of experienced sexual arousal in response to erotic stimuli through misattribution of unrelated residual excitation. Journal of Personality and Social Psychology, 32, 69-75.

Davison, G. C., Robins, C., \& Johnson, M. K. (1983). Articulated thoughts during simulated situations: A paradigm for studying cognition in emotion and behavior. Cognitive Therapy and Research, 7, 17-40.

De Ruiter, C., \& Hildebrand, M. (2007). Risk assessment and treatment in Dutch forensic psychiatry. Netherlands Journal of Psychology, 63, 152-160. doi: 10.1007/BF03061078

Dienst Justitiële Inrichtingen (DJI), (2012). PPC I Penitentiair Psychiatrische Centra. Facts \& Figures. Den Haag: Ministerie van Veiligheid en Justitie.

Dolan, M., \& Doyle, M. (2000). Violence risk prediction. The British Journal of Psychiatry, 177, 303-311. doi: 10.1192/bjp.177.4.303

Douglas, K., S., Hart, S. D., Webster, C. D., Belfrage, H., Guy, L. S., \& Wilson, C. M. (2014). Historical-Clinical-Risk Management-20, Version 3 (HCR-20V3): Development and Overview, International Journal of Forensic Mental Health, 13, 93-108. doi: 10.1080/14999013.2014.906519

Eckhardt, C., \& Jamison, T. R. (2002). Articulated thoughts of male dating violence perpetrators during anger arousal. Cognitive Therapy and Research, 26, 289-308. doi: 10.1023/A:1016045226185

Forensisch Psychiatrisch Centrum de Rooyse Wissel (DRW), (2012). Jaarverslag 2011. Venray: FPC de Rooyse Wissel.

Freud, S., \& Brill, A. A. (1995). The basic writings of Sigmund Freud. New York: Modern Library. 
Gentile, D. A. (2013). Catharsis and media violence: A conceptual analysis. Societies, 3, 491-510. doi:10.3390/soc3040491

George, D., \& Mallery, P. (2003). SPSS for Windows step by step: A simple guide and reference11.0 update (4th ed.). Boston: Allyn \& Bacon.

Gottfredson, M. R., \& Hirschi, T. (1990). General theory of crime. Stanford: Stanford University Press.

Grochowska, K. \& Kossowska, M. (2012). Fact sheet violent offenders. European Association of Psychology and Law - Student Society Publishing House (EAPL-s): Poland.

Hare, R. D., Clark, D., Grann, M., \& Thornton, D. (2000). Psychopathy and the predictive validity of the PCL-R: An international perspective. Behavioral Sciences \& the Law, 18, 623-645. doi: 10.1002/ 1099-0798(200010)

Harmon-Jones, E., Harmon-Jones, C., \& Price, T. F. (2013). What is approach motivation?. Emotion Review, 5, 291-295. doi: 10.1177/1754073913477509

Harmon-Jones, E., Peterson, C. K., \& Harmon-Jones, C. (2010). Anger, motivation, and asymmetrical frontal cortical activations. In M. Potegal, G. Stemmler, \& C. Spielberger (Eds.), International handbook of anger (pp. 61-78). New York: Springer.

He, J., Degnan, K. A., McDermott, J. M., Henderson, H. A., ... \& Fox, N. A. (2010). Anger and approach motivation in infancy: Relations to early childhood inhibitory control and behavior problems. Infancy, 15, 246-269. doi: 10.1111/j.1532-7078.2009.00017.x

Howells, K., \& Howells, K. (2002). Anger management and violence prevention: Improving effectiveness. Trends \& issues in crime and criminal justice. 227. Canberra: Australian Institute of Criminology.

Kogel, C. H. de, Hartogh, V. E. den (2005). Termination of the Dutch TBS-order by court against the advice of the institution treating or supervising the patient. Frequency, nature, causes and relationship with subsequent criminal recidivism. Onderzoek en beleid, 236, The Hague: Boom Juridische uitgevers/WODC.

Kuin, F. (2000). Impulscontroleproblematiek. Oosterbeek: NVPMT.

Kuin, F. (1996). Voorspelbaar boksen: een manier om volgens procesgerichte therapiebeginselen een agressiedysregulatie te behandelen. Bewegen en Hulpverlening, 13, 53-65.

Leslie, C. (2008, April 11). Boxing is the best way to stop violence in kids. The Guardian. https://www.theguardian.com/politics/blog/2008/apr/14/boxingisthebestwaytostopScheff, T. J. (2001). Catharsis in healing, ritual, and drama. Lincoln, NE: iUniverse.com.

Lievaart, M., Huijding, J., van der Veen, F. M., Hovens, J. E., \& Franken, I. H. (2017). The impact of angry rumination on anger-primed cognitive control. Journal of Behavior Therapy and Experimental Psychiatry, 54, 135-142. doi: 10.1016/j.jbtep.2016.07.016

Lown, B. A. (2007). Difficult conversations: anger in the clinician-patient/family relationship. Southern Medical Journal, 1, 34-39. doi: 10.1097/01.smj.0000223950.96273.61

Loza, W. \& Loza-Fanous, A. (1999). Anger and Prediction of Violent and Nonviolent Offenders' Recidivism. Journal of Interpersonal Violence, 14, 1014-1029. doi: 10.1177/088626099014010002

Nagtegaal, M. H., van der Horst, R. P., \& Schönberger, H. J. M. (2011). Inzicht in de verblijfsduur van tbsgestelden. Cijfers en mogelijke verklaringen. Den Haag: WODC/Boom Juridische uitgevers. 
Raine, A., Dodge, K., Loeber, R., Gatzke-Kopp, L., Lynam, D., ... \& Liu, J. (2006). The Reactive-Proactive Aggression Questionnaire: Differential correlates of reactive and proactive aggression in adolescent boys. Aggressive Behavior, 32, 159-171. doi: 10.1002/ab.20115

Siever, L. J. (2008). Neurobiology of Aggression and Violence. American Journal of Psychiatry, 165, 429-442. doi: 10.1176/appi.ajp.2008.07111774

Tonnaer, F., Siep, N., van Zutphen, L., Arntz, A. \& Cima, M. (2017). Anger provocation in violent offenders leads to emotion dysregulation. Scientific Reports, 7, 3583. doi: 10.1038/s41598-017-03870-y.

Wener, R. E. (2012). The Psychology of Isolation in Prison Settings. In The Environmental Psychology of Prisons and Jails: Creating Humane Spaces in Secure Settings (Environment and Behavior). Cambridge: Cambridge University Press.

Wesselius, J. (2013). Het Penitentiair Psychiatrisch Centrum: een volwaardige psychiatrische kliniek in de gevangenis? [The Penitentiary Psychiatric Centre: a full-fledged psychiatric clinic within the prison?]. Ontmoetingen: Voordrachtenreeks van het Lutje Psychiatrisch-Juridisch Gezelschap, 17, 9-20.

Zillmann, D. (1983). Arousal and aggression. In R. G. Geen \& E. I. Donnerstein (Eds.), Aggression: Theoretical and empirical reviews (pp. 75-102). New York: Academic Press. 


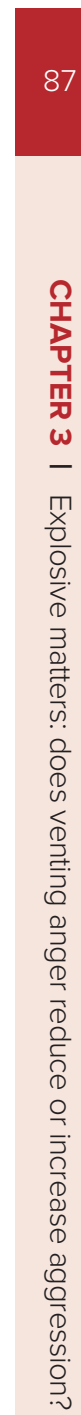




\section{CHAPTERY}

Executive (dys)functioning and impulsivity as possible vulnerability factors for aggression in forensic patients

This chapter has been published as Tonnaer, F., Cima, M., \& Arntz, A. (2016). Executive (dys)functioning and impulsivity as possible vulnerability factors for aggression in forensic patients. Journal of Mental and Nervous Disease, 204, 280-286. 


\section{Abstract}

In the current study we investigated whether executive dysfunction and impulsivity are both predictors of reactive aggression. This study is the first to employ behavioral assessment of aggression in response to provocation by means of a personalized boxing body opponent bag giving harassing feedback. Aggressive behavior, self-reported aggression, executive functioning (i.e., working memory, flexibility and divided attention) and impulsivity dimensions (i.e., Sensation Seeking, Impulsive Decision Making, and (inadequate) Response Inhibition) were measured in 44 incarcerated psychiatric patients. Results show that both executive functioning (working memory) and impulsivity (Impulsive Decision Making) predicted self-reported reactive aggression, whereas Response Inhibition was the only predictor for reactive aggressive behavioral responses. The results of this study suggest that Response Inhibition is a stronger predictor of reactive aggressive behavior than executive capacities of working memory, flexibility and divided attention. Therefore, future research should investigate whether (inadequate) Response Inhibition could be a valuable predictor for violent recidivism.

Keywords Executive Functioning, Impulsivity, Aggression, Forensic, Offenders. 


\section{Introduction}

'The Price of Victory, the Cost of Aggression' as Alexander Orlov, a veteran of the Great Patriotic War, says in a reflection on the Battle for Berlin indicating the negative impact of violence and aggression (Orlov, 2005). Aggression can be defined as 'hostile, injurious or destructive behavior' (Siever, 2008 p. 429) and can be distinguished in reactive and proactive aggression. Reactive aggression indicates spontaneous and emotion-driven responses to perceived threats (Cima \& Raine, 2009), and is also referred to as hostile, impulsive, or angry aggression (Anderson \& Bushman, 2002). Proactive aggression refers to forethought and planned, instrumental, goal directed aggression (Berkowitz, 1993; Raine et al., 2006). Research shows that reactive aggression is associated with violent behavior (Van Honk, Harmon-Jones Morgan \& Schutter, 2010; Mooney \& Daffern, 2011).

A convenient and common approach to assess aggression is self-report, like the Aggression Questionnaire (AQ, Buss, \& Perry, 1992), or pencil and paper version vignettes about provocative aggressive situations (O'Connor, Archer, \& Wul, 2001). While self-reports and vignettes are proven effective and valid in reflecting a persons' characteristics and beliefs towards aggression (Edwards \& Bond, 2012), and vignettes are valid methods to assess response to real life provoking situations (van Goozen, Frijda, Kindt, \& van de Poll, 1994), they are susceptible to social desirability, especially within forensic populations (Cima, 2003). Moreover, there are laboratory-based behavioral paradigms assessing aggression such as the Competitive Reaction Time Paradigm (Taylor, 1976), the Aggression Machine Paradigm (Buss, 1961), and the Performance Evaluation Paradigm (Berkowitz, 1962). All these behavioral paradigms include the punishment of another individual by giving electric shocks to the 'opponent' as a measure of direct physical aggression. However, punishing someone by giving electric shocks might be more an indication of sadistic willingness than an indication of reactive aggressive behavioral response. We aim to contribute to a behavioral response measure that might be more ecologically valid than delivering shocks. Therefore, we developed a measurement of reactive behavioral aggression in the form of a personalized Boxing Body Opponent bag (BOB) accompanied by boxing gloves with force sensors. To replicate a real life provocation, the $\mathrm{BOB}$ is giving harassing feedback triggered by punching (see the Measures section). In the current manuscript, reactive aggressive behavioral response is the mean punching force after harassment.

Impulsivity has been defined in various ways (Bickel, Jarmolowicz, Mueller, Gatchalain, \& McClure, 2012). The International Society for Research on Impulsivity (ISRI) defines impulsivity rather broadly as 'behavior without adequate thought, the tendency to act with less forethought than do most individuals of equal ability and knowledge, or a predisposition toward rapid, unplanned reactions to internal or external stimuli without regard to the negative consequences of these reactions (ISRI, http1://impulsivity.org/).' We define and assess impulsivity in a 3-dimensional model, containing Sensation Seeking, Impulsive Decision Making, and (inadequate) Response Inhibition (Tonnaer, Cima \& Arntz, 2016, see the Measures section). 
Like impulsivity, executive functioning has been defined and measured in various ways (Elliott, 2013). For instance, Baker and Ireland (2007) used a word fluency test to tap into cognitive control of organization, while Hoaken and colleagues (2003) used a self-ordered pointing task to measure the ability to organize, and monitor a series of responses. Executive functioning refers to cognitive control of planning and organization, attention, alertness, abstract reasoning, and regulation of behavior. In the current study, we conceptualized executive functioning in three different components, namely working memory, divided attention and flexibility. These three different components have been selected because they all represent different aspects of executive functioning thereby capturing the scope of this broad concept (Elliot, 2013; Suchy, 2009; Swami, 2013). Moreover, impairments in the three selected components are linked to elevated aggressive behavior (De Brito, Viding, Kumari, Blackwood, \& Hodgins, 2013; Feichtinger, 2007; Wilson \& Scarpa, 2011).

Empirical evidence shows that reactive aggressive behavior not only correlates with impulsivity (Chan \& Chui, 2012), but also with problems in executive functioning (Baker \& Ireland, 2007). Although both impulsivity and executive (dys)functioning relate to reactive aggressive behavior, the possible interrelation between both indicators of aggressive behavior remains unclear. Even more relevant to clinical practice and interventions, the possible interrelation between both indicators for aggressive behavior as a result of provocation remains unclear. For instance, it is not clear whether it is one of these factors or both that predispose to aggressive behavior. In the current study we aimed to investigate these relationships, in particular in a male offender sample, because the prevalence of maladaptive aggression tends to be specifically high in mental health treatment populations (Connor, 2002) like the study sample, as is the proneness towards aggression (Smith \& Waterman, 2003).

We hypothesized that executive dysfunction and impulsivity are both predictors of aggression, and most particular for reactive aggressive behavior (Bickel et al., 2012; Fischer \& Smith, 2008). More specific, we expect an inverse relationship between executive functions and reactive aggressive behavior. For instance research shows working memory - as a component of executive functioning - capacity relates to externalizing problem behavior such as aggression and antisocial behavior in children (Ziermans et al., 2012). Consequently we expect an inverse relationship between working memory and reactive aggressive behavior in the current study. Additionally, we expect an inverse relationship between all impulsivity dimensions and reactive aggressive behavior as e.g. a lack of self-control - operationalized in the (inadequate) Response Inhibition dimension - is frequently stated as a central cause of aggressive behavior (Gottfredson \& Hirschi, 1990; Swann \& Hollander, 2002).

\section{Method}

\section{Participants}

In the current study, 44 incarcerated psychiatric patients undergoing mandatory treatment within Forensic Psychiatric Centre de Rooyse Wissel participated in the current study. The 
current study sample is a subsample of the database aimed to present a multidimensional model of impulsivity (Tonnaer et al., 2016). The Ethical Committee of Maastricht University and the research committee of FPC de Rooyse Wissel approved the research protocol. Participants were recruited by means of an information letter, by which they could give their consent to participate. All participants participated on a voluntary basis. They received written and oral instruction emphasizing that participation was not related to treatment or prospects for release, and that participants were free to withdraw from the study at any time. Originally 46 offenders were recruited, but two withdraw due to a lack of interest or outplacement. All participants were male and ranged in age from 26 to 57 years $(M=38.2, S D=8.3)$. All participants were Dutch, 73\% white non-Hispanic, 12\% black non-Hispanic, 7\% multiracial, 5\% Asian/pacific islander, and $2 \%$ with Hispanic ethnicity. As to their educational level, $2 \%$ had attended only elementary school, $81 \%$ secondary school and $17 \%$ had attended college. Regarding the type of offences, 33\% participants had been convicted for actual or attempted manslaughter or murder, $21 \%$ for sexual offences such as rape, $16 \%$ for sexual offences with minors, $14 \%$ for bodily harm, $7 \%$ for property crime with violence, and $9 \%$ were convicted for arson.

The three exclusion criteria were the presence of psychotic disorders, IQ-score below 80, and insufficient comprehension of the Dutch language. Psychopathy Checklist-Revised (PCL-R, Hare, 1991, 2003) data was collected for all participants: total scores ranged from 10 to $36(M=23.6, S D=6.9)$. All PCL-R interviews were scored for and discussed by two trained forensic professionals resulting in a consensus score. In the current sample, 45,5\% was psychopathic ( $N=20$, scored 26 or above indicating psychopathy) and $54.5 \%(N=24)$ non-psychopathic.

Regarding the type of psychopathology, $57 \%$ of participants met diagnostic criteria for substance dependence (in full remission), 59\% for antisocial personality disorder (antisocial PD), 20\% for intermittent explosive disorder, 32\% for a single episode of an major depressive disorder (in full remission), 16\% for borderline PD, 11\% for post-traumatic stress disorder 11\%, pathological gambling and $11 \%$ for autism (all with a comorbidity rate of $89 \%$ ).

All pathology was scored for scientific purpose (the current study) by semi-structured interviews based on the fourth edition text revision of the Diagnostic and Statistical Manual of mental disorders (DSM, 2013). All interviews were scored and discussed by professionals who were trained to administer the interview, resulting in a consensus score arrived by discussion of scoring differences.

\section{Measures}

\section{Aggression.}

Reactive-Proactive Questionnaire (RPQ, Raine et al., 2006). The RPQ was used as a self-report of aggression during life time $(M=18.61$, range $=3-40, S D=9.38$ for $\mathrm{RPQ}$-Total; $M=11.84$, range $=3-21, \mathrm{SD}=4.30$ for RPQ-R; $M=6.77$, range $=3-21, \mathrm{SD}=5.77$ for RPQ-P in the current sample). The RPQ consists of 23 items that are rated on a 3-point scale $(0=$ never and 2 = always). The questionnaire includes two subscales of aggression: 
the proactive subscale, which measures proactive aggression in items such as 'How often have you got others to gang up on someone else?', and the reactive subscale measuring reactive aggression in items such as 'How often have you got angry or mad or hit others when teased?'. Research has shown good internal reliabilities for total RPQ, and reactive and proactive subscale scores with all reliability coefficients exceeding .81 (Cima, Raine, Meesters, \& Popma, 2013; Raine et al., 2006). The RPQ demonstrated good construct validity, convergent validity, riterion validity, and discriminant validity (Raine et al., 2006). Internal consistency in the current sample was excellent (Cronbach's alpha $=.92$ for RPQ total score, .83, for the proactive subscale, and .90 , for the reactive subscale).

Body Opponent Bag with harassing feedback (BOB, Tonnaer, Cima, \& Arntz, in preparation). $\mathrm{BOB}$ is used as behavioral assessment of reactive aggression in response to provocation. The Plastisol Body Opponent Bag includes an in height adjustable full size lifelike mannequin opponent bag including a water filled base and weighs about $150 \mathrm{~kg} / 330 \mathrm{lbs}$. four Flexiforce (A201 type) pressure sensors with a force range of $0-445 \mathrm{~N}$ are constructed on Lonsdale training gloves and connected with a laptop recording the force associated with punch impact in a frequency of 1 ms (Büscher, Kõiva, Schürmann, Haschke, \& Ritter, 2015; Lowe, King, Lovett, \& Papakostas, 2004). Maastricht University has developed a BOB software program aimed to record and save the force in newtons $(\mathrm{N})$ of each punch given by participants. In order to maximize the force sensitivity, the mean force of all four force sensors is registered (Falco et al., 2009; for a more detailed description and the validation of the current BOB assessment, see: Tonnaer, Cima, \& Arntz, submitted). Before the BOB testing procedure starts, participants are asked to weigh themselves and the weight is registered in the software program. Participants are then instructed to 'punch BOB', knowing that the beginning and end of the recording is indicated with a loud auditory start and stop signal. However, participants do not know that 15 seconds after the auditory start signal is given, harassing feedback is triggered by punching. Hereafter, a total of six different auditory feedback fragments are triggered in set order by a punch, each starting related to a punch and minimum 7 seconds after the last feedback. BOB gives the following auditory feedback; 1) 'You have to do better, this is nothing!', 2) 'Can't you hit harder? We cannot measure anything!', 3) ‘Even my sister hits harder than you!', 4) 'I don't feel anything yet!', 5) 'The other participants hit much harder than you!' and 6) 'Are you a man?'. Recording stops 15 seconds after the last feedback. For the current study, the mean force after the last feedback was used to assess reactive aggressive behavior, after this defined as the Reactive Aggressive Behavior (RAB) response $(M=17.89$ N.s, range $=6-120, S D=18.46$ in the current sample).

\section{Impulsivity.}

Impulsivity Model (Tonnaer, Cima, \& Arntz, 2016). The impulsivity model consists of the factor scores of three distinctive impulsivity dimensions (Tonnaer et al., 2016; $M=.0$, range = $-2.55-2.20, S D=1$ for SS; $M=.0$, range $=-1.48-2.46, S D=1$ for IDM; $M=.0$, range $=-2.34-$ 
2.28, $S D=1$ for $I N H$ in the current sample). The first dimension, - incorporating the BIS-11 (Patton, Stanford \& Barratt, 1995; $M=16.64$, range $=10-24, S D=3.10$ for $A l ; M=21.32$, range $=14-30, S D=4.21$ for $\mathrm{Ml} ; M=24.45$, range $=14-34, S D=4.59$ for NPI in the current sample) and the 17 (Eysenck, Pearson, Easting, \& Allsopp, 1985; $M=7.75$, range $=3-15, S D=3.04$ in the current sample) Impulsiveness scale - named 'Impulsive Decision Making' reflects acting without thinking about the consequences (Field, 1986) and is in the literature defined as the inability to delay gratification when tolerance results in a less risky outcome (Rachlin, 1974; Reynolds, Richards, \& de Wit, 2006) and the tendency to engage in spontaneous behavior, restlessness and impatience (Field, 1986). The second dimension, - incorporating the Balloon Analogue Risk Task (BART, Lejuez et al., 2002; $M=8.93$, range =1 - 18, SD = 3.76 for Explosions; $M=917.23$, range $=267-1572, S D=306.35$ for Pumps) and the 17 Venturesomeness scale - named 'Sensation Seeking' reflects a risk appetite and is in the literature related to actual risk taking, and aggressive, but not necessarily criminal behavior (Eysenck et al., 1985; $M=$ 11.77, range $=5-16, S D=2.92$ in the current sample). The third dimension, - incorporating the GoStop Impulsivity Paradigm (GoStop, Dougherty et al., 2005; $M=178.64$, range $=-28-332$, $S D=66.84$ for GoStop Stop Latency (ms); $M=66.68$, range $=40-86, S D=12.20$ for GoStop Inhibition (\%); $M=403.76$, range $=172-626, S D=98.76$ for GoStop Latency (ms) in the current sample), and the Sensation Seeking Scale (SSS, Zuckerman, Kolin, Price \& Zoos, 1964) Disinhibition scale $(M=4.12$, range $=2-6, S D=1.13$ in the current sample) - named (inadequate) Response Inhibition' reflects the failure to inhibit responding and disinhibited social behavior. Alike the selected components of executive functions, all three selected impulsivity dimensions are related to aggressive behavior (Denny \& Siemer, 2012; Lynam \& Miller, 2004; Ramírez, Millana, Toldos-Romero, Bonniot-Cabanac, \& Cabanac, 2009; Wilson, \& Scarpa, 2011).

\section{Executive Functioning.}

Test battery of Attentional Performance (TAP, Zimmerman \& Fimm, 2002). The TAP is a neuropsychological assessment of executive functioning (EF). The TAP includes various subtests developed to assess a variety of visuo-spatial, non-spatial and executive attention aspects such as alertness, divided attention, flexibility of focused attention, inhibitory processes and working memory. In the current study, three subtests are used to assess executive functioning:

1) Working Memory; in this subtest, a series of digits are presented on a screen. The participant is asked to react by pushing a button when the presented digit is identical to the second last digit shown. The TAP working memory test $(M=597.65$, range $=313-954, S D=$ 135.35 in the current sample) has been able to show group differences between schizophrenic and healthy controls in working memory (Huguelet, Zanello, \& Nicastor, 2000);

2) Divided Attention (dual-task condition, visual and auditory); this subtest presents a number of crosses simultaneously on the screen, combined with a series of high and low tones. The participants are asked to attend to two conditions, namely when four crosses form a square on a 4 $\times 4$ dot matrix (visual target), and when the same tone occurs twice (auditive target). In both instances, 
the participants have to press a button. The divided attention task of the TAP $(M=733.43$, range = $530-1195, S D=123.68$ in the current sample) has shown acceptable reliability, expressed in coefficient alpha of 75 (Goldhammer, Moosbrugger, \& Schweizer, 2007);

3) Flexibility (shapes alternating); this subtest presents two different stimuli (one angular and one round) simultaneously and randomly at the right and left side of the screen. The participants have two response buttons; one placed at the left and one at the right hand, and are asked to attend to the angular and the round target in turns, starting with the angular stimulus. The flexibility task of the TAP $(M=908.08$, range $=492-1820, S D=274.98$ in the current sample) has shown good reliability, expressed in coefficient alpha of 97 (Goldhammer et al., 2007), and good validity and reliability in the neuropsychological assessment of executive functioning (Fimm et al., 2001; Rozas, Juncos-Rabadán, \& González, 2008).

\section{Data Reduction and Analysis}

Normality of the raw data was checked and outliers were corrected if necessary. Participants scoring higher or lower than three standard deviations from the mean were considered outliers (Tush et al., 2008). The following outliers were identified prior to the analysis and the maximum value was set in to a maximum of 3 SD plus 1 scale point from the mean plus (or minus) one scale point: for divided attention, 1 outlier was corrected; for the TAP flexibility score, 2 outliers were corrected. Moreover, one individual did not complete the TAP in accordance to the instruction resulting in missing values for this person. To investigate the relationship between executive functioning, impulsivity and reactive aggressive behavior, a correlational analysis was completed. Moreover, we did check for possible correlations between the level of education of all participants on one hand and the measures of interest (aggression, impulsivity and executive function) on the other hand, but no significant correlation was found. Therefore, we did not correct for the level of education in the following analysis. Furthermore, to check for possible moderation effects, all variables were centered and nine interaction variables were created (impulsivity dimensions * 3 executive functioning components). In order to examine whether executive dysfunction and impulsivity were predictive for reactive aggressive behavior (both RAB response and self-report), two stepwise linear regression analyses ( $p \leq .05$ to $\geq$.1) were conducted. The executive functioning components (working memory, divided attention and flexibility), the impulsivity dimensions (Sensation Seeking, Impulsive Decision Making, and (inadequate) Response Inhibition), along with their interaction variables were stepwise entered simultaneously.

\section{Results}

\section{Correlations between aggression measurements}

The correlation between self-reported reactive aggressive behavior (RPQ total and subscale scores) and reactive aggressive behavior in response to provocation (RAB response) was not significant (see Table 1), indicating possible distinct components of aggression. Additionally, results 
corrected for the time interval duration and for mean force before feedback was given were similar to the reported results. Moreover, there was no relation between BOB results and weight.

\section{Correlations between executive functioning and impulsivity}

The correlations between the three executive functioning components (working memory, divided attention and flexibility) and the three impulsivity dimensions (Sensation Seeking, Impulsive Decision Making, and (inadequate) Response Inhibition) showed no significant relations, indicating distinct mechanisms (see Table 1).

\section{Correlations between impulsivity and aggression}

The correlations between the three impulsivity dimensions on one hand (Sensation Seeking, Impulsive Decision Making, and (inadequate) Response Inhibition) and both the self-reported reactive aggressive behavior (RPQ total and subscale scores) as well as the reactive aggressive behavior in response to provocation (RAB response) on the other hand, showed a significant relation between Impulsive Decision Making and the self-reported reactive aggressive behavior, and between (inadequate) Response Inhibition and the RAB response (see Table 1).

\section{Correlations between executive functioning and aggression}

The correlation between the three executive functioning components (working memory, divided attention and flexibility) and self-reported reactive aggressive behavior showed a significant negative relationship between working memory and the reactive aggression scale of the RPQ (see Table 1). The correlations between the executive components and the reactive aggressive behavior in response to provocation (RAB response) were not significant (Table 1).

Table 1. Correlations of aggression, impulsivity dimensions and executive functions ( $N=44)$.

\begin{tabular}{|c|c|c|c|c|c|c|c|c|c|}
\hline Measure & вов & RPQ & RPQ-R & RPQ-P & ss & IDM & RINH & WM & DA \\
\hline RPQ (Total) & -.23 & & & & & & & & \\
\hline$R P Q-R$ & -.17 & $.91 *$ & & & & & & & \\
\hline RPQ-P & -.25 & $.95^{*}$ & $.73^{* *}$ & & & & & & \\
\hline Sensation Seeking (SS) & .30 & -.11 & -.08 & -.12 & & & & & \\
\hline ImpulsiveDecision Making (IDM) & .03 & $.38^{\circ}$ & $.40^{\prime \prime}$ & $.32^{*}$ & .13 & & & & \\
\hline Response Inhibition (RINH) & $.34^{\circ}$ & -.17 & -.16 & -.16 & .04 & .00 & & & \\
\hline Working Memory (WM) & .01 & -.21 & -.34 & -.09 & -.08 & -.06 & -.07 & & \\
\hline Divided Attention (DA) & .04 & -.10 & -.12 & -.07 & -.28 & -.07 & -.05 & $.31^{*}$ & \\
\hline Flexibility (Flex.) & -.02 & -.13 & -.14 & -.10 & -.20 & -.11 & .01 & .13 & $.60^{\circ}$ \\
\hline
\end{tabular}

Note. $" p<.05, " p<.01$ 


\section{Prediction of aggression}

Results of the stepwise linear regression ( $p \leq .05$ (enter); $\geq .1$ (remove)) with the different executive functioning components, the impulsivity dimensions and their interaction variables as predictors and self-reported reactive aggressive behavior (RPQ-R) as target variable, show that both executive functioning and impulsivity predict self-reported reactive aggressive behavior, in particular Impulsive Decision Making and working memory (see Table 2). Moreover, results showed a significant $F$ Change indicating that the model with both predictors adds a significant value to the one predictor (Impulsive Decision Making) model (see Table 2).

Results of the stepwise linear regression $p \leq .05$ (enter); $\geq .1$ (remove)) with the different executive functioning components, the impulsivity dimensions and their interaction variables as predictors and the reactive aggressive behavior in response to provocation (RAB response) as target variable, show that only (inadequate) Response Inhibition predicts the RAB response (see Table 2).

Table 2. Stepwise regression analysis results predicting reactive aggressive behavior ( $N=44)$.

\begin{tabular}{lcccccccc}
\hline & $\boldsymbol{B}$ & SEB & $\boldsymbol{\beta}$ & $\boldsymbol{t}$ & $\boldsymbol{p}$ & $\boldsymbol{R}$ & $\boldsymbol{R}^{\mathbf{2}}$ & $\boldsymbol{R}^{\mathbf{2}}$ \\
& & & & & & & & change \\
\hline $\begin{array}{l}\text { RAB Response } \\
\text { Constant }\end{array}$ & 17.91 & 2.97 & & 6.03 & .00 & .35 & .12 & .12 \\
Inadequate Response Inhibition (RINH) & 6.17 & 2.86 & .35 & 2.15 & $.04^{*}$ & & & \\
RPQ-R & & & & & & & & \\
Model 1 & & & & & & & & \\
Constant & 11.86 & .62 & & 19.25 & .00 & .40 & .16 & $.15^{* *}$ \\
Impulsive Decision Making (IDM) & 1.74 & .63 & .40 & 2.78 & $.01^{* *}$ & & & \\
$\begin{array}{l}\text { Model 2 } \\
\text { Constant }\end{array}$ & & & & & & & & \\
Impulsive Decision Making (IDM) & 11.86 & .59 & & 20.25 & .00 & .51 & .26 & $.10^{*}$ \\
Working Memory (WM) & 1.66 & .60 & .38 & 2.78 & $.01^{* *}$ & & & \\
\hline
\end{tabular}

Note. ${ }^{*} p<.05 ;{ }^{* *} p<.01$

\section{Discussion}

In the current study we aimed to investigate whether executive dysfunctions and impulsivity dimensions contribute to a greater risk for aggression, in particular for reactive aggressive behavior in an offender sample. Our results can be summarized as follows. First, no significant relationship between executive functions and different impulsivity dimensions was found, indicating distinct components. Second, only working memory was correlated negatively with self-reported reactive aggressive behavior, but no relation between executive functioning and the reactive aggressive behavior in response to provocation (Reactive Aggression Behavioral, RAB response) 
assessed with the BOB test was found. Third, Impulsive Decision Making was related to self-reported reactive aggressive behavior, while (inadequate) Response Inhibition was related to reactive aggressive behavioral response (RAB response). Finally, stepwise regression analysis indicated that both executive functioning (working memory) and impulsivity (impulsive decision making) predicts self-reported reactive aggression, while the impulsivity dimension (inadequate) Response Inhibition was the only predictor for the RAB response.

For this study, we hypothesized that executive dysfunction and impulsivity dimensions would be both predictors of reactive aggressive behavior, since both are related to greater risk for reactive aggressive behavior (Blair, 2004; Mooney \& Daffern, 2011; Raine et al., 2000). Our results indicated that executive dysfunction and impulsivity dimensions are distinct components. This is in contrast to earlier results that indicated two related construct (Bickel et al., 2012; Tedeschi et al., 2013). Due to the absence of generally accepted definitions for both concepts (Pennington \& Ozonoff, 1996; Sergeant, Guerts, Huijbregts, Scheres, \& Oosterlaan, 2003), studies focusing on executive functioning often also include impulsivity as a component of executive functioning (Mar et al., 2013; Sabbagh, Xu, Carlson, Moses, \& Lee, 2006; Spinella, 2005). An explanation for the absence of a relationship between executive dysfunction and impulsivity dimensions is that the utilized methods tap into different processes representing differences in stable (trait, long-term) versus instable (state, short-term) concepts. Earlier research failed to show a significant relationship between state and trait impulsivity measurements (Wingrove \& Bond, 1997). The current results point out that further research should not only distinguish both concepts, but also study them in various situations in order to learn more about these distinct mechanisms (Spielberger, Krasner, \& Solomon, 1988).

Further, the current results showed a negative relationship between one executive functioning component (working memory) and self-reported reactive aggressive behavior. But, in contrast to our expectations, no relationship between any executive functioning variable and reactive aggressive behavior in response to provocation (RAB response) was found. This cross-domain finding between behavioral task performance of executive functioning (working memory) and self-reported aggression as opposed to the behavioral assessment of reactive aggression is informative in itself, given other research showing no relationship between self-report and behavioral assessment e.g. in aggression (Henry, 2006), as in other concepts like impulsivity (Cyders \& Coskunpinar, 2011; Reynolds et al., 2006). Moreover, the behavioral operationalized executive functioning measures as well as the current utilized self-report of aggression might represent typical stable (trait) concepts (Bannon, Gonsalvez, Croft, \& Boyce, 2006; Teten Tharp et al., 2011), while a behavioral measure such as the RAB response using BOB more likely represents a state dependent concept (Anguera et al., 2013; Leshem \& Glicksohn, 2007), that are not necessarily related (Wingrove \& Bond, 1997).

More specifically, working memory as opposed to divide attention and flexibility seems especially trait like (Bailey, Watts, Littlefield, \& Geary, 2014), since working memory is a top-down cognitive control centre of attention (Ilkowska \& Engle, 2010), with increasing 
working memory capacity resulting in better focus of attention (Colflesh \& Conway, 2007) and cognitive flexibility (Blackwell, Cepeda, \& Manakata, 2009).

Furthermore, we hypothesized a direct relationship between impulsivity and reactive aggressive behavior, since research shows that reactive aggression is closely related to impulsivity (Bickel et al., 2012; Fischer \& Smith, 2008). Indeed, Impulsive Decision Making was related to self-reported reactive aggressive behavior which is in line with research in youth (Fontaine \& Dodge, 2006), while (inadequate) Response Inhibition was related to reactive aggressive behavior in response to provocation. This result is in line with aggression theories explaining aggression as a result of inhibition problems (Finkel et al., 2012) and low self-control (Gottfredson \& Hirschi, 1990).

A combination of both executive dysfunction (working memory) and impulsivity (Decision Making) predicted reactive aggressive behavior. However, this was only the case for self-reported reactive aggressive behavior and not for the actual reactive aggressive behavior in response to provocation. Apart from the trait versus state explanation referring to different concepts (Anguera et al., 2013; Leshem \& Glicksohn, 2007), another explanation could be that our experimental task for assessing the reactive aggressive behavior in response to provocation (RAB response) might fail in validity. Indeed, the validation of $\mathrm{BOB}$ within a male forensic population has yet to be presented in a manuscript that we are currently preparing for publication, but we aim to be as transparent is possible on the implementation of the RAP response with respect to its replicability. However, research indicates that hitting a punching bag increases anger (Bushman, 2002). Furthermore, several aggression theories, such as the self-control theory of crime, explain aggression as a result of low self-control (Gottfredson \& Hirschi, 1990). The exciting transfer theory (Zillmann, 1983) indicates that physical activity during a prevocational situation might increases anger. Punching a fictive person, who gives harassing feedback, therefore seems an adequate method to elicit aggressive behavior in an ecological valid way.

Ultimately, it would be interesting to investigate whether (inadequate) Response Inhibition is not only a predictive factor for reactive aggressive behavior, but also for violent recidivism because reactive aggressive behavior is often associated with violent behavior (Van Honk et al., 2010).

The results of the present study must be seen in light of the following limitations. First, the sample size was small, thus results should be interpreted with caution. For instance, with higher sample size, additional predictors might emerge. One avenue for further research could therefore be to test whether type of pathology and psychopathy moderates the relationships between predictors and dependent variables. Second, no control groups and no female participants were included. We recommend that further research include non-patient as well as non-forensic clinical control groups including women. Third, the generalizability of our study might be limited due to the context of a high security hospital. Perhaps, a less restricted setting is more suitable to provoke reactive aggression.

Fourth, the generalizability of the results on executive functioning and impulsivity is only limited to the assessed aspects in the current study (working memory, divided attention, flexibility and 
Sensation Seeking, Impulsive Decision Making and (inadequate) Response Inhibition respectively), research using other aspects of executive functioning for example might result in different findings. Moreover, given the results of De Brito, Viding, Kumari, Blackwood and Hodgins (2013) indicating possible difference between 'cool' and 'hot' executive functioning processes, future research should incorporate both processing types as we only tapped the cool' type in the current study.

In conclusion, the literature shows that both impulsivity and executive dysfunction are related to aggression and violent crimes (Baker \& Ireland, 2007; Hoaken et al., 2003; Lane \& Cherek, 2000; Scarpa \& Raine, 2000). The results in current study not only show that both executive dysfunction and impulsivity seem distinct components - in a forensic population -, but even more important, it showed that the impulsivity component of (inadequate) Response Inhibition was the essential predictor for reactive aggressive behavior in response to provocation. Consequently, future research should investigate if (inadequate) Response Inhibition could also be a valuable predictor for violent recidivism. Further, risk management and aggression management programs for violent individuals with impulsivity problems should target specific on inhibition problems. 


\section{References}

American Psychiatric Association (APA). (2013). Diagnostic and statistical manual of mental disorders (5th ed.). Arlington, VA: American Psychiatric Publishing. doi:10.1176/appi.books.9780890423349

Anderson, C. A., \& Bushman, B. J. (2002). Human aggression. The Annual Review of Psychology, 53, 27-51. doi: 10.1146/annurev.psych.53.100901.135231

Anguera, J. A., Lyman, K., Zanto, T. P., Bollinger, J., \& Gazzaley, A. (2013). Reconciling the influence of task-set switching and motor inhibition processes on stop signal after-effects. Frontiers in Psychology, 4. 649. doi: 10.3389/fpsyg.2013.00649

Bailey, D. H., Watts, T. W., Littlefield, A. K., \& Geary, D C. (2014). State and trait effects on individual differences in children's mathematical development. Psychological Science, Advance online publication. doi:10.1177/0956797614547539

Baker, S. F., \& Ireland, J. L. (2007). The link between dyslexic traits, executive functioning, impulsivity and social self-esteem among an offender and non-offender sample. International Journal of Law and Psychiatry, 30, 492-503. doi: 10.1016/j.jilp.2007.09.010

Bannon, S. Gonsalvez, C. J., Croft, R. J., \& Boyce, P. M. (2006). Executive functions in obsessive-compulsive disorder: state or trait deficits? The Australian and New Zealand Journal of Psychiatry, 40, 1031-1038. doi: 10.1080/j.1440-1614.2006.01928.x

Barratt, E. S. (1994). Impulsiveness and aggression. In J. S. Monahan, \& H. J. Steadman (Eds.), Violence and mental disorder: developments in risk assessment (p. 61-79). Chicago: University of Chicago Press.

Berkowitz, L. (1962). Aggression: A social psychological analysis. New York: McGraw-Hill.

Berkowitz, L. (1993). Pain and aggression: some findings and implications. Motivation and Emotion, 17, 277-293. doi: 10.1007/BF00992223

Bickel, W. K., Jarmolowicz., D. P., Mueller, E. T., Gatchalain, K. M., \& McClure, S. M. (2012). Are executive functions and impulsivity antipodes? A conceptual reconstruction with special references to addiction. Psychopharmacology, 221, 361-387. doi: 10.1007/s00213-012-2689-x

Billieux, J., Gay, P., Rochat, L., Khazaal, Y., Zullino, D., \& Van der Linden, M. (2010). Lack of inhibitory control predicts cigarette smoking dependence: evidence from a non-deprived sample of light to moderate smokers. Drug and Alcohol Dependence, 112, 164-167. doi: 10.1016/j.drugalcdep.2010.06.006

Blackwell, K. A., \& Cepeda, N. J., \& Munakata, Y. (2009). When Simple Things Are Meaningful: Working Memory Strength Predicts Children's Cognitive Flexibility. The Journal of Experimental Child Psychology, 103, 241-249. doi: 10.1016/j.jecp.2009.01.002

Blair, R. J. R. (2004). The roles of the orbital frontal cortex in the modulation of antisocial behavior. Brain and Cognition, 55, 198-208. doi: 10.1016/S0278-2626(03)00276-8

Büehner, M., Köning, C. J., Pick, M., \& Krumm, S. (2006). Working memory dimensions as differential predictors of the speed and error aspect of multitask performance. Human Performance, 19, 253-275. doi: 10.1207/s15327043hup1903_4

Bunch, K. (2009). Risk taking behavior in bipolar affective disorder. Leeds: University of Leeds. URL: http://etheses.whiterose.ac.uk/1176/1/bunchthesis_final.pdf 
Büscher, G. H., Kõiva, R., Schürmann, C., Haschke, R., \& Ritter, H. J. (2015). Flexible and stretchable fabric-based tactile sensor. Robotics and Autonomous Systems, 63, 244-252. doi: 10.1016/j.robot.2014.09.007

Bushman, B. J. (2002). Does venting anger feed or extinguish the flame? Catharsis, rumination, distraction, anger, and aggressive responding. Personality and Social Psychology Bulletin, 28, 724-731. doi: $10.1177 / 0146167202289002$

Buss, A. H. (1961). The psychology of aggression. New York: Wiley.

Buss, A. H., \& Perry, M. (1992). The Aggression Questionnaire. Journal of Personality and Social Psychology, 63, 452-459. doi: 10.1037/0022-3514.63.3.452

Canning, A. H. M. (2011). An investigation of the relationship between self-esteem and aggression in care leavers. Cardiff: Cardiff University.

Chaplin, W. E., John, O. P., \& Goldberg, L. R. (1988). Conceptions of states and traits: dimensional attributes with ideals as prototypes. Journal of Personality and Social Psychology, 54, 541-557.

Cima, M. (2003). Faking good, bad and ugly; malingering in forensic psychiatric inpatients. Maastricht: Maastricht University. http://digitalarchive.maastrichtuniversity.nl/fedora/get/guid:4751c1af-9ddc4bb3-87f9-5512054f03d4/ASSET1

Cima, M., \& Raine, A. (2009). Distinct characteristics of psychopathy relate to different subtypes of aggression. Personality and Individual Differences, 47, 835-840. doi: 10.1016/j.paid.2009.06.031

Cima, M., Raine, A., Meesters, C., \& Popma, A. (2013). Validation of the Dutch Reactive Proactive Questionnaire (RPQ); differential correlates of reactive and proactive aggression from childhood to adulthood. Aggressive Behavior, 39, 99-113. doi: 10.1002/ab.21458

Chan, H. C., \& Chui, W. H. (2012). Psychological correlates of violent and non-violent Hong Kong juvenile probationers. Behavioral Sciences \& the Law, 30, 103-120. doi: 10.1002/bsl.2003

Colflesh G. J., \& Conway, A. R. (2007). Individual differences in working memory capacity and divided attention in dichotic listening. Psychonomic Bulletin \& Review, 14, 699-703. doi: 10.3758/BF03196824

Connor, D. F. (2002). Aggression and antisocial behavior in children and adolescents. New York: The Guilford Press.

Crews, F. T., \& Boettiger, C. A. (2009). Impulsivity, frontal lobes and risk for addiction. Pharmacology, Biochemistry and Behavior, 93, 237-247. doi: 10.1016/j.pbb.2009.04.018

Cyders, M. A., \& Coskunpinar, A. (2011). Measurement of constructs using self-report and behavioral lab tasks: Is there overlap in homothetic span and construct representation for impulsivity? Clinical Psychology Review, 31, 965-982. doi: 10.1016/j.cpr.2011.06.001

Dambacher, F., Sack, A. T., Lobbestael, J., Arntz, A., Brugman, S. \& Schuhmann, T. (2014). Out of control Evidence for anterior insula involvement in motor impulsivity and reactive aggression. Social Cognitive and Affective Neuroscience, 9, 1-9. doi: 10.1093/scan/nsu077

De Brito, S. A., Viding, E., Kumari, V., Blackwood, N., \& Hodgins, S. (2013). Cool and hot executive function impairments in violent offenders with antisocial personality disorder with and without psychopathy. PLOS ONE, 8, e65566. doi:10.1371/journal.pone.0065566

Denny, K. G., \& Siemer, M. (2012). Trait aggression is related to anger-modulated deficits in response inhibition. Journal of Research in Personality, 46, 450-454. doi: 10.1016/j.jrp.2012.04.001 
Dimitrova, A., Fronczek, R., Van der Ploeg, J., Scammell, T., Gautam, S., Pascual-Leone, A. \& Lemmens, G. J. (2011). Reward-seeking behavior in human narcolepsy. Journal of Clinical Sleep Medicine, 7, 293-300. doi: 10.5664/JCSM.1076

Dougherty, D. M., Mathias, C. W., Marsh, D. M., \& Jagar, A. A. (2005). Laboratory behavioral measures of impulsivity. Behavior Research Methods, 37, 82-90. doi: 10.4135/9781412952644

Edwards, R., \& Bond, A. (2012). Narcissism, self-concept clarity and aggressive cognitive bias amongst mentally disordered offenders. The Journal of Forensic Psychiatry \& Psychology, 23, 620-634. doi: 10.1080/14789949.2012.715180

Elliot, R. (2013). Executive functions and their disorders. Imaging in clinical neuroscience. British Medical Bulletin, 65, 49-59. doi: 10.1093/bmb/65.1.49

Evenden, J. L. (1999). Varieties of impulsivity. Psychopharmacology, 146, 348-361. doi: 10.1007/PL00005481

Eysenck, S. B. G., Pearson, P. R., Easting, G., \& Allsopp, J. F. (1985). Age norms for impulsiveness, venturesomeness, and empathy in adults. Personality and Individual Differences, 6, 613-619. doi: 10.1016/0191-8869(85)90011-X

Falco, C., Alvarez, O., Castillo, I., Estevan, I., Martos, J., Mugarra, F., \& Iradi, A. (2009). Influence of the distance in a roundhouse kick's execution time and impact force in Taekwondo. Journal of Biomechanics, 42, 242-8. doi: 10.1016/j.jbiomech.2008.10.041

Feichtinger, D. M. (2007). Cognitive flexibility in a forensic population. Origon: Pacific University. http://commons.pacificu.edu/spp/29/

Field, G. (1986). The psychological deficits and treatment needs of chronic criminality. Federal Probation, 50, 60-66. https://www.ncjrs.gov/pdffiles1/Digitization/111886NCJRS.pdf

Fimm, B., Vohn, R., Daumann, J., Gouzoulis-Mayfrank, E., Thron, A. \& Willmes-von Hinckeldey, K. (2001). Different functional representation of verbal working memory for numbers or letters: an fMRI study. Neurolmage, 13, 664-664. doi: 10.1016/S1053-8119(01)92007-5

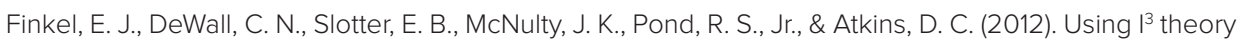
to clarify when dispositional aggressiveness predicts intimate partner violence perpetration. Journal of Personality and Social Psychology, 102, 535-549. doi: 10.1037/a0025651

Fischer, S., \& Smith, G. T. (2008). Binge eating, problem drinking, and pathological gambling: linking behavior to shared traits and social learning. Personality and Individual Differences, 44, 789-800. doi: 10.1016/j.paid.2007.10.008

Fontaine, R. G., \& Dodge, K. A. (2006). Real-Time decision making and aggressive behavior in youth: a heuristic model of response evaluation and decision (RED). Aggressive Behavior, 1, 604-624. doi: 10.1002/ab.20150 Gottfredson, M. R., \& Hirschi, T. A. (1990). General Theory of Crime. Stanford, CA: Stanford University Press. Goldhammer, F., Moosbrugger, H., \& Schweizer, K. (2007). On the separability of cognitive abilities related to Posner's attention components and their contributions to conceptually distinct attention abilities related to working memory, action theory, and psychometric assessment. European Psychologist, 12, 103-118. doi: 10.1027/1016-9040.12.2.103

Hare, R. D. (1991). Manual of the Psychopathic Checklist-Revised (PCL-R). North Tonawanda, NW: Multi-Health Systems. 
Hare, R. D. (2003). Manual for the Hare psychopathy Checklist-Revises, 2nd ed. Toronto: Multi-Health Systems.

Henry, D. B. (2006). Associations between peer nominations, teacher ratings, self-reports, and observations of malicious and disruptive behavior. Assessment, 3, 241-252. doi: 10.1177/1073191106287668

Herrero, O., \& Colom, R. (2008). Distinguishing impulsive, unsocialzed sensation seeking. A comparison between criminal offenders and the general population. Journal of Individual Differences, 29, 199-204. doi: 10.1027/1614-0001.29.4.199

Hirschi, T., \& Gottfredson, M. (1983). Age and the explanation of crime. American Journal of Sociology, 89, 552-584. doi: 10.1086/227905

Hoaken, P. N. S., Schaughnessy, V. K., \& Pihl, R. O. (2003). Executive cognitive functioning and aggression: is it an issue of impulsivity? Aggressive Behavior, 29, 15-30. doi: 10.1002/ab.10023

Huguelet, P., Zanello, A., \& Nicastor, R. (2000). A study of visual and auditory verbal working memory in schizophrenic patients compared to healthy subjects. European Archives of Psychiatry and Clinical Neuroscience, 250, 79-85. doi: 10.1007/s004060070039

Ilkowska, M., \& Engle, R. (2010). Trait and state differences in working memory capacity. In A. Gruszka, G. Matthews, \& B. Szymura (Eds.), Handbook of individual differences in cognition: Attention, memory, and executive control (pp. 295-320). New York, NY: Springer.

Kunert, H. J., Druecke, H. W., Sass, H., \& Herpertz, S. C. (2003). Frontal lobe dysfunctions in borderline personality disorder? Neuropsychological findings. Journal of Personality Disorders, 17, 497-506. doi: 10.1521/pedi.17.6.497.25354

Lane, S. D., \& Cherek, D. R. (2000). Analysis of risk taking in adults with a history of high risk behavior. Drug and Alcohol Dependence, 60, 179-187. doi: 10.1016/S0376-8716(99)00155-6

Lejuez, C. W., Read, J. P., Kahler, C. W., Richards, J. B., Ramsey, S. E., Stuart, G. L., Strong, D. R., \& Brown, R. A. (2002). Evaluation of a behavioral measure of risk taking: The Balloon Analogue Risk Task (BART). Journal of Experimental Psychology, 8, 75-84 doi: 10.1037//1076-898X.8.2.75

Leshem, R. \& Glicksohn, J. (2007). The construct of impulsivity revisited. Personality and Individual Differences, 43, 681-691. doi: 10.1016/j.paid.2007.01.015

Lowe, M., King, A., Lovett, E., \& Papakostas, T. (2004). Flexible tactile sensor technology: bringing haptics to life, Sensor Review, 24, 33-36. doi: 10.1108/02602280410515798

Lynam, D. R., \& Miller, J. D. (2004). Personality pathways to impulsive behavior and their relations to deviance: results from three samples. Journal of Quantitative Criminology, 20, 319-341. doi: 10.1007/s10940-004-5867-0

Mar, A. C., Horner, A. E., Nilsson, S. R., Alsiö, J., Kent, B. A., Kim, C. H., Holmes, A., Saksida, L. M., \& Bussey, T. J. (2013). The touch screen operant platform for assessing executive function in rats and mice. Nature Protocols, 8, 1985-2005. doi: 10.1038/nprot.2013.123

Maxwell, J.P. (2007). Do undergraduate students' ratings of perceived aggression in sport reflect athletes' self-reported aggression? Comments on Pedersen. Perceptual and Motor Skills, 105, 1136-1138. doi: 10.2466/pms.105.4.1136-1138 
Mooney, J. L., \& Daffern, M. (2011). Institutional aggression as a predictor of violent recidivism: implications for parole decision making. International Journal of Forensic Mental Health, 10, 52-63. doi: 10.1080/14999013.2010.550984

Morgan, J. E., Gray, N. S., \& Snowden, R. J. (2011). The relationship between psychopathy and impulsivity: a multi-impulsivity measurement approach. Personality and Individual Differences, 51, 429-434. doi: 10.1016/j.paid.2011.03.043

Morgan, A. B., \& Lilienfeld, S. O. (2000). A meta-analytic review of the relation between antisocial behavior and neuropsychological measures of executive function. Clinical Psychological Review, 20, 113-136. doi: 10.1016/S0272-7358(98)00096-8

Muris, P., Merckelbach, H., Wessel, I., \& van de Ven, M. (1999). Psychopathological correlates of self-reported behavioral inhibition in normal children. Behavior Research and Therapy, 37, 575584. doi: 10.1016/S0005-7967(98)00155-7

Nagoshi, C. T., Wood, M., Cote, C. C., \& Abbit, S. M. (1994). College drinking game participation within the context of other predictors of alcohol use and problems. Psychology of Addictive Behaviors, 8 , 203-213. doi: 10.1037/0893-164X.8.4.203

O'Connor, D. B., Archer, J., \& Wul, F. W. C. (2001). Measuring aggression: self-reports, partner reports, and responses to provoking scenarios. Aggressive Behavior, 27, 79-101. doi: 10.1002/ab.2

Orlov, A. (2005). The price of victory, the cost of aggression, History Today, 55, 24-26.

Patton, J. H., Stanford, M. S., \& Barratt, E. S. (1995). Factor structure of the Barratt Impulsiveness Scale. Journal of Clinical Psychology, 51, 768-774. doi: 10.1002/1097-4679(199511)

Pennington, B. F., \& Ozonoff, S. (1996). Executive functions and developmental psychopathology. Journal of Child Psychology and Psychiatry, 37, 51-87. doi: 10.1111/j.1469-7610.1996.tb01380.x

Perry, B. D. (2001). The neurodevelopmental impact of violence in childhood. In D. Schetky \& E. P. Benedek (Eds.), Textbook of child an adolescent forensic psychiatry (pp. 221-238). Washington: American Psychiatric Press.

Rachlin, H. (1974). Self-control. Behaviorism, 4, 64-107.

Raine, A., Dodge, K., Loeber, R., Gatzke-Kopp, L., Lynam, D., Reynolds, C., Stouthamer-Loeber, M., \& Liu, J. (2006). The Reactive-Proactive Aggression Questionnaire: differential correlates of reactive and proactive aggression in adolescent boys. Aggressive Behavior, 32, 159-171. doi: 10.1002/ab.20115

Raine, A., Lencz, T., Bihrle, S., Lacasse, L., \& Colletti, P. (2000). Reduced prefrontal gray matter volume and reduced autonomic activity in antisocial personality disorder. Archives of General Psychiatry, 57, 119-127. doi: 10.1001/archpsyc.57.2.119

Raine, A., Stoddard, J., Bihrle, S. \& Buchsbaum, M. S. (1998). Prefrontal glucose deficits in murderers lacking psychosocial deprivation Neuropsychiatry. Neuropsychology, and Behavioral Neurology, 11, 1-7. doi: $10.1177 / 0004867413512690$

Ramírez, J. M., Millana, L., Toldos-Romero, M. P., Bonniot-Cabanac, M.-C., \& Cabanac, M. (2009). The pleasure of being aggressive in incarcerated criminals. The Open Criminology Journal, 2, 1-9. doi: $10.2174 / 1874917800902010001$ 
Reynolds, B., Ortengren, A., Richards, J. B., \& de Wit, H. (2006). Dimension of impulsive behavior: personality and behavioral measures. Personality and Individual differences, 40, 305-315. doi: 10.1016/j.paid.2005.03.024 Reynolds, B., Richards, J. B., \& de Wit, H. (2006). Acute-alcohol effects on the Experiential Discounting Task (EDT) and a question-based measure of delay discounting. Pharmacology, Biochemistry and Behavior, 83, 194-202. doi: 10.1016/j.pbb.2006.01.007

Rozas, A. X. P., Juncos-Rabadán, O., \& González, M. S. R. (2008). Processing speed, inhibitory control and working memory: three important factors to account for age-related cognitive decline. International Journal of Aging and Human Development, 66, 115-130. doi: 10.2190/AG.66.2.b

Sabbagh, M. A., Xu, F., Carlson, S. M., Moses, L. J. \& Lee, K. (2006). The development of executive functioning and the theory of mind, a comparison of Chinese and U. S. preschoolers. Psychological Science, 17, 74-81. doi: 10.1111/j.1467-9280.2005.01667.x

Scarpa, A., \& Raine, A. (2000). Violence associated with anger and impulsivity. In J. C., Borod (Eds.), The neuropsychology of emotion: series in affective science (p. 320-339). New York: Oxford University Press.

Sergeant, J. A., Geurts, H., Huijbregts, S., Scheres, A., Oosterlaan, J. (2003). The top and the bottom of ADHD: a neuropsychological perspective. Neuroscience \& Biobehavioral Reviews, 27, 583-592. doi: 10.1016/j.neubiorev.2003.08.004

Siever, L. J. (2008). Neurobiology of Aggression and Violence. American Journal of Psychiatry, 165 , 429-442. doi: 10.1176/appi.ajp.2008.07111774

Smith, P., \& Waterman, M. (2003.) Processing bias for aggression words in forensic and non-forensic samples. Cognition and Emotion, 17, 681-701. doi: 10.1080/02699930302281

Spielberger, C. D., Krasner, S., \& Solomon, E. (1988). The experience, expression, and control of anger. In M. P. Janisse (Eds.), Health Psychology: Individual Differences and Stress (pp. 89-108). New York, NY: Springer.

Spinella, M. (2007). Normative data and a short form of the Barratt Impulsiveness Scale. International Journal of Neuroscience, 117, 359-368. doi: 10.1080/00207450600588881

Spinella, M. (2005). Self-rated executive function: development of the executive function index. International Journal of Neuroscience, 115, 649-667. doi: 10.1080/00207450590524304

Suchy, Y. (2009). Executive functioning: overview, assessment, and research issues for non-neuropsychologists. Annals of Behavioral Medicine, 37, 106-116. doi: 10.1007/s12160-009-9097-4

Sullivan, T. N., Helms, S. W., Kliewer, W., \& Goodman, K. L. (2010). Associations between Sadness and Anger Regulation Coping, Emotional Expression, and Physical and Relational Aggression among Urban Adolescents. Social Development, 19, 30-51. doi: 10.1111/j.1467-9507.2008.00531.x

Swami, S. (2013). Executive functions and decision making: a managerial review. IIMB Management Review, 25, 203-212. doi: 10.1016/j.iimb.2013.07.005

Swann, A. C., \& Hollander, E. (2002). Impulsivity and Aggression: Diagnostic Challenges for the Clinician. A Monograph for Continuing Medical Education Credit. Illinois: ACCESS Medical Group.

Taylor, S. P. (1967). Aggressive behaviour and physiological arousal as a function of provocation and the tendency to inhibit aggression. Journal of Personality, 35, 197-310. doi: 10.1111/.1467-6494.1967.tb01430.x 
Tedeschi, D., Martinotti, G., Di Nicola, M., De Vita, O., Hatzigiahoumis, D. S., Pozzi, G., \& Janiri, L. (2013). Executive functions and impulsivity in alcohol dependence: Focus on drinking behaviour. $21^{\text {st }}$ European Congress of Psychiatry, Nice: EPA. doi: 10.1016/S0924-9338(13)76848-2

Teten Tharp, A. L., Sharp, C., Stanford, M. S., Lake, S.L., Raine, A., \& Kent, T. A. (2011). Correspondence of aggressive behavior classifications among young adults using the Impulsive Premeditated Aggression Scale and the Reactive Proactive Questionnaire. Personality and Individual Differences, 50, 279-285. doi: 10.1016/j.paid.2010.10.003

Tonnaer, F., \& Chakhssi, F. (2007). Incident profiling on patients characteristics. Paper presented at the 5th EU-Violence in Clinical Psychiatry: Amsterdam.

Tonnaer, F., Cima, M., \& Arntz, A. (2016). Modeling impulsivity in forensic patients: a three-dimensional model of impulsivity. American Journal of Psychology, 129, 429-441. doi:10.5406/amerjpsyc.129.4.0429

Tush, C., Wiers, R. W., Ames, S. L., Grenard, J. L., Sussman, S., \& Stacy, A. W. (2008). Interactions between implicit and explicit cognition and working memory capacity in the prediction of alcohol use in at-risk adolescents. Drug and Alcohol Dependence, 94, 116-124. doi: 10.1016/j.drugalcdep.2007.10.019

Van Goozen S. H. M., Frijda N. H., Kindt M. \& Van de Poll N. E. (1994). Anger proneness in women: development and validation of the Anger Situation Questionnaire. Aggressive Behavior, 20, 79-100. doi: 10.1002/1098-2337(1994)20:2<79::AID-AB2480200202>3.0.CO;2-K

Van Honk, J., Harmon-Jones E., Morgan B. E., \& Schutter, D. J. L. G. (2010). Socially explosive minds: The triple imbalance hypothesis of reactive aggression. Journal of Personality, 78, 67-94. doi: 10.1111/j.1467-6494.2009.00609.x.

Webster, C. D., Douglas, K. S., Eaves, D., \& Hart, S. D. (1997). HCR-20: Assessing risk for violence, Version 2. Burnaby, British Columbia: Simon Fraser University.

Wilson, L. C., \& Scarpa, A. (2011). The link between sensation seeking and aggression: a meta-analytic review. Aggressive Behavior, 37, 81-90. doi: 10.1002/ab.20369

Wingrove, J., \& Bond, A. J. (1997). Impulsivity: a state as well as trait variable. Does mood awareness explain low correlations between trait and behavioural measures of impulsivity? Personality and Individual Differences, 22, 333-339. doi: 10.1016/S0191-8869(96)00222-X

Ziermans, T., Dumontheil, I., Roggeman, C., Peyrard-Janvid, M., Matsson, H., Kere, J., \& Klingberg, T. (2012). Working memory brain activity and capacity link MAOA polymorphism to aggressive behavior during development. Trans/ational Psychiatry, 2, 1-9. doi: 10.1038/tp.2012.7

Zillmann, D. (1983). Arousal and aggression. In R. G. Geen \& E. I. Donnerstein (Eds.), Aggression: Theoretical and empirical reviews (pp. 75-102). New York: Academic Press.

Zuckerman, M. Kolin, E. A., Price, L., \& Zoos, I. (1964). Development of a Sensation-Seeking Scale. Journal of Consulting Psychology, 28, 477-482. doi: 10.1037/h0040995 


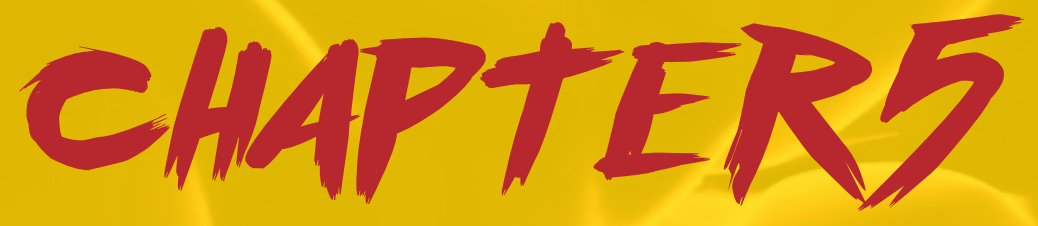

Anger provocation increases limbic and decreases medial prefrontal cortex connectivity with the left amygdala in reactive aggressive violent offenders.

This chapter has been published as Siep, N., Tonnaer, F., Ven, V., van de, Arntz, A., Raine, A., \& Cima, M. (2018). Anger provocation increases limbic and decreases medial prefrontal cortex connectivity with the left amygdala in reactive aggressive violent offenders. Brain Imaging and Behavior, doi: 10.1007/s11682-018-9945-6 


\section{Abstract}

Neurobiological models propose reactive aggression as a failure in emotion regulation, caused by an imbalance between prefrontal cortical control and excessive bottom-up signals of negative affect by limbic regions, including the amygdala. Therefore, we hypothesize a negative correlation between PFC and amygdala activity (pre/post resting-state scans) in violent offenders. In this study resting-state fMRI was administered before and after an emotion (anger and happiness) provocation or engagement task within 18 male violent offenders scoring high on reactive aggression, and 18 male non-offender controls. Research in emotional pre and post resting-state showed altered connectivity by task performance. Therefore, we examined a bilateral amygdala region of interest (ROI) whole brain functional connectivity analysis testing dynamic change differences between pre and post resting-state connectivity between groups. Self-reported anger showed a positive significant relationship with medial prefrontal cortex activity in the pre-task scan and significantly increased during the emotion task in both the violent and control group. Imaging results showed a significant decrease in amygdala - medial prefrontal functional connectivity in the violent offenders and an increase in the non-offender controls after the emotion task. The opposite pattern was found for amygdala connectivity with the (para)limbic regions: violent offenders showed increased connectivity and non-offender controls showed decreased connectivity. The present results indicate that reactive aggression might stem from a focus on emotion processing, as indicated by an increase in limbic functional connectivity. The combination of a focus on emotion, along with a lack of medial prefrontal cortex regulation, has the potential to grow out of control e.g. in reactive aggression.

Keywords impulsive aggression, emotion regulation, resting-state fMRI, functional connectivity, amygdala seed 


\section{Introduction}

Violence is a significant problem in our society. Reactive aggression, as opposed to proactive aggression, has been reported to be one of the major causes of violent behavior (World Health Organization, 2007).

Functional magnetic resonance imaging (fMRI) and especially resting state functional connectivity analysis might help in unraveling the 'default mode network' of reactive aggression (Shen, 2015). Resting state functional connectivity focusses on the functional organization of both healthy and abnormal brain activity while 'in rest'. Research conducting resting-state scans pre and post an emotional experimental task, testing for brain differences in functional connectivity has shown that pre and post resting state connectivity can be altered by fMRI task performance (Tung et al., 2013).

Emotion regulation research (Kohn, Eickhoff, Scheller, Laird, Fox, \& Habel, 2014) based on the theoretical framework of Gross and Ochsner (Gross, 1998; Ochsner et al., 2012), suggests that the prefrontal cortex is the core brain structure in the neural network of cognitive emotion regulation (Kose et al., 2015; Marxen et al., 2016). Research in offender populations linking the origin of reactive aggression to specific brain regions, indicate that a combination of decreased prefrontal activity along with increased, hyperactive limbic activity (amygdala) is related to reactive aggression (e.g. Blair, 2012; Coccaro, et al., 2016; da Cunha-Bang et al., 2017; da Cunha-Bang et al., 2018; Diano et al., 2017; Heesink et al., 2018; Marxen et al., 2016; McCloskey et al., 2016; Skibsted et al., 2017). And research in youths with conduct problems link callous-unemotional traits to aberrant amygdala activity as a risk factors for aggression (Cardinale et al., 2017) and adolescent antisocial behavior (Dotterer, Hyde, Swartz, Hariri, \& Williamson, 2017).

Empirical neuroimaging findings indicate that aggressive people have functional (Anderson \& Kiehl, 2012; Bobes et al., 2013; Raine et al., 1998) abnormalities in the PFC and limbic structures, especially the amygdala (Buades-Rotger, Beyer, \& Krämer, 2017). Research on maladaptive emotion regulation shows a negative correlation between limbic regions, with a main focus on the amygdala, and the PFC (Coombs, Loggia, Greve, \& Holt, 2014; McCloskey et al., 2016; Quaedflieg et al., 2015; Roy et al., 2009; Varkevisser, Gladwin, Heesink, van Honk, \& Geuze, 2017). Maladaptive emotion regulation can take two forms: 1) under-regulation, which refers to the inability to contain emotional experiences sufficiently to engage in goal-directed behavior, and 2) over-regulation, which occurs when emotion regulation strategies are used to consistently stop emotion experience from unfolding (Greenberg \& Bolger, 2001; Roberton, Daffern, \& Bucks, 2014). At the present, much of the aggression research has focused on the hypothesized emotion under-regulation of anger, and seems to support this theory by findings of prefrontal hypo-metabolism and prefrontal serotonergic hypoactivity (New et al., 2002; Siever et al., 1999).

In the present resting-state fMRI study we aimed to investigate brain connectivity using the amygdala as a region of interest (ROI) before and after an emotion task. By measuring 
functional connectivity using the amygdala as a ROI, we investigate the inter-relationship of other brain regions simultaneously engaged with the amygdala in an emotion task (Rogers, Morgan, Newton, \& Gore, \& 2007).

However, to our knowledge, no resting-state study has yet investigated the hypothesized abnormalities in functional connectivity between limbic structures and the PFC in reactive aggressive offenders, independent of any comorbid mental disorder. Moreover, the use of resting state scans before and after an emotion task gives the opportunity to investigate whether the negative correlation between limbic regions and the PFC (Coombs, Loggia, Greve, \& Holt, 2014; McCloskey et al., 2016; Quaedflieg et al., 2015; Roy et al., 2009; Varkevisser, Gladwin, Heesink, van Honk, \& Geuze, 2017) is related to maladaptive under-regulation or over-regulation in violent offenders.

Violent offenders are characterized by extreme aggressive behaviour (Grochowska \& Kossowska, 2012), with past aggression as a risk factor for violent recidivism (Mooney \& Daffern, 2011; Mooney \& Daffern, 2015). Therefore, we investigate a paradigm that is able to provoke anger (Tonnaer, Siep, van Zutphen, Arntz, \& Cima, 2017), resulting in reactive aggression (Blair, 2012). We focused on anger engagement, because anger is the emotional drive or motive behind reactive aggression (Averill, 1983). As the reactive aggression diathesis is generally interpreted as a breakdown in amygdala - PFC connectivity causing under-regulation, it was predicted that emotion engagement (including anger) would decrease amygdala resting-state connectivity with the PFC in the violent offender group, compared to non-offender, age- and education matched controls.

\section{Methods}

\section{Participants}

The violent offenders (VOF, $N=19$ ), hereafter referred to as the violent group, were recruited from an incarcerated male population at Forensic Psychiatric Centre de Rooyse Wissel (FPC dRW; Venray, the Netherlands), who were convicted for a violent crime (e.g. (attempted) manslaughter or murder, property crime with violence, bodily harm, domestic violence). The non-offender control group (NOC, $N=18$ ), was recruited from a participant database and consisted of male participants with no history of violent behavior, matched on age, education level, and left/right handedness with the violent group. Participants were excluded if they had MRI contraindications, had an IQ below 80, reported psychotic symptoms, or were younger than 18 years. Exclusion criteria for the NOC included major neurological disorders, history of brain injury, current psychiatric disorders or substance abuse. Demographic and clinical characteristics of the sample are summarized in Table 1 with exception of one violent offender who was discarded because of poor fMRI data quality (see fMRI data preprocessing section).

Psychopathy Checklist-Revised (PCL-R, Hare, 2003) data was collected for a subsample of $N=12$ VOF of which data was available. PCL-R total scores in general ranging from 0-40, ranged in the current sample from 12 to $28(M=21.2, S D=6.2$, showing that this is a sample 
displaying psychopathy characteristics). However, using the PCL-R as a diagnostic tool for the assessment of psychopathy (Acheson, 2005; Lynam \& Gudonis, 2005, p 383), with scoring 30 or above indicating the diagnosis of psychopathy (Cooke, Michie, Hart, \& Clark, 2004) indicates no diagnostic psychopathic individuals within the tested sample of violent offenders.

Table 1. Demographic and clinical characteristics of the sample.

\begin{tabular}{|c|c|c|c|c|c|}
\hline & $\begin{array}{l}\text { VOF } \\
N=18\end{array}$ & $\begin{array}{l}\text { NOC } \\
N=18\end{array}$ & $\begin{array}{l}t \text {-test } \\
p \text {-value }\end{array}$ & $d f$ & $\begin{array}{l}\chi^{2} \\
p \text {-value }\end{array}$ \\
\hline Age, $M(S D)$ & $35.17(7.12)$ & $37.06(15.24)$ & .64 & 34 & - \\
\hline Education, $N(\%)$ & & & & 3 & \\
\hline primary & $15(83.33)$ & $10(55.56)$ & - & & .07 \\
\hline secondary & $1(5.56)$ & $4(22.22)$ & - & & .15 \\
\hline college & $2(11.11)$ & $3(16.67)$ & - & & .63 \\
\hline Axis-I disorder, $N(\%)$ & & & & 2 & \\
\hline alcohol abuse & $4(22.22)$ & 0 & - & & .03 \\
\hline alcohol dependence & $5(27.780)$ & 0 & - & & .02 \\
\hline substance dependence & $13(72.22)$ & 0 & - & & $<.001$ \\
\hline depressive episode past & 6(33.33) & $1(5.56)$ & - & & .04 \\
\hline PTSD & $8(44.44)$ & 0 & - & & $<.001$ \\
\hline Axis-II disorder, $N(\%)$ & & 2 & & & \\
\hline antisocial PD & $11(61.11)$ & 0 & & & $<.001$ \\
\hline borderline PD & $3(16.67)$ & 0 & & & .07 \\
\hline paranoid PD & $3(16.67)$ & 0 & & & .07 \\
\hline
\end{tabular}

Note. PTSD = posttraumatic stress disorder; PD = personality disorder.

\section{Procedure}

Participants first completed the Reactive-Proactive Questionnaire (RPQ, Raine et al., 2006). Then, the fMRI scan started with a resting-state scan (see Figure 1). After the first resting-state scan, participants completed an emotion engagement or distraction task (counterbalanced in order, see Figure 1). After the first run of the emotion task an anatomical scan was started, during which the participant was instructed to relax. Then the second run of the emotion task was started. Immediately after the second run of the emotion task, the second resting-state fMRI scan was started. After the scanning session, the participant completed an exit-questionnaire. 


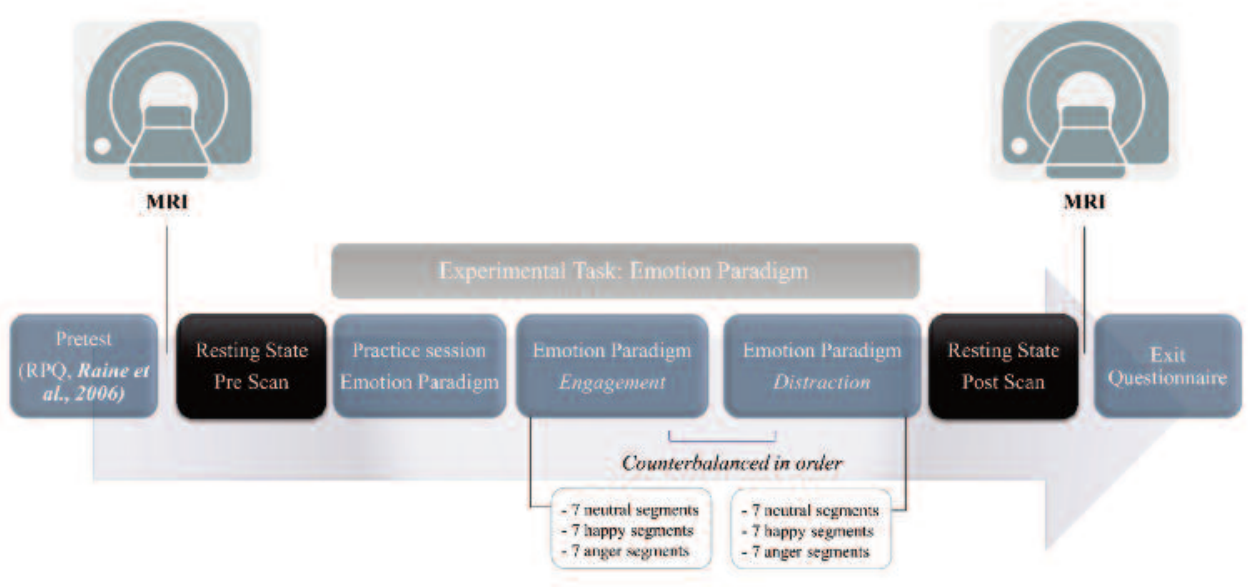

Figure 1. Procedure

\section{Ethical approval and informed consent}

The Ethical Committee of Maastricht University and the Research Committee of de Rooyse Wissel approved the methods and procedures described in the research protocol, all of which were performed in accordance with the Helsinki Declaration of 1975, as revised in 2009. All participants enrolled in the study received verbal and written information about the purpose and procedure of the study and signed written informed consent.

\section{Measures}

\section{Experimental paradigm (Tonnaer, Siep, van Zutphen, Arntz, Cima, 2017).}

Two 6 min resting-state scans were administered, one before and one after an emotional provocation or engagement (anger and happy) and distraction paradigm. Participants were instructed to lie still, relax and keep their eyes open. An adapted MRI version of the Anger Articulated Thoughts during Simulated Situations (ATSS) paradigm (Davison, Navarre, \& Vogel, 1995) was utilized in order to elicit anger and happy provocation and regulation. In the current study we focus on data of the resting-state scans pre and post the experimental paradigm, testing for brain differences in functional connectivity as previous research has shown that pre and post resting state connectivity can be altered by fMRI task performance (Tung et al., 2013). FMRI data results on the experimental task, along with a more detailed description of the paradigm, its instructions and the immediate effects are reported elsewhere (Tonnaer et al., 2017). In this task participants were presented with audio audiotaped (anger, neutral and happy) stories, each within an Engagement condition instructing participants to focus on one's emotional feeling, and a Distraction condition instructing participants to distract themselves from the presented stories during fMRI scanning. The order of these stories was randomized per participant. Each story was divided into seven segments of 15-20 seconds. At the end of each segment there was a tone, followed by a silence of 15 seconds. During this silence the participant either focused on one's emotional (emotion engagement), or tried to distract himself 
from whatever he was feeling or thinking at that moment (emotion distraction). The order of the engagement and distraction task was randomized per participant and counterbalanced. The silence was followed by a visual analogue scale (VAS; 9s), which participants used to rate the emotion intention at that moment $(0=$ very happy and, $100=$ very angry $)$.

The two anger stories were especially designed to elicit cognitions and feelings of anger. One anger story tells how the participant's colleagues are spreading untrue rumors; the principal actor gets reprimanded by the boss because of these rumors; that one of these colleagues harasses the principal actor on the way home from work; the principal actor gets involved in a car crash because of this and is unrightfully blamed for the crash. The other anger story tells how the principal actor is waiting for the train, which is delayed, to go to the club. In the train the principal actors ' partner is harassed by a drunken man and other people behave obnoxious. In the club it is impossible to order drinks and the man from the train punches the principal actors' partner in the face. The happy stories include situations about the weather being sunny, being in love and winning the lottery. The neutral situations are about going grocery shopping or going through the routine of a normal workday.

\section{Reactive-Proactive Aggression Questionnaire (RPQ, Raine et al., 2006).}

To validate the expected difference in reactive aggression between the VOF and the NOC, the Reactive-Proactive Aggression Questionnaire (Raine et al., 2006) was administered. The RPQ consists of 23 items: 11 items that measure reactive (i.e. impulsive) aggression and 12 items that measure proactive (i.e. instrumental) aggression, rated on a 3-point likert scale $(0=$ never and $2=$ always $)$. The internal reliability coefficients of the RPQ reactive and proactive-subscales are $\alpha=.81$, and $\alpha=.84$ respectively (Raine et al., 2006).

\section{Exit-Questionnaire.}

The exit-questionnaire consisted of $100 \mathrm{~mm}$ visual analogue scale, assessing representing variables that might influence resting-state functional connectivity other than the intended emotion engagement-distraction manipulation. These variables included physical discomfort inside the scanner $(0=$ no physical complaints and, $100=a$ lot of physical complaints), nervousness ( 0 = very nervous and, $100=$ not nervous at all), disturbance by the scanner noise ( $0=$ no annoyance at all and, $100=$ very annoying $)$ or concentration problems $(0$ = could not concentrate and, 100 = could concentrate very well). In addition, participants were asked about difficulty $(0=$ very difficult, and $100=$ not difficult at all $)$ and success $(0=$ not at all successful, and 100 = very successful) in performing the emotion engagement and distraction tasks.

\section{Image acquisition}

Anatomical images were acquired using a Magnetom Allegra 3T scanner (Siemens Healthcare, Netherlands) located at the Faculty of Psychology and Neuroscience, Maastricht 
University with a T1-weighted gradient echo (196 slices, TR $=2250 \mathrm{~ms}$, TE $=26 \mathrm{~ms}$, flip angle $=90^{\circ}$, field of view $=256 \mathrm{~mm}$ and voxel dimensions $1 \times 1 \times 1 \mathrm{~mm}$ ). T2*-weighted functional measurements were acquired using a standard echo-planar imaging (EPI) sequence. Repetition time (TR) was set at $2000 \mathrm{~ms}$, TE $30 \mathrm{~ms}$, flip angle $=90^{\circ}, 32$ slices, 180 volumes, $3 \times 3 \times 3 \mathrm{~mm}$. A slice tilt correction of -30 degrees was used to minimize inhomogeneity artefacts (Weiskopf, Hutton, Josephs, \& Deichmann, 2006).

\section{fMRI data preprocessing}

Data preprocessing and analyses was conducted with Brainvoyager QX v2.4 (Brain Innovations, Maastricht, The Netherlands). The first two volumes of the functional images were omitted due to magnetization artifacts. Preprocessing of the remaining functional data included slice time correction using sinc interpolation, 3D motion correction using sinc interpolation, spatial smoothing (Gaussian kernel with full-width-at-half-maximum of $4 \mathrm{~mm}$ ) and temporal filtering (linear trend removal). Individual functional datasets were then co-registered with structural images of the same participant and subsequently normalized using the Talairach and Tournoux transformation procedure (Talairach \& Tournoux, 1988). A quality check of functional brain coverage indicated that one of the violent offenders had insufficient amygdala coverage. This participant was removed from further analysis. Talairach coordinates were subsequently transformed to Montreal Neurological Institute (MNI) coordinates based on the ICBM-152 brain template (Lancaster et al., 2007) and all coordinates reported in this article are $\mathrm{MNI}$ coordinates. Individual volume time course (VTC) datasets were then averaged to create a group-based VTC functional brain mask to exclude voxels belonging to the outside of the functional brain.

\section{Resting-state functional connectivity analysis}

We used a mixed design with group (VOF vs. NOC) as between-subject factor and two fMRI runs (pre and post emotion task) as within subject factor (see the method sections 'Image acquisition' and 'fMRI data preprocessing' for more detailed information). In order to determine amygdala functional connectivity before and after the emotion task, an amygdala seed based connectivity analysis was performed, with amygdala seed MNI coordinates selected following the results of previous amygdala seed resting-state studies (Baeken et al., 2014; Cisler et al., 2013, Figure 2). The seed regions were two 6-mm-diameter spheres designed to encompass the left and right amygdala (Figure 2). In order to perform the analysis in Brainvoyager QX, first single study design matrix (SDM) files were created for each run of each participant using the NeuroElf matlab toolbox (www.neuroelf.net) and a custom-written resting state analysis toolbox developed at Maastricht University (Oertel-Knocel et al., 2013; van de Ven, Wingen, Ramaekers, \& Formisano, 2013). These SDM files included the BOLD time series of the left and right amygdala seed regions and 122 z-normalized nuisance confound regressors: six $3 \mathrm{D}$ head motion parameters ( $x, y, z$ translations and $x, y, z$ rotations) and their first derivatives, 
mean signal from the ventricles and white matter, global signal, and modelled oscillations at a frequency above $1 \mathrm{~Hz}$ (sine-cosine pairs). These SDM files were then used to run a random effects (RFX) GLM to find voxels that showed significant correlations with the left and right amygdala seeds separately, for each run of each participant.

\section{A}

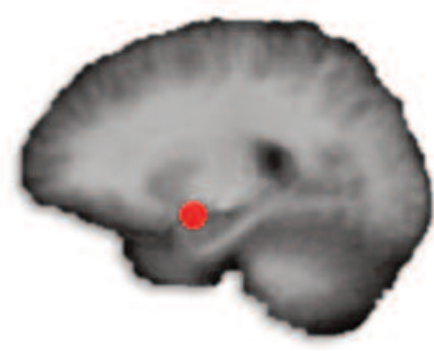

B

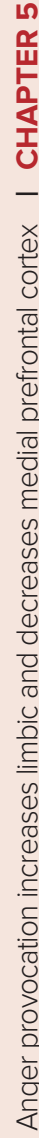

LH
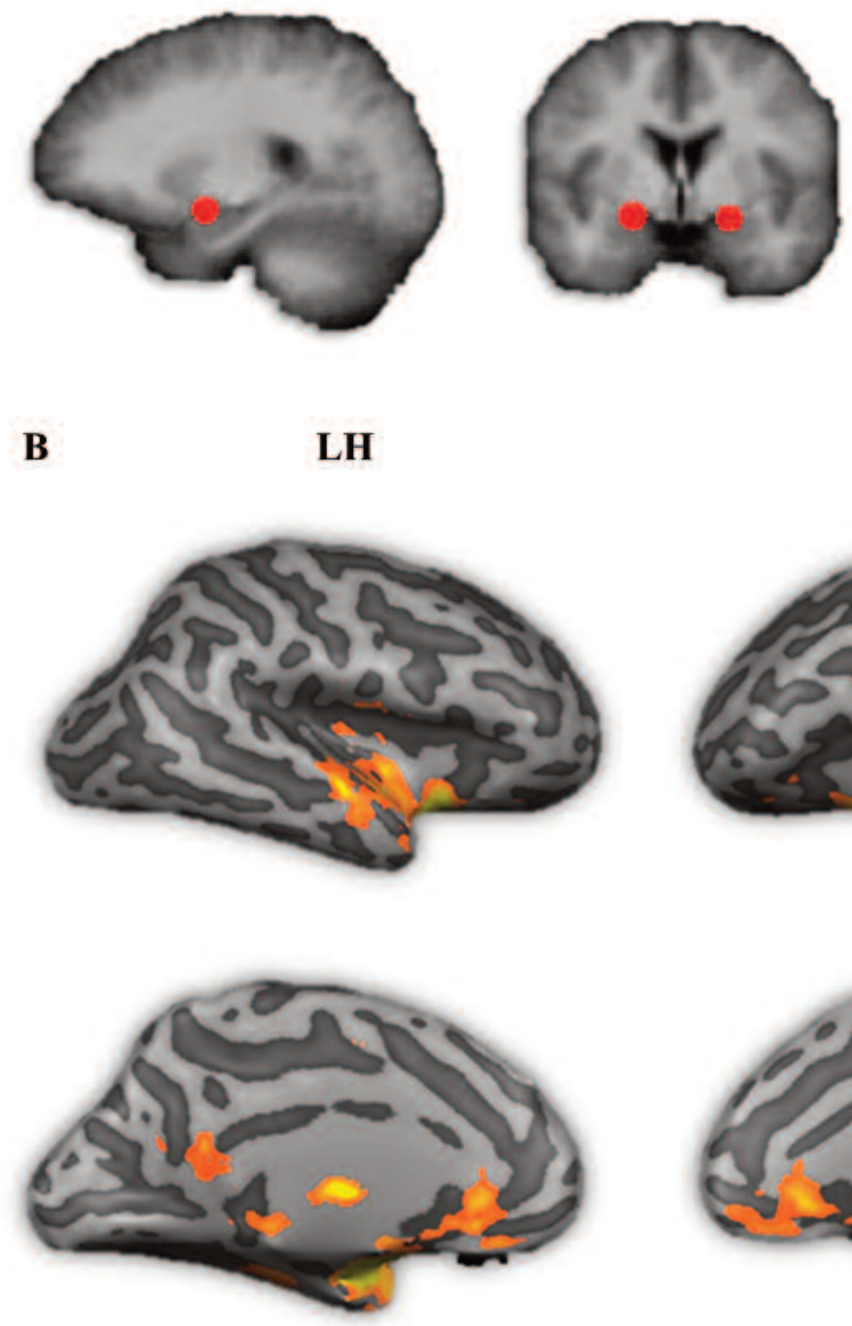

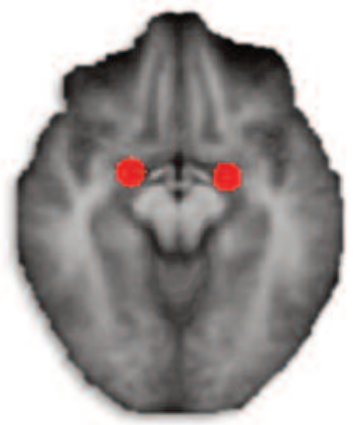

RH
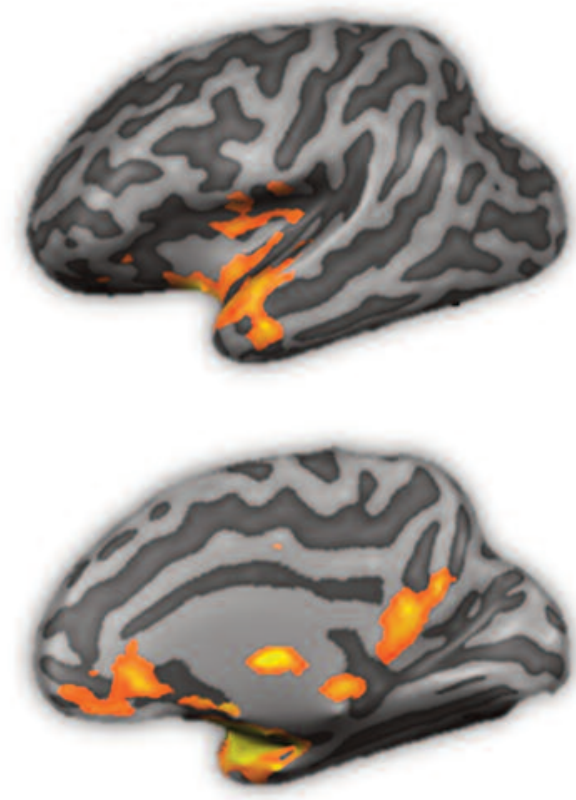

Figure 2. Panel A: A $6 \mathrm{~mm}$ sphere of the amygdala seeds used in the functional connectivity analysis were centered on the coordinates (MNI: $\mathrm{x}=-20, y=-4, \mathrm{z}=-15$ ) left, and (MNI: $\mathrm{x}=22, \mathrm{y}=-2, \mathrm{z}=-15)$ right. Panel B: Bilateral amygdala seed based functional connectivity mask, including posterior cingulate cortex, insula, medial prefrontal cortex, anterior temporal cortex with inclusion of the amygdala. 
The strategy of separate left versus right amygdala seed analysis was chosen due to the often reported strong correlational activity found between bilateral brain structures, resulting in multicollinearity and therefore reducing reliability when entering these two independent variables into the same model. To confirm this assumption we performed a post-hoc correlation analysis on the left and right amygdala seeds, which indeed showed significant correlations before $(r=.61, p<.001)$ and after $(r=.60, p<.001)$ the emotion task between the two seeds.

The Pearson correlation coefficients ( $r$ ) maps resulting from the RFX GLM analysis were transformed using Fisher's $R$-to- $Z$ transformation $(Z=.5$ Ln $[(1+R) /(1-R)])$, which yields variates that are approximately normally distributed. Then an F-group map was created, showing all voxels that had a significant correlation with the amygdala seeds at a conservative false discovery rate (FDR) of .001 for all participants over all runs. This map was transformed into a bilateral amygdala seed functional connectivity network mask (Figure 2), which was used to limit the final main and group $x$ time effects.

In the final analysis, a repeated measures ANOVA analysis with group (VOF vs. NOC) as a between subject factor and emotion task (pre/post) as a within-subject factor was conducted for the left and the right amygdala seed separately, to test for the hypothesized difference in amygdala connectivity. The resulting two F-maps were thresholded at a $p$-value of .01 and a cluster size threshold of $108 \mathrm{~mm}^{3}$ (4 voxels) as determined by the calculation of a minimum cluster which protected against false positive clusters at 5\% after 1000 Monte Carlo simulations (Forman et al., 1995). The Talairach coordinates of the peak voxels of the resulting functional regions of interest (ROIs) of these maps were converted into MNI space. Post-hoc analyses of simple effects within and between groups within these ROls were corrected for multiple comparisons using Bonferroni.

\section{Results}

\section{Self-report data}

\section{Reactive-Proactive Aggression Questionnaire (RPQ, Raine et al., 2006).}

Results indicated a significant difference $(p<.001)$ between the reactive aggression score of the $\operatorname{VOF}(M=14.67, S D=5.17)$ and the $\operatorname{NOC}(M=5.17, S D=3.43)$, with only one control participant falling within the $1 \mathrm{SD}$ range of the VOF. These results confirmed the expectation of higher reactive aggression in the VOF. The VOF also scored significantly higher on proactive aggression than the NOC (NOC, $M=1.00, S D=1.61$; VOF, $M=7.62, S D=4.74 ; p<.001$ ). However, analysis of group differences in proactive aggression while controlling for reactive aggression (i.e. ANCOVA) showed that group differences in proactive aggression were no longer significant $(p=.07)$. On the contrary, group differences in reactive aggression were still significant when controlling for proactive aggression $(p=.004)$, indicating that differences in reactive aggression in this study are primary. 


\section{Exit-questionnaire.}

On average there were no self-reported differences between the groups for physical discomfort (VOF, $M=22.11, S D=27.60 ; \mathrm{NOC}, M=28.47, S D=25.96 ; p=.49$ ) and concentration (VOF, $M=72.24, S D=24.05 ; \mathrm{NOC}, M=77.74, S D=19.18 ; p=.47)$. There was a trend for a difference in nervousness, with the NOC scoring higher than the VOF (VOF, $M=65.24$, SD = 34.63; NOC, $M=$ $82.59, S D=17.43 ; p=.08$ ). The VOF reported being significantly more disturbed by the scanner noise (VOF, $M=55.00, S D=33.37$; NOC, $M=30.76, S D=17.43 ; p=.02$ ). Both groups indicated that the task was not too difficult, with no significant difference between the groups for the emotion engagement (VOF, $M=73.35, S D=27.68 ; \mathrm{NOC}, M=69.35, S D=29.94 ; p=.69$ ) and the emotion distraction task (VOF, $M=89.18, S D=10.02$; NOC, $M=87.53, S D=15.86 ; p=.72$ ). However, the VOF did report that they expected to be significantly less successful in performing the emotion engagement (VOF, $M=$ $64.88, S D=33.27$; NOC, $M=84.29, S D=15.52 ; p=.04$ ). Difference in expected success between groups was almost significant for the emotion distraction task, again with the VOF expected to be significantly less successful in performing the emotion distraction (VOF, $M=57.76$, $S D=31.66$; NOC, $M=77.41, S D=22.36 ; p=.05)$. Further, no participants reported falling asleep. Pearson correlation coefficients analysis on the exit-questionnaire data and scan results indicate a significant negative correlation between disturbance by scanner noise and the superior temporal gyrus $(r=-.37, p<.05)$, only for the pre resting state scan.

\section{Anger.}

During the emotion task participants were asked to rate their experienced emotional state by means of a visual analogue scale (VAS; 0 = very happy and, 100 = very angry). Results for both groups (Figure 3) indicated that anger was increased during the anger engagement segments compared to the neutral and happy story segments (both $p s<.001$ ). Results were similar for changes in self-reported anger during the anger distraction task (both $p s<.001$ ). An independent-samples $t$-test (uncorrected) indicated that there was a significant difference in self-reported anger between the two groups, with the NOC reporting less anger after the anger segments while distracting, compared to the $\operatorname{VOF}(\mathrm{VOF}, M=71.64, S D=13.12 ; p=.04$; $\mathrm{NOC}, M=58.34, S D=22.73$ ).

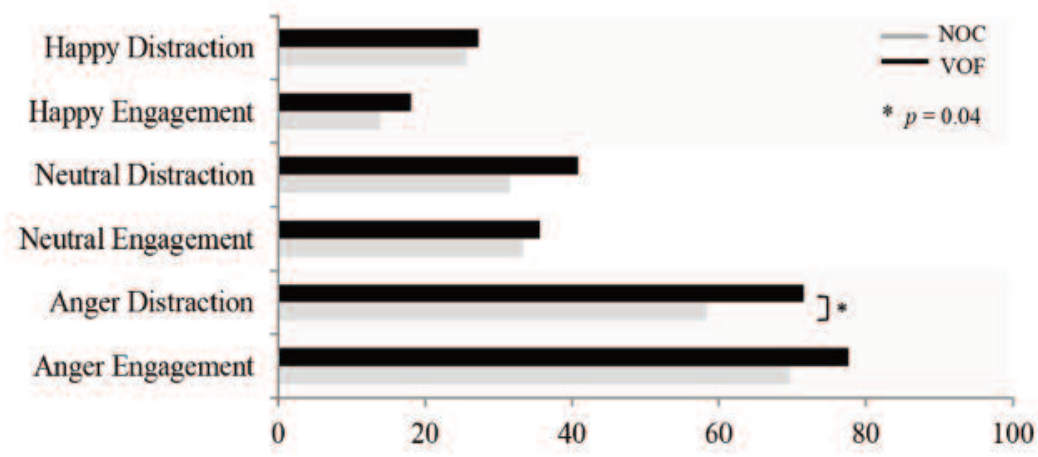

Figure 3. Mean VAS rating per group during ATSS. P-value uncorrected for multiple comparisons. 


\section{fMRI results}

\section{Right amygdala connectivity.}

The mixed effects ANOVA, with group as the between subject factor and emotion task performance as the within-subject factor, for the right amygdala seed did not reveal any significant results.

\section{Left amygdala connectivity.}

Four ROls with significant group $\times$ emotion engagement interactions were identified (Figure 4, Table 2), including the left medial PFC, the left uncus/amygdala, the right posterior insula and the right superior temporal gyrus. In line with our hypothesis, there was a significant decrease in left medial PFC connectivity with the left amygdala seed from pre- to post-task in the VOF $(p=.002)$, whereas the NOC showed a significant increase in left medial PFC connectivity with the left amygdala seed $(p=.006)$.

For the (para)limbic regions (i.e., the left uncus/amygdala, the right posterior insula and the right superior temporal gyrus) the opposite pattern was found; the VOF showed a significant pre- to post-task increase in left amygdala functional connectivity with the right posterior insula $(p=.018)$ and right superior temporal gyrus $(p=.022)$, but not the left uncus/amygdala $(p=.18)$. The NOC showed a significant pre- to post-task decrease in left amygdala functional connectivity with the right posterior insula $(p=.028)$, the right superior temporal gyrus $(p=$ .014) and the left uncus/amygdala $(p=.004)$.

Table 2. ROI details identified for interaction between group and within subject factor.

\begin{tabular}{|c|c|c|c|c|c|c|c|c|}
\hline \multirow[b]{2}{*}{ Brain region } & \multirow[b]{2}{*}{ L/R } & \multirow[b]{2}{*}{ MNI $(x, y, z)$} & \multirow[b]{2}{*}{$\mathbf{F}$} & \multirow[b]{2}{*}{$p$-value* } & \multicolumn{2}{|c|}{$\begin{array}{l}\text { Average } \\
\text { connectivity } \\
\text { change Fisher's z }\end{array}$} & \multicolumn{2}{|c|}{$\begin{array}{l}\text { Cohen's d } \\
\text { (change within } \\
\text { groups) }\end{array}$} \\
\hline & & & & & VOF & NOC & VOF & NOC \\
\hline Medial prefrontal cortex & L & $-1,64,-4$ & 27.32 & $<.001$ & -.15 & .17 & -.76 & .74 \\
\hline Uncus / amygdala & L & $-20,-6,-27$ & 14.81 & $<.001$ & .08 & -.16 & .51 & -.80 \\
\hline Posterior insula & $\mathrm{R}$ & $46,-9,9$ & 16.05 & $<.001$ & .11 & -.10 & .84 & -.64 \\
\hline Superior temporal gyrus & $\mathrm{R}$ & $52,-12,9$ & 17.55 & $<.001$ & .12 & -.15 & .66 & -.70 \\
\hline
\end{tabular}

Note. L/R = Left / Right; Cohen's d = Mean difference/pooled SD, "df=1

Post-hoc simple-effects analysis revealed that the largest difference between groups were pre-task, with a larger left medial prefrontal connectivity with the left amygdala seed in the VOF compared to the NOC $(p=.004)$. Post-task the difference in left medial prefrontal connectivity with the left amygdala seed between groups was no longer significant ( $p=.34$ ). There were also significant pre-task differences in left amygdala functional connectivity between groups in the left uncus/amygdala $(p=.006)$ and the right posterior insula $(p=.006)$, and during the post-emotion engagement condition in the right superior temporal gyrus $(p=.034)$. 


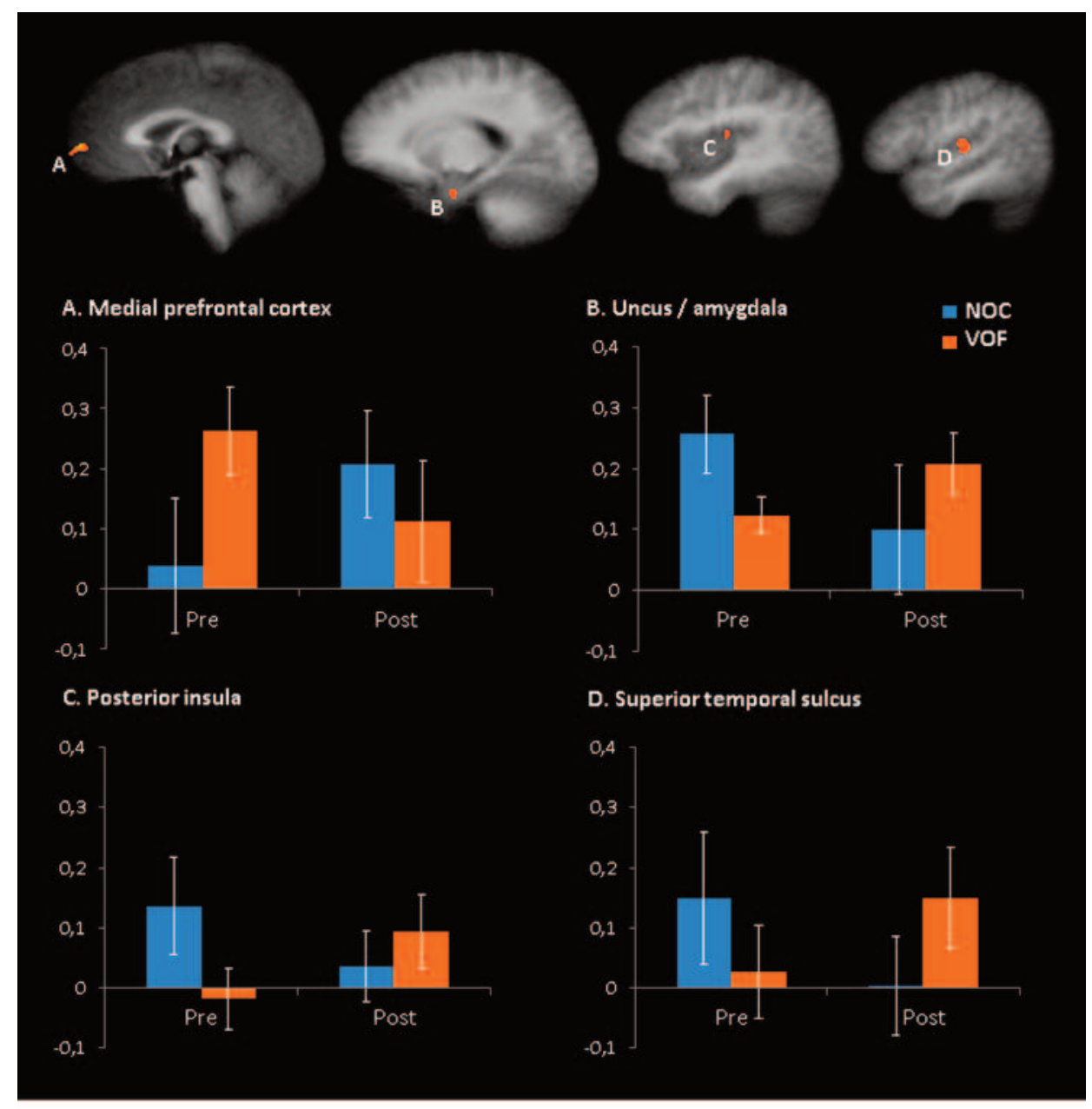

Figure 4. Significant group (VOF vs. NOC) $\times$ emotion engagement/distraction (pre vs. post) interactions. The $y$-axis of the graphs depicts the mean z values of functional connectivity of the left amygdala seed within each region. Error bars depict \pm 2 SE.

\section{Correlation baseline left amygdala and subjective measures.}

To investigate whether the significant difference between groups in self-reported noise hindrance and also nervousness (almost significant) related to group differences in left amygdala functional connectivity in the resulting ROls, we performed a correlation analysis on self-reported scanner noise disturbance and nervousness with the change z-scores in amygdala functional connectivity (post-task minus pre-task) in the resulting ROls. Analysis results also did not reveal any significant correlation (all $r s<.21$; all $p s>.24$ ), indicating that changes in connectivity from pre- to post task cannot be explained by influences of noise disturbance or nervousness. 


\section{Correlation aggression and baseline resting scan results.}

Since post-hoc simple-effects analysis revealed that the largest difference between groups were pre-task, we performed correlation analyses between aggression questionnaires and the baseline resting scan results to explore whether differences in aggression might relate to general differences already reflected in the pre-task scan results. Results showed a significant relation between activity in the medial PFC connectivity during the pre-task scan and (reactive as well as proactive) aggression ( $r=.36, p<.05$ for reactive aggression and $r=$ $.45, p<.01$ for proactive aggression). Moreover, results showed a significant negative relation between reactive aggression and activity in the posterior insula and the amygdala during the pre-task scan ( $r=-.45, p<.01$ for the posterior insula and $r=-.35, p<.05$ for the amygdala) and a significant negative relationship between proactive aggression and activity in the superior temporal sulcus $(r=-.42, p<.05)$.

\section{Discussion}

With the present resting-state fMRI study we aimed to investigate brain connectivity using the amygdala as a region of interest (ROI) before and after an emotion task in reactive aggressive violent offenders (VOF, $N=18$ ) versus non-offender controls ( $N O C, N=18$, age and education matched). We used resting-state scans pre and post an emotional task, testing for brain differences in functional connectivity as earlier research has shown that pre and post resting state connectivity can be altered by fMRI task performance (Tung et al., 2013). In the emotion task participants were required to listen to anger, happy, and neutral stories while paying attention to whatever they were feeling or thinking at that moment (i.e. anger engagement) or to distract themselves from whatever they were feeling or thinking at that moment (i.e. anger distraction). By measuring functional connectivity using the amygdala as a ROI, we investigate the inter-relationship of other brain regions simultaneously engaged with the amygdala in this emotion task (Rogers, Morgan, Newton, \& Gore, \& 2007). Previous research on maladaptive emotion regulation has indicated that a combination of decreased prefrontal activity along with increased, hyperactive limbic activity (amygdala) is related to reactive aggression (e.g. Blair, 2012; Coccaro, et al., 2016; da Cunha-Bang et al., 2017; da Cunha-Bang et al., 2018; Diano et al., 2017; Heesink et al., 2018; Marxen et al., 2016; McCloskey et al., 2016; Skibsted et al., 2017).

In line with the study's primary hypothesis results showed that left amygdala - medial PFC connectivity was decreased from pre- to post-emotion task in the VOF and increased in the control group. No changes in right amygdala functional connectivity were found. In addition, we also found significant interactions in (para)limbic regions, including the uncus/amygdala, posterior insula and superior temporal gyrus. These effects were opposite from that found in the medial PFC; the emotion task significantly increased amygdala connectivity with (para)limbic regions in the VOF and decreased connectivity in the NOC. 
Interestingly, additional analysis indicated that group differences in amygdala - medial PFC were present only prior to the emotion task, with stronger connectivity in the VOF. It could be speculated that the pre-task scan differences reflect general differences in aggression as a correlational analysis between aggression questionnaires and pre-task scan activity showed a relationship between medial PFC functioning during the pre-task scan and (reactive as well as proactive) aggression. This is in line with earlier research showing a link between mPFC functioning or prefrontal cortical control and anger or aggression (Lotze, Veit, Anders, \& Birbaumer, 2007; Potegal, Stemmler, \& Spielberger, 2010; Takahashi, Nagayasu, Nishitani, Kaneko, \& Koide, 2014). Further, as it proposed that amygdala - PFC connectivity is the neurobiological correlate of emotion regulation (Ochsner \& Gross, 2005). This suggests that the VOF were regulating their emotions. However, the NOC did not show this connectivity pattern. In other words, VOF were regulating emotions in a situation in which the NOC did not find it necessary to do so. Therefore, these results can be interpreted as emotional over-regulation in the VOF. Emotional over-regulation occurs when an individual uses emotion regulation strategies in an effort to consistently stop the emotion experience from unfolding (Greenberg \& Bolger, 2001). Although speculative, current self-report measures suggest that the VOF might have attempted to hide, avoid or suppress signs of nervousness. In addition, previously it has been suggested that aggressive acts of the over-regulated people are typically of greater intensity, because a greater level of anger arousal is necessary to overcome the intense over-regulation strategies (Willner \& Blackburn, 1988). This proposition fits with the general observation of increased emotional intensity of reactive aggressive acts compared to that of proactive aggressive acts.

At first instance, the present additional indications of over-regulation might seem contradictory to previous findings of emotional under-regulation in reactive aggressive people. However, in our opinion, these findings are not necessarily incongruous and can be explained twofold. First, while using emotional avoidance or expressive suppression can be beneficial in certain situations (Butler et al., 2003), for example in macho-environment where emotions like sadness and anxiety are interpreted as signs of weakness, the constant use of these strategies require considerable effort and energy (Kashdan, Barrios, Forsyth, \& Steger, 2006). If much of the available processing resources are used for continuous default over-regulation, this also means that less resources are available when more active executive control is required, e.g. when the person is provoked, resulting in emotion under-regulation. This hypothesis nicely fits with the passive paradigm used in this resting-state study which indicates overregulation already visible in the pre-test scans, compared to a more active neuroimaging paradigm (i.e. instructing participants to perform an executive functioning task), indicating under-regulation in aggressive people (Raine et al., 1998). A second explanation is that trait aggressiveness is higher in the VOF, requiring constant regulation. This argument is in line with the model by Megargee (later augmented by Blackburn (1993), which proposes that VOF can be classified into either the under-controlled type or the chronically over-controlled type. 
In this model the over-controlled type is inhibiting angry feelings until stress may exceed his ability to resist. As a result of provocation their defense breaks down and consequently, violent behavior occurs. Future studies should address these different hypotheses.

The mechanism of over-control of anger is also worked out in more recent cognitive theories (Denson, Pedersen, Friese, Hahm, \& Roberts, 2011; Rusting \& Nolen-Hoeksema, 1998), emphasizing the role of rumination regarding provocation. Indeed, the present results reported additionally that left amygdala functional connectivity with the superior temporal gyrus was increased after emotion engagement, in the VOF only. Increased activity in the superior temporal sulcus has been previously linked to rumination (Cooney, Joormann, Eugene, Dennis, \& Gotlib, 2010), which may be broadly defined as a pattern of recursive thinking focused on one's negative mood. Rumination is associated with the worsening of negative mood states, greater affective responding to negative material, and increased access to negative memories (for a review see Cooney et al., 2010). For example, self-reported rumination has been found to be associated with amygdala activation during the up-regulation of negative affect in healthy people, suggesting that an increased tendency to ruminate exacerbates the neural processing of negative information (Ray et al., 2005). Therefore, it is possible that reactive aggressive people are more likely to ruminate after being exposed to an emotionally challenging situation. In turn, this may lead to increased negativity bias (Cima, Vancleef, Lobbestael, Meesters, \& Koerbrits, 2014; Lobbestael, Cima, \& Arntz, 2013), making them more sensitive to negative stimuli and consequently and increasing the change of reactive aggressive behavior. This proposition is in line with neurobiological models of reactive aggression (Blair, 2004; Davidson, Putnam, \& Larson, 2000; Phelps, Delgado, Nearing, \& LeDoux, 2004; Raine, \& Yang, 2006) stating that individuals with faulty regulation of negative emotions propose a serious risk for aggressive behaviour.

As this is, to our knowledge, the first study to examine the dynamics in amygdala functional connectivity in people with reactive aggressive behavior before and after an emotion engagement and distraction task. Present results should be interpreted with caution and replication studies are encouraged. In addition, the following limitation should be considered. Although both groups followed the exact same experimental procedure, the exit questionnaire revealed that the VOF were significantly more disturbed by the scanner noise. Interactions in amygdala resting-state functional could therefore also be attributed to other factors other than the emotion engagement (e.g. time), which remains a general limitation of resting-state studies. However, the increased disturbance by the scanner noise might also be explained by a decrease in frustration tolerance, which seems characteristic for those with reactive aggressive behavior and therefore highly dependent. In addition, self-report of scanner disturbance and nervousness did not correlate with pre-task connectivity or pre- to post-task change scores in any of the implicated ROls, and could therefore not explain present results. In addition, as the whole brain analysis revealed a network known to be involved in emotion regulation it is assumed that the present results can indeed be attributed to the emotion en- 
gagement. Moreover, the use of one VAS with anchors of very happy to very angry within the experimental task is unfortunate, given that these do not represent opposite poles of a single construct. In future research two VAS scales are needed indicating not at all happy to very happy, and not at all angry to very angry. Another limitation is the fact that although substance use is prohibited for all incarcerated offenders and regularly drug tests are executed randomly during their stay by means of breathalyzers and urine tests, no arrangements have been made in advance for standard substance use testing within the day of the fMRI testing session.

In conclusion, in the current study we investigated dynamic changes in amygdala connectivity resting-state functional connectivity in violent offenders showing reactive aggression, before and after an emotion (engagement and distraction) task. In line with neurobiological models of reactive aggression, results indicate that there is a decrease in amygdala - medial PFC functional connectivity in the VOF and an increase in the NOC. An opposite pattern was found in (para)limbic regions. Present results indicate that reactive aggression can be seen as resulting from a dominance of emotion processes, as indicated by an increase in limbic functional connectivity. This is especially problematic given the combination of emotion processing dominance along with a lack of medial prefrontal cortex regulation, leading to a loss of behavioral control when aroused with reactive aggression as a result. In addition, an increase in amygdala - superior temporal gyrus connectivity was found after the emotion task, which has been previously linked to rumination. Most treatment protocols regarding reactive aggression have focused on improving anger control with the underlying impression of decreasing violence. In line with the current finding we suggest that treatment of reactive aggression should focus on rumination, acceptance, skills to handle anger expression and adaptive regulation of emotions. 


\section{References}

Acheson, S. K. (2005). Review of the Hare Psychopathy Checklist-Revised. In: R. A., Spies, \& B. S., Plake BS, (Eds). The sixteenth mental measurements yearbook, pp. 429-431. Lincoln, NE: Buros Institute of Mental Measurements.

Anderson, N. E., \& Kiehl, K. A. (2012). The psychopath magnetized: insights from brain imaging. Trends in Cognitive Sciences, 16, 52-60. doi: 10.1016/j.tics.2011.11.008

Averill, J. R. (1983). Studies on anger and aggression: Implications for theories of emotion. American Psychologist, 38, 1145-1160. doi: 10.1037/0003-066X.38.11.1145

Baeken, C., Marinazzo, D., Van Schuerbeek P., Wu, G. R., De Mey, J., Luypaert, R., \& De Raedt, R. (2014). Left and right amygdala - mediofrontal cortical functional connectivity is differentially modulated by harm avoidance. PLoS One, 9, e95740. doi: 10.1371/journal.pone.0095740

Blackburn, R. (1993). The Psychology of Criminal Conduct: Theory, Research and Practice. Wiley \& Sons: New York.

Blair, R. J. R. (2012). Considering anger from a cognitive neuroscience perspective. Wiley Interdisciplinary Reviews: Cognitive Science, 3, 65-74. doi: 10.1002/wcs.154

Blair, R. J. R. (2004). The roles of orbital frontal cortex in the modulation of antisocial behavior. Brain and Cognition, 55, 198-208. doi: 10.1016/S0278-2626(03)00276-8

Bobes, M. A., Ostrosky, F., Diaz, K., Romero, C., Borja, K., Santos, Y., \& Valdés-Sosa, M. (2013). Linkage of functional and structural anomalies in the left amygdala of reactive-aggressive men. Social Cognitive and Affective Neuroscience, 8, 928-936. doi: 10.1093/scan/nss101

Buades-Rotger, M., Beyer, F., \& Krämer, U. M. (2017). Avoidant responses to interpersonal provocation are associated with increased amygdala and decreased mentalizing network activity. eNeuro, 4, ENEURO-0337. doi: 10.1523/ENEURO.0337-16.2017

Butler, E. A., Egloff, B., Wilhelm, F. H., Smith, N. C., Erickson, E. A., \& Gross, J. J. (2003). The social consequences of expressive suppression. Emotion, 3, 48-67. doi: 10.1037/1528-3542.3.1.48

Cardinale, E. M., Breeden, A. L., Robertson, E. L., Lozier, L. M., Vanmeter, J. W., \& Marsh, A. A. (2017). Externalizing behavior severity in youths with callous-unemotional traits corresponds to patterns of amygdala activity and connectivity during judgments of causing fear. Development and Psychopathology, 1-11. doi: 10.1017/S0954579417000566

Cima, M., Vancleef, L. M. G., Lobbestael, J., Meesters, C., \& Korebrits, A. (2014). Don’t you dare look at me, or else: negative and aggressive interpretation bias, callous unemotional traits and type of aggression. Journal of Child and Adolescent Behavior, 2, 1-9. doi: 10.4172/jcalb.1000128

Cisler, J. M., James, G. A., Tripathi, S., Mletzko, T., Heim, C., Hu, X. P., ... \& Kitts, C. D. (2013). Differential functional connectivity within an emotion regulation neural network among individuals resilient and susceptible to the depressogenic effects of early life stress. Psychological Medicine, 43, 507-518. doi: $10.1017 / S 0033291712001390$

Coccaro, E. F., Keedy, S. K., Gorka, S. M., King, A. C., Fanning, J. R., Lee, R. J., \& Phan, K. L. (2016). Differential fMRI BOLD responses in amygdala in intermittent explosive disorder as a function of past Alcohol Use Disorder. Psychiatry Research: Neuroimaging, 257, 5-10. doi: 10.1016/j.pscychresns.2016.09.001 
Cooke, D. J., Michie, C. Hart, S. D. \& Clark, D. A. (2004). Reconstructing Psychopathy: Clarifying the Significance of Antisocial and Socially Deviant Behavior in the Diagnosis of Psychopathic Personality Disorder. Journal of Personality Disorders, 18, 337-357. doi: 10.1521/pedi.2004.18.4.337

Cooney, R. E., Joormann, J., Eugene, F., Dennis, E. L., \& Gotlib, I. H. (2010). Neural correlates of rumination in depression. Cognitive, Affective, \& Behavioral Neuroscience, 10, 470-478. doi: 10.3758/CABN.10.4.470

Coombs, G., 3rd, Loggia, M. L., Greve, D. N., \& Holt, D. J. (2014). Amygdala perfusion is predicted by its functional connectivity with the ventromedial prefrontal cortex and negative affect. PloS One, 9, e97466. doi 10.1371/journal.pone.0097466

da Cunha-Bang, S., Fisher, P. M., Hjordt, L. V., Perfalk, E., Beliveau, V., Holst, K., \& Knudsen, G. M. (2018). Men with high serotonin $1 \mathrm{~B}$ receptor binding respond to provocations with heightened amygdala reactivity. Neurolmage, 166, 79-85. doi: 10.1016/j.neuroimage.2017.10.032

da Cunha-Bang, S., Fisher, P. M., Hjordt, L. V., Perfalk, E., Persson Skibsted, A., Bock, C., ... \& Knudsen, G. M. (2017). Violent offenders respond to provocations with high amygdala and striatal reactivity. Social Cognitive and Affective Neuroscience, 12, 802-810. doi: 10.1093/scan/nsx006

Davidson, R. J., Putnam, K. M., \& Larson, C. L. (2000). Dysfunction in the neural circuitry of emotion regulation-a possible prelude to violence. Science, 289, 591-594. doi: 10.1126/science.289.5479.591

Davison, C. G., Navarre, S. G., \& Vogel, R. S. (1995). The articulated thoughts in simulated situations paradigm: a think-aloud approach to cognitive assessment. Current Directions in Psychological Science, 4, 29-33. http://www.jstor.org/stable/20182318

Denson, T. F., Pedersen, W. C., Friese, M., Hahm, A., \& Roberts, L. (2011). Understanding impulsive aggression: Angry rumination and reduced self-control capacity are mechanisms underlying the provocation-aggression relationship. Personality and Social Psychology Bulletin, 37, 850-62. doi: $10.1177 / 0146167211401420$

Diano, M., Tamietto, M., Celeghin, A., Weiskrantz, L., Tatu, M. K., Bagnis, A., ... \& Costa, T. (2017). Dynamic changes in amygdala psychophysiological connectivity reveal distinct neural networks for facial expressions of basic emotions. Scientific Reports, 7, 45260. doi: 10.1038/srep45260

Dotterer, H. L., Hyde, L. W., Swartz, J. R., Hariri, A. R., \& Williamson, D. E. (2017). Amygdala reactivity predicts adolescent antisocial behavior but not callous-unemotional traits. Developmental cognitive neuroscience, 24, 84-92. doi: 10.1016/j.dcn.2017.02.008

Forman, S. D., Cohen, J. D., Fitzgerald, M., Eddy, W. F., Mintun, M. A., \& Noll, D. C. (1995). Improved assessment of significant activation in functional magnetic resonance imaging (fMRI): use of a cluster-size threshold. Magnetic Resonance in Medicine, 33, 636-647. doi: 10.1002/mrm.1910330508

Greenberg, L. S., \& Bolger, E. (2001). An emotion-focused approach to the overregulation of emotion and emotional pain. Journal of Clinical Psychology, 57, 197-211. doi: 10.1002/10974679(200102)57:2<197::AID-JCLP6>3.0.CO;2-O

Grochowska, K., \& Kossowska, M. (2012). Fact sheet violent offenders. European Association of Psychology and Law - Student Sociaty Publishing House (EAPL-S): Poland. https://www.eaplstudent.com/component/content/article/193-fact-sheet-violent-offenders 
Gross, J. (1998). The Emerging Field of Emotion Regulation: An Integrative Review. Review of General Psychology, 2. 271-299. doi: 10.1037/1089-2680.2.3.271.

Hare, R. D. (2003). Manual for the Hare psychopathy Checklist-Revises (2nd ed.) Multi-Health Systems: Toronto. Heesink, L., Gladwin, T. E., Vink, M., van Honk, J., Kleber, R., \& Geuze, E. (2018). Neural activity during the viewing of emotional pictures in veterans with pathological anger and aggression. European Psychiatry, 47, 1-8. doi: 10.1016/j.eurpsy.2017.09.002

Hoptman, M. J., D’angelo, D., Catalano, D., Mauro, C. J., Shehzad, Z. E., Kelly, A. C., ... \& Milham, M. P. (2009). Amygdalofrontal functional disconnectivity and aggression in schizophrenia. Schizophrenia Bulletin, 36, 1020-1028. doi: 10.1093/schbul/sbp012

Kashdan, T. B., Barrios, V., Forsyth, J. P., \& Steger, M. F. (2006). Experiential avoidance as a generalized psychological vulnerability: comparisons with coping and emotion regulation strategies. Behaviour Research and Therapy, 44, 1301-1320. doi: 10.1016/j.brat.2005.10.003

Kohn, N., Eickhoff, S. B., Scheller, M., Laird, A. R., Fox, P. T., \& Habel, U. (2014). Neural network of cognitive emotion regulation-an ALE meta-analysis and MACM analysis. Neurolmage, 87, 345-355. doi: 10.1016/j.neuroimage.2013.11.001

Kose, S., Steinberg, J. L., Moeller, F. G., Gowin, J. L., Zuniga, E., Kamdar, Z. N., ... \& Lane, S. D. (2015). Neural correlates of impulsive aggressive behavior in subjects with a history of alcohol dependence. Behavioral Neuroscience, 129, 183. doi: 10.1037/bne0000038

Lancaster, J. L., Tordesillas-Gutierrez, D., Martinez, M., Salinas, F., Evans, A., Zilles, K., ...\& Fox, P. T. (2007). Bias between MNI and Talairach coordinates analyzed using the ICBM-152 brain template. Human Brain Mapping, 28, 1194-205. doi: 10.1002/hbm.20345

Lobbestael, J., Cima, M., \& Arntz, A. (2013). The relationship between adult reactive and proactive aggression, hostile interpretation bias, and antisocial personality disorder. Journal of Personality Disorders, 27, 53-66. doi: 10.1521/pedi.2013.27.1.53

Lotze, M., Veit, R., Anders, S., \& Birbaumer, N. (2007). Evidence for a different role of the ventral and dorsal medial prefrontal cortex for social reactive aggression: An interactive fMRI study. Neuroimage, 34, 470-478. doi: 10.1016/j.neuroimage.2006.09.028

Lynam, D. R., \& Gudonis, L. (2005). The development of psychopathy. Annual Review of Clinical Psycholog, 1, 381-407. doi: 10.1146/annurev.clinpsy.1.102803.144019

Marxen, M., Jacob, M. J., Müller, D. K., Posse, S., Ackley, E., Hellrung, L., ... \& Smolka, M. N. (2016). Amygdala regulation following fMRI-neurofeedback without instructed strategies. Frontiers in Human Neuroscience, 10, 183. doi: 10.3389/fnhum.2016.00183

McCloskey, M. S., Phan, K. L., Angstadt, M., Fettich, K. C., Keedy, S., \& Coccaro, E. F. (2016). Amygdala hyperactivation to angry faces in intermittent explosive disorder. Journal of Psychiatric Research, 79, 34-41. doi: 10.1016/j.jpsychires.2016.04.006

Mooney, J. L., \& Daffern, M. (2015). The relationship between aggressive behaviour in prison and violent offending following release. Psychology, Crime and Law, 21, 314-329. doi: 10.1080/1068316X.2014.989163 
Mooney, J. L., \& Daffern, M. (2011). Institutional aggression as a predictor of violent recidivism: implications for parole decision making. International Journal of Forensic Mental Health, 10, 52-63. doi: 10.1080/14999013.2010.550984

New, A. S., Hazlett, E. A., Buchsbaum, M. S., Goodman, M., Reynolds, D., Mitropoulou, V., Sprung, L., Shaw, R. B., Koenigsberg, H., Platholi, J., Silverman, J., \& Siever, L. J. (2002). Blunted prefrontal cortical 18fluorodeoxyglucose positron emission tomography response to meta-chlorophenylpiperazine in impulsive aggression. Archives of General Psychiatry, 59, 621-629. doi: 10.1001/archpsyc.59.7.621

Ochsner, K. N., \& Gross, J. J. (2005). The cognitive control of emotion. Trends in Cognitive Sciences, 9 , 242-249. doi: 10.1016/j.tics.2005.03.010

Ochsner, K. N., Silvers, J. A., \& Buhle, J. T. (2012). Functional imaging studies of emotion regulation: a synthetic review and evolving model of the cognitive control of emotion. Annals of the New York Academy of Sciences, 1251, E1-E24. doi: 10.1111/j.1749-6632.2012.06751.x

Oertel-Knochel, V., Knochel, C., Matura, S., Prvulovic, D., Linden, D. E., \& van de Ven, V. (2013). Reduced functional connectivity and asymmetry of the planum temporale in patients with schizophrenia and first-degree relatives. Schizophrenia Research, 147, 331-338. doi: 10.1016/j.schres.2013.04.024

Phelps, E. A., Delgado, M. R., Nearing, K. I., \& LeDoux, J. E. (2004). Extinction learning in humans: role of the amygdala and vmPFC. Neuron, 43, 897-905. doi: 10.1016/j.neuron.2004.08.042

Potegal, M., Stemmler, G., \& Spielberger, C. (Eds.). (2010). International handbook of anger: Constituent and concomitant biological, psychological, and social processes. Minneapolis: University of Minnesota.

Quaedflieg, C. W. E. M., van de Ven, V., Meyer, T., Siep, N., Merckelbach, H. L. G. J., \& Smeets, T. (2015). Temporal dynamics of stress-induced alternations of intrinsic amygdala connectivity and neuroendocrine levels. PloS One, 10, e0124141. doi: 10.1371/journal.pone.0124141

Raine, A., Dodge, K, Loeber, R., Gatzke-Kopp, L., Lynam, D., Reynolds, C., ... \& Lui J (2006). The Reactive-Proactive Aggression Questionnaire: differential correlates of reactive and proactive aggression in adolescent boys. Aggressive Behavior, 32, 159-171. doi: 10.1002/ab.20115

Raine, A., Meloy, J. R., Bihrle, S., Stoddard, J., LaCasse, L., \& Buchsbaum, M. S. (1998). Reduced prefrontal and increased subcortical brain functioning assessed using positron emission tomography in predatory and affective murderers. Behavioral Sciences \& the Law, 16, 319-332.

Raine, A., \& Yang, Y. (2006). Neural foundations to moral reasoning and antisocial behavior. Social Cognitive and Affective Neuroscience, 1, 203-13. doi: 10.1093/scan/nsI033

Ray, R. D., Ochsner, K. N., Cooper, J. C., Robertson, E. R., Gabrieli, J. D., \& Gross, J. J. (2005). Individual differences in trait rumination and the neural systems supporting cognitive reappraisal. Cognitive, Affective, \& Behavioral Neuroscience, 5, 156-168. doi: 10.3758/CABN.5.2.15

Roberton, T., Daffern, M., \& Bucks, R. S. (2014). Maladaptive emotion regulation and aggression in adult offenders. Psychology, Crime \& Law, 20, 933-954. doi: 10.1080/1068316X.2014.893333

Rogers, B. P., Morgan, V. L., Newton, A. T., \& Gore, J. C. (2007). Assessing functional connectivity in the human brain by fMRI. Magnetic Resonance Imaging, 25, 1347-1357. doi: 10.1016/j.mri.2007.03.007 
Roy, A. K., Shehzad, Z., Margulies, D. S., Kelly, A. M., Uddin, L. Q., Gotimer, K., ... \& Milham, M. P. (2009). Functional connectivity of the human amygdala using resting state fMRI. Neuroimage, 45, 614-626. doi: 10.1016/j.neuroimage.2008.11.030

Rusting, C. L., \& Nolen-Hoeksema, S. (1998). Regulating responses to anger: effects of rumination and distraction on angry mood. Journal of Personality and Social Psychology, 74, 790-803. doi: 10.1037/0022-3514.74.3.790

Shen, H. H. (2015). Core concept: Resting-state connectivity. Proceedings of the National Academy of Sciences, 112, 14115-14116. doi: 10.1073/pnas.1518785112

Skibsted, A. P., Cunha Bang, S. D., Carré, J. M., Hansen, A. E., Beliveau, V., Knudsen, G. M., \& Fisher, P. M. (2017). Aggression related brain function assessed with the Point Subtraction Aggression Paradigm in fMRI. Aggressive Behavior, 43, 601-610. doi: 10.1002/ab.21718

Siever, L. J., Buchsbaum, M. S., New, A. S., Spiegel-Cohen, J., Wei, T., Hazlett, E. A., ... \& Mitropoulou,

V. (1999). d,l-fenfluramine response in impulsive personality disorder assessed with [18F]fluorodeoxyglucose positron emission tomography. Neuropsychopharmacology, 20, 413-423. doi: 10.1016/S0893-133X(98)00111-0

Takahashi, A., Nagayasu, K., Nishitani, N., Kaneko, S., \& Koide, T. (2014) Control of Intermale Aggression by Medial Prefrontal Cortex Activation in the Mouse. PLoS ONE9: e94657. doi: 10.1371/journal.pone.0094657

Talairach, J., \& Tournoux, P. (1988). Co-planar stereotaxic atlas of the human brain. Thieme: New York.

Tonnaer, F., Siep, N., van Zuthpen, L., Arntz, A., \& Cima, M. (2017). Anger provocation in violent offenders leads to emotion dysregulation. Scientific Reports, 7, 3583. doi: 10.1038/s41598-017-03870-y.

Tung, K. C., Uh, J., Mao, D., Xu, F., Xiao, G., \& Lu, H. (2013). Alterations in resting functional connectivity due to recent motor task. Neuroimage, 78, 316-324. doi: 10.1016/j.neuroimage.2013.04.006

van de Ven, V., Wingen, M., Kuypers, K. P., Ramaekers, J. G., \& Formisano, E. (2013). Escitalopram decreases cross-regional functional connectivity within the default-Mode network. PLoS One, 8, e68355. doi: 10.1371/journal.pone.0068355

Varkevisser, T., Gladwin, T. E., Heesink, L., van Honk, J., \& Geuze, E. (2017). Resting-state functional connectivity in combat veterans suffering from impulsive aggression. Social Cognitive and Affective Neuroscience, 12, 1881-1889. doi: 10.1093/scan/nsx113

Weiskopf, N., Hutton, C., Josephs, O., \& Deichmann, R. (2006). Optimal EPI parameters for reduction of susceptibility-induced BOLD sensitivity losses: a whole-brain analysis at 3 T and 1.5 T. Neuroimage, 33, 493-504. doi: 10.1016/j.neuroimage.2006.07.029

World Health Organisation. (2007). Third milestones of a blobal campaign for violence prevention report 2007. Scaling up. World Health Organization (WHO) Press: Geneva, Switzerland. http://apps.who.int/iris/bitstream/10665/43671/1/9789241595476_eng.pdf

Willner, A. H., \& Blackburn, R. (1988). Interpersonal style and personality deviation. British Journal of Clinical Psychology, 27, 273-274. 


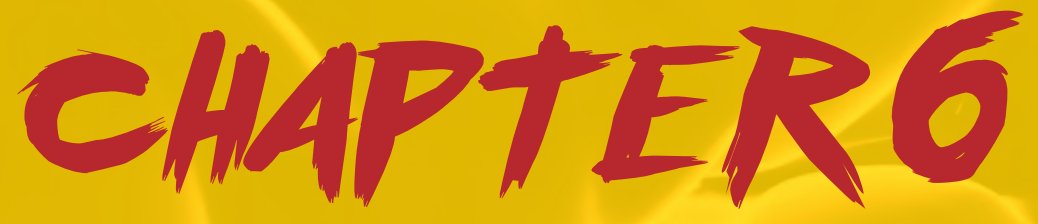

\section{Anger provocation in violent offenders leads to emotion dysregulation}

This chapter has been published as Tonnaer, F., Siep, N., van Zutphen, L., Arntz, A. \& Cima, M. (2017). Anger provocation in violent offenders leads to emotion dysregulation. Nature Scientific Reports, 7, Article number: 3583. 


\section{Abstract}

Anger and anger regulation problems that result in aggressive behaviour pose a serious problem for society. In this study we investigated differences in brain responses during anger provocation or anger engagement, as well as anger regulation or distraction from anger, and compared 16 male violent offenders to 18 non-offender controls. During an fMRI adapted provocation and regulation task participants were presented with angry, happy and neutral scenarios. Prior research on violent offenders indicates that a combination of increased limbic activity (involved in emotion), along with decreased prefrontal activity (involved in emotion regulation), is associated with reactive aggression. We found increased ventrolateral prefrontal activity during anger engagement in violent offenders, while decreased dorsolateral and ventrolateral prefrontal activity was found during anger distraction. This activity pattern was specific for anger. We found no exclusive pattern for happiness. In violent offenders, this suggests an increased need to regulate specifically during anger engagement and regulation difficulties when explicitly instructed to distract. The constant effort required for violent offenders to regulate anger might exhaust the necessary cognitive resources, resulting in a risk for self-control failure. Consequently, continuous provocation might ultimately contribute to reactive aggression.

Keywords anger, emotion regulation, provocation, fMRI, violent offenders 


\section{Introduction}

Although anger is one of the most basic emotions, it is still widely misunderstood and ignored (Richardson \& Halliwell, 2008). Elevated anger and inability to regulate anger are related to problematic and destructive conduct, including aggressive and violent behaviour, and therefore constitute a large burden to society (Blair, 2012; Howells \& Howells, 2002). Violent offenders are characterized by extreme aggressive behaviour (Grochowska \& Kossowska, 2012), with anger as a risk factor for violent recidivism (Loza \& Loza-Fanous, 1999).

While previous cognitive research using brain imaging techniques focused on punishment (Dambacher et al., 2015; Emmerling et al., 2016; Tonnaer, Cima, \& Arntz, 2016), frustration (Blair, 2012), or perceived threat as a trigger of anger or aggression (Blair, 2012), emotion research has focused on the recognition of anger as an indicator for dysfunctions in experience and perception of anger (Kret \& de Gelder, 2013; Lindquist, Wager, Kober, Bliss-Moreau, \& Barrett, 2012). For instance, cognitive research using laboratory measurements tested the willingness to punish an opponent by giving electric shocks as assessment of aggression (Dambacher et al., 2015; Emmerling et al., 2016). Furthermore, anger was operationalized by means of frustration after the lack of expected reward, ultimately resulting in anger (Blair, 2012). Others confronted participants with a threatening environment or situation, with reactive aggression as a result (Blair, 2012).

In emotion research anger is for instance operationalized in brain response differences during the perception of violent versus neutral images (Bueso-Izquierdo et al., 2016). Another commonly used approach is assessing brain response differences during the perception of facial expressions contrasting neutral expressions with emotional ones, such as angry (Werner, Kühnel, \& Markowitsch, 2013), happy, fearful and sad (Pardini \& Phillips, 2010). Moreover, avoidance-approach paradigms have been utilized measuring the automatic action tendency responses to facial expressions while participants were instructed to avoid angry and approach happy faces (Volman et al., 2016). Consequently, it is expected that deficits in emotion recognition within these emotion paradigms, ultimately lead to aggressive and violent behaviour (Howells \& Howells, 2002).

In other words, earlier studies using fMRI in violent offenders focused on punishment (Dambacher et al., 2015; Emmerling et al., 2016), frustration (Blair, 2012), recognition of anger and automatic action tendency responses to facial expressions (Volman et al., 2016). Up until now no fMRI study actually investigated anger engagement as well as anger distraction within a group of violent offenders (VOF) exhibiting anger problems, comparing them to non-offender controls (NOC).

Contributing to the theoretical understanding of the mechanisms underlying the regulation of anger, the present study is unique because of the comparison of violent offenders and non-offender controls during anger engagement and distraction. Nevertheless, in order to study specific effects of anger, one needs to know regulation responses to other emotions. The difference between anger engagement as opposed to a happy state (Jack, Garrod, \& Schyns, 2014) in violent offenders is not well examined. 
In this study we aimed to investigate engagement versus distraction of anger as well as happiness in the participants while measuring brain responses. To achieve this goal, we presented participants with audiotaped (anger, neutral and happy) stories, each within an Engagement condition instructing participants to focus on one's emotional feeling, and a Distraction condition instructing participants to distract themselves from the presented stories during fMRI scanning. The current paradigm has demonstrated to provoke anger in a violent offender population (Babcock, Green, Webb, \& Yerington, 2005), but the paradigm has never been utilised in $\mathrm{fMRI}$ research before.

Research in violent offender populations, linking the reactive aggression to specific brain regions, suggests that a combination of decreased prefrontal activity along with increased limbic activity (e.g., amygdala) is related to antisocial behaviour and reactive aggression (Blair, 2012). Following previous research of emotion regulation in non-patients and in violent offender populations, we hypothesized that the violent offenders displayed a neural network involved in emotion regulation, containing increased limbic activity, more specific in the amygdala, along with decreased prefrontal activity including the ventromedial, ventrolateral and dorsolateral prefrontal cortices (Blair, 2012; Ochsner, Silvers, \& Buhle, 2012).

\section{Methods}

\section{Participants}

A total of 34 males participated in the study. The violent offenders (VOF, $N=16$ ) were convicted for a violent crime (e.g. (attempted) manslaughter or murder, property crime with violence, bodily harm, domestic violence), and recruited from a male population at the Forensic Psychiatric Centre de Rooyse Wissel and its ambulatory care at De Horst. The non-offender control group (NOC, $N=18$ ), were recruited from a participants database and consisted of male participants with no history of violent behavior, matched on age, education level, and dominant handedness with the VOF (see Table 1).

Participants were screened for MRI contraindications and were excluded if they were younger than 18 years, had an IQ below 80 , or reported psychotic symptoms. All participants were Dutch, and ranged in age from 20 to 58 years $(M=35.1, S D=10.77)$. As to their educational level, $88.2 \%$ had attended secondary school and $11.8 \%$ had attended college. Exclusion criteria for the non-offender controls included current DSM-V psychiatric disorders. Demographic and clinical characteristics of the sample are summarized in Table 1.

Psychopathy Checklist-Revised (PCL-R, Hare, 1991; Hare, 2003) data was collected for a subsample of $N=10$ VOF of which data was available: total scores ranged from 12 to 28 ( $M$ $=21.4, S D=6.2$, with a score of 26 or above indicating psychopathy, Cooke, 1995; Grann, Långström, Tengström, \& Stålenheim, 1998). Internal consistency in the current sample was excellent (Cronbach's alpha $=.83$ for PCL-R total score). Pathology was scored for scientific purpose by semi-structured interviews (First, Spitzer, Gibbon, \& Williams, 1994; First, Spitzer, Gibbon, Williams, Benjamin, 1997) based on the Diagnostic and Statistical Manual of Mental 
Disorders (DSM-IV, APA, 2013). All interviews were scored by forensic psychologists who were trained to administer the interview, resulting in a consensus score arrived through discussion of scoring differences.

In line with our assumption that VOF showed a higher general level of anger compared to the NOC (measured with the Aggression Questionnaire, Buss, A. H., \& Perry, 1992) and a tendency towards higher reactive aggression scores (measures with the Reactive-Proactive Questionnaire, Raine et al., 2006; $t(32)=-6.0, p<.001)$. Furthermore, results show faster response time in the post Anger-Single Target Implicit Association Test (Lobbestael, Arntz, Cima, \& Chakhssi, 2009), indicating a stronger 'self'-'anger' concept association after provocation, but these results are non-significant and there is no differences in implicit anger between VOF and NOC (see Table 1).

\section{Ethics}

The Ethical Committee of Maastricht University and the Research Committee of de Rooyse Wissel approved the methods and procedures described in the research protocol, all of which were performed in accordance with the Declaration of Helsinki. They received written and oral instruction emphasizing that participation was not related to treatment or prospects for release, and that participants were free to withdraw from the study at any time. After description of the study, written informed consent was obtained from each subject in accordance with de Rooyse Wissel, its ambulatory care De Horst and Maastricht University. Moreover, participants received a financial compensation for their participation. Originally 45 participants were recruited. However, five participants withdraw due to a lack of interest (two VOF, and three NOC), one VOF did not enter the scanner because of fMRI contraindications (history of epilepsy), data of four participants (two VOF, and two NOC) was never processed due to technical problems during scanning (e.g. malfunction of the joystick, of audio or incomplete functional coverage), and one control participant was recruited purely to pilot the test setting.

\section{Procedure}

Participants first completed the Reactive-Proactive Questionnaire (RPQ, Raine et al., 2006), the Aggression Questionnaire (AQ, Buss \& Perry, 1992) and the Anger-Single Target Implicit Association Test (Anger-STIAT, Tonnaer, Siep, Arntz, \& Cima, 2016) in randomized order to determine the general anger level and possible preference towards specific types of aggression. In order to familiarize with the study paradigm and to check the auditory comprehension, participants started with a practice session of the emotion paradigm in the MRI (including active task engagement by means of subjective VAS state-emotional ratings after each audio fragment). To measure provocation and regulation of anger and happiness an adapted version of the Articulated Thoughts in Simulated Situations paradigm (ATSS) for fMRI (Tonnaer et al., 2016) was used. In the ATSS paradigm participants either were provoked 
or needed to attend and respond naturally, or they were instructed to regulate their emotional state by distracting themselves from, six narrative stories differing in their affective content (happy, anger, and neutral). In order to capture the subjective rate of experienced emotion a visual analogue scale (VAS) was used. As part of the scanning session participants also underwent two resting state scans (data presented separately, Siep et al., 2018). After the scan session, all participants again completed the AQ (Buss \& Perry, 1992) and the Anger-STIAT (Tonnaer et al., 2016) to determine the post anger level, followed by an Exit-Questionnaire evaluating scanner and task experience (Table 3).

Table 1. Demographic and clinical characteristics of the sample and group differences for behavioral anger measurements using Independent-Samples $t$-Tests.

\begin{tabular}{|c|c|c|c|c|c|c|}
\hline & \multicolumn{2}{|c|}{ Violent offenders (VOF) } & \multicolumn{2}{|c|}{ Non-offender controls (NOC) } & \multicolumn{2}{|c|}{ Statistics } \\
\hline & $M / N$ & (SD/\%) & $M / N$ & (SD/\%) & $t / \chi^{2}$ & $p$ \\
\hline Age, $M S D$ & 35.81 & $(7.17)$ & 34.39 & (13.37) & .39 & .70 \\
\hline \multicolumn{7}{|l|}{ Education, N\% } \\
\hline Secondary school & 16 & (88.9) & 14 & $(87.5)$ & -.12 & .90 \\
\hline College & 2 & $(11.1)$ & 2 & $(12.5)$ & .12 & .90 \\
\hline \multicolumn{7}{|l|}{ Disorder, N\% } \\
\hline Substance dependence & 13 & $(81.3)$ & 0 & - & 8.06 & .001 \\
\hline Depressive episode past & 5 & (33.3) & 1 & (5.6) & 1.95 & .07 \\
\hline PTSS & 8 & $(50.0)$ & 0 & - & 3.87 & .002 \\
\hline Antisocial PD & 9 & (56.3) & 0 & - & 4.39 & .001 \\
\hline Borderline PD & 3 & (18.8) & 0 & - & 1.86 & .08 \\
\hline Other PD & 4 & $(25.0)$ & 0 & - & 2.24 & .04 \\
\hline
\end{tabular}

General Anger, M SD

RPQ-Total
RPQ-Reactive
RPQ-Proactive

6.0

(4.)

$6.7<.001$

14.4

5.0

$6.0<.001$

7.6

1.0

(1.6)

$5.3<.001$

Anger Pre Scanning, MSD

AQ-Total

Anger-STIAT

51.8

(18.3)

781.6

(280.2)

28.3

767.8

53.4

(16.1)

27.4

(152.0)

719.9

Anger Post Scanning, M SD
(13.1)

(166.4)

$4.3<.001$

$.30 \quad .77$

$\begin{array}{lllllll}\text { AQ-Total } & 53.4 & (16.1) & 27.4 & (14.3) & 4.8 & <.001 \\ \text { Anger-STIAT } & 679.3 & (152.0) & 719.9 & (138.6) & 1.6 & .12\end{array}$

Note. PTSS = posttraumatic stress disorder; PD = personality disorder; RPQ = Reactive-Proactive Questionnaire, $\mathrm{AQ}=$ Aggression Questionnaire, Anger-STIAT = Anger-Single Target Implicit Association Test. 


\section{Measures}

\section{Experimental task.}

In the current study an adapted MRI version of the Anger Articulated Thoughts during Simulated Situations (ATSS) paradigm (Davison, Robins, \& Johnson, 1983) was utilized in order to elicit anger and happy provocation and regulation. The ATSS is a cognitive assessment of audio taped thoughts and beliefs, in which subjects are asked to imagine and respond to audiotape presented situations. In the fMRI version of the ATSS (Davison, Robins, \& Johnson, 1983) participants were presented with two ATSS conditions: an Engagement condition and a Distraction condition. During the Engagement condition participants were instructed to focus on their emotional feelings during the presented audio situations. The Distraction condition required participants to regulate their emotional state by distracting themselves from the presented audio situations. Both conditions included three different situations; a happy, neutral, and an anger situation (Davison, Robins, \& Johnson, 1983). The presentations of the conditions were counterbalanced and the order of the audio taped situation was randomized per participant. Each situation was divided into seven segments of 15 to 20 seconds. At the end of each segment there was a tone, followed by a silence of 15 seconds. The silence was followed by a visual analogue scale ( 9 seconds), which participants used to rate their emotional state at that moment $(0=$ very angry and, $100=$ very happy). Previous research shows the ATSS is able to induce anger in a violent offender population (Babcock, Green, Webb, \& Yerington, 2005) and is related to specific anger cognition biases in inmate partner abusers (Eckhardt, Barbour, \& Davison, 1998). Additional assessments included the RPQ, the $A Q$, the Anger-STIAT and an Exit-Questionnaire.

\section{Reactive-Proactive Questionnaire (RPQ, Raine et al., 2006).}

The RPQ was used as a self-report of aggression during life time. The RPQ consists of 23 items that are rated on a 3-point Likert-scale ( 0 = never and $2=$ always). The questionnaire includes two subscales of aggression: the proactive subscale, which measures proactive aggression in items such as 'How often have you used force to get others so what you want?', and the reactive subscale measuring reactive aggression in items such as 'How often have you got angry or mad or hit others when teased?'. Scores of the subscales are calculated by summing the values for the items. Research has shown good internal reliabilities for total RPQ, and reactive and proactive subscale scores with all reliability coefficients exceeding .81 (Cima, Raine, Meesters, \& Popma, 2013; Raine et al., 2006). The RPQ demonstrated good construct validity, convergent validity, criterion validity, and discriminant validity (Raine et al., 2006). Internal consistency in the current sample was excellent (Cronbach's alpha $=.95$ for RPQ total score, .91 , for the proactive subscale, and .95 , for the reactive subscale).

\section{The Aggression Questionnaire (AQ, Buss \& Perry, 1992).}

The $A Q$ is a self-report of 29 items, each of which is evaluated on a 5-point Likert scale 
$(0$ = definitely disagree and 4 = definitely agree). Scores of two items are recoded reversed and the total score (29 items) and subscales are calculated by summing the values for the items. The AQ contains a four factor structure, presented in according subscales denoting; 1) Physical Aggression (9 items such as 'Once in a while I can't control the urge to strike another person.'), 2) Verbal Aggression (5 items such as 'I can't help getting into arguments when people disagree with me.'), 3) Hostility (8 items such as 'When people are especially nice, I wonder what they want.') and 4) Anger (7 items such as 'I sometimes feel like a powder keg ready to explode.). The $A Q$ has a test-retest reliability, ranging between .72 and .80 (Buss \& Perry, 1992; Hornsveld, Muris, Kraaimaat, \& Meesters, 2009) and good construct validity (Buss \& Perry, 1992). Internal consistency in the current sample was excellent (Cronbach's alpha = .92 for $A Q$ total score before scanning and .93 for $A Q$ total score after scanning).

\section{Anger-Single Target Implicit Association Test (Anger-STIAT, Lobbestael, Arntz, Cima, \& Chakhssi, 2009).}

The STIAT is a single target variant of the Implicit Association Test (IAT, Greenwald, McGhee, \& Schwartz, 1998). The STIAT (Greenwald et al., 1998) measures the extent to which a target concept (e.g., a cake) is associated with two attributes (e.g., pleasant and unpleasant). When highly associated categories share the same response key (e.g., flower-pleasant and insect-unpleasant) performance is fast and accurate. Conversely, when negative associated categories share a response key (e.g., flower-unpleasant and insect-pleasant) performance is slow and errors increase. For this Anger-STIAT, self-concept was the target category stated as 'I' and the two attribute categories were 'anger' and 'peaceful'. In the congruent condition the same response key is assigned for both the target words (the participants first name, last name, date of birth, age, address) and the peaceful words (e.g., calm, relaxed, happy, pleasant, balanced). In the incongruent condition the target words and the anger words (angry, furious, rebellious, irascible) share the same response key. The STIAT effect is calculated by subtracting the reaction time for the incongruent condition from the congruent condition (Greenwald et al., 1998; Karpinski, \& Hilton, 2001). Responses were taken via the keyboard of the computer, comprising two response buttons ( $Q$ and $P$ ). Response keys were counterbalanced, as were the congruent and incongruent trials. Computer recorded all reaction times and errors. Words were presented on the center of the screen, blue in the target category and black in the attribute category, against a white background. Each word was presented on the screen and participants were required to respond as quickly as possible. Whenever the participant responded, the word disappeared and the next trial commenced later. The reliability and validity of the IAT has been proven in different social domains as racism (Dasgupta, \& Greenwald, 2001) and self-esteem (Greenwald, \& Farnham, 2000). The current Anger-STIAT has proven its validity in earlier research on aggression and the self-concept (Lobbestael et al., 2009). Internal consistency in the current sample was good before scanning (Cronbach's alpha = .84) and poor after scanning (Cronbach's alpha $=.53$ ). 


\section{Exit-Questionnaire.}

The exit-questionnaire consisted of various $100 \mathrm{~mm}$ visual analogue scales, assessing possible influential aspects as physical discomfort inside the scanner $(0=$ no physical complaints and, $100=$ a lot of physical complaints $)$, nervousness $(0=$ very nervous and, $100=$ not nervous at all), disturbance by the scanner noise $(0=$ no hinder and, $100=a$ lot of hinder $)$ or concentration problems ( 0 = could not concentrate and, 100 = could concentrate very well). In addition, participants were asked about task difficulty $(0=$ very difficult, and $100=$ not difficult at $a l l)$ and success $(0=$ not at all successful, and 100 = very successful $)$ in performing the emotion engagement and distraction task. Moreover, we asked all participants about the strategy they used to engage and to regulate their emotional state by distracting themselves from their emotions.

\section{fMRI data acquisition}

Data was collected using a Siemens Magnetom Allegra 3T head-only scanner equipped with a birdcage headcoil (Siemens Medical Systems, Erlangen, Germany). Participants were scanned in head first supine position. Head movements were minimalized using foam paddings. Functional data was acquired using a standard echo-planar imaging (EPI) sequence resulted from $T 2^{*}$-weighted functional measurements with a repetition time (TR) of $2000 \mathrm{~ms}$, echo time (TE) $30 \mathrm{~ms}$, flip angle $=90^{\circ}, 435$ volumes with 32 axial slices, $3 \times 3 \times 3 \mathrm{~mm}$, field of view (FoV) $192 \mathrm{~mm}$ and matrix $64 \times 64$. The T2*-weighted slices were optimized with a negative tilt of $30^{\circ}$, to minimize susceptibility and distortion artifacts within the amygdala (Morawetz et al., 2008). Anatomical data was collected using a high resolution T1-weighted gradient echo with the following parameters: TR $=2250 \mathrm{~ms}$, TE $=26 \mathrm{~ms}$, flip angle $=9^{\circ}, 192$ volumes in the sagittal plane, voxel dimensions $1 \times 1 \times 1 \mathrm{~mm}$ and FoV $=256 \mathrm{~mm}$.

\section{fMRI data preprocessing}

FMRI data preprocessing and analyses was conducted with Brainvoyager QX v2.8 (Brain Innovation, Maastricht, The Netherlands). The first two volumes of each run were discarded due to saturation effects. Preprocessing included sinc interpolation slice time correction, mean intensity adjustment if necessary due to scanner noise $(n=7)$, high-pass GLM-Fourier temporal filtering with 2 sines/cosines cycles and motion correction with trilinear interpolation for 3D motion detection and sinc interpolation actual motion correction (Goebel, Esposito, \& Formisano, 2006). In all anatomical scans the tissue was peeled from the skull and corrected for intensity in homogeneities. Then, functional and anatomical data was coregistered per run and for each run a volume time course (VTC) was created, followed by spatial normalization using standard Talairach transformation and $6 \mathrm{~mm}$ spatial smoothing with a full-width-at-half-maximum isotropic Gaussian kernel. 
Table 3. Group differences in exit questionnaire using Independent-Samples t-Tests.

\begin{tabular}{lllllll}
\hline & VOF & \multicolumn{3}{c}{ NOC } & \multicolumn{3}{c}{ Statistics } \\
\cline { 2 - 7 } & $\boldsymbol{M}$ & (SD) & $\boldsymbol{M}$ & (SD) & $\boldsymbol{t}$ & $\boldsymbol{p}$ \\
\hline General scanning comfort & & & & & & \\
$\quad$ Physical discomfort & 24.4 & $(28.3)$ & 30.8 & $(26.9)$ & -.66 & .51 \\
$\quad$ Concentration & 75.3 & $(21.2)$ & 74.1 & $(21.8)$ & -.15 & .88 \\
Nervousness & 68.3 & $(35.5)$ & 85.2 & $(15.2)$ & -1.62 & .12 \\
$\quad$ Disturbance scanner noise & 49.8 & $(29.4)$ & 34.9 & $(24.6)$ & -1.71 & .10 \\
Task evaluation & & & & & & \\
$\quad$ Task apprehensibility & 75.9 & $(22.6)$ & 69.8 & $(30.0)$ & .66 & .52 \\
$\quad$ Task identifiability & 90.9 & $(9.4)$ & 89.6 & $(13.8)$ & .33 & .75 \\
$\quad$ Difficulty emotion engagement & 62.2 & $(32.4)$ & 85.1 & $(15.6)$ & -2.50 & .02 \\
$\quad$ Difficulty emotion distraction & 61.2 & $(34.0)$ & 75.4 & $(22.9)$ & -1.38 & .18 \\
Success emotion engagement & 67.7 & $(21.2)$ & 83.6 & $(12.1)$ & -2.58 & .02 \\
Success emotion distraction & 64.5 & $(17.8)$ & 75.6 & $(22.7)$ & -1.53 & .14 \\
\hline
\end{tabular}

\section{Statistical analysis}

Because each condition (engagement and distraction) was recorded in a separate run, condition was dummy coded. Therefore, the applied general linear model included 10 predictors: anger-engagement, anger-distraction, happy-engagement, happy-distraction, neutral-engagement, neutral-distraction, sound fragments during engagement, sound fragments during distraction, visual analogue scale rating during engagement and visual analogue scale rating during distraction. Moreover, white matter and ventricle reference time courses were created for each participant and added to the general linear model (GLM) along with the six motion correction parameters. The following four whole brain random effect (RFX) ANOVA were carried out (the first two to measure engagement and the latter two to measure distraction): first, to investigate anger engagement: stimulus (anger-engagement vs. neutral-engagement) x group (VOF vs. NOC); second, to investigate happy engagement: stimulus (happy-engagement vs. neutral-engagement) $\times$ group (VOF vs. NOC); third, to examine anger distraction contrasting the engagement to the distraction condition within the anger valence: stimulus (anger-distraction vs. anger-engagement) $\times$ group (VOF vs. NOC), and fourth, to examine happy distraction contrasting the engagement to the distraction condition within the happy valence: stimulus (happy-distraction vs. happy-engagement) x group (VOF vs. NOC). The resulting F-maps were thresholded at significance level of $p<.01$, and cluster size being 16 for the anger maps and 15 for the happy maps. The minimal cluster size was determined with the cluster-level estimation plug-in in BrainVoyager, which implements a Monte Carlo simulation for multiple comparisons correction of $p<.05$ (1000 simulation, Forman et al., 1995). For detailed analyses of the resulting clusters beta values of each predictor per participant were exported to SPSS 
version 22 (IBM Corporation, New York). When Mauchly Test of Sphericity was affected Greenhouse-Geisser correction was applied. Additionally, all resulting brain regions were checked for medication effects by means of pairwise comparisons of all contrasts (emotion engagement and emotion distraction) $x$ medication interaction in VOF only (see Figure 3). Medication was only prescribed for clinical reasons within the VOF $(N=9$, within the VOF sample of $N=16$, all psychotropic medication, mostly antidepressants), and no psychotropic medication was reported in the non-offender controls. The relationship between self-reported aggressiveness (AQ, RPQ) and brain activity in the VLPFC as well as the amygdala assessed with correlational analyses.

\section{Results}

\section{Manipulation check}

The success of provocation and regulation was measured by analyzing the subjective rating of experienced emotional state by means of a visual analogue scale (VAS, 0 = very happy and, 100 = very angry) during scanning. The condition (engagement vs. distraction) $x$ valence (anger, happiness vs. neutral) interaction was significant $(F(1.34,44.19)=11.42, p=.001$, Greenhouse-Geisser). In line with our assumption pairwise comparisons showed that participants reported to be more angry during the engagement compared to the distraction condition $(t(33)=-3.10, p=.004)$. This effect was also present for the happy stories $(t(33)=3.23, p=.002)$, with participants reported to be more happy during the engagement compared to the distraction condition. The neutral stories elicited no difference in responding between the engagement compared to the distraction condition $(t(33)=-1.31, p=.199)$. Ratings per valence for each condition indicated group differences only in the subjective experience of anger, with the violent offenders (VOF) reporting more anger during both the engagement $(t(32)=$ 2.14, $p=.040)$ as well as the distraction condition ( $t(32)=2.54, p=.016)$ compared to the non-offender controls (NOC). Moreover, in the self-evaluation of task success, VOF reported more difficulties with the engagement condition and believed to be less successful in focusing on their emotions compared to the NOC (Table 3). No group differences were found regarding difficulties and success of the distraction condition.

\section{fMRI analyses}

We investigated group differences in brain activity during anger (and happy) minus neutral (Koenigsberg, Siever et al., 2009) engagement and distraction (Koenigsberg, Fan et al., 2009) by means of four whole brain Random Effects (RFX) ANOVA's, thresholded at $p<.01$ and corrected for multiple comparisons with a cluster size threshold.

\section{fMRI analyses during emotion provocation.}

The F-map of the provocation condition comprising anger stories [stimulus (anger-engagement versus neutral-engagement) $\times$ group (VOF versus NOC)] showed three 
clusters; the right posterior cingulate cortex (PCC)/Precuneus, left cerebellum and left ventrolateral prefrontal cortex (VIPFC) (Table 2). Happy provocation [stimulus (happy-engagement versus neutral-engagement) $\times$ group (VOF versus NOC)] showed significant activation of the right PCC (Table 2). Simple effects analyses of these resulting regions, indicated less PCC activity during anger as well as happy engagement in VOF, compared to NOC (Figure 1, Table 2). Additionally, VOF exhibited a decreased activity during anger and happy engagement compared to neutral engagement, while NOC showed the opposite pattern. Concerning the cerebellum, in VOF, decreased activity during anger engagement versus neutral engagement was revealed (Figure 1, Table 2). The vIPFC showed stronger activity for the VOF during anger versus neutral engagement compared to the NOC (Figure 1, Table 2).

Taken together, the vIPFC was exclusively active during anger engagement, whereas the PCC was active during anger and happiness engagement. All resulting brain regions were checked for confounding effects of medication within the VOF. No significant stimulus $x$ medication interaction effect was found for any of the clusters.

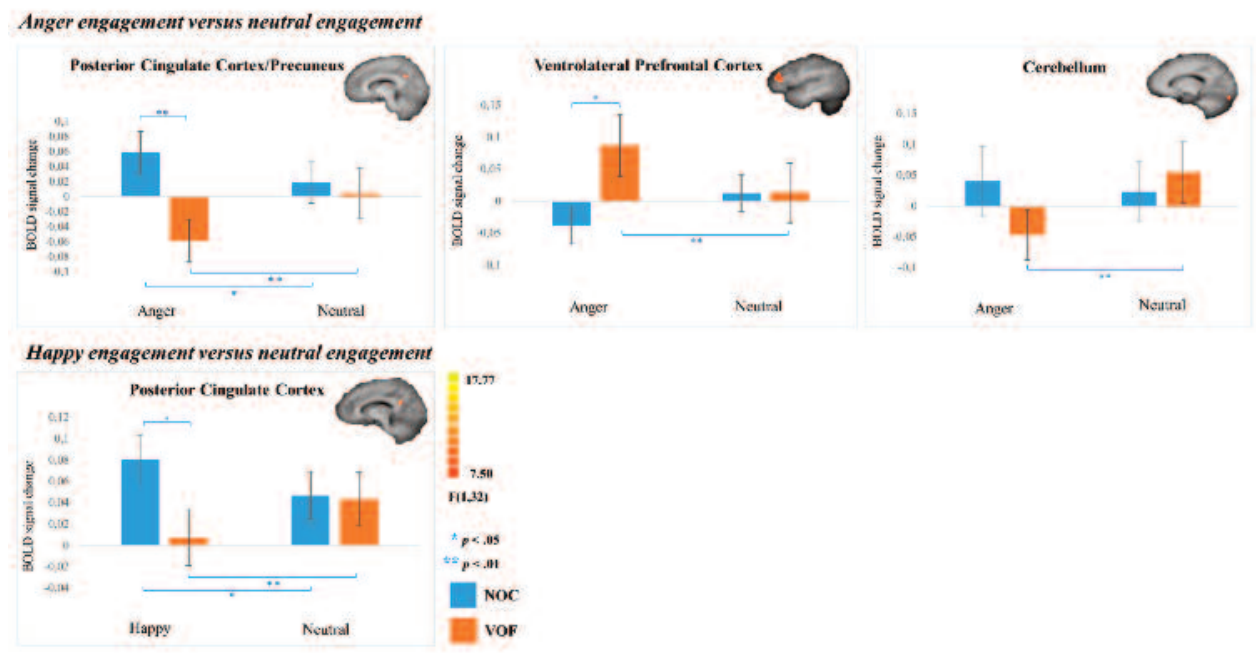

Figure 1. Cluster results on emotion provocation. Bar plots of beta values (+/- SEM) of clusters resulting from whole brain RFX ANOVA testing differences during engagement of anger and happy versus neutral stories.

\section{fMRI analyses during emotion regulation.}

The F-map of anger regulation [condition (anger-distraction versus anger-engagement) $x$ group (VOF versus NOC)], showed three brain regions; the left PCC, left dorsolateral prefrontal cortex (dIPFC), and left vIPFC (Table 2). With respect to regulation of happy stories [condition (happy-distraction versus happy-engagement) $x$ group (VOF versus NOC)], also showed significant activation in the left PCC, and left dIPFC (Table 2). Simple effects analyses 
of these resulting regions showed a decreased activity for distraction versus engagement during anger as well as happy stories in the PCC (Figure 2, Table 2). In comparison to NOC, VOF revealed more activity in the dIPFC during the anger and happy engagement condition compared to the distraction condition. Furthermore, NOC showed decreased activity during distraction versus engagement in both angry and happy stories. Finally, VOF showed less activity when distracting from anger stories, and more activity during anger engagement than the NOC in the left VIPFC (Figure 2, Table 2). Moreover, a decreased activity during distraction from anger versus engagement in anger was observed in VOF in the VIPFC, while NOC showed the opposite pattern with increased activity during anger distraction versus anger engagement.

Briefly, for all participants the VIPFC was exclusively active in the anger contrast of distraction versus engagement, while the PCC was again active in both emotional stories, along with the dIPFC. All resulting brain regions were checked for medication effects within the VOF. Only during anger stories the PCC showed a significant condition $\mathrm{x}$ medication interaction within $\operatorname{VOF}(F(1,14)=6.32, p=.025)$, therefore these results should be interpreted with caution. Simple effects showed no main effect of medication. Moreover, both groups showed significantly less PCC activity during anger distraction compared to anger engagement, though the medication group showed a stronger difference between the two conditions (see Figure 3). For this reason, the effect of medication in the PCC during anger distraction appears marginal.
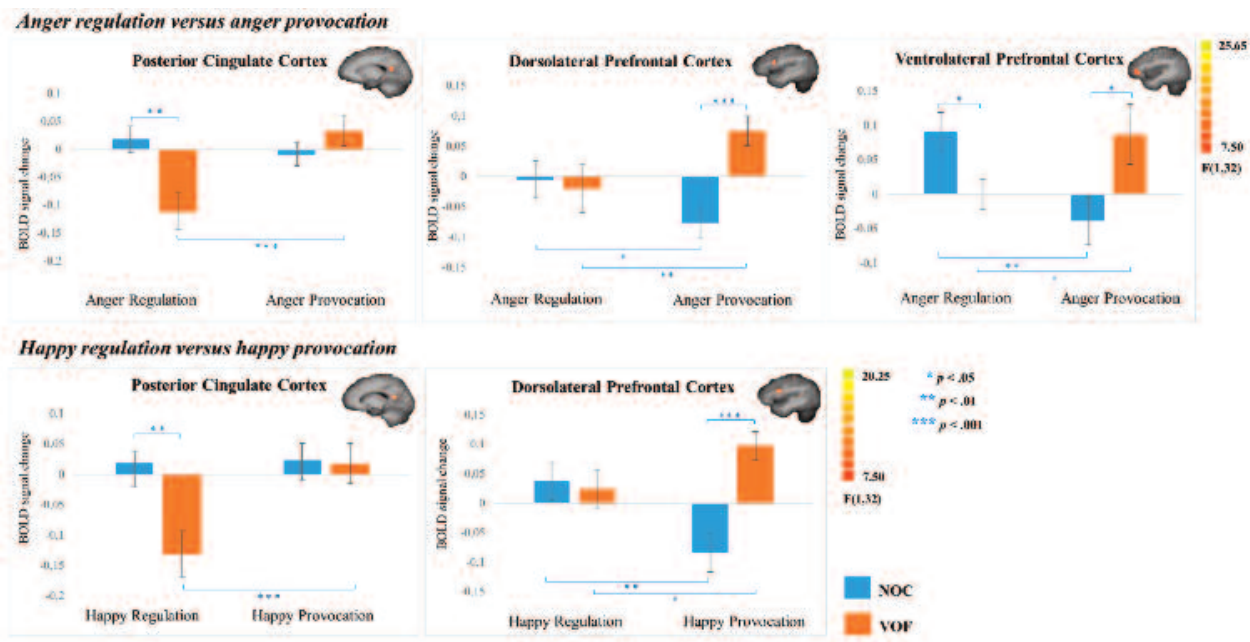

Figure 2. Cluster results on emotion regulation. Bar plots of beta values (+/- SEM) of clusters resulting from whole brain RFX ANOVA testing differences in distraction versus engagement in anger or happy stories. 


\section{Anger distraction versus anger engagement}

\section{Posterior Cingulate Cortex}

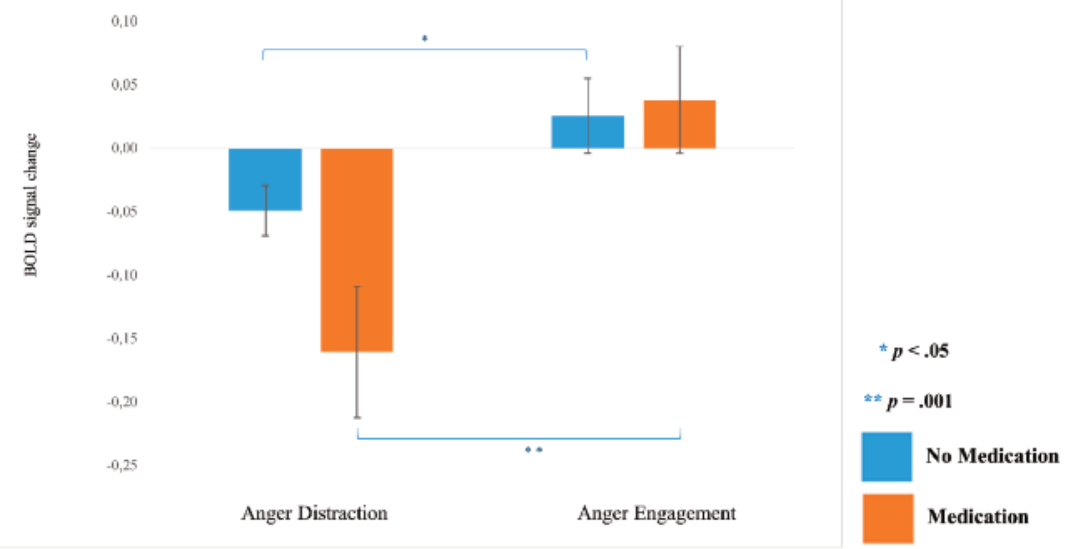

Figure 3. Bar plots of beta values (+/- SEM) of Posterior Cingulate Cortex activity resulting from simple effects analyses testing medication differences in distraction versus engagement during anger stories in the violent offender sample only.

Table 2. Resulting clusters for RFX ANOVA testing differences between violent offenders (VOF) and non-offender controls (NOC).

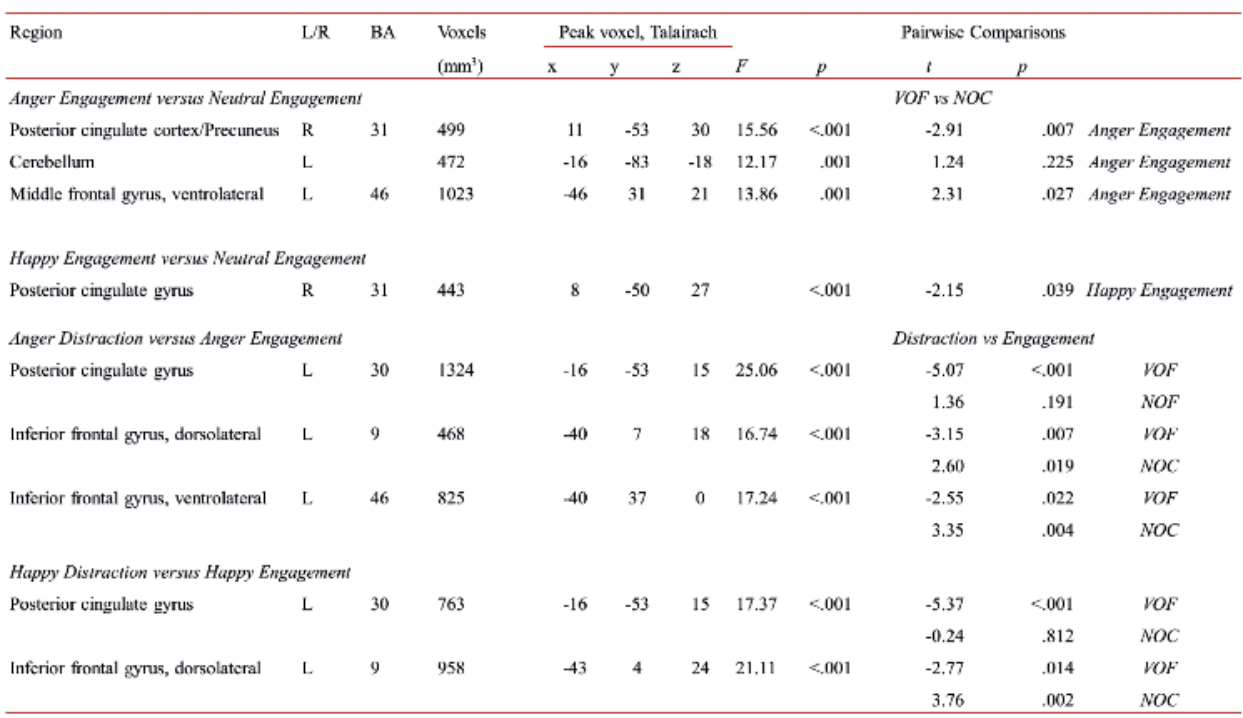




\section{fMRI analyses focussed on the amygdala.}

Research in violent offender populations suggests amygdala hyperactivity in the brain network related to reactive aggression (Blair, 2012; Bobes et al., 2013). In the whole brain analyses we did not find a differential activity in the amygdala. However, the amygdala is particularly sensitive for artifacts during scanning due to its location next to air-filled spaces. This may lead to null findings reflecting rather signal loss than absence of brain activity (Boubela et al., 2015). Therefore, we additionally examined whole brain RFX amygdala activity at a more lenient significance level. In the left amygdala VOF showed, relative to NOC (t(32) $=2.93, p=.006)$, a decreased activity during anger distraction compared to anger engagement $(t(15)=-2.359, p=.032$; Figure 4). VOF showed less amygdala activity during distraction from anger compared to $\operatorname{NOC}(t(32)=2.925, p=.006$; Figure 4$)$, while no group differences were found during anger engagement $(t(30.36)=-.012, p=.991)$.

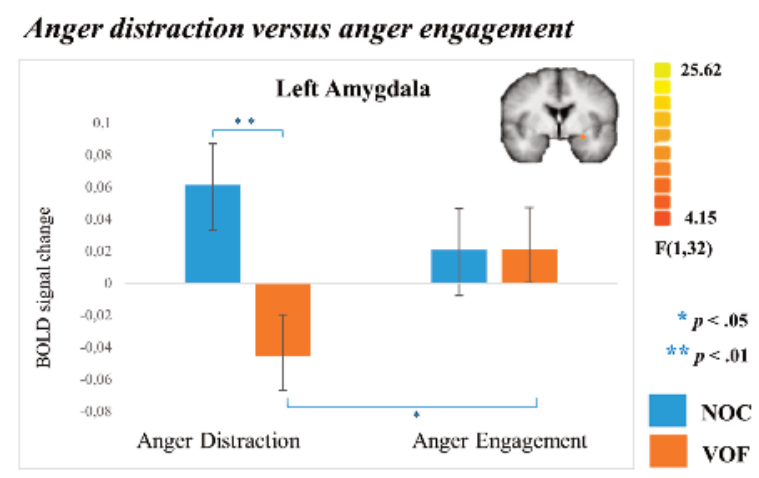

Figure 4. Amygdala results. Bar plots of beta values (+/- SEM) of Amygdala activity resulting from whole brain RFX ANOVA at a more lenient significance level, testing differences in distraction versus engagement during anger stories.

\section{Correlation Aggressiveness, VLPFC and Amygdala.}

Additional analysis on the correlation between the brain activity in the VLPFC and the amygdala on one hand and data on self-reported aggressiveness (Aggression Questionnaire (AQ, Buss, A. H., \& Perry, 1992) \& Reactive-Proactive Questionnaire (RPQ, Raine et al., 2006)) on the other hand, revealed that less activity in the amygdala during anger regulation is related to aggression assessed with the RPQ $(r(32)=-.45, p=.007$ for RPQ-Total Score; $r(32)=-.41$, $p=.018$ for the RPQ-Reactive Scale; $r(32)=-.45, p=.008$ for the RPQ-Proactive Scale). And less activity in the VLPFC during anger regulation is related to aggression assessed with both the RPQ $(r(32)=-.47, p=.005$ for RPQ-Total Score; $r(32)=-.44, p=.01$ for the RPQ-Reactive Scale; $r(32)=$ $-.44, p=.01$ for the RPQ-Proactive Scale) and the AQ $(r(32)=-.45, p=.005$ for AQ-Total Score before the task paradigm and $r(30)=-.45, p=.01$ for $A Q$-Total Score after the task paradigm). 


\section{Discussion}

In the current study we aimed to examine the brain responses during an anger engagement and distraction task (Koenigsberg, Fan et al., 2009; Koenigsberg, Siever et al., 2009) in violent offenders compared to non-offender controls. In contrast to our expectations violent offenders showed higher activity in the VIPFC and less activity in the PCC during anger engagement compared to non-offender controls. The results of the distraction condition showed decreased activity in the PCC, dIPFC and VIPFC when violent offenders were instructed to regulate, or distract themselves during anger stories, whereas non-offender controls showed an increase activity in dIPFC and vIPFC. However, the effects in the PCC and dIPFC were not specific for anger, as similar responses were shown for happy stories. Activity in the VIPFC during engagement and distraction was specific for anger stories. And, less activity in the VLPFC during anger distraction was related to self-reported aggression (both $R P Q$, Raine et al., 2006, and the AQ, Buss, A. H., \& Perry, 1992) indicating a potential link between aggression and decreased VLPFC activity.

Amygdala activity was only found at a liberal level of significance, showing decreased activity in violent offenders during distraction from anger compared to anger engagement. Moreover, no group differences were found during anger engagement, while during anger distraction the violent offenders showed less amygdala activity compared to the non-offender controls, indicating less amygdala sensitivity during anger distraction. Additional, less activity in the amygdala during anger distraction was related to self-reported aggression (RPQ, Raine et al., 2006) indicating a potential link between aggression and decreased amygdala activity.

Kohn and colleagues (2014) suggest that the VIPFC is a relay station of information towards the dIPFC and selects and initiates reappraisals, while they marked the dIPFC as the central regulatory brain area, engaged in attending to and maintaining reappraisal in working memory. According to this framework, less activity in the VIPFC for the violent offenders specific during anger distraction might indicate a dysfunction in signaling the need to regulate. Though initiation to regulate is primary expected in the distraction condition as shown in the non-offender controls, violent offenders already showed overactive initiation to regulate emotions during the anger engagement instruction. This constant initiated reactivity, specific for anger stories, might exhaust cognitive sources required to regulate or distract from anger in violent offenders. Furthermore, the dIPFC is associated with regulatory and inhibitory processes of cognitive control (Jack et al, 2014; Ochsner et al., 2012). The reduced dIPFC activity shown in the violent offenders during anger as well as happy distraction might indicate a general top-down problem resulting in impaired cognitive control of emotions. This is in line with previous research in antisocial and aggressive behavior (Lane, Kjome, \& Moeller, 2011; Yang \& Raine, 2009). Remarkable, self-report after scanning did not indicate any regulation difficulties within violent offenders, suggesting not being attentive of these potential difficulties indicated by overactive initiation to regulate.

We had no specific expectations about the PCC as regulation theories and earlier research in offenders did not point to this brain area as specific for anger (or emotion) 
distraction. The PCC has been associated with self-referential processing and recall of autobiographic emotional events (Brewer, Garrison, \& Whitfield-Gabrieli, 2013; Cavanna \& Trimble, 2006; Damasio et al., 2000; Kim et al., 2015). It could be speculated that the decreased activity of the PCC found in the violent offenders during anger and happy engagement indicate that violent offenders interpret, or recall, the emotional stories less in relation to themselves. Moreover, earlier research in offender populations showed that offenders characterized with emotional detachment and antisocial behavior were more impaired in the recall of emotional material than healthy control males (Dolan \& Fullam, 2005). The current results might indicate less emotional regulation during affective processing in violent offenders.

Though strengths of the current study are the direct comparison of violent offenders with non-offender controls, the naturalistic provocation, and the use of not only anger and neutral, but also happy stories, a number of limitations should also be acknowledged. First, as previously described we only tested men, which limits the generalizability of our results. Second, the sample size was small, thus results should be interpreted with caution. Although it is challenging to collect data in forensic samples future studies should increase the statistical power by increasing the sample size and examine more subtle effects. Third, the generalizability of the forensic sample from a high security hospital might be limited due to the fact that all offenders received a treatment program including anger management. Perhaps, adding a non-care (e.g. penitentiary) forensic sample in future research could provide more insight. Fourth, some offenders acquired prescribed medication for clinical reasons. As medication is known to affect the neural brain responses (Honey \& Bullmore, 2004), this might have influenced our results. Therefore, pairwise comparisons were performed within the violent offenders to check for any possible relation between medication intakes. With the exception of the PCC during anger distraction, interactions of medication within the clusters were not significant, suggesting medication did not influence these results. Further, pairwise comparisons of the PCC showed that although the medication $x$ condition interaction was significant, both the medicated and the non-medicated group showed a significant pattern of reduced PCC activation during anger distraction compared to anger engagement, though this effect was stronger in the medicated group. Thus, it seems unlikely that medication caused the effects found in the PCC during anger distraction. It seems more likely that violent offenders with a stronger reduction in PCC activation during anger distraction are more likely to get medication, further suggesting that reduced PCC activation plays a role in causing problems in these offenders. Fifth, we cannot rule out interference of distracting themselves during the task, and unequal task engagement, even though participants were explicitly instructed not to do so. Alternatively, less activity in the vIPFC for the violent offenders specific during anger distraction might indicate difficulties in distracting themselves from the stories, instead of a dysfunction in signaling the need to regulate. However, we explicitly used emotional (anger and happy) versus neutral story contrasts with equal instructions and equal length to rule out the effect of story processing. Further, all participants were asked to review the difficulty and 
success of the engagement as well as the distraction condition and no group differences were found regarding difficulties and success of the distraction condition. Moreover, interference during the experimental task seems unlikely since participants reported focusing on emotion (e.g. imagination) in the engagement condition and using regulation strategies (like thinking about other situations, counting etc.) during distraction in self-report after scanning, as well as in the manipulation check of the subjective rating of experienced emotion during scanning.

In conclusion, our results suggest increased initiation to regulate as indicated by increased VIPFC activity during anger engagement and less during anger distraction in violent offenders. Additionally, when explicitly instructed to regulate by means of distraction, results hint to general emotion regulation impairments in violent offenders. The constant effort for regulation in violent offenders might exhaust cognitive sources required to regulate anger in violent offenders, resulting in a risk factor for self-control failure (Wagner, Altman, Boswell, Kelley, \& Heatherton, 2013). Ultimately this might contribute to reactive aggression when continuously provoked. Consequently, future research should investigate whether this decreased dIPFC during anger distraction is a result of VIPFC dysfunction, or signals a broader regulation problem. Moreover, more insight in the effects of dysregulation and possible regulatory exhaustion risk to regulate anger in violent offenders is needed. A recent study showed that failure of self-control may have little to do with depleted resources (Inzlicht, Schmeichel, \& Macrae, 2014), therefore future research should test the possible explanation of exhaustion and should be replicated in extent. 


\section{Reference}

American Psychiatric Association. (2013). Diagnostic and statistical manual of mental disorders (5th ed.) Arlington, VA: American Psychiatric Publishing. doi: 10.1176/appi.books.9780890423349

Babcock, J. C., Green, C. E., Webb, S. A., \& Yerington, T. P. (2005). Psychophysiological profiles of batterers: autonomic emotional reactivity as it predicts the antisocial spectrum of behavior among intimate partner abusers. Journal of Abnormal Psychology, 114, 444-455. doi: 10.1037/0021-843X.114.3.444

Blair, R. J. R. (2012). Considering anger from a cognitive neuroscience perspective. Wiley Wiley Interdisciplinary Reviews: Cognitive Science, 3, 65-74. doi: 10.1002/wcs.154

Bobes, M. A., Ostrosky, F., Diaz, K., Romero, C., Borja, K., Santos, Y., \& Valdés-Sosa, M. (2013). Linkage of functional and structural anomalies in the left amygdala of reactive-aggressive men. Social Cognitive and Affective Neuroscience, 8, 928-936. doi: 10.1093/scan/nss101

Boubela, R. N., Kalcher, K., Huf, W., Seidel, E. M., Derntl, B., Pezawas, L., ... \& Moser, E. (2015). fMRI measurements of amygdala activation are confounded by stimulus correlated signal fluctuation in nearby veins draining distant brain regions. Scientific Reports, 5, 10499. doi: 10.1038/srep10499

Brewer, J. A., Garrison, K. A., \& Whitfield-Gabrieli, S. (2013). What about the "self" is processed in the posterior cingulate cortex? Frontiers in Human Neuroscience, 7, Article 647, 1-7.doi: 10.3389/fnhum.2013.00647

Bueso-Izquierdo, N., Verdejo-Román, J., Contreras-Rodríguez, O., Carmona-Perera, M., Pérez-García, M., \& Hidalgo-Ruzzante, N. (2016). Are batterers different from other criminals? An fMRI study. Social Cognitive and Affective Neuroscience, nsw020. doi: 10.1093/scan/nsw020

Buss, A. H., \& Perry, M. (1992). The Aggression Questionnaire. Journal of Personality and Social Psychology, 63, 452-459. doi: 10.1037/0022-3514.63.3.452

Cavanna, A. E., \& Trimble, M. R. (2006). The precuneus: a review of its functional anatomy and behavioural correlates. Brain, 129, 564-583. doi: 10.1093/brain/awl004

Cooke, D. J. (1995). Psychopathic disturbance in the Scottish prison population: cross-cultural generalizability of the Hare psychopathy checklist. Psychology, Crime \& Law, 2, 101-118. doi: 10.1080/10683169508409769

Cima, M. J., Raine, A., Meesters, C. \& Popma, A. (2013). Validation of the Dutch Reactive Proactive Questionnaire (RPQ): Differential correlates of reactive and proactive aggression from childhood to adulthood. Aggressive Behavior, 39, 99-113. doi: 10.1002/ab.21458

Damasio, A. R., Grabowski, T. J., Bechara, A., Damasio, H., Ponto, L. L., Parvizi, J., \& Hichwa, R. D. (2000). Subcortical and cortical brain activity during the feeling of self-generated emotions. Nature Neuroscience, 3, 1049-1056. doi: 10.1038/79871

Dambacher, F., Sack, A. T., Lobbestael, J., Arntz, A., Brugman, S., \& Schuhmann, T. (2015). Out of control: evidence for anterior insula involvement in motor impulsivity and reactive aggression. Social Cognitive and Affective Neuroscience, 10, 508-516. doi: 10.1093/scan/nsu077

Dasgupta, N., \& Greenwald, A. G. (2001). On the malleability of automatic attitudes: Combating automatic prejudice with images of admired and disliked individuals. Journal of Personality and Social Psychology, 81, 800-814. doi: 10.1037//0022-3514 81.5.800

Davison, G. C., Robins, C., \& Johnson, M. K. (1983). Articulated thoughts during simulated situations: A paradigm for studying cognition in emotion and behavior. Cognitive Therapy and Research, 7, 17-40. 
Dolan, M., \& Fullam, R. (2005). Memory for emotional events in violent offenders with antisocial personality disorder. Personality and Individual Differences, 38, 1657-1667. doi: 10.1016/j.paid.2004.09.028

Eckhardt, C. I., Barbour, K. A., \& Davison, G. C. (1998). Articulated irrational thoughts in maritally violent and nonviolent men during anger arousal. Journal of Consulting and Clinical Psychology, 66, 259-269.

Emmerling, F., Schuhmann, T., Lobbestael, J., Arntz, A., Brugman, S., \& Sack, A. T. (2016). The Role of the Insular Cortex in Retaliation. PloS One, 11, e0152000. doi: 10.1371/journal.pone.0152000

First, M. B., Spitzer, R.L., Gibbon, M., \& Williams, J. B. W. (1994). Structured clinical interview for DSM-IV axis I disorders (SCID-I). New York: Biometric Research Department.

First, M. B., Spitzer, R.L., Gibbon, M., Williams, J. B. W., \& Benjamin, L. (1997). Structured clinical interview for DSM-IV axis II personality disorders (SCID-II). New York: Biometric Research Department.

Forman, S. D., Cohen, J. D., Fitzgerald, M., Eddy, W. F., Mintun, M. A., \& Noll, D. C. (1995). Improved assessment of significant activation in functional magnetic resonance imaging (fMRI): use of a cluster】size threshold. Magnetic Resonance Imaging, 335, 636-647. doi: 10.1002/mrm.1910330508

Goebel, R., Esposito, F., \& Formisano, E. (2006). Analysis of functional image analysis contest (FIAC) data with BrainVoyager QX: from single-subject to cortically aligned group general linear model analysis and self-organizing group independent component analysis. Human Brain Mapping, 27, 392-401. doi: $10.1002 / \mathrm{hbm} .20249$

Greenwald, A. G., \& Farnham, S. D. (2000). Using the implicit association test to measure self-esteem and self-concept. Journal of Personality and Social Psychology, 79, 1022-1038. doi: 10.1037/KK122-3514.79.6.1022

Grann, M., Långström, N., Tengström, A., \& Stålenheim, E. G. (1998). Reliability of file-based retrospective ratings of psychopathy with the PCL-R. Journal of Personality Assessment, 70, 416-426. doi: 10.1207/s15327752jpa7003_2

Greenwald, A. G., McGhee, D. E., \& Schwartz, J. K. L. (1998). Measuring individual differences in implicit cognition: The implicit association test. Journal of Personality and Social Psychology, 74, 1464-1480.

Grochowska K. \& Kossowska, M. (2012). Fact sheet violent offenders. European Association of Psychology and Law - Student Society Publishing House https://www.eaplstudent.com/component/content/ article/193-fact-sheet-violent-offenders Poland: EAPL-s.

Hare, R. D. (2003). Manual for the Hare psychopathy Checklist-Revises (2nd ed.). Toronto: Multi-Health Systems.

Hare, R. D. (1991). Manual of the Psychopathic Checklist-Revised (PCL-R). (North Tonawanda, NW: Multi-Health Systems.

Honey, G., \& Bullmore, E. (2004). Human pharmacological MRI. Trends in Pharmacological Sciences, 25, 366-374. doi:10.1016/j.tips.2004.05.009

Hornsveld, R. H. J., Muris, P., Kraaimaat, F. W., \& Meesters, C. (2009). The Aggression Questionnaire in Dutch violent forensic psychiatric patients and secondary vocational students. Assessment, 16, 181-192. doi: 10.1177/1073191108325894

Howells, K., \& Howells, K. (2002). Anger management and violence prevention: Improving effectiveness. Trends \& issues in crime and criminal justice. 227. Canberra: Australian Institute of Criminology. http://aic.gov.au/publications/current\%20series/tandi/221-240/tandi227.html 
Inzlicht, M., Schmeichel, B. J., \& Macrae, C. N. (2014). Why self-control seems (but may not be) limited. Trends in Cognitive Sciences, 18, 127-133. doi: 10.1016/j.tics.2013.12.009

Jack, R. E., Garrod, O. G. B., \& Schyns, P. G. (2014). Dynamic facial expressions of emotion transmit an evolving hierarchy of signals over time. Current Biology, 24, 187-192. doi: 10.1016/j.cub.2013.11.064

Karpinski, A., \& Hilton, J. L. (2001). Attitudes and the Implicit Association Test. Journal of Personality and Social Psychology, 81, 774. doi: 10.1037//0022-3514.81.5.774

Kim, J., Schultz, J., Rohe, T., Wallraven, C., Lee, S. W., \& Bülthoff, H. H. (2015). Abstract representations of associated emotions in the human brain. Journal of Neuroscience, 35, 5655-5663. doi: 10.1523/JNEUROSCI.4059-14.2015

Koenigsberg, H. W., Siever, L. J., Lee, H., Pizzarello, S., New, A. S., Goodman, M., ... \& Prohovnik, I. (2009). Neural correlates of emotion processing in borderline personality disorder. Psychiatry Research: Neuroimaging, 172, 192-199. doi: 10.1016/j.pscychresns.2008.07.010

Koenigsberg, H. W., Fan, J., Ochsner, K. N., Liu, X., Guise, K. G., Pizzarello, S., ... \& New, A. (2009). Neural correlates of the use of psychological distancing to regulate responses to negative social cues: a study of patients with borderline personality disorder. Biological Psychiatry, 66, 854-863. doi: 10.1016/j.biopsych.2009.06.010

Kohn, N., Eickhoff, S. B., Scheller, M., Laird, A. R., Fox, P. T., \& Habel, U. (2014). Neural network of cognitive emotion regulation-an ALE meta-analysis and MACM analysis. Neurolmage, 87, 345-355. doi: 10.1016/j.neuroimage.2013.11.001

Kret, M. E., \& de Gelder, B. (2013). When a smile becomes a fist: the perception of facial and bodily expressions of emotion in violent offenders. Experimental Brain Research, 228, 399-410. doi: 10.1007/s00221-013-3557-6

Lane, S. D., Kjome, K. L., \& Moeller, F. G. (2011). Neuropsychiatry of aggression. Neurologic Clinics, 29, 49-64. doi: 10.1016/j.ncl.2010.10.006

Lindquist, K. A., Wager, T. D., Kober, H., Bliss-Moreau, E., \& Barrett, L. F. (2012). The brain basis of emotion: a meta-analytic review. Behavioral and Brain Science, 35, 121-202. doi: 10.1017/S0140525X11000446

Lobbestael, J., Arntz, A., Cima, M., \& Chakhssi, F. (2009). Effects of induced anger in patients with antisocial personality disorder. Psychological Medicine, 39, 557-568. doi: 10.1017/S0033291708005102

Loza, W. \& Loza-Fanous, A. (1999). Anger and Prediction of Violent and Nonviolent Offenders' Recidivism. Journal of Interpersonal Violence, 14, 1014-1029. doi: 10.1177/088626099014010002

Morawetz, C., Holz, P., Lange, C., Baudewig, J., Weniger, G., Irle, E., \& Dechent, P. (2008). Improved functional mapping of the human amygdala using a standard functional magnetic resonance imaging sequence with simple modifications. Magnetic Resonance Imaging, 26, 45-53. doi: 10.1016/j.mri.2007.04.014

Ochsner, K. N., Silvers, J. A., \& Buhle, J. T. (2012). Functional imaging studies of emotion regulation: a synthetic review and evolving model of the cognitive control of emotion. Annals of the New York Academy of Sciences, 1251, E1-E24. doi: 10.1111/j.1749-6632.2012.06751.x

Pardini, D. \& Phillips, M. L. (2010). Neural responses to emotional and neutral facial expressions in chronically violent men. Journal of Psychiatry \& Neuroscience, 35, 390-398. doi: 10.1503/jpn.100037 
Raine, A., Dodge, K., Loeber, R., Gatzke $\square$ Kopp, L., Lynam, D., Reynolds, C., ... \& Liu, J. (2006). The Reactive-Proactive Aggression Questionnaire: Differential correlates of reactive and proactive aggression in adolescent boys. Aggressive Behavior, 32, 159-171. doi: 10.1002/ab.20115

Richardson, C., \& Halliwell, E. (2008). Boiling Point Problem anger and what we can do about it. London: Mental Health Foundation. https://www.mentalhealth.org.uk/sites/default/files/boilingpoint.pdf

Siep, N., Tonnaer, F., Ven, V., van de, Arntz, A., Raine, A., \& Cima, M. (2018). Anger provocation increases limbic and decreases medial prefrontal cortex connectivity with the left amygdala in reactive aggressive violent offenders. Brain Imaging and Behavior, doi: 10.1007/s11682-018-9945-6

Tonnaer, F. Cima, M. \& Arntz, A. (2016). Executive (dys) functioning and impulsivity as possible vulnerability factors for aggression in forensic patients. Journal of Nervous and Mental Disease, 204, 280-286. doi: 10.1097/NMD.0000000000000485

Tonnaer, F., Siep, N., Arntz, \& Cima, M. (2016). An fMRl adapted version of the Articulated Thoughts in Simulated Situations paradigm (ATSS). Maastricht: Maastricht University,

Volman, I., von Borries, A. K. L., Bulten, B. H., Verkes, R. J., Toni, I., \& Roelofs, K. (2016). Testosterone modulates altered prefrontal control of emotional actions in psychopathic offenders. Eneuro, 3 , ENEURO-0107. doi: 10.1523/ENEURO.0107-15.2016

Wagner, D. D., Altman, M., Boswell, R. G., Kelley, W. M., \& Heatherton, T. F. (2013). Self-regulatory depletion enhances neural responses to rewards and impairs top-down control. Psychological Science, 24, 2262-2271. doi: 10.1177/0956797613492985

Werner, N. S., Kühnel, S., \& Markowitsch, H. J. (2013). The neuroscience of face processing and identification in eyewitnesses and offenders. Frontiers in Behavioral Neuroscience, 7, 189. doi: 10.3389/fnbeh.2013.00189

Yang, Y., \& Raine, A. (2009). Prefrontal structural and functional brain imaging findings in antisocial, violent, and psychopathic individuals: a meta-analysis. Psychiatry Research, 174, 81-88. doi: 10.1016/ j.pscychresns.2009.03.012 


\section{Summary and General Discussion}

The principle aim of the current dissertation research is twofold. Firstly, we aim to provide a conceptual clarification about the main concepts of interest, namely (reactive) aggression, and impulsivity (García-Forero, Gallardo-Pujol, Maydeu-Olivares, \& Andrés-Pueyo, 2009). Secondly, the work in this dissertation aims to unravel the neurocognitive correlates as well as possible vulnerability factors of aggression and impulsivity in a forensic population. In the first research part of the thesis we aim to both address conceptual controversy and to provide definitions plus concrete models of reactive aggression and impulsivity for forensic practice. Consequently, in the dissertation we start with definitions, assessment models and suggestions for interventions regarding (reactive) aggression and impulsivity (Chapter $\mathbf{1}$ and $\mathbf{2}$ ). In the second part of the dissertation we present paradigms able to provoke anger that might result in reactive aggression (Blair, 2012). In order to investigate reactive aggression in a controlled setting, it is necessary to investigate the effectiveness of provocation paradigms within violent offender populations (Chapter $\mathbf{3}$ ). Next we investigated different rneurocognitive correlates and vulnerability factors of reactive aggression as well as impulsivity (Chapter $\mathbf{4 , 5}$ and $\mathbf{6}$ ). In the current chapter we will give a summary of the main findings, followed by a general discussion including limitations, suggestions for future research, and clinical implications of the presented findings. We end this chapter with overall concluding remarks on the current dissertation research.

\section{Summary of the main findings \\ Conceptual clarification}

First, the various definitions of (reactive) aggression and impulsivity were explained in Chapter 1. In the current dissertation Aggression is defined as 'hostile, injurious or destructive behavior' (Siever, 2008 p. 429). Aggression is often divided into reactive and proactive aggression. Reactive aggression indicates spontaneous and emotion-driven responses to perceived threats (Cima \& Raine, 2009), whereas proactive aggression referring to planned, goal directed aggression (Raine et al., 2006). In the first chapter different historical and developmental theories (Berkowitz, 1989; Lorenz, 1974; Freud, 1955), social theories (Bandura, 1983; Becker, 1963; Mischel, 1973; Sutherland, 1939; Tedeschi \& Felson, 1994; Tomkins, 1954) and biological theories (e.g. Hawkins \& Trobst, 2000; Séguin, 2013; Swann \& Hollander, 2002) on the etiology of aggression are described. Nowadays the focus of interests is shifted from specific domain related theories to integrative models of aggression, such as the differential susceptibility perspective (Belsky, 2005), the general theory of crime (Gottfredson \& Hirschi, 1990), and the General Aggression Model (GAM, Anderson \& Bushman, 2002). To sum up, as earlier theories explained aggression as an instinctive, innate system, more recent theories describe aggression as a learning process in which some individuals may have a biological 
predisposition, making them more vulnerable to react aggressively in certain circumstances (Raine, 2002; Tiihonen et al., 2015). Environmental influences regarding the development of aggression remain based on social learning and labeling models.

In Chapter $\mathbf{2}$ we focus on Impulsivity, defined in the current dissertation as: "behavior without adequate thought, the tendency to act with less forethought than do most individuals of equal ability and knowledge, or a predisposition toward rapid, unplanned reactions to stimuli without regard to the negative consequences of these reactions' (International Society for Research on Impulsivity). However, impulsivity not only signals dysfunctional behavior with negative consequences, but can also be functional (Dickman, 1990). For example, functional impulsivity is the ability to rapidly implement an effective conflict resolution strategy in a situation of disagreement, preventing escalation (Pitts \& Leventhal, 2012). Yet, the prevalence of pathological impulsivity in forensic populations is reported to be extremely high (up to 88\%, Bjørkly, 2006).

Hence, in the second chapter we present a 3-dimensional model of impulsivity, based on both self-reports (BIS-11, Patton, Stanford, \& Barratt, 1995; SSS, Zuckerman, Kolin, Price \& Zoos, 1964; 17, Eysenck, Pearson, Easting, \& Allsopp, 1985) and behavioral impulsivity instruments (GoStop, Dougherty, Mathias, Marsh, \& Jagar, 2005; BART, Lejuez et al., 2002) in a forensic sample. All three presented impulsivity dimensions are related to aggressive behavior (Denny \& Siemer, 2012; Lynam \& Miller, 2004; Ramírez, Millana, Toldos-Romero, Bonniot-Cabanac, \& Cabanac, 2009; Wilson, \& Scarpa, 2011).

The first dimension, we named 'Impulsive Decision Making' reflects acting without thinking about the consequences (Field, 1986), and is defined as the inability to delay gratification (Rachlin, 1974; Reynolds, Richards, \& de Wit, 2006) and the tendency to engage in spontaneous behavior, restlessness and impatience (Field, 1986). The second dimension, we named 'Sensation Seeking' reflects risk appetite and is related to actual risk taking, and aggressive, but not necessarily criminal behavior (Eysenck et al., 1985). The third dimension, we named '(inadequate) Response Inhibition' reflects the failure to inhibit responding and disinhibited social behavior. Notably, we found no relationship between the three dimensions, indicating distinct impulsivity components. The results of the study underline the importance to consider impulsivity as a multidimensional construct.

Furthermore, we investigated the predictive validity of this multidimensional impulsivity model for psychopathology. Results have shown that impulsive decision making was a predictor for (a history of) drug dependence, the impulsive lifestyle facet of psychopathy, and antisocial personality disorder, while sensation seeking was not related to any psychopathology. We found that inadequate response inhibition was a predictor for (a history of) drug dependence, (facets of) psychopathy, and antisocial personality disorder. Given the importance of the concept of impulsivity with regard to forensic risk assessment (Bailey \& Dolan, 2004; Browne, Beech, Craig, \& Chou, 2017; Hare, 2003; Roesch \& Cook, 2017), practical implications of these results for forensic practice comprise individual multidimensional impulsivity risk profiles generated for risk management plans, managing possible risk of violent recidivism. 


\section{Neurocognitive vulnerability factors of provoked reactive aggression}

Further, in order to examine the underlying mechanisms of anger, we investigated if venting anger reduces, or it rather increases aggression. Therefore, we allowed venting anger and measuring its effect on anger and aggression response after two different anger provocation paradigms; the Articulated Thoughts during Simulated Situations (ATSS) paradigm containing anger stories, and Reactive Aggressive Behavior (RAB) response using a harassing body opponent punching bag (BOB) within a sample of violent incarcerated offenders

(Chapter 3). We focused on anger, because anger is often the emotional drive or motive behind aggression (Averill, 1983). The violent offenders were recruited from a forensic psychiatric hospital and a special care unit of a penitentiary psychiatric centre. The ATSS is a cognitive assessment of thoughts and beliefs, in which subjects are asked to imagine one in that particular situation and react to audiotape presented situations. In the current dissertation

(Chapter 3, 4 and 6), happy, neutral and anger situations were presented. All response statements were scored using the ATSS scoring manual (Eckhardt \& Jamison, 2002). Next to ATSS, BOB with harassing feedback was developed as behavioral assessment of Reactive Aggressive Behavior (RAB) in response to provocation. Participants were instructed to 'punch BOB', but after the start, harassing feedback was triggered by punching. Mean force, measured with pressure sensor (constructed on the gloves) after the last feedback, was used as a measurement of Reactive Aggressive Behavior (RAB) response. Results indicate that venting anger is effective in reducing aggression in forensic psychiatric offenders, but shows mixed results in penitentiary offenders. Forensic psychiatric offenders showed a decrease in self-reported aggression after both provocation paradigms. The penitentiary offenders demonstrated an increase in reported aggression after the ATSS provocation. As the ATSS is a cognitive provocation paradigm assessing thoughts and beliefs related to anger, this finding of an increase in self-reported aggression propensity only in the penitentiary offender group is actually in line with the observation of very high rates of anger rumination in prison population (Bullock, 2010; Wener, 2012) that result in intensified anger, but not necessarily to less inhibitory control (Lievaart, Huijding, van der Veen, Hovens, \& Franken, 2017). Regarding $\mathrm{BOB}$, a more behavioral (physical) provocation paradigm, no increase nor decrease of aggression was found. Furthermore, results show group differences in provocation sensitivity with the forensic psychiatric group showing significant more anger response in ATSS provocation, whereas the penitentiary group showed significant more reactive aggression after harassing feedback. These group differences in provocation paradigm sensitivity result could also indicate external validity concerns for the provocation paradigms, with anger provocation assessment methods only effective in specific (e.g. violent offender) populations. Moreover, context (residence regime, length of stay and level of therapeutic interventions) could have influenced the results. The residence regime is very different between forensic hospital and penitentiary care units, with a sanction in the forensic group for physical aggression within the clinical setting, while the penitentiary care group is admitted within the special care 
unit because of unmanageable behavior elsewhere in the penitentiary (Wesselius, 2013). Further, there is a big difference in length of stay between both groups. While the penitentiary population has a mean length of stay of a few months (3-5 months, DJI, 2012), the forensic psychiatric population has a mean length of stay of a few years (62 months, DRW, 2012). One could speculate that especially the forensic psychiatric group is more used to be 'tested' on their response to provocation by daily interaction of other psychiatric patients at their ward for quite a long time. Another explanation for the provocation sensitivity difference could be the level of therapeutic interventions. The forensic psychiatric group has a considerable history of therapy aiming to prevent violent outburst, in which they are trained to actual reflect on their feelings - resulting in more anger statements on (ATSS) - and not acting out on anger. Additionally, in this chapter, the relationship between anger provocation response, (self-reported) aggression, and recidivism risk was assessed (with psychopathy as a risk factor for violent recidivism, Harris, Boccaccini, \& Rice, 2017; Pedersen, Kunz, Rasmussen, \& Elsass, 2010). Moreover, results show a relationship between the ATSS dimension automatic cognitive biases towards anger and psychopathy in the forensic psychiatric group. In the penitentiary group, a relationship between the ATSS dimension aggressive behavioral intentions and self-reported (reactive) aggression was found. Both automatic cognitive biases towards anger and psychopathy are strongly associated with violent recidivism (Dolan \& Doyle, 2000; Douglas et al., 2014). Consequently, the presence of these automatic cognitive biases towards anger in forensic psychiatric populations, and in individuals with psychopathic characteristics in particular, could be identified using the ATSS paradigm. Also, utilizing ATSS might provide more detailed information about the nature of these biases, giving insights for therapeutic treatment.

Empirical evidence shows that reactive aggression not only correlated with impulsivity (Chan \& Chui, 2012), but also with problems in executive functioning (Baker \& Ireland, 2007). Therefore, the study described in Chapter $\mathbf{4}$ of this dissertation, examines whether both impulsivity and executive functioning contribute simultaneously to a greater risk for reactive aggression. Since the prevalence of maladaptive aggression tends to be specifically high in mental health treatment populations (Connor, 2002), as is the proneness towards aggression (Smith \& Waterman, 2003), more insight in possible vulnerability factors for reactive aggression is of particular interest for forensic offender samples. Therefore, we measured reactive aggression using self-report and RAB response in a male forensic offender sample. The concept of executive functioning has been defined and measured in various ways (Elliot, 2013). Alike the concept of impulsivity, executive functioning too can be conceptualized into three different components, namely working memory, divided attention and flexibility. Impairments in these three specific components are linked to elevated aggressive behavior (De Brito, Viding, Kumari, Blackwood, \& Hodgins, 2013; Feichtinger, 2007; Wilson \& Scarpa, 2011). The results in the current dissertation (Chapter $\mathbf{4}$ ), showed no correlation between impulsivity and executive (dys)functioning. This non correlation indicates two distinct vulnerability factors with no overlap in the current operationalization in the examined forensic patient population. 
Further, results indicated that a combination of impulsivity (impulsive decision making) and executive (dys)functioning (working memory) predicted self-reported reactive aggression, while impulsivity (inadequate response inhibition) on its own, is a better predictor for reactive aggressive behavior.

Neurobiological models propose that reactive aggression is the result of a dysfunction in emotion regulation, caused by an imbalance between prefrontal cortical control and excessive bottom-up signals by limbic regions, including the amygdala (Blair, 2012; Siever, 2008). However, the exact nature of this imbalance remains unknown. Therefore, in Chapter $\mathbf{5}$ the dynamic changes in amygdala resting-state functional connectivity produced by emotional provocation in reactive aggressive violent offenders versus non-offender controls were investigated. Brain activity was scanned while participants rested for $6 \mathrm{~min}$, before and after an emotion (anger and happiness) provocation and regulation task. Moreover, during this emotion task, participants were asked to rate their emotional feelings (happy to anger) using a $100 \mathrm{~mm}$ visual analogue scale (VAS). Results showed that self-reported (VAS) anger significantly increased during the emotion regulation task in both the violent offender and the non-offender control group. Imaging results showed that there was a significant decrease in amygdala medial prefrontal functional connectivity in the violent offender group and an increase in the non-offender control group after the anger regulation task. The opposite patterns were found for amygdala connectivity with the (para)limbic regions including the right posterior insula, the right superior temporal gyrus and the left uncus/amygdala (although the last was non-significant). Within this amygdala - (para)limbic functional connectivity the violent offender group showed increased connectivity, and the non-offender control group showed a decreased connectivity. The post-hoc simple-effects analysis results revealed that the largest difference between groups were pre-task, apart from the right superior temporal gyrus with only post-anger provocation group differences. The present results indicated that reactive aggression might stem from a attentional focus on emotion processing within violent offenders, as indicated by an increase in limbic functional connectivity. The combination of a focus on emotion, along with a lack of medial prefrontal cortex regulation, has the potential to grow out of control (e.g. in reactive aggression). In addition, an increased connectivity between the amygdala and the superior temporal gyrus connectivity in violent offenders was found after the emotion task, which has been previously related to rumination (Cooney, Joormann, Eugene, Dennis, \& Gotlib, 2010; Denson, Pedersen, Friese, Hahm, \& Roberts, 2011). Most interventions for reactive aggression have focused on improving anger control with the underlying intention to decrease violence. In line with the current finding (Chapter 5) we suggested that interventions for reactive aggression should focus on rumination, acceptance, skills to handle anger expression and adaptive regulation of emotions.

Furthermore, in Chapter 6 we investigated differences in brain responses between violent offenders and non-offender controls during anger provocation and anger regulation. During an fMRI adapted provocation and regulation task, we asked participants to alternate 
between attend towards anger (provocation), happy and neutral stories, and distract themselves from the emotions elicited by these stories (regulation). Research in violent offenders suggests that a combination of increased limbic activity, involved in emotion generation, along with decreased prefrontal activity, involved in emotion regulation, is associated with reactive aggression. In the current results violent offenders showed more activity in the ventrolateral prefrontal cortex (VIPFC) and less activity in the posterior cingulate cortex (PCC) and cerebellum during anger provocation, compared to non-offender controls. The results of the regulation condition showed decreased activity in the PCC, dorsolateral prefrontal cortex (dIPFC) and VIPFC when violent offenders were instructed to regulate during anger stories, whereas non-offender controls showed an increased activity in dIPFC and VIPFC. However, the effects in the PCC and dIPFC were not specific for anger, as similar responses were shown for happy stories. In violent offenders, results indicate increased need to regulate (vIPFC activity) specifically during anger provocation, while regulation difficulties emerged when they were explicitly instructed to regulate (reflected in decreased activity in dIPFC and VIPFC). Moreover, amygdala activity was only found at a liberal level of significance, showing decreased activity in violent offenders during anger regulation compared to anger provocation. This pattern might be expected, however, no group differences were found during anger provocation, while the violent offenders showed less amygdala activity during anger regulation compared to non-offender controls. The initial lack of differential activity in the amygdala might well be a consequence of the amygdala's specific location next to air-filled spaces in the brain, leading to high signal-to-noise ratio's and resulting in null findings reflecting rather signal loss than absence of brain activity (Boubela et al., 2015). In conclusion, results indicate an increased need (i.e. initiate) to regulate during anger provocation and less during anger regulation in violent offenders. Additionally, when explicitly instructed to regulate, results hint to general emotion regulation impairments in violent offenders. The constant effort for regulation in violent offenders in combination with an approach tendency towards aggressive scenes (Lobbestael, Cousijn, Brugman, \& Wiers, 2016) might exhaust cognitive sources required to regulate or distract from anger in violent offenders, resulting in a risk factor for self-control failure (Wagner, Altman, Boswell, Kelley, \& Heatherton, 2013). Ultimately this might contribute to reactive aggression when provoked.

\section{General Discussion}

\section{Clinical Implications}

Most aggression interventions focus on reactive aggression (Buchmann, Hohmann, Brandeis, Banaschewski, \& Poustka, 2014), while prevention primarily focuses on proactive aggression (Henggeler, Cunningham, Pickrel, Schoenwald, \& Brondino, 1996) (e.g. bully prevention school programs, Kolbert, Williams, Morgan, Crothers, \& Hughes, 2016). Moreover, different subtypes of aggression benefit from distinct treatment components. Reactive aggressors seem to have more profit from psychosocial interventions based on anger control 
(Barker et al., 2010; Vitaro, Brendgen, \& Barker, 2006) and emotion regulation (Skripkauskaite et al., 2015; Röll, Koglin, \& Petermann, 2012), while children and adolescents with severe problems of conduct disorder, and proactive aggression in general, are often more unwilling and unaffected by treatment, resulting in less clinical improvement (Barker et al., 2010; Haas et al, 2011; Masi et al., 2011).

Most interventions for reactive aggression have focused on pharmacotherapy interventions (Swann \& Hollander, 2002) and improving anger control with the underlying intention to decrease violence. Pharmacotherapy interventions show a supplemented value for impulsivity (hyper activity) and reactive aggression (Swann \& Hollander, 2002), possibly helping the regulation of increased limbic functional connectivity and supporting medial prefrontal cortex regulation as shown in the results of Chapter 5. In interventions for reactive aggressors focusing not only on the individual (e.g. individual provocation sensitivity, Chapter $\mathbf{3}$ ), but also on its interactions with others (like MultiSystemic Therapy, MST) (Borduin, 1999; Henggeler, Schoenwald, Borduin, Rowland \& Cunningham, 1998), encouraging results with long-term reductions in criminal activity and general aggression after treatment have bee found (Henggeler et al., 1996, p.1). In line with the current findings described in Chapter $\mathbf{5}$ and $\mathbf{6}$ it is suggested that interventions for reactive aggression should also focus on rumination and adaptive regulation of emotions. More specifically, results in Chapter $\mathbf{5}$ indicate that an increase in amygdala-limbic functional connectivity combined with a lack of medial prefrontal cortex regulation, has the potential to grow out of control e.g. in reactive aggression. In addition, an increased connectivity between the amygdala and the superior temporal gyrus connectivity was found after the anger provocation, which has been previously related to rumination (Cooney, Joormann, Eugene, Dennis, \& Gotlib, 2010; Denson, Pedersen, Friese, Hahm, \& Roberts, 2011). Self-reported rumination has been associated with amygdala activation during the up-regulation of negative affect in healthy people, suggesting that an increased tendency to ruminate increases intensity of the neural processing of negative information in limbic areas (Ray et al., 2005). Therefore, one could speculate that reactive aggressive offenders ruminate more after being exposed to emotionally provoking situations. In turn, this may lead to increased negativity bias (Cima, Vancleef, Lobbestael, Meesters, \& Korebrits, 2014; Lobbestael, Cima, Arntz, 2013), making them more sensitive to negative stimuli and consequently increasing the change of reactive aggressive behavior. This proposition is in line with neurobiological models of reactive aggression (Blair, 2004; Davidson, Putnam, \& Larson, 2000; Phelps, Delgado, Nearing, \& LeDoux, 2004; Raine, \& Yang, 2006) stating that individuals with faulty regulation of negative emotions popose a serieus risk for aggessive behaviour. Moreover, research in adolescents showed anger rumination as a risk factor for reactive aggression (McLaughlin, Aldao, Wisco, \& Hilt, 2014; Smith, Stephens, Repper, \& Kistner, 2016). Therefore, interventions reducing anger rumination like Rumination Focused Cognitive Behavioural Therapy (RFCBT) might be an effective method reducing reactive aggression in anger rumination offenders. 
Further, the results in Chapter $\mathbf{6}$ suggest an increased need to regulate in violent offenders, specifically during anger provocation, and regulation difficulties when explicitly instructed to regulate. The constant effort for regulation in violent offenders might exhaust cognitive sources required to regulate anger in violent offenders, resulting in a risk factor for self-control failure. Ultimately this might contribute to reactive aggression when continuously provoked. As a result, improving anger behavioral control and emotion regulation in order to decrease aggression and impulsivity, treatment focusing on up-regulating prefrontal cortex functions supporting the ability to reappraise negative stimuli may also be successful. In this regard, research showed that reappraisal is the most effective anger regulation strategy (Denson, Moulds, \& Grisham, 2012; Fabiansson, Denson, Moulds, Grisham, \& Schira, 2012) and may lead to less negative, hostile interpretational biases, consequently altering behavioral response to perceived threat in reactive aggression (Lobbestael et al., 2013). Supportive studies demonstrated neurobiological changes after behavioral interventions (Cornet, De Kogel, Nijman, Raine, \& de Laan, 2013; Karlsson, 2011; Vaske, Galyean, \& Cullen, 2011). Recently, non-invasive brain stimulation methods such as transcranial Direct Current Stimulation (tDCS) and Transcranial Magnetic Brain Stimulation (TMS) showed promising results in reducing aggression (proactive as well as reactive), and aggression as a result of social exclusion in healthy males (Dambacher et al., 2015; Riva et al, 2015; Zaman, 2014). TMS refers to administrating series of pulsed magnetic stimuli, or electromagnetic induction, direct to the brain by means of a stimulating coil placed directly to the head (Dambacher et al., 2015; Schlaepfer, George, \& Mayberg, 2010). Both non-invasive brain stimulation methods aim to alter brain functioning. In TMS by disturbing or enhancing brain activity in the stimulated brain areas selected, and in tDCS by either decreasing or increasing excitability of the stimulated areas (Dambacher et al., 2015). Both methods are administered supporting interventions, or are applied following other therapeutic interventions. Research has shown the usage of non-invasive brain stimulation methods for e.g. the treatment of cortical epilepsy, managing acute pain, decreasing negative symptoms in schizophrenia (Schlaepfer, George, \& Mayberg, 2010), and the treatment of impulsivity in neuropsychiatric disorders as Attention Deficit Hyperactivity Disorder (ADHD), Antisocial and Borderline Personality Disorders (Zaman, 2014). Notably, with regard to brain stimulation methods enhancing treatment effect of aggression, Dambacher and colleagues (2016) demonstrated reduced proactive aggression in healthy males using tDCS. Dambacher and colleagues achieved this result by stimulating the (right) dIPFC, aiming to enhance right hemispheric dominance. Results of Chapter $\mathbf{6}$ in the current dissertation show decreased (left) dIPFC activity in violent offenders during anger (and happy) regulation compared to provocation, while the non-offender controls showed the opposite pattern. Subsequently, inducing right hemispheric dominance might be effective in violent offenders aiming to result in better cortical balance, ultimately leading to stronger anger regulation capacity. Moreover, Perach-Barzilay and colleagues (2012) stimulated both the left and the right dIPFC separately in a healthy community sample using TMS. They showed that the stimulation of the left dIPFC resulted in greater aggression increase (both reactive and proactive), than the stimulation of the right dIPFC, which lead them 
to the conclusion that dIPFC asymmetry is a key element in aggression regulation. Therefore, future research should investigate the effects of inducing right hemispheric dominance using TMS during anger provocation within a violent offender population. Since the current results indicate regulation difficulties in the dIPFC and the VIPFC, it would be interesting to examine the stimulation of both areas separately.

Interventions for proactive aggression should better focus on teaching the individual alternative strategies in achieving instrumental goals, since children and adolescents with severe problems of conduct disorder, and proactive aggression in general, are often more unwilling and unaffected by treatment than dominantly reactive aggressive adolescents, resulting in less clinical improvement than the dominantly reactive aggressive adolescents (Barker et al., 2010; Haas et al, 2011; Masi et al., 2011). These alternative strategies include negotiation and compromising (Hubbard, Morrow, Romano, \& McAuliffe, 2010) as alternative strategies. Additionally, treatment interventions based on cognitive behavioral approaches aimed to alter cognitions and behavior, such as Aggression Replacement Training (ART, Goldstein, 1996) are promising in reducing reactive as well as proactive aggressive behavior, especially in adolescence (de Ruiter, \& Hildebrand, 1999; Down, Willner, Watts, \& Griffiths, 2011; Smeets et al., 2015).

Concluding, evidence shows that Cognitive Behavioral Therapy focusing on cognitions (cognitive distortions) and emotion, but also pharmacotherapy interventions (Swann \& Hollander, 2002) and brain stimulation methods all seem promising opportunities in reducing mainly reactive but also proactive aggression. However, more research on predictors and possible moderators of treatment response in decreasing aggression is needed. Deficits in emotion regulation, either a lack of regulating anger (reactive aggression) or overregulating anger emotions in the presence of lacking empathy (instrumental goal directed aggression), seem essential in understanding treatment aimed at helping individuals to control their aggressive behavior more effectively.

\section{Strengths and limitations}

The main strength of the work described in the thesis is the study population, including forensic offender participants (forensic psychiatric and penitentiary offenders). The advantage of working with forensic offender participants lies in the fact that the concepts of interest, namely reactive aggression and impulsivity, might manifest different in offender samples. And the prevalence of reactive aggression and impulsivity is higher in this specific population. For instance, pathological impulsivity is reported to be extremely high (up to 88\%, Bjørkly, 2006) within forensic (incarcerated) samples, and violent offenders are characterized by extreme aggressive behavior (Grochowska \& Kossowska, 2012), with anger as a risk factor for violent recidivism (Loza \& Loza-Fanous, 1999). Testing the effectiveness of venting anger in reducing aggression within violent offender populations with anger problems was one of our core aims.

Further, in this dissertation we aimed to investigated whether (forensic psychiatric) offenders do show different brain responses during emotion provocation. Therefore, we investigated differences within brain responses during emotion provocation between violent 
offenders and matched healthy controls using fMRI technique. Another strength is the wide range of assessment methods used in order to fulfill the aims of the research presented in this dissertation. The assessment methods included not only self-reports but also behavioral measurements, and different innovative emotion provocation paradigms that have been adapted for fMRI usage measuring brain responses. This is innovative because previous cognitive research using brain imaging techniques focused on frustration, punishment (Dambacher et al., 2015; Emmerling et al., 2015) or perceived threat as a trigger of anger or aggression (Blair, 2012), emotion research has focused on the recognition of anger as an indicator for dysfunctions in anger experience and perception (Kret \& de Gelder, 2013; Lindquist, Wager, Kober, Bliss-Moreau, \& Barrett, 2012), with deficits in emotion recognition ultimately leading to aggressive and violent behaviour (Howells et al., 2002). In other words, earlier studies using fMRI in violent offenders focused on the recognition of anger (e.g. perception of emotional pictures) (Bueso-Izquierdo et al., 2016; Werner, Kühnel \& Markowitsch, 2013) and automatic action tendency responses (avoid anger and approach happy) to facial expressions (Volman et al., 2016). Up until now no fMRI study actually investigated anger provocation and anger regulation within a group of violent offenders exhibiting anger problems and compared them to non-offender controls.

Finally, we are the first to investigate actual brain response differences in emotion (anger and happy) provocation compared to regulation within a group of violent offenders exhibiting anger problems comparing them to non-offender controls (Chapter 6). To understand the mechanism underlying the regulation of aggressive behavior we examined anger expression in both violent offenders and non-offender controls during provocation as well as regulation. Therefore, the results in Chapter 6 provide new insights for the development of effective treatment interventions for reactive aggression.

However, the findings of the current dissertation research should be considered in light of several limitations. First, although the strength of this dissertation research is that the study population is mainly based on forensic male offender participants, generalizability of the studies described in the first four chapters might be limited to similar populations only. Nevertheless, our findings e.g. from the study examining a multidimensional impulsivity model, were similar to research findings, also leading to multidimensional models (Harris et al., 2014; Reynolds, Penfold \& Patak, 2008; Whiteside \& Lynam, 2001). Furthermore, in the current dissertation we deliberately selected only male offenders because research showed significant gender differences in anger expression and violence rates between men and women (Staniloiu \& Markowitsch, 2012), even when no sex differences in anger can be found (Archer, 2004; Evers, 2005). Men tend to show more physical and direct, reactive aggression than women (Archer, 2004). Therefore, the provocation paradigms for reactive aggression might be more effective in male samples.

Second, some offenders acquired prescribed medication for clinical reasons. Since medication might have affected responses, in particular in the brain imaging studies, post hoc 
analyses were performed to check for any possible relation between medication intakes within the violent offender group. These analyses suggested that medication did not affect the results, though it cannot be excluded that medication affected the outcomes as medication was not experimentally manipulated. Third, the sample size in some of the studies was relatively small

(Chapters 3, 4, 5 and 6), which might have limited the statistical power. Fourth, we used a mix of self-reports and behavioral measurements aiming to design a robust multidimensional model capturing the broth concept of impulsivity as complete as possible. Results in the current dissertation

(Chapter 2) however showed that only two of three impulsivity dimensions included both self-reports and behavioral measurements, namely sensation seeking and (inadequate) response inhibition. It cannot be excluded that rather than content, method variance influenced the dimensions of the model that resulted. Moreover, a critical reflection on the current results described within Chapter $\mathbf{2}$ and the literature, lead to the preference of a four dimensional model of impulsivity, adding one dimension to the presented model. This four dimensional model of impulsivity includes: 1.) impulsive decision making (reflecting acting without thinking and non-planning), 2.) sensation seeking (reflecting a risk appetite and venturesomeness), 3.) (inadequate) response inhibition (reflecting response inhibition dysfunction) and 4.) sustained attention (reflecting perseverance).

\section{Recommendations for future scientific research}

The current dissertation research shows the importance to consider impulsivity as a multidimensional construct (Chapter 2). Future research should focus on possible relations between impulsivity dimensions and risk for criminal behavior, because impulsivity is linked to high and stable levels of (re)offending (Higgings, Kirchner, Ricketts, \& Marcum, 2013). Moreover, as the results of Chapter $\mathbf{4}$ suggests, future research should investigate whether specifically (inadequate) response inhibition could also be a valuable predictor for violent recidivism.

Moreover, two different anger provocation paradigms are presented in this dissertation, with different effectiveness. Consequently, future research should carefully select provocation paradigms proven to be effective in a violent offenders and investigate their effectiveness on other samples. Additionally, it would be informative to examine which automatic cognitive biases relate to recidivism risk within psychopathic forensic offenders (Dolan \& Doyle, 2000; Hare, Clark, Grann, \& Thornton, 2000).

Further, given the imaging results, future research should investigate whether the decreased dIPFC activity during anger regulation is a result of ventrolateral prefrontal cortex dysfunction, or signals a broader regulation problem. Additionally, more insight in the effects of dysregulation and possible regulatory exhaustion risk to regulate anger in violent offenders is needed.

\section{Recommendations for forensic practice and policy makers}

For practical purposes, multidimensional impulsivity risk profiles could be generated as input for risk management plans, managing possible risk of violent recidivism. Moreover, the 
results in Chapter $\mathbf{2}$ have shown that specific impulsivity dimensions can be seen as vulnerability factor predicting psychopathology. More specific, impulsive decision making as well as inadequate response inhibition were predictors for drug dependence, psychopathy, and antisocial personality disorder. Consequently, special attention within the treatment path is needed, in case of combined and possible reinforcing pathology (drug dependence, psychopathy, and antisocial personality disorder) with impulsive decision making and inadequate response inhibition.

In order to improve treatment effects, ATSS paradigm could give insights on possible automatic cognitive biases towards anger, especially in forensic offenders with psychopathic characteristics.

Further, an important goal of treatment and anger management programs for violent offenders should focus on appropriate regulation or more specific on reflective emotion regulation (Holodynski, Seeger, Kortas-Hartmann, \& Wörmann 2013), saving effort for emotion regulation only in situations where regulation is necessary, avoiding the risk for regulatory exhaustion risk for regulating anger in violent offenders.

\section{Concluding Remarks}

In conclusion, the current dissertation results show that impulsivity is a multidimensional concept including impulsive decision making, sensation seeking, and (inadequate) response inhibition. Further, results indicated that not only multidimensional impulsivity, but a combination of impulsivity (Impulsive Decision Making) and executive (dys)functioning (working memory) can predict self-reported reactive aggression, while impulsivity (inadequate response Inhibition) on its own, is a better predictor for actual reactive aggressive behavior. While testing the effectiveness of venting anger showed that venting anger is effective in reducing aggression, at least in the forensic psychiatric offenders. Neuroimaging results indicate an increased need (i.e. initiate) to regulate during anger provocation, and regulation difficulties when explicitly instructed to regulate in violent offenders. Additionally, when explicitly instructed to regulate, results hint to general emotion regulation impairments in violent offenders. The constant effort for regulation in violent offenders in combination with a known approach tendency towards aggressive scenes might exhaust cognitive sources required to regulate anger in violent offenders, resulting in a risk factor for self-control failure. Ultimately this might contribute to reactive aggression when provoked.

\footnotetext{
"Anybody can become angry - that is easy,

but to be angry with the right person and to the right degree and

at the right time and for the right purpose, and in the right way

- that is not within everybody's power and is not easy."
} 


\section{References}

Anderson, C. A., \& Bushman, B. J. (2002). Human Aggression. The Annual Review of Psychology, 53, 27-51. http://www.annualreviews.org/doi/pdf/10.1146/annurev.psych.53.100901.135231

Archer, J. (2004). Sex differences in aggression in real-world settings: A meta-analytic review. Review of General Psychology, 8, 291. doi: 10.1037/1089-2680.8.4.291

Averill, J. R. (1983). Studies on anger and aggression: Implications for theories of emotion. American Psychologist, 38, 1145-1160. doi: 10.1037/0003-066X.38.11.1145

Bailey, S., \& Dolan, M. (2004). Adolescent Forensic Psychiatry. Boca Raton, FL: CRC Press.

Baker, S. F., \& Ireland, J. L. (2007). The link between dyslexic traits, executive functioning, impulsivity and social self-esteem among an offender and non-offender sample. International Journal of Law and Psychiatry, 30, 492-503. doi: 10.1016/j.jijp.2007.09.010

Barker, E. D., Vitaro, F., Lacourse, E., Fontaine, N. M. G., Carbonneau, R., \& Tremblay, R.E. (2010). Testing the developmental distinctiveness of male proactive and reactive aggression with a nested longitudinal experimental intervention. Aggressive Behavior, 36, 127-140. doi: 10.1002/ab.20337

Bandura, A. (1983). Psychological mechanism of aggression. In R. G. Geen, \& E. I. Donnerstein (Eds.), Aggression: Theoretical and empirical reviews (pp. 1-40). New York: Academic Press.

Becker, H. S. (1963). Outsider: Studies in the sociology of deviance. New York: The Free Press.

Belsky, J. (2005). Differential susceptibility to rearing influence: An evolutionary hypothesis and some evidence. In B. Ellis \& D. Bjorklund (Eds.), Origins of the social mind: Evolutionary psychology and child development (pp. 139-163). New York: Guilford.

Berkowitz, L. (1989). Frustration-aggression hypothesis: examination and reformulation. Psychological Bulletin, 106, 59-73.

Bjørkly, S. (2006). Empirical evidence of a relationship between insight and risk of violence in the mentally ill - A review of the literature. Aggression and Violent Behavior, 11, 414-423. doi: 10.1016/j.avb.2006.01. 006

Blair, R. J. R. (2012). Considering anger from a cognitive neuroscience perspective. Wiley Interdisciplinary Reviews: Cognitive Science, 3, 65-74. doi: 10.1002/wcs.154

Blair, R. J. R. (2004). The roles of orbital frontal cortex in the modulation of antisocial behavior. Brain and cognition, 55, 198-208. doi: 10.1016/S0278-2626(03)00276-8

Borduin, C. M. (1999). Multisystemic treatment of criminality and violence in adolescents. Journal of the American Academy of Child \& Adolescent Psychiatry, 38, 242-49. doi: http://dx.doi.org/10.1097/ 00004583-199903000-00009

Boubela, R. N., Kalcher, K., Huf, W., Seidel, E. M., Derntl, B., Pezawas, L., Našel, C., \& Moser, E. (2015). fMRI measurements of amygdala activation are confounded by stimulus correlated signal fluctuation in nearby veins draining distant brain regions. Scientific Reports, 5. Article number: 10499. doi: 10.1038/srep10499

Browne, K. D., Beech, A. R., Craig, L. R., \& Chou, S. (2017). Assessments in forensic practice: a handbook. Chichester, West Sussex: Wiley-Blackwell.

Buchmann, A., Hohmann, S., Brandeis, D., Banaschewski, T., \& Poustka, L., (2014). Aggression in Children and Adolescents. In Miczek, K. A., Meyer-Lindenberg, A. (Eds.), Neuroscience of Aggression. New York: Springer. 
Bueso-Izquierdo, N., Verdejo-Román, J., Contreras-Rodríguez, O., Carmona-Perera, M., Pérez-García, M., \& Hidalgo-Ruzzante N. (2016). Are batterers different from other criminals? An fMRI study. Social Cognitive and Affective Neuroscience, nsw020. doi: 10.1093/scan/nsw020

Bullock, J. S. (2010). The relation between anger rumination, provocation, and aggressive behavior. Tallahassee, Florida: Florida State University. http://diginole.lib.fsu.edu/islandora/object/fsu:176369/ datastream/PDF/view

Chan, H. C., \& Chui, W. H. (2012). Psychological correlates of violent and non-violent Hong Kong juvenile probationers. Behavioral Sciences \& the Law, 30, 103-120. doi: 10.1002/bsl.2003

Cima, M., Vancleef, L. M. G., Lobbestael, J., Meesters, C., \& Korebrits, A. (2014). Don't you Dare Look at me, or else: Negative and Aggressive Interpretation Bias, Callous Unemotional Traits and Type of Aggression. Journal of Child \& Adolescent Behavior, 2:128. doi: 10.4172/jcalb.1000128

Cima, M., \& Raine, A. (2009). Distinct characteristics of psychopathy relate to different subtypes of aggression. Personality and Individual Differences, 47, 835-840. doi: 10.1016/j.paid.2009.06.031

Connor, D. F. (2002). Aggression and Antisocial Behavior in Children and Adolescents. New York: The Guilford Press.

Cooney, R. E., Joormann, J., Eugene, F., Dennis, E. L., \& Gotlib, I. H. (2010). Neural correlates of rumination in depression. Cognitive, Affective, \& Behavioral Neuroscience, 10, 470-478. doi: 10.3758/CABN.10.4.470

Cornet, L., De Kogel, C., Nijman, H., Raine, A., \& van der Laan, P. (2013). Neurobiological factors as predictors of cognitive-behavioral therapy outcome in individuals with antisocial behavior: a review of the literature. International Journal of Offender Therapy and Comparative Criminology, 9, 1-18. doi: $10.1177 / 0306624 \times 13494694$

Dambacher, F., Sack, A. T., Lobbestael, J., Arntz, A., Brugman, S., \& Schuhmann, T. (2015). Out of control: evidence for anterior insula involvement in motor impulsivity and reactive aggression. Social Cognitive and Affective Neuroscience, 10, 508-516. doi: 10.1093/scan/nsu077

Dambacher, F., Schuhmann, T., Lobbestael, J., Arntz, A., Brugman, S., \& Sack, A. T. (2015). Reducing proactive aggression through non-invasive brain stimulation. Social Cognitive and Affective Neuroscience, nsv018. doi:10.1093/scan/nsv018

Davidson, R. J., Putnam, K.M., \& Larson, C. L. (2000). Dysfunction in the neural circuitry of emotion regulation-a possible prelude to violence. Science, 289(5479), 591-4. doi: 10.1126/science.289.5479.591

De Brito, S. A., Viding, E., Kumari, V., Blackwood, N., \& Hodgins, S. (2013). Cool and Hot Executive Function Impairments in Violent Offenders with Antisocial Personality Disorder with and without Psychopathy. PLOS ONE, 8, e65566. doi: 10.1371/journal.pone.0065566

Denny, K. G., \& Siemer, M. (2012). Trait aggression is related to anger-modulated deficits in response inhibition. Journal of Research in Personality, 46, 450-454. doi: 10.1016/j.jrp.2012.04.001

Denson, T. F., Moulds, M. L., \& Grisham, J. R. (2012). The effects of rumination, reappraisal, and distraction on anger experience. Behavior Therapy, 43, 355-364. doi: 10.1016/j.beth.2011.08.001

Denson, T. F., Pedersen, W. C., Friese, M., Hahm, A., \& Roberts, L. (2011). Understanding impulsive aggression: Angry rumination and reduced self-control capacity are mechanisms underlying the provocation-aggression relationship. Personality and Social Psychology Bulletin, 37, 850-862._doi: 10.1177/0146167211401420 
Dolan, M., \& Doyle, M. (2000). Violence risk prediction. The British Journal of Psychiatry, 177, 303-311. doi: 10.1192/bjp.177.4.303

Dougherty, D. M., Mathias, C. W., Marsh, D. M., \& Jagar, A. A. (2005). Laboratory Behavioral Measures of Impulsivity. Behavior Research Methods, 37, 82-90. doi: 10.4135/9781412952644

Douglas, K., S., Hart, S. D., Webster, C. D., Belfrage, H., Guy, L. S., \& Wilson, C. M. (2014). Historical-Clinical-Risk Management-20, Version 3 (HCR-20V3): Development and Overview, International Journal of Forensic Mental Health, 13, 93-108. doi: 10.1080/14999013.2014.906519

Down, R., Willner, P., Watts, L., \& Griffiths, J. (2011). Anger Management groups for adolescents: a mixed-methods study of efficacy and treatment preferences. Clinical Child Psychology \& Psychiatry, 16, 33-52. doi: 10.1177/1359104509341448

Eckhardt, C. I., Barbour, K. A., \& Davison, G. C. (1998). Articulated thoughts of maritally violent and nonviolent men during anger arousal. Journal of Consulting and Clinical Psychology, 66, 259-69. doi: 10.1037/0022-006X.66.2.259

Eckhardt, C., \& Jamison, T. R. (2002). Articulated thoughts of male dating violence perpetrators during anger arousal. Cognitive Therapy and Research, 26, 289-308. doi: 10.1023/A:1016045226185

Elliot, R. (2013). Executive functions and their disorders. Imaging in clinical neuroscience. British Medical Bulletin, 65, 49-59. doi: 10.1093/bmb/65.1.49

Emmerling, F., Schuhmann, T., Lobbestael, J., Arntz, A., Brugman, S., \& Sack, A. T. (2016). The Role of the Insular Cortex in Retaliation. PloS One, 11(4), e0152000. doi: 10.1371/journal.pone.0152000

Evers, C. (2005). Sex differences in anger expressions: The shaping role of social appraisals. Kurt Lewin Instituut: Utrecht.

Eysenck, S. B. G., Pearson, P. R., Easting, G., \& Allsopp, J. F. (1985). Age norms for impulsiveness, venturesomeness, and empathy in adults. Personality and Individual Differences, 6, 613-619. doi: 10.1016/0191-8869(85)90011-X

Fabiansson, E. C., Denson, T. F., Moulds, M. L., Grisham, J. R., \& Schira, M.M. (2012). Don't look back in anger: Neural correlates of reappraisal, analytical rumination, and angry rumination during recall of an anger-inducing autobiographical memory. Neurlmage, 59, 2974-2981. doi: 10.1016/j.neuroimage.2011.09.078

Field, G. (1986). The psychological deficits and treatment needs of chronic criminality. Federal Probation, 50, 60-66.

Feichtinger, D. M. (2007). Cognitive flexibility in a forensic population. [dissertation manuscript]. Origon: Pacific University.

Freud, S. (1955). Beyond the pleasure principle. (J. Strachey, Trans.). London: Hogaths Press (Original work published in 1920).

García-Forero, C., Gallardo-Pujol, D., Maydeu-Olivares, A., \& Andrés-Pueyo, A. (2009). Disentangling impulsiveness, aggressiveness and impulsive aggression: an empirical approach using self-report measures. Psychiatry Research, 168, 40-49. doi: 10.1016/j.psychres.2008.04.002

Goldstein, A. P. (1996). Aggression Replacement Training: Teaching prosocial behaviors to antisocial youth. In R. Ross, D. H. Antonowicz, \& K. Dhuluval (eds.), Effective Delinquency Prevention and Offender Rehabilitation. Ottawa: AIR Training and Publications. 
Grochowska, K. \& Kossowska, M. (2012). Fact sheet violent offenders. European Association of Psychology and Law - Student Sociaty Publishing House (EAPL-s): Poland. https://www.eaplstudent.com/component/ content/article/193-fact-sheet-violent-offenders

Haas, S. M., Waschbusch, D. A., Pelham, W. E. Jr, King, S., Andrade, B. F., \& Carrey, N. J. (2011). Treatment response in CP/ADHD children with callous/unemotional traits. Journal of Abnormal Child Psychology, 39, 541-552. doi: 10.1007/s10802-010-9480-4

Harris, M., Penfold, R B., Hawkins, A., Maccomb, J., Wallace, B., \& Reynolds, B. (2014). Dimensions of Impulsive Behavior and Treatment Outcomes for Adolescent Smokers. Experimental and Clinical Psychopharmacology, 22, 57-64. doi: 10.1037/a0034403

Harris, P. B., Boccaccini, M. T., \& Rice, A. K. (2017). Field measures of psychopathy and sexual deviance as predictors of recidivism among sexual offenders. Psychological Assessment, 29, 639- 651. doi: 10.1037/pas0000394.

Hawkins, K. A., \& Trobst, K. K. (2000). Frontal lobe dysfunction and aggression: conceptual issues and research findings, Aggression and Violent Behaviour, 5, 147-157. doi: 10.1016/S1359-1789(98)00033-0

Henggeler, S. W., Cunningham, P. B., Pickrel, S. G., Schoenwald, S. K., \& Brondino, M. J. (1996). Multisystemic therapy: an effective violence prevention approach for serious juvenile offenders. Journal of Adolescence, 19, 47-61. doi: 10.1006/jado.1996.0005

Henggeler, S. W., Schoenwald, S. K., Borduin, C. M., Rowland, M. D., \& Cunningham, P. B. (1998). Multisystemic Treatment of Antisocial Behavior in Children and Adolescents. New York: Guilford.

Hibbeln, J. R., Ferguson, T. A., \& Blasbalg, T. L. (2006). Omega-3 fatty acid deficiencies in neurodevelopment, aggression and autonomic dysregulation: opportunities for intervention. International Review of Psychiatry, 18, 107-118. doi: 10.1080/09540260600582967

Higgins, G. E., Kirchner, E. E., Ricketts, M. L., \& Marcum, C. D. (2013). Impulsivity and offending from childhood to young adulthood in the United States: a developmental trajectory analysis. International Journal of Criminal Justice Sciences, 8, 182.

Holodynski, M., Seeger, D., Kortas-Hartmann, P., \& Wörmann, V. (2013). Placing emotion regulation in a developmental framework of selfregulation. In K. C. Barrett, N. A. Fox, G. A. Morgan, D. J. Fidler., \& L. A. Daunhauer (Eds.). Handbook of self-regulatory processes in development: New directions and international perspectives (pp 27-59). London: Routledge Psychology Press. doi: 10.4324/9780203080719.ch3

Howells, K., Day, A., Bubner, S., Jauncey, S., Williamson, P., Parker, A., \& Heseltine, K. (2002). Anger management and violence prevention: Improving effectiveness. Australian Institute of Criminology. Trends \& issues in crime and criminal justice. 227. http://aic.gov.au/publications/current\%20series/tandi/221-240/tandi227.html (Canberra, Australian Institute of Criminology, 2002).

Hubbard, J. A., Morrow, M. T., Romano, L. J., \& McAuliffe, M. D. (2010). The role of anger in children's reactive versus proactive aggression: review of findings, issues of measurement, and implications for intervention. In W. F. Arsenio, E. A. Lemerise (Eds.), Emotions, aggression, and morality in children: bridging development and psychopathology. Washington DC: American Psychological Association.

Karlsson, H. (2011). How psychotherapy changes the brain: Understanding the mechanisms. Psychiatric Times, 28, 1-5. http://www.psychiatrictimes.com/psychotherapy/how-psychotherapy-changes-brain 
Kolbert, J. B., Williams, R. L., Morgan, L. M., Crothers, L. M., \& Hughes, T. L. (2016). Introduction to Professional School Counseling: Advocacy, Leadership, and Intervention. Oxford: Routledge.

Kret, M. E., \& de Gelder, B. (2013). When a smile becomes a fist: the perception of facial and bodily expressions of emotion in violent offenders. Experimental Brain Research, 228, 399-410. doi: 10.1007/s00221-013-3557-6

Lejuez, C. W., Read, J. P., Kahler, C. W., Richards, J. B., Ramsey, S. E., Stuart, G. L., Strong, D. R., \& Brown, R. A. (2002). Evaluation of a behavioral measure of risk taking: The Balloon Analogue Risk Task (BART). Journal of Experimental Psychology, 8, 75-84. doi: 10.1037//1076-898X.8.2.75

Lievaart, M., Huijding, J., van der Veen, F. M., Hovens, J. E., \& Franken, I. H. (2017). The impact of angry rumination on anger-primed cognitive control. Journal of Behavior Therapy and Experimental Psychiatry, 54, 135-142. doi: 10.1016/j.jbtep.2016.07.016

Lindquist, K. A., Wager, T. D., Kober, H., Bliss-Moreau, E., \& Barrett, L. F. (2012).The brain basis of emotion: a meta-analytic review. Behavioral and Brain Sciences, 35, 121-202. doi: 10.1017/S0140525X11000446

Lobbestael, J., Cima, M., \& Arntz, A. (2013). The relationship between adult reactive and proactive aggression, hostile interpretation bias, and antisocial personality disorder. Journal of Personality Disorders, 27, 53-66. doi: 10.1521/pedi.2013.27.1.53

Lobbestael, J., Cousijn, J., Brugman, S., \& Wiers, R. W. (2016). Approach and avoidance towards aggressive stimuli and its relation to reactive and proactive aggression. Psychiatry Research, 240, 196-201. doi: 10.1016/j.psychres.2016.04.038

Lorenz, K. (1974). On aggression. New York: Harcourt Brace Jovanovich.

Loza, W. \& Loza-Fanous, A. (1999). Anger and Prediction of Violent and Nonviolent Offenders' Recidivism. Journal of Interpersonal Violence, 14, 1014-1029. doi: 10.1177/088626099014010002

Lynam, D. R., \& Miller, J. D. (2004). Personality pathways to impulsive behavior and their relations to deviance: Results from three samples. Journal of Quantitative Criminology, 20, 319-341. doi: 10.1007/s10940-004-5867-0

Masi, G., Manfredi, A., Milone, A., Muatori, P., Polidori, L., Ruglioni, L., \& Muratori, F. (2011). Predictors of nonresponse to psychosocial treatment in children and adolescents with disruptive behaviour disorders. Journal Child Adolescent Psychopharmacology, 21, 51-55. doi: 10.1089/cap.2010.0039

McLaughlin, K. A., Aldao, A., Wisco, B. E., \& Hilt, L. M. (2014). Rumination as a transdiagnostic factor underlying transitions between internalizing symptoms and aggressive behavior in early adolescents. Journal of Abnormal Psychology, 123, 13-23. doi: 10.1037/a0035358.

Mischel, W. (1973). Toward a cognitive social learning reconceptualization of personality. Psychological Review, 80, 252-283.

Novaco, R. W. (1975). Anger control: The development and evaluation of an experimental treatment. Lexington: Heath.

Patton, J. H., Stanford, M. S., \& Barratt, E. S. (1995). Factor structure of the Barratt Impulsiveness Scale. Journal of Clinical Psychology, 51, 768-774. doi: 10.1002/1097-4679(199511)

Pedersen, L., Kunz, C., Rasmussen, K., \& Elsass, P. (2010). Psychopathy as a risk factor for violent recidivism: Investigating the Psychopathy Checklist Screening Version (PCL: SV) and the Comprehensive 
Assessment of Psychopathic Personality (CAPP) in a forensic psychiatric setting. International Journal of Forensic Mental Health, 9, 308-315. doi: 10.1080/14999013.2010.526681

Perach-Barzilay, N., Tauber, A., Klein, E., Chistyakov, A., Ne'eman, R., \& Shamay-Tsoory, S. G. (2013). Asymmetry in the dorsolateral prefrontal cortex and aggressive behavior: a continuous theta-burst magnetic stimulation study. Social Neuroscience, 8, 178-188. doi: 10.1080/17470919.2012.720602

Phelps, E. A., Delgado, M. R., Nearing, K. I., \& LeDoux, J. E. (2004). Extinction learning in humans: role of the amygdala and vmPFC. Neuron, 43, 897-905. doi: 10.1016/j.neuron.2004.08.042

Raine, A. (2002). The biological basis of crime. In J. Q. Wilson and J. Petrsilia (Eds.), Crime: Public policies for crime control (pp. 43- 74). Oakland, California: ICS Press.

Raine, A., Dodge, K., Loeber, R., Gatzke-Kopp, L., Lynam, D., Reynolds, C., Stouthamer-Loeber, M., \& Liu, J. (2006). The Reactive-Proactive Aggression Questionnaire: Differential correlates of reactive and proactive aggression in adolescent boys. Aggressive Behavior, 32, 159-171. doi: 10.1002/ab.20115

Raine, A., \& Yang, Y. (2006). Neural foundations to moral reasoning and antisocial behavior. Social Cognitive and Affective Neuroscience, 1, 203-213. doi: 10.1093/scan/nsI033

Rachlin, H. (1974). Self-control. Behaviorism, 4, 64-107.

Ramírez, J. M., Millana, L., Toldos-Romero, M. P., Bonniot-Cabanac, M.-C., \& Cabanac, M. (2009). The pleasure of being aggressive in incarcerated criminals. The Open Criminology Journal, 2, 1-9. doi: 10.2174/1874917800902010001

Ray, R. D., Ochsner, K. N., Cooper, J. C., Robertson, E. R., Gabrieli, J. D., \& Gross, J. J. (2005). Individual differences in trait rumination and the neural systems supporting cognitive reappraisal. Cognitive, Affective, \& Behavioral Neuroscience, 5, 156-168. doi: 10.3758/CABN.5.2.156

Reynolds, B., Penfold, R. B., \& Patak, M. (2008). Dimensions of impulsive behavior in adolescents: Laboratory behavioral assessments. Experimental and Clinical Psychopharmacology, 16, 124-131. doi: 10.1037/1064-1297.16.2.124

Reynolds, B., Richards, J. B., \& de Wit, H. (2006). Acute-alcohol effects on the Experiential Discounting Task (EDT) and a question-based measure of delay discounting. Pharmacology, Biochemistry and Behavior, 83, 194-202. doi: 10.1016/j.pbb.2006.01.007

Riva, P., Lauro, L. J. R., DeWall, C. N., Chester, D. S., \& Bushman, B. J. (2014). Reducing aggressive responses to social exclusion using transcranial direct current stimulation (tDCS). Social Cognitive and Affective Neuroscience, nsu053. doi:10.1093/scan/nsu053

Roesch, R. \& Cook, A. N. (2017). Handbook of Forensic Mental Health Services. New York: Taylor \& Francis Ltd. Röll, J., Koglin, U., \& Petermann, F. (2012). Emotion regulation and childhood aggression: Longitudinal associations. Child Psychiatry \& Human Development, 43, 909-923. doi: 10.1007/s10578-012-0303-4 de Ruiter, C., \& Hildebrand, M. (1999). Behandelingsstrategieën bij Forensich-psychiatrische patiënten. [Treatment strategies with forensic psychiatric patients]. Bohn Stafleu van Loghum: Houten.

Séguin, J. R. (2013). The frontal lobe and aggression. European Journal of Developmental Psychology, 6 , 100-119. doi: 10.1080/17405620701669871

Schlaepfer, T. E., George, M. S., \& Mayberg, H. (2010). WFSBP guidelines on brain stimulation treatments in psychiatry. The World Journal of Biological Psychiatry,11, 2-18. doi: 10.3109/15622970903170835 
Siever, L. J. (2008). Neurobiology of Aggression and Violence. American Journal of Psychiatry, 165, 429-442. doi: 10.1176/appi.ajp.2008.07111774

Skripkauskaite, S., Hawk, S. T., Branje, S. J., Koot, H. M., van Lier, P. A., \& Meeus, W. (2015). Reactive and proactive aggression: Differential links with emotion regulation difficulties, maternal criticism in adolescence. Aggressive Behavior, 41, 214-226. doi: 10.1002/ab.21583

Smeets, K. C., Leeijen, A. A. M., van der Molen, M. J., Scheepers, F. E., Buitelaar, J. K., \& Rommelse, N. N. J. (2015). Treatment moderators of cognitive behavior therapy to reduce aggressive behavior: a meta-analysis. European Child and Adolescent Psychiatry, 24, 255-264. doi: 10.1007/s00787-014-0592-1

Smith, S. D., Stephens, H. F., Repper, K., \& Kistner, J. A. (2016). The Relationship between Anger Rumination and Aggression in Typically Developing Children and High-Risk Adolescents. Journal of Psychopathology and Behavioral Assessment, 38,1-13. doi:10.1007/s10862-016-9542-1

Smith, P., \& Waterman, M. (2003.) Processing bias for aggression words in forensic and non-forensic samples. Cognition and Emotion, 17, 681-701. doi: 10.1080/02699930302281

Staniloiu, A., \& Markowitsch, H. (2012). Gender differences in violence and aggression-a neurobiological perspective. Procedia-Social and Behavioral Sciences, 33, 1032-1036. doi:10.1016/j.sbspro.2012.01.279

Sutherland, E. H. (1939). Principles of criminology, 3rd Ed., Philadelphia: J.B. Lippincott.

Swann, A. C. \& Hollander, E. (2002). Impulsivity and Aggression: Diagnostic Challenges for the Clinician. A Monograph for Continuing Medical Education Credit. Illinois: ACCESS Medical Group.

Tedeschi, J. T., \& Felson, R. B. (1994.). Violence, Aggression, \& Coercive Actions. Washington: APA.

Tiihonen, J., Rautiainen, M. R., Ollila, H. M., Repo-Tiihonen, E., Virkkunen, M., Palotie, A., ... \& Saarela, J. (2015). Genetic background of extreme violent behavior. Molecular Psychiatry, 20, 786-792. doi: $10.1038 / \mathrm{mp} .2014 .130$

Tomkins, S. S. (1954). Script theory: Differential magnification of affects. Fourteenth International Congress of Psychology. Montreal: Canada.

Young, J. L., \& Hillbrand, M. (1994). Carbamazepine Lowers. Aggression: A Review. Bulletin of the American Academy of Psychiatry and the Law, 22, 53-61.

Vaske, J., Galyean, K., \& Cullen, F. T. (2011). Toward a biosocial theory of offender rehabilitation: Why does cognitive-behavioral therapy work? Journal of Criminal Justice, 39, 90-102. doi: 10.1016/j.jcrimjus.2010.12.006

Vasquez, E. A., Bartsch, V. O., Pedersen, W. C., \& Miller, N. (2007). The impact of aggressive priming, rumination, and frustration on prison sentencing. Aggressive Behavior, 33, 477-485. doi: 10.1002/ab.20203

Vitaro, F., Brendgen, M., \& Barker, E. D. (2006). Subtypes of aggressive behaviors: a developmental perspective. International Journal of Behavioural Development, 30, 12-19. doi: 10.1177/0165025406059968

Volman, I., von Borries, A. K. L., Bulten, B. H., Verkes, R. J., Toni, I., \& Roelofs, K. (2016). Testosterone modulates altered prefrontal control of emotional actions in psychopathic offenders. eneuro, 3 , ENEURO-0107. doi: 10.1523/ENEURO.0107-15.2016

Wagner, D. D., Altman, M., Boswell, R. G., Kelley, W. M., \& Heatherton, T. F. (2013). Self-regulatory depletion enhances neural responses to rewards and impairs top-down control. Psychological Science, 24, 2262-2271. doi: 10.1177/0956797613492985 
Werner, N. S., Kühnel, S., \& Markowitsch, H. J. (2013). The neuroscience of face processing and identification in eyewitnesses and offenders. Frontiers in Behavioral Neuroscience, 7, 189. doi: 10.3389/fnbeh.2013.00189 Wener, R. E. (2012). The Psychology of Isolation in Prison Settings. In The Environmental Psychology of Prisons and Jails: Creating Humane Spaces in Secure Settings (Environment and Behavior). Cambridge: Cambridge University Press. doi:10.1017/CBO9780511979682.012

Wesselius, J. (2013). Het Penitentiair Psychiatrisch Centrum: een volwaardige psychiatrische kliniek in de gevangenis? [The Penitentiary Psychiatric Centre:a full-fledged psychiatric clinic within the prison? ]. Ontmoetingen: Voordrachtenreeks van het Lutje Psychiatrisch-Juridisch Gezelschap, 17, 9-20.

Whiteside, S. P., \& Lynam, D. R. (2001). The Five Factor Model and impulsivity: Using a structural model of personality to understand impulsivity. Personality and Individual Differences, 30, 669-689. doi: 10.1016/S0191-8869(00)00064-7

Wilson, L. C., \& Scarpa, A. (2011). The link between sensation seeking and aggression: a meta-analytic review. Aggressive Behavior, 37, 81-90. doi: 10.1002/ab.20369.

Zaalberg, A., Nijman, H., Bulten, E., Stroosma, L., \& van der Staak, C. (2010). Effects of

Nutritional Supplements on Aggression, Rule-Breaking, and Psychopathology Among Young Adult Prisoners. Aggressive Behavior, 36, 117-126. doi: 10.1002/ab.20335

Zaman, R. (2014). Role of Transcranial magnetic stimulation (TMS \& rTMS) in investigation and possible treatment of impulsivity in neuropsychiatric disorders with ADHD and BPD as examples. Psychiatria Danubina, 26, Suppl. 1, pp 347-350.

Zuckerman, M. Kolin, E. A., Price, L., \& Zoos, I. (1964). Development of a Sensation-Seeking Scale. Journal of Consulting Psychology, 28, 477-482. doi: 10.1037/h0040995 


\section{Valorization Addendum}

In this dissertation we aimed firstly to provide conceptual clarification about the main concepts of interest, namely (reactive) aggression and impulsivity. Secondly, we aimed to unravel the neurocognitive and vulnerability factors of aggression and impulsivity in a forensic population. Therefore, in this dissertation we start with definitions, assessment models and suggestions for interventions regarding aggression and impulsivity. Followed by neurocognitive findings from neurological, behavioral and brain imaging tests of provoked reactive aggression. The theoretical and practical implications of our findings were described in the various chapters throughout this thesis. In this valorization addendum we discuss the societal value of the research methods and findings of the present thesis.

\section{Societal and economic relevance}

In the Netherlands, as in the rest of Europe, 3\% of all global burden of disease (GBD) (or cause-specific mortality, Wang et al., 2016) is a result of injury by violence or aggression. The cost of injury due to aggression has been estimated up to $€ 30$ million yearly in medical costs and $€ 66$ million in absenteeism costs because of an injury by violence (Snijders et al., 2016). In the case of forensic offender samples as recruited in the dissertation research, the prevalence of maladaptive aggression tends to be specifically high (Connor, 2002), as is the proneness towards aggression (Smith \& Waterman, 2003). Also, the prevalence of pathological impulsivity is extremely high in forensic offenders (up to 88\%; Bjørkly, 2006). In the literature the definitions and conceptualizations of both reactive aggression and impulsivity do overlap (García-Forero et al., 2009), but research indicates that impulsivity is a key risk factor for (reactive) aggressive behavior (Pratt \& Cullen, 2000; Vazsonyi \& Belliston, 2007) and violent crime (Scarpa \& Raine, 2000). Subsequently, more insight in uniform conceptualizations and possible vulnerability factors for reactive aggression is of particular importance for understanding and treating forensic offender samples. At the very least, the types of aggressive acts that are assumed to be related to impulsivity vary greatly. For instance, impulsivity might be involved in acting out sexual drive (in various sexual disorders), compulsive drive (e.g., in kleptomania), or explosive anger outbursts (in intermittent explosive disorder; American Psychiatric Association (APA), 2013). Furthermore, it is questionable whether all variances of impulsive behavior require the same risk management strategy in preventing recidivism (Byrne \& Roberts, 2007; Douglas et al., 2014).

In essence, in order to get a better understanding about the concepts of impulsivity and aggression, it is essential to disentangle the different concepts and definitions (García-Forero et al., 2009). This is especially important in relation to forensic offender populations, since these different facets of impulsivity all relate to various forms of psychopathology (Fields et al., 2015) 
and (violent) recidivism risk, but not necessarily through the same process. Moreover, they might have a different cause. In chapter 4 we describe of the role of different impulsivity dimensions as possible vulnerability factors for aggression in forensic patients. In the following chapters we focus on aggression, anger provocation and anger regulation in a violent population. And the general discussion of this thesis gives a more detailed description of the theoretical, clinical, and research implications of our findings and provides directions for future research.

\section{Target groups}

First, the results are relevant for forensic offenders and their relatives because research results might give them more insight into the mechanisms of (reactive) aggression and impulsivity usable in reflective regulation of anger, reducing aggressive responses. Second, the results of this thesis are relevant for forensic health care professionals by providing new insights for effective treatment. Third, the current results are of interest for researchers in the field of forensic practice, impulsivity and aggression to verify and refine theoretical models. And fourth, we hope that the results of this thesis ultimately help society to lower the (social) costs of injury by violence or aggression.

\section{Approach}

The design of the studies described in this thesis have been evaluated as PhD research proposal for the Experimental Psychopathology (EPP) research school, as a project proposal for the ethical commission of Maastricht University, as a project proposal for the scanner lab Brains Unlimited scanner staff, and discussed with forensic health care professionals. For instance the design of different behavioural measurements of impulsivity has been subject of discussion with the psychomotor therapists.

During the execution of this dissertation research, various assessment methods have been tested. For example, the development of the multidimensional impulsivity construct started with brainstorm sessions within the forensic clinic searching for various assessment measures of all impulsivity dimensions. This resulted in new, non-consensus assessment methods as jumping mattresses measuring risk taking and self-control. However, scoring results of these methods as well as some known assessments as the lowa Gambling task indicated unreliable results for a substantial part of the subject sample. Consequently, (and unfortunately) these methods were not included within the final impulsivity model analyses.

\section{Activities and service}

As already noted, in this thesis we aim to provide conceptual clarification about (reactive) aggression and impulsivity and to unravel the neurocognitive and vulnerability factors of aggression and impulsivity in a forensic population. Therefore, a clarification of the different definitions is provided within chapter $\mathbf{1}$ of this dissertation, assessment models (see chapter

$\mathbf{2}$ and chapter $\mathbf{3}$ for more detailed information) and suggestions for more effective treatment interventions regarding aggression and aggression regulation. 
More specific, in chapter $\mathbf{2}$ we describe a multidimensional model of impulsivity and the predictive validity of distinct impulsivity dimensions for psychopathology. With impulsivity as a crucial target for diagnosis and interventions, a combination of past research results combined with the current results led to the preference of a four-dimensional model of impulsivity resulting in the following dimensions: impulsive decision making (reflecting acting without thinking and nonplanning), sensation seeking (reflecting a risk appetite and venturesomeness), (inadequate) response inhibition (reflecting response inhibition dysfunction), and sustained attention (reflecting perseverance). The current results signal the importance to consider impulsivity as a multidimensional construct for clinical practice.

Moreover, our results show differences in provocation sensitivity between forensic psychiatric offenders and penitentiary offenders. While forensic psychiatric offenders showed significant more anger response statements while provoked with angers stories (ATSS; Davison, Robins, \& Johnson, 1983, see chapter 3 for more detailed information), penitentiary offenders showed significant more reactive aggression provoked by a Body Opponent Bag (BOB) with harassing feedback. Consequently, future research should carefully select provocation paradigms proven to be effective in a violent offender subsample with equal characteristics. In the forensic psychiatric offenders provocation response was related to automatic cognitive biases towards anger and psychopathy. In the penitentiary group provocation response was related to aggressive behavioral intentions, anger control problems, and self-reported aggression. Consequently, it would be informative to investigate which automatic cognitive biases towards anger relate to recidivism risk within forensic offenders with psychopathic characteristics. Further, these specific angers stories could be utilized as a supplemented assessment tool exploring cognitive biases towards anger, subsequently providing input for treatment.

In addition, the current results in chapter $\mathbf{3}$ showed that venting anger is effective in reducing aggression, at least in the forensic psychiatric offenders. However, following results of chapter $\mathbf{5}$ and $\mathbf{6}$ regarding fMRI research on anger provocation and regulation, showed regulation difficulties in violent (forensic psychiatric) offenders, with an increased initiation to (implicitly) regulate during anger provocation. The constant effort required for violent offenders to regulate anger might exhaust the necessary cognitive resources, resulting in a risk for self-control failure. Therefore, venting anger in a controlled setting like during psychomotor therapy could be helpful for the forensic psychiatric group reducing aggressive feelings and behaviors, preventing cognitive exhaustion when provoked.

\section{Innovation}

In this dissertation we aimed to investigated whether (forensic psychiatric) offenders do show different brain responses during emotion provocation. Therefore, we examined differences within brain responses between violent offenders and matched healthy controls during emotion provocation using fMRI technique. The assessment methods included not only self-reports but also behavioral measurements, and different innovative emotion provocation 
paradigms that have been adapted for fMRI usage measuring brain responses. This is innovative because previous cognitive research using brain imaging techniques focused on frustration, punishment (Dambacher et al., 2015; Emmerling et al., 2015) or perceived threat as a trigger of anger or aggression (Blair, 2012), emotion research has focused on the recognition of anger as an indicator for dysfunctions in anger experience and perception (Kret \& de Gelder, 2013; Lindquist, Wager, Kober, Bliss-Moreau, \& Barrett, 2012), with deficits in emotion recognition ultimately leading to aggressive and violent behaviour (Howells et al., 2002). In other words, earlier studies using fMRI in violent offenders focused on the recognition of anger (e.g. perception of emotional pictures) (Bueso-Izquierdo et al., 2016; Werner, Kühnel \& Markowitsch, 2013) and automatic action tendency responses (avoid anger and approach happy) to facial expressions (Volman et al., 2016). Up until now no fMRI study actually investigated anger provocation and anger regulation within a group of violent offenders exhibiting anger problems and compared them to non-offender controls.

Finally, the current thesis is the first to investigate actual brain response differences in emotion (anger and happy) provocation compared to regulation within a group of violent offenders exhibiting anger problems and compared them to non-offender controls (chapter

6). To understand the mechanism underlying the regulation of aggressive behavior the present thesis is unique in examining anger expression in both violent offenders and non-offender controls during provocation as well as regulation. Therefore, the results in chapter $\mathbf{6}$ provide new insights for the development of effective treatment interventions for reactive aggression.

\section{Knowledge dissemination and communication}

Transfer of the practical skills needed for the process of conducting the studies (e.g., impulsivity measures, clinical semi-structured interviews based on the Diagnostic and Statistical Manual) has taken place via teaching (i.e., internships). The outcomes of the studies have been and will be communicated within scientific community by international peer-reviewed journal publications and national and international conferences. The outcome of each study described in this thesis has been presented to participants and staff of the Forensic Psychiatric Center (FPC) and the Penitentiary Psychiatric Centre (PPC) in separate meetings followed by discussions on the impact of the results for clinical practice. Further, communications outside the scientific field have been published in the (local) media. 


\section{References}

American Psychiatric Association (APA). (2013). Diagnostic and statistical manual of mental disorders (5th ed.). Arlington, VA: American Psychiatric Publishing. doi:10.1176/appi.books.9780890423349

Bjørkly, S. (2006). Empirical evidence of a relationship between insight and risk of violence in the mentally ill - A review of the literature. Aggression and Violent Behavior, 11, 414-423. doi:10.1016/j.avb.2006.01. 006

Byrne, J. M., \& Roberts, A. R. (2007). New directions in offender typology design, development, and implementation: Can we balance risk, treatment and control? Aggression and Violent Behavior, 12, 483-492. doi: 10.1016/j.avb.2007.02.009

Connor, D. F. (2002). Aggression and Antisocial Behavior in Children and Adolescents. New York: The Guilford Press.

Fields, S., Edens, J. F., Smith, S. T., Rulseh, A., Donnellan, M. B., Ruiz, M. A., McDermott, B. E., \& Douglas, K. S. (2015). Examining the psychometric properties of the Barratt Impulsiveness Scale-Brief Form in justice-involved samples. Psychological Assessment, 27, 1211-1218. doi: 10.1037/a0039109

García-Forero, C., Gallardo-Pujol, D., Maydeu-Olivares, A., \& Andrés-Pueyo, A. (2009). Disentangling impulsiveness, aggressiveness and impulsive aggression: an empirical approach using self-report measures. Psychiatry Research, 168, 40-49. doi: 10.1016/j.psychres.2008.04.002

Pratt, T. C., \& Cullen, F. T. (2000). The empirical status of Gottfredsons and Hirschi's General Theory of Crime: A meta analysis. Criminology, 38, 931-964. doi: 10.1111/j.1745-9125.2000.tb00911.x

Scarpa, A., \& Raine, A. (2000). Violence associated with anger and impulsivity. In J. C. Borod (Eds.), The neuropsychology of emotion: series in affective science (pp. 320-339). New York: Oxford University Press.

Smith, P., \& Waterman, M. (2003.) Processing bias for aggression words in forensic and non-forensic samples. Cognition and Emotion, 17, 681-701. doi: 10.1080/02699930302281

Snijders, B. E. P., Gommer, A. M., Haagsma, J. A., Panneman, M. J., Polinder, S., van Beeck, M-C. E. F. (2016). Ziektelast en kosten van letsel door geweld. RIVM Rapport 2015-0179, Rijksinstituut voor Volksgezondheid en Milieu (RIVM): Bilthoven. http://www.rivm.nl/bibliotheek/rapporten/2015-0179.pdf Vazsonyi, A. T. \& Belliston, L. M. (2007). The family> low self-control > deviance: A Cross-Cultural and Cross-National Test of Self-Control Theory. Criminal Justice and Behavior, 34, 505-530. doi: 10.1177/0093854806292299

Wang, H., Naghavi, M., Allen, C. ... et al. (2016). Global, regional, and national life expectancy, all-cause mortality, and cause-specific mortality for 249 causes of death, 1980-2015: a systematic analysis for the Global Burden of Disease Study 2015. The Lancet, 388, No. 10053. Published Online: October 08, 2016. doi: 10.1016/S0140-6736(16)31012-1 


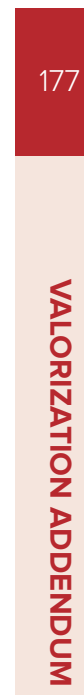




\section{Nederlandse samenvatting (outch summan)}

Het belangrijkste doel van het onderzoek beschreven in dit proefschrift is tweeledig. Het eerste doel is het geven van een verheldering van de voor dit proefschrift belangrijkste concepten, namelijk (reactieve) agressie en impulsiviteit (Deel 1, García-Forero, Gallardo-Pujol, Maydeu-Olivares en Andrés-Pueyo, 2009). Vervolgens beogen we in dit proefschrift de neurocognitieve correlaten en de mogelijke risicofactoren te ontrafelen die zorgen voor een grotere kwetsbaarheid ten aanzien van zowel agressie als impulsiviteit in een forensische populatie (Deel 2). In het eerste deel van het proefschrift streven we ernaar om definities te presenteren van, en concrete modellen voor de forensische praktijk ten aanzien van de belangrijkste concepten, namelijk (reactieve) agressie en impulsiviteit. Daarom begint het onderzoek beschreven in dit proefschrift met het formuleren van definities, het schetsen van modellen en geeft het suggesties voor interventies gericht op (reactieve) agressie en impulsiviteit (hoofdstukken 1 en 2). In het tweede deel van het proefschrift worden paradigma's die woede provoceren en tot reactieve agressie kunnen leiden gepresenteerd (Blair, 2012). Om de effectiviteit van deze paradigma's die woede provoceren bij een populatie van gewelddadige delinquenten vast te kunnen stellen, is het noodzakelijk om deze provocatieve paradigma's in een gecontroleerde omgeving te kunnen onderzoeken (hoofdstuk 3). Het proefschrift vervolgt met een studie naar de mogelijke risicofactoren die zorgen voor een grotere kwetsbaarheid ten aanzien van reactieve agressie en impulsiviteit in een forensische populatie (hoofdstukken 4, 5 en 6). Deze samenvatting beschrijft de belangrijkste bevindingen en de algemene conclusie van de onderzoeken aan de basis van dit proefschrift. In het proefschrift zelf wordt de samenvatting gevolgd door een algemene discussie inclusief beperkingen en suggesties voor toekomstig onderzoek.

\section{Deel 1: Conceptuele verheldering ten aanzien van (reactieve) agressie en impulsiviteit}

In hoofdstuk 1 van het voorliggende proefschrift wordt agressie gedefinieerd als 'vijandig, schadelijk of destructief gedrag' (Siever, 2008, blz. 429). Agressie wordt vaak onderverdeeld in reactieve en proactieve agressie. Reactieve agressie verwijst naar spontane en emotionele reacties op bedreigingen of provocaties (Cima \& Raine, 2009), terwijl proactieve agressie duidt op geplande, doelgerichte agressie (Raine et al., 2006). Het eerste hoofdstuk beschrijft de verschillende historische theorieën, de ontwikkelingstheorieën (Berkowitz, 1989; Lorenz, 1974; Freud, 1955); sociale theorieën (Bandura 1983; Becker 1963; Sutherland 1939; Tedeschi \& Felson 1994; Tomkins, 1954) en biologische theorieën (bijv. Hawkins \& Trobst, 2000; Séguin, 2013; Swann \& Hollander, 2002) over de etiologie van agressie. Recent is de aandacht verplaatst van specifieke, domeingerichte theorieën naar integrale modellen van agressie. Voorbeelden 
van integrale modellen van agressie zijn het door Belsky beschreven perspectief van differentiële kwetsbaarheid ('differential susceptibility perspective', Belsky, 2005), de algemene theorie van criminaliteit (Gottfredson \& Hirschi, 1990), en het Generiek Agressie Model (GAM, Anderson \& Bushman, 2002). Samenvattend kan gezegd worden dat waar eerdere theorieën agressie als een instinctief, aangeboren proces verklaarden, de recentere theorieën agressie beschrijven vanuit een sociaal ontwikkelingsperspectief, waarin sommige individuen een biologische predispositie tot agressie kunnen hebben, wat ze meer kwetsbaar maakt om onder bepaalde omstandigheden en/of omgevingsfactoren agressief te reageren.(Raine, 2002; Tiihonen et al., 2015).

Hoofdstuk 2 richt zich op impulsiviteit, wat in dit proefschrift gedefinieerd is als 'gedrag zonder adequate beschouwing vooraf, de neiging om minder doordacht en sneller dan gemiddeld te handelen, of een aanleg naar snelle, ongeplande reacties op stimuli zonder inachtneming van de negatieve gevolgen van deze reacties' (International Society for Research on Impulsivity). Impulsiviteit is echter niet enkel kenmerkend als disfunctioneel gedrag met negatieve gevolgen, maar kan ook functioneel zijn (Dickman, 1990). Functionele impulsiviteit is bijvoorbeeld de mogelijkheid om een strategie van effectieve conflictoplossing snel toe te passen in een conflicterende situatie, ter voorkoming van escalatie (Pitts \& Leventhal, 2012). Toch blijkt dat de prevalentie van juist de pathologische impulsiviteit in forensische populaties extreem hoog is (tot 88\%, Bjørkly, 2006).

In het tweede hoofdstuk presenteren we een 3-dimensionaal model van impulsiviteit, getest binnen een forensische populatie. Dit 3-dimensionaal model van impulsiviteit is gebaseerd op zowel zelfrapportage (BIS-11, Patton, Stanford, \& Barratt, 1995; SSS, Zuckerman, Kolin, Price \& Zoos, 1964; 17, Eysenck, Pearson, Easting, \& Allsopp, 1985) als gedragsinstrumenten (GoStop, Dougherty, Mathias, Marsh \& Jagar, 2005; BART, Lejuez et al., 2002). Alle drie de impulsiviteitsdimensies in het model hangen samen met agressief gedrag (Denny \& Siemer, 2012; Lynam \& Miller, 2004; Ramírez, Millana, Toldos-Romero, Bonniot-Cabanac, \& Cabanac, 2009; Wilson, \& Scarpa, 2011). De eerste dimensie, door ons genaamd 'Impulsieve Besluitvorming', weerspiegelt het handelen zonder te denken aan de gevolgen (Field, 1986) en wordt gedefinieerd als het onvermogen om directe behoeftebevrediging uit te stellen (Rachlin, 1974; Reynolds, Richards \& de Wit, 2006) en de neiging tot spontaan gedrag, rusteloosheid en ongeduld (Field, 1986). De tweede dimensie, door ons genaamd 'Sensatiezucht', refereert naar risicobereidheid en is gerelateerd aan risicogedrag en agressief, maar niet noodzakelijkerwijs crimineel gedrag (Eysenck et al., 1985). De derde dimensie, door ons genaamd '(inadequate) Responses Inhibitie', weerspiegelt het onvermogen tot het inhiberen van een reactie en ongeremd sociaal gedrag. Tussen de drie impulsiviteitsdimenties werd geen relatie gevonden, want duidt op drie afzonderlijke dimensies. De resultaten van deze studie onderstrepen het belang om impulsiviteit als een multidimensionale construct te beschouwen.

Verder beschrijt dit hoofdstuk de voorspellende waarde, oftewel de validiteit van het voorgestelde 3-dimensionaal impulsiviteitsmodel ten aanzien van psychopathologie. Resultaten toonden aan dat de dimensie impulsieve bes/uitvorming een voorspeller is voor 
(een geschiedenis van) drugsafhankelijkheid, voor de impulsieve levensstijl facet van psychopathie en voor de antisociale persoonlijkheidsstoornis. Er werd geen voorspellende waarde gevonden voor de impulsiviteitsdimensie sensatiezucht richting enige psychopathologie. De dimensie (inadequate) Responses Inhibitie was een voorspeller voor (een geschiedenis van) drugsafhankelijkheid, voor (facetten van) psychopathie en voor de antisociale persoonlijkheidsstoornis. Gezien het belang van het concept impulsiviteit in de forensische risico inschatting (Bailey \& Dolan, 2004; Browne, Beech, Craig, \& Chou, 2017; Hare, 2003; Roesch \& Cook, 2017), is de praktische implicatie van deze resultaten vooral te vertalen in individuele multidimensionale impulsiviteitsprofielen voor risicobeheersplannen ter voorkoming van gewelddadige recidive.

\section{Deel 2: Neurocognitieve kwetsbaarheidsfactoren voor geprovoceerde reactieve agressie}

Om de onderliggende processen van reactieve agressie te kunnen onderzoeken, is in het tweede deel van dit proefschrift, in hoofdstuk 3, woede geprovoceerd en onderzocht of het uitageren op, of ventileren van woede daadwerkelijk agressie kan verminderen (Bennett, 1991; Gentile, 2013; Leslie, 2008), of juist zorgt voor meer reactieve agressie (Bushman, 2002; Zillmann, 1983). Om het provoceren van woede op een gecontroleerde manier te bewerkstelligen hebben we gebruik gemaakt van twee verschillende paradigma's voor woedeprovocatie: het ATSS ('articulated thoughts under simulated situations', ofwel het uitspreken van de gedachtes tijdens een gesimuleerde situatieschets) paradigma met woedeverhalen en een bokspop BOB ('body opponent punching bag') die beledigende feedback geeft als je iemand slaat. Deze paradigmata zijn getest in een populatie van gewelddadige delinquenten. We provoceren woede, omdat de emotionele oorzaak van agressie vaak woede is (Averill, 1983). De gewelddadige daders zijn geworven in een forensisch psychiatrisch centrum (FPC, ofwel een tbs-kliniek) en een psychiatrisch penitentiair centrum (PPC, een zorgafdeling in de gevangenis). De ATSS is een cognitief instrument dat de gedachten en overtuigingen als reactie op een specifiek beschreven situatieschets bepaalt.

In dit proefschrift (hoofdstukken 3, 4 en 6) zijn blije, neutrale en woedesituaties gepresenteerd. Alle reacties zijn gescoord met behulp van de handleiding voor ATSS-scoring (Eckhardt \& Jamison, 2002). Naast ATSS werd BOB met beledigende feedback ingezet als woede-provocatie. Deelnemers werd gevraagd om BOB te slaan, maar na de eerste klap werd tot acht keer toe beledigende feedback gegeven door BOB. De bokshandschoenen waarmee $\mathrm{BOB}$ is geslagen, bevatten krachtsensoren waarmee de kracht van de boksstoten is gemeten. De gemiddelde kracht na de laatste feedback is gebruikt als de meting van reactieve agressie. Om na te gaan of het ventileren van woede-agressie kan verminderen of juist zorgt voor meer reactieve agressie, werd het (impliciete) woede- en agressieniveau zowel vooraf als na de provocatie gemeten. De resultaten laten zien dat het ventileren van woede effectief is in het verminderen van agressie bij forensische psychiatrische delinquenten (FPC), maar laten een gemengd resultaat zien in de gevangenispopulatie (PPC). Forensische psychiatrische delinquenten laten een vermindering zien van de door henzelf vermelde 
agressie na beide provocatieparadigma's. De gevangenispopulatie laat een toename zien van de zelfgerapporteerde agressie nà de provocatie van ATSS, de cognitief gerichte provocatie waarin gedachten en overtuigingen met betrekking tot agressie worden gemeten. De resultaten van de gevangenispopulatie komen overeen met eerder onderzoek dat zeer hoge percentages woede ruminatie toont bij gevangenispopulaties (Bullock, 2010; Vasquez, Bartsch, Pedersen \& Miller, 2007; Wener, 2012), iets wat dan weer resulteert in geïntensiveerde woede (Lievaart, Huijding, van der Veen, Hovens \& Franken, 2017). Wat BOB betreft, in het meer fysiek of gedragsgerichte provocatieparadigma, is er in beide populaties geen toename noch een vermindering van agressie gevonden.

Verder blijkt uit de resultaten dat de groepen verschillen in reacties op de provocaties. Daar waar de forensische psychiatrische groep aanzienlijk meer woede laat zien in relatie tot de ATSS- provocatie, toont de penitentiaire groep aanzienlijk meer reactieve agressie tijdens de BOB-provocatie. Het verschil in gevoeligheid in de groepen ten aanzien van de provocatieparadigma`s kunnen ook wijzen op externe validiteitsproblemen, waarbij de woedeprovocaties enkel effectief zijn in heel specifieke (gewelddadige) populaties. Bovendien is het ook mogelijk dat de residentiële context (het type verblijf met bijpassende regelgeving, de verblijfsduur en het niveau van therapeutische interventies) de resultaten heeft beïnvloed.

Aanvullend werd in het onderzoek beschreven in dit hoofdstuk de relatie gemeten tussen de reactie op de woedeprovocatie, (zelf-gerapporteerde) de agressie, en het recidive-risico (met psychopathie als risicofactor voor gewelddadig recidivisme, Harris, Boccaccini \& Rice, 2017; Pedersen, Kunz, Rasmussen , \& Elsass, 2010). De resultaten tonen een relatie tussen de ATSS-dimensie, genaamd 'automatische cognitieve vooroordelen ('biases') ten aanzien van woede' en psychopathie binnen de forensische psychiatrische groep. In de penitentiaire groep is er een relatie tussen de ATSS-dimensie, genaamd 'agressieve gedragsintenties' en zelf-gerapporteerde (reactieve) agressie gevonden. Zowel de 'automatische cognitieve vooroordelen ten aanzien van woede' als psychopathie hebben in eerder onderzoek ook een sterke relatie getoond met gewelddadige recidive (Dolan \& Doyle, 2000; Douglas et al., 2014). Mogelijk kan de aanwezigheid van automatische cognitieve vooroordelen ten aanzien van woede in een forensische psychiatrische populatie en bij patiënten met psychopathische eigenschappen in het bijzonder, worden geïdentificeerd met behulp van het ATSS-paradigma. Aanvullend kan het ATSS-paradigma meer gedetailleerde informatie verstrekken over de aard van deze vooroordelen, waardoor inzichten worden verkregen die bruikbaar zijn voor de therapeutische behandeling.

Uit empirisch bewijs blijkt dat reactieve agressie niet alleen verband houdt met impulsiviteit (Chan \& Chui, 2012), maar ook met problemen in het executief functioneren (Baker \& lerland, 2007). Daarom wordt in hoofdstuk 4 van dit proefschrift onderzocht of zowel impulsiviteit als executief functioneren beide simultaan bijdragen aan een verhoogd risico op reactieve agressie. Aangezien de prevalentie van onaangepaste agressie erg hoog blijkt bij patiënten binnen de geestelijke gezondheidszorg (Connor, 2002), evenals de geneigdheid 
tot het uiten van agressie (Smith \& Waterman, 2003), is meer inzicht in de mogelijke kwetsbaarheidsfactoren voor reactieve agressie van bijzonder belang voor de forensische psychiatrische praktijk. Daarom zijn de onderzoeken in deze dissertatie gericht op reactieve agressie, gemeten met behulp van zelfrapportage en BOB, binnen een populatie van mannelijke forensisch psychiatrische patiënten.

Het concept van executief functioneren is op verschillende manieren gedefinieerd en gemeten (Elliot, 2013). Daarnaast is het concept van executief functioneren, net als het concept impulsiviteit te concipiëren in drie verschillende componenten, namelijk werkgeheugen, verdeelde aandacht en flexibiliteit. Afwijkingen of tekortkomingen binnen deze drie specifieke componenten zijn gerelateerd aan verhoogd agressief gedrag (De Brito, Viding, Kumari, Blackwood, \& Hodgins, 2013; Wilson \& Scarpa, 2011). De resultaten in het onderzoek beschreven in dit proefschrift (hoofdstuk 4) tonen geen verband tussen impulsiviteit en executief (dis)functioneren. Dit wijst op twee verschillende, uitzonderlijke kwetsbaarheidsfactoren (impulsiviteit én executief (dys)functioneren) binnen de onderzochte populatie van forensisch psychiatrische patiënten. Verder blijkt dat een combinatie van impulsiviteit (impulsieve bes/uitvorming) en executief (dis)functioneren (het werkgeheugen) reactieve agressie (vanuit zelfrapportage) te voorspellen, terwijl impulsiviteit ((inadequate) responses inhibitie) een betere voorspeller is voor reactief agressief gedrag.

Neurobiologische modellen veronderstellen dat reactieve agressie het gevolg is van disfuncties in de emotieregulatie, veroorzaakt door een onbalans tussen de prefrontale corticale controlegebieden en overmatige signalen vanuit de limbische emotiegebieden, waaronder de amygdala (Blair, 2012; Siever, 2008). De exacte aard van deze onbalans blijft echter onbekend. Daarom worden in hoofdstuk $\mathbf{5}$ de dynamische veranderingen in functionele connectiviteit vanuit de amygdala voor en na een emotieprovocatie onderzocht bij gewelddadige delinquenten en vergeleken met de functionele amygdala connectiviteit van een controlegroep van niet-delinquenten. Tijdens een hersenscan is de hersenactiviteit van de deelnemers in rust gedurende 6 minuten gemeten, zowel voor als na een emotie - (woede en blijdschap) provocatie en regulatietaak. Bovendien werd de deelnemers gevraagd hun emoties aan te geven tijdens deze emotietaak, met behulp van een $100 \mathrm{~mm}$ visuele analoge schaal (VAS, met $0=$ erg blij en 100 = erg boos). Resultaten toonden een significante toename van woede aan tijdens de emotieregulatie in zowel de gewelddadige daders als de controlegroep.

De scanresultaten toonden een significante afname aan amygdala - mediale prefrontale functionele connectiviteit in de gewelddadige dadergroep na de woederegulatie en een toename aan amygdala - mediale prefrontale functionele connectiviteit bij de controlegroep. Het tegenovergestelde patroon werd gevonden voor de amygdala connectiviteit met de (para)limbische gebieden, waaronder de rechter posterior insula, de rechter superior temporale gyrus en de linker uncus/amygdala (hoewel de laatste niet significant was). Binnen deze amygdala - (para)limbische functionele connectiviteit vertoonde de gewelddadige dadergroep een verhoogde connectiviteit, en de controlegroep juist een verminderde 
connectiviteit. Uit de post-hoc simple-effectanalyse bleek dat het grootste verschil tussen beide groepen al aanwezig was voor de experimentele emotietaak, met uitzondering van rechter superior temporale gyrus die enkel groepsverschillen toonde nà de emotieprovocatie. De huidige resultaten laten zien dat agressie kan voortvloeien uit een focus op emotieverwerking bij gewelddadige delinquenten, geïndiceerd door een toename in limbische functionele connectiviteit. De combinatie van een focus op emotie, samen met een gebrek aan regulatie vanuit de mediale prefrontale cortex, kan in potentie oncontroleerbaar worden (en bijvoorbeeld uitgroeien tot reactieve agressie). Hier komt bij dat bij gewelddadige delinquenten een verhoogde connectiviteit gevonden is tussen de amygdala en de superior temporal gyrus na de emotietaak. De superior temporal gyrus is een gebied dat gerelateerd wordt aan ruminatie (Cooney, Joormann, Eugene, Dennis \& Gotlib, 2010; Denson, Pedersen, Friese, Hahm, \& Roberts, 2011). De meeste interventies voor reactieve agressie zijn gericht op het versterken van agressiehantering met de uiteindelijke intentie om geweld te kunnen verminderen. Naar aanleiding van de huidige resultaten (in hoofdstuk 5) wordt voorgesteld om interventies voor reactieve agressie te richten op ruminatie, het aanleren van vaardigheden om agressie te hanteren en adaptieve emotieregulatie.

In hoofdstuk 6 zijn verschillen in hersenactiviteit gemeten tussen geweldsdelinquenten en niet-delinquenten als controlegroep. Tijdens een provocatie- en regulatietaak in de fMRI scanner, werd de deelnemers gevraagd zich in te leven in (provocatie), dan wel af te leiden van (regulatie), de emoties die door deze verhalen worden opgewekt in afwisselend woede, blijde en neutrale verhalen. Eerder onderzoek bij gewelddadige delinquenten suggereert dat een combinatie van verhoogde limbische activiteit gerelateerd aan emotieverwerking, samen met verminderde prefrontale activiteit gerelateerd aan emotieregulatie, geassocieerd wordt met reactieve agressie. De huidige resultaten tonen tijdens de provocatie van woede bij gewelddadige delinquenten meer activiteit in de ventrolaterale prefrontale cortex (VIPFC) en minder activiteit in de posterior cingulate cortex (PCC) en cerebellum in vergelijking met de niet-delinquenten. De resultaten van de emotieregulatie bij de gewelddadige delinquenten tijdens woederegulatie tonen een verminderde activiteit in de PCC, de dorsolaterale prefrontale cortex (dIPFC) en de vIPFC, terwijl de niet-delinquenten een verhoogde activiteit vertoonden in dIPFC en vIPFC. De effecten in de PCC en dIPFC waren echter niet specifiek voor woede, aangezien het patroon van reageren hetzelfde was voor de blijde verhalen. De resultaten tonen een verhoogde behoefte aan regulatie (vIPFC-activiteit) bij gewelddadige daders tijdens de woedeprovocatie, terwijl ze regulatie- problemen vertonen als expliciet gevraagd wordt om te reguleren (te zien in een verminderde activiteit in de dIPFC en de VIPFC tijdens de regulatietaak).

Bovendien werden er enkel groepsverschillen in amygdala- activiteit gevonden, als er getest werd op een meer liberaal niveau van significantie. De resultaten tonen een verminderde activiteit bij gewelddadige daders tijdens woederegulatie in vergelijking met de woedeprovocatie. Dit patroon is te verwachten, maar er zijn geen groepsverschillen gevonden tijdens de provocatie van woede, terwijl de gewelddadige daders juist minder amygdala- activiteit lieten 
zien tijdens de woederegulatie in vergelijking met de van niet-delinquenten. Het initiële gebrek aan differentiële activiteit in de amygdala zou wellicht een gevolg zijn van de specifieke locatie van de amygdala in het brein. De amygdala is gelegen naast met lucht gevulde ruimtes in de hersenen, wat leidt tot een hoge signaal-ruisverhouding en resulteert in nul bevindingen die het gevolg zijn van signaalverlies dan van de afwezigheid van hersenactiviteit (Boubela et al., 2015).

Concluderend wijzen de resultaten op een verhoogde regulatie- behoefte bij gewelddadige delinquenten tijdens de woedeprovocatie en minder tijdens de woederegulatie. En wanneer uitdrukkelijk de instructie wordt gegeven om te reguleren, tonen de resultaten aanwijzingen voor algemene afwijkingen van de emotieregulatie bij gewelddadige daders. De constante inspanning bij gewelddadige delinquenten tot regulatie, in combinatie met een verhoogde aandacht richting agressieve situaties (Lobbestael, Cousijn, Brugman, \& Wiers, 2016) kan tot gevolg hebben dat de cognitieve beheersing die nodig is voor een succesvolle zelfbeheersing faalt (Wagner, Altman, Boswell, Kelley, \& Heatherton, 2013). Uiteindelijk kan deze combinatie leiden tot reactieve agressie bij provocatie. 


\section{Referenties}

Anderson, C. A., \& Bushman, B. J. (2002). Human Aggression. The Annual Review of Psychology, 53, 27-51. http://www.annualreviews.org/doi/pdf/10.1146/annurev.psych.53.100901.135231

Averill, J. R. (1983). Studies on anger and aggression: Implications for theories of emotion. American Psychologist, 38, 1145-1160. doi: 10.1037/0003-066X.38.11.1145

Bailey, S., \& Dolan, M. (2004). Adolescent Forensic Psychiatry. Boca Raton, FL: CRC Press.

Baker, S. F., \& Ireland, J. L. (2007). The link between dyslexic traits, executive functioning, impulsivity and social self-esteem among an offender and non-offender sample. International Journal of Law and Psychiatry, 30, 492-503. doi: 10.1016/j.jilp.2007.09.010

Bandura, A. (1983). Psychological mechanism of aggression. In R. G. Geen, \& E. I. Donnerstein (Eds.), Aggression: Theoretical and empirical reviews (pp. 1-40). New York: Academic Press.

Becker, H. S. (1963). Outsider: Studies in the sociology of deviance. New York: The Free Press.

Belsky, J. (2005). Differential susceptibility to rearing influence: An evolutionary hypothesis and some evidence. In B. Ellis \& D. Bjorklund (Eds.), Origins of the social mind: Evolutionary psychology and child development (pp. 139-163). New York: Guilford.

Bennett, J. C. (1991). The irrationality of the catharsis theory of aggression as justification for educators' support of interscholastic football. Perceptual and Motor Skills, 72, 415-418. doi: https://doi.org/10.2466/pms.1991.72.2.415

Berkowitz, L. (1989). Frustration-aggression hypothesis: examination and reformulation. Psychological Bulletin, 106, 59-73.

Bjørkly, S. (2006). Empirical evidence of a relationship between insight and risk of violence in the mentally ill - A review of the literature. Aggression and Violent Behavior, 11, 414-423. doi: 10.1016/j.avb.2006.01. 006

Blair, R. J. R. (2012). Considering anger from a cognitive neuroscience perspective. Wiley Interdisciplinary Reviews: Cognitive Science, 3, 65-74. doi: 10.1002/wcs.154

Boubela, R. N., Kalcher, K., Huf, W., Seidel, E. M., Derntl, B., Pezawas, L., Našel, C., \& Moser, E. (2015). fMRI measurements of amygdala activation are confounded by stimulus correlated signal fluctuation in nearby veins draining distant brain regions. Scientific Reports, 5. Article number: 10499. doi: 10.1038/srep10499

Browne, K. D., Beech, A. R., Craig, L. R., \& Chou, S. (2017). Assessments in forensic practice: a handbook. Chichester, West Sussex: Wiley-Blackwell.

Bushman, B. J. (2002). Does Venting Anger Feed or Extinguish the Flame? Catharsis, Rumination, Distraction, Anger, and Aggressive Responding. Personality and Social Psychology Bulletin, 28, 724-731. doi: 10.1177/0146167202289002

Bullock, J. S. (2010). The relation between anger rumination, provocation, and aggressive behavior. Tallahassee, Florida: Florida State University. http://diginole.lib.fsu.edu/islandora/object/fsu:176369/datastream/PDF/view

Chan, H. C., \& Chui, W. H. (2012). Psychological correlates of violent and non-violent Hong Kong juvenile probationers. Behavioral Sciences \& the Law, 30, 103-120. doi: 10.1002/bsl.2003

Cima, M., \& Raine, A. (2009). Distinct characteristics of psychopathy relate to different subtypes of aggression. Personality and Individual Differences, 47, 835-840. doi: 10.1016/j.paid.2009.06.031

Connor, D. F. (2002). Aggression and Antisocial Behavior in Children and Adolescents. New York: The Guilford Press. 
Cooney, R. E., Joormann, J., Eugene, F., Dennis, E. L., \& Gotlib, I. H. (2010). Neural correlates of rumination in depression. Cognitive, Affective, \& Behavioral Neuroscience, 10, 470-478. doi: 10.3758/CABN.10.4.470

De Brito, S. A., Viding, E., Kumari, V., Blackwood, N., \& Hodgins, S. (2013). Cool and Hot Executive Function Impairments in Violent Offenders with Antisocial Personality Disorder with and without Psychopathy. PLOS ONE, 8, e65566. doi: 10.1371/journal.pone.0065566

Denny, K. G., \& Siemer, M. (2012). Trait aggression is related to anger-modulated deficits in response inhibition. Journal of Research in Personality, 46, 450-454. doi: 10.1016/j.jrp.2012.04.001

Denson, T. F., Pedersen, W. C., Friese, M., Hahm, A., \& Roberts, L. (2011). Understanding impulsive aggression: Angry rumination and reduced self-control capacity are mechanisms underlying the provocation-aggression relationship. Personality and Social Psychology Bulletin, 37, 850-862._doi: $10.1177 / 0146167211401420$

Dolan, M., \& Doyle, M. (2000). Violence risk prediction. The British Journal of Psychiatry, 177, 303-311. doi: 10.1192/bjp.177.4.303

Dougherty, D. M., Mathias, C. W., Marsh, D. M., \& Jagar, A. A. (2005). Laboratory Behavioral Measures of Impulsivity. Behavior Research Methods, 37, 82-90. doi: 10.4135/9781412952644

Douglas, K., S., Hart, S. D., Webster, C. D., Belfrage, H., Guy, L. S., \& Wilson, C. M. (2014). Historical-Clinical-Risk Management-20, Version 3 (HCR-20V3): Development and Overview, International Journal of Forensic Mental Health, 13, 93-108. doi: 10.1080/14999013.2014.906519

Eckhardt, C., \& Jamison, T. R. (2002). Articulated thoughts of male dating violence perpetrators during anger arousal. Cognitive Therapy and Research, 26, 289-308. doi: 10.1023/A:1016045226185

Elliot, R. (2013). Executive functions and their disorders. Imaging in clinical neuroscience. British Medical Bulletin, 65, 49-59. doi: 10.1093/bmb/65.1.49

Field, G. (1986). The psychological deficits and treatment needs of chronic criminality. Federal Probation, 50, 60-66.

Freud, S. (1955). Beyond the pleasure principle. (J. Strachey, Trans.). London: Hogaths Press (Original work published in 1920).

García-Forero, C., Gallardo-Pujol, D., Maydeu-Olivares, A., \& Andrés-Pueyo, A. (2009). Disentangling impulsiveness, aggressiveness and impulsive aggression: an empirical approach using self-report measures. Psychiatry Research, 168, 40-49. doi: 10.1016/j.psychres.2008.04.002

Gentile, D. A. (2013). Catharsis and media violence: A conceptual analysis. Societies, 3, 491-510. doi:10.3390/soc3040491

Harris, P. B., Boccaccini, M. T., \& Rice, A. K. (2017). Field measures of psychopathy and sexual deviance as predictors of recidivism among sexual offenders. Psychological Assessment, 29, 639- 651. doi: 10.1037/pas0000394.

Hawkins, K. A., \& Trobst, K. K. (2000). Frontal lobe dysfunction and aggression: conceptual issues and research findings, Aggression and Violent Behaviour, 5, 147-157. doi: 10.1016/S1359-1789(98)00033-0

Lejuez, C. W., Read, J. P., Kahler, C. W., Richards, J. B., Ramsey, S. E., Stuart, G. L., Strong, D. R., \& Brown, R. A. (2002). Evaluation of a behavioral measure of risk taking: The Balloon Analogue Risk Task (BART). Journal of Experimental Psychology, 8, 75-84. doi: 10.1037//1076-898X.8.2.75 
Leslie, C. (2008, April 11). Boxing is the best way to stop violence in kids. The Guardian. https://www.theguardian.com/ politics/blog/2008/apr/14/boxingisthebestwaytostopScheff, T. J. (2001). Catharsis in healing, ritual, and drama. Lincoln, NE: iUniverse.com.

Lievaart, M., Huijding, J., van der Veen, F. M., Hovens, J. E., \& Franken, I. H. (2017). The impact of angry rumination on anger-primed cognitive control. Journal of Behavior Therapy and Experimental Psychiatry, 54, 135-142. doi: 10.1016/j.jbtep.2016.07.016

Lobbestael, J., Cousijn, J., Brugman, S., \& Wiers, R. W. (2016). Approach and avoidance towards aggressive stimuli and its relation to reactive and proactive aggression. Psychiatry Research, 240, 196-201. doi: 10.1016/j.psychres.2016.04.038

Lorenz, K. (1974). On aggression. New York: Harcourt Brace Jovanovich.

Lynam, D. R., \& Miller, J. D. (2004). Personality pathways to impulsive behavior and their relations to deviance: Results from three samples. Journal of Quantitative Criminology, 20, 319-341. doi: 10.1007/s10940-004-5867-0

Patton, J. H., Stanford, M. S., \& Barratt, E. S. (1995). Factor structure of the Barratt Impulsiveness Scale. Journal of Clinical Psychology, 51, 768-774. doi: 10.1002/1097-4679(199511)

Raine, A. (2002). The biological basis of crime. In J. Q. Wilson and J. Petrsilia (Eds.), Crime: Public policies for crime control (pp. 43- 74). Oakland, California: ICS Press.

Raine, A., Dodge, K., Loeber, R., Gatzke-Kopp, L., Lynam, D., Reynolds, C., Stouthamer-Loeber, M., \& Liu, J. (2006). The Reactive-Proactive Aggression Questionnaire: Differential correlates of reactive and proactive aggression in adolescent boys. Aggressive Behavior, 32, 159-171. doi: 10.1002/ab.20115

Rachlin, H. (1974). Self-control. Behaviorism, 4, 64-107.

Ramírez, J. M., Millana, L., Toldos-Romero, M. P., Bonniot-Cabanac, M.-C., \& Cabanac, M. (2009). The pleasure of being aggressive in incarcerated criminals. The Open Criminology Journal, 2, 1-9. doi: 10.2174/1874917800902010001

Reynolds, B., Richards, J. B., \& de Wit, H. (2006). Acute-alcohol effects on the Experiential Discounting Task (EDT) and a question-based measure of delay discounting. Pharmacology, Biochemistry and Behavior, 83, 194-202. doi: 10.1016/j.pbb.2006.01.007

Roesch, R. \& Cook, A. N. (2017). Handbook of Forensic Mental Health Services. New York: Taylor \& Francis Ltd.

Séguin, J. R. (2013). The frontal lobe and aggression. European Journal of Developmental Psychology, 6, 100-119. doi: 10.1080/17405620701669871

Siever, L. J. (2008). Neurobiology of Aggression and Violence. American Journal of Psychiatry, 165 , 429-442. doi: 10.1176/appi.ajp.2008.07111774

Smith, P., \& Waterman, M. (2003.) Processing bias for aggression words in forensic and non-forensic samples. Cognition and Emotion, 17, 681-701. doi: 10.1080/02699930302281

Sutherland, E. H. (1939). Principles of criminology, 3rd Ed., Philadelphia: J.B. Lippincott.

Swann, A. C. \& Hollander, E. (2002). Impulsivity and Aggression: Diagnostic Challenges for the Clinician. A Monograph for Continuing Medical Education Credit. Illinois: ACCESS Medical Group.

Tedeschi, J. T., \& Felson, R. B. (1994.). Violence, Aggression, \& Coercive Actions. Washington: APA. 
Tiihonen, J., Rautiainen, M. R., Ollila, H. M., Repo-Tiihonen, E., Virkkunen, M., Palotie, A., ... \& Saarela, J. (2015). Genetic background of extreme violent behavior. Molecular Psychiatry, 20, 786-792. doi: 10.1038/mp.2014.130 Tomkins, S. S. (1954). Script theory: Differential magnification of affects. Fourteenth International Congress of Psychology. Montreal: Canada.

Vasquez, E. A., Bartsch, V. O., Pedersen, W. C., \& Miller, N. (2007). The impact of aggressive priming, rumination, and frustration on prison sentencing. Aggressive Behavior, 33, 477-485. doi: 10.1002/ab.20203

Wagner, D. D., Altman, M., Boswell, R. G., Kelley, W. M., \& Heatherton, T. F. (2013). Self-regulatory depletion enhances neural responses to rewards and impairs top-down control. Psychological Science, 24, 2262-2271. doi: 10.1177/0956797613492985

Wener, R. E. (2012). The Psychology of Isolation in Prison Settings. In The Environmental Psychology of Prisons and Jails: Creating Humane Spaces in Secure Settings (Environment and Behavior). Cambridge: Cambridge University Press. doi:10.1017/CBO9780511979682.012

Wesselius, J. (2013). Het Penitentiair Psychiatrisch Centrum: een volwaardige psychiatrische kliniek in de gevangenis? [The Penitentiary Psychiatric Centre: a full-fledged psychiatric clinic within the prison? ]. Ontmoetingen: Voordrachtenreeks van het Lutje Psychiatrisch-Juridisch Gezelschap, 17, 9-20.

Wilson, L. C., \& Scarpa, A. (2011). The link between sensation seeking and aggression: a meta-analytic review. Aggressive Behavior, 37, 81-90. doi: 10.1002/ab.20369.

Zillmann, D. (1983). Arousal and aggression. In R. G. Geen \& E. I. Donnerstein (Eds.), Aggression: Theoretical and empirical reviews (pp. 75-102). New York: Academic Press.

Zuckerman, M. Kolin, E. A., Price, L., \& Zoos, I. (1964). Development of a Sensation-Seeking Scale. Journal of Consulting Psychology, 28, 477-482. doi: 10.1037/h0040995 


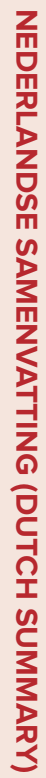




\section{Dankwoord (Acknowedgements)}

Allereerst dank ik graag mijn promotoren, mijn grote voorbeelden, Arnoud en Maaike. Bedankt dat jullie me de mogelijkheid en het vertrouwen hebben gegeven om dit promotieonderzoek te doen. Arnoud, ik heb veel geleerd van je, niet enkel over de technische en methodologische aspecten van de studies, of het duidelijker, meer concreet schrijven, maar vooral ook het overzien van het grotere geheel; het overtuigen dat de data wel van meerwaarde is op momenten van demotivatie. Maar ook, dank voor het behoud van de rust bij mijn ongeduld.

Maaike, dank voor het zijn van mijn steun en toeverlaat, mijn dagelijks begeleider in dit traject. Je intelligente, creativiteit, energie en passie werken zeer aanstekelijk. Dank, voor antwoord op alle vragen dat je steeds had. Dank ik je elke keer voor alles heb kunnen benaderen, niet eens enkel de wetenschappelijke vragen. Als ik tijdens congressen aanschoof bij je lezingen weet je me steeds het voorbeeld te geven, de maatstaf waar ik naartoe werk. Je onophoudelijk enthousiaste houding heeft me enorm geholpen in dit promotieonderzoek.

Dank aan Prof. dr. M. Jelicic, Prof. dr. P. van Koppen Dr. J. Lobbestael, Prof. dr. H. Nijman en Dr. S. Verwaaijen voor de bereidwilligheid om dit proefschrift te beoordelen.

Dank aan alle patiënten en alle medewerkers FPC de Rooyse Wissel en PPC Overmaze, meer specifiek alle patiënten die me het vertrouwen hebben gegeven en deel hebben genomen aan een van de onderzoeken. Ik dank de (oud)collegae van het stafbureau voor de gezellige, prettige samenwerking en de mogelijkheid tot sparring op lastige momenten. Sanne, dank voor het vertrouwen dat je me vaker dan enkel in dit promotieonderzoek gegeven hebt. Farid, dank voor je humor, programmeerkennis en prettige gesprekken als reflectie op werken in justitieland, de tbs. Ik heb je als een mentor beschouwd en veel van je geleerd, ook in houding en mentaliteit.

Graag dank ik Nadja Lemeer, Maudy Diependaal, Sanne Bongers, Nadine van der ploeg, Anne Douven, Simone Delorme, Jolien van Gorkum, Carolien Severens, Niels Doorn, Daan Pepping, Davy Saarloos, Jorg Melis, Noëlle Vandenbooren, Nina Nita, Vera Meesters, Malgosia van Hoepen voor de prettige samenwerking de afgelopen jaren in scriptie of onderzoeksbegeleiding. Ik hoop aan jullie ook een beetje de passie voor het onderzoek te hebben overgedragen.

Nicolette dank voor je hulp in de fMRI studies als inhoudelijk, dank!

Linda, als iemand me heeft geleerd dat schrijven schrappen is, ben jij dat wel. Wat heb ik veel van je geleerd! Je bent mijn steun en toeverlaat op fMRI gebied. Dank voor alle hulp en kritische reflectie (met resultaat :)). Maar inmiddels mogelijk nog wel meer bedankt voor het zijn van een steun en toeverlaat, een goede, lieve vriendin. Ik zie uit naar nog vele 
bijklets-momenten, diner dates en dagjes weg. Dank ook voor je hulp straks in de ceremonie als paranimf.

Angelique, dank voor de melige avonden, het eeuwige geduld met me en vooral de gezelligheid en afleiding. Dank aan Veerle voor het zijn van mijn lieve tegenpool, dank aan Nel, Bram, Nicole, Mario, Christje en Nicole, Vera en Bartel, hoorngroep van de KHT, Kim, voor de vriendschap en steun.

Dank aan alle PHI collegae voor het bieden van een goede motivatie om de dissertatie af te ronden: een fijne werkplek in een topteam. Ook dank aan de fractie, Bert, Richard, Claudia, Ingrid, Harald, Johan, Paul, Guido, Manon, Richard S. en ook net zo Joëlle en Liedewij, voor het bieden van een goed tegenwicht aan dit promotiewerk.

Dank aan de warme familie, de familie Tonnaer, Hoenen, Eurlings en Prevoo. Alles is relatief behalve familie en met jullie als familie is dat een groot, royaal en warm bad.

Marie-José dank dat je mijn peettante bent, de coolste, meligste, gezelligste tante die er is. Dank voor de de vele melige avonden bijv. tijdens de tienertour aan de keukentafel of in de tuin, wat was dat genieten! Dank voor voor het opofferen van je huis voor Linda en mij in een volle week van afzondering om meters te kunnen maken met beide proefschriften. Je ziet, het duurde hier nog wel even, maar heeft wel veel opgeleverd: de publicatie in Nature is in jouw appartement 'geboren'.

Léon Hoenen, Kuf, meest creatieve, humorvolle, gevoelige en gezelligste oom die er is. Ik kijk met veeeeeel genot terug op de gezellige, heerlijke diner dates ook met vriendinnen bij Han en jou, Josse en Joris. De ovenschotel die ik met Sacha bij jullie in het appartement in Roermond heb gegeten, zo lekker heb ik nooit meer gegeten en daarna volgden vele verwoede pogingen tot eigen creaties van die overschotel. Dank voor je hulp in het delen van de meest belangrijkste levensmomenten; bij het maken van gepersonaliseerde trouwkaarten, de geboortekaartjes van onze kinderen en nu dit proefschrift.

Marloes en Roel, Monique en Frans, Aline en Wouter, Alice en Jeroen, Stephanie en Léon dank dat jullie er zijn. Marloes voor je warme moederhart, ook voor onze kinderen $<3$, Frans voor je 'Friese humor, droger dan de Engelse humor', Aline voor je relativerings-vermogen en je recht-toe-recht aan mentaliteit waar ik van houd, Léon voor je creativiteit, je laat me nog dagelijks leren. Alice, voor de morele ondersteuning, de gedeelde passie, het kunnen sparren en spuien van frustraties en net zo veel geluk samen. Dank ook voor je hulp straks in de ceremonie als paranimf.

Mam en pap, dank voor de warmte in het gezellig grote thuis. Mam, dank dat je er altijd voor me bent en me in alles begrijpt. Pap, mijn academische voorbeeld, ik ben trots als me wordt gevraagd of ik 'de dochter van' ben.

Lei, leeve, mijn alles, zonder jou ben ik niks. Dank dat je er altijd bent. Cleo en Joshua, dank voor jullie knuffels, er is niets dat me meer energie geeft dan dat. 


\section{Curriculum vitae \& Publications}

\section{About the author}

Franca Tonnaer was born on February 4th, 1980 in Limbricht, the Netherlands. In 2000, she completed secondary education at the Koninklijk Technisch Atheneum in Maaseik, Belgium. In 2001 she completed propaedeutic at the Pedagogical Academy, Zuyd Hogeschool. Then, she started studying Psychology at the University of Maastricht (UM). During her study, she combined various courses from the Faculty of Psychology, the Faculty of Law, and the Faculty of Medicine. As a student, she was selected for an Innocent Project at the The Maastricht Forensic Institute (TMFI) reporting on possible errors in criminal law cases. She graduated in 2006 and received her master's degree in Forensic Psychology.

After graduation, she worked as a research assistant of Maaike Cima at the University of Maastricht. Meanwhile, she started working as a junior researcher at Forensic Psychiatric Centre 'de Rooyse Wissel' (FPC dRW). Clinically, she provided risk assessment training and she was a member of the advice board deciding on leave of absence of individual patients. In 2009, her PhD proposal was accepted by the UM's research institute of Experimental Psychopathology ('EPP') and co-funded by FPC dRW. She is a member of the International Society for Research on Impulsivity (ISRI). During her PhD, (in 2014) she was assigned as a transitory project manager 'care and treatment', responsible for the transition of national policy and performance indicators to multidisciplinary policy and practical output performance. This position made her realize that management opportunities focusing on transitions and effective practice is what she does best and gives her energy and satisfaction. Since December 2017 she is a regional manager at Premium Healthcare Interventions BV (PHI BV), a specialized GGZ mental healthcare provider for depression, anxiety disorder, somatic symptom disorder, and stressor-related disorder. Moreover, since 2010 she is a member of the City Council of Maastricht. 


\section{Publications}

Siep, N.', Tonnaer, F., Ven, V., van de, Arntz, A., Raine, A., \& Cima, M. (2018). Anger provocation increases limbic and decreases medial prefrontal cortex connectivity with the left amygdala in reactive aggressive violent offenders. Brain Imaging and Behavior, doi: 10.1007/s11682-018-9945-6

Tonnaer, F., Siep, N., van Zutphen, L., Arntz, A. \& Cima, M. (2017). Anger provocation in violent offenders leads to emotion dysregulation. Nature Scientific Reports, 7, 3583. doi: 10.1038/s41598-017-03870-y

Tonnaer, F., Cima, M., \& Arntz, A. (2016). Modeling Impulsivity in Forensic Patients: A Three-Dimensional Model of Impulsivity. American Journal of Psychology, 129, 429-441. doi: 10.5406/amerjpsyc.129.4.0429.pdf

Tonnaer, F., Cima, M., \& Arntz, A. (2016). Aggression. In M. Cima (Eds.), The Handbook of Forensic Psychopathology and Treatment (pp. 270 - 312). London: Routledge Mental Health.

Tonnaer, F., Cima, M., \& Arntz, A. (2016). Executive (dys)functioning and impulsivity as possible vulnerability factors for aggression in forensic patients. Journal of Mental and Nervous Disease, 204, 280-286. doi: 10.1097/NMD.0000000000000485

Tonnaer, F., Chakhssi, F., \& Verwaaijen, S., (2015). Recidive tijdens en na behandeling in FPC de Rooyse Wissel. Een terugblik op 10 jaren behandeling. FPC De Rooyse Wissel: Venray. https://www.derooysewissel.nl/media/23124/DRW_Onderzoek-2-DEF-LR-LOS.pdf

Tonnaer, F., Cima, M., Sijtsma, K., Uzieblo, K., \& Lilienfeld, S. O. (2013). Screening for Psychopathy: Validation of the Psychopathic Personality Inventory-Short Form with Reference Scores, Journal of Psychopathology and Behavioral Assessment, 35, 153-161. doi: 10.1007/s10862-012-9333-2

Cima, M., Tonnaer, F., \& Hauser, M., (2010). Psychopaths know right from wrong, but they just don't care. Social Cognitive and Affective Neuroscience, 4, 1-9. doi: 10.1093/scan/nsp051

Hauser, M., Tonnaer, F., \& Cima, M. (2009). When moral intuitions are immune to the law: a case study of euthanasia and the act-omission distinction in The Netherlands. Journal of Cognition and Culture, 9, 149-169. doi: 10.1163/156770909X12489459066147

Cima M., Tonnaer, F., \& Lobbestael, J. (2007). Moral emotion in reactive and proactive offenders using implicit measures. Netherlands Journal of Psychology, 4, 144-155. doi: 10.1007/BF03061076

Submitted

Tonnaer, F., Cima, M. \& Arntz, A. (2018). Explosive matters: does venting anger reduce or increase aggression? Differences in anger venting effects in violent offenders. 


\section{Presentations}

Tonnaer, F. (2018). Bestaat het agressieve brein? Pleasure, Art \& Science Festival (PAS Festival). Universiteit Maastricht, Studium Generale: Maastricht.

Tonnaer, F. (2016). Het emotionele brein: bestaat het? Symposium 'Agressie (be)handelbaar?', 15-jarig jubileum FPC De Rooyse Wissel: Venray. Utrecht.

Tonnaer, F., Cima, M., \& Arntz, A. (2016). De neurobiologie van het emotionele brein. Festival Forensiche Zorg: Utrecht.

De Boer, M., Van der Stoep, T. Tonnaer, F. (2016). De Lerende Praktijk in actie. Festival Forensiche Zorg: Utrecht.

Tonnaer, F., Van Zutphen, L., Cima, M., Arntz, A., \& Siep., N. (2015). Control or outburst: the neurobiological correlates of anger provocation vs distraction. InSRI: Amsterdam.

Tonnaer, F., de Boer, M., Diependaal, M., Verwaaijen, S. \& Cima, M. (2015). Forensic Recidivism Monitored: Lessons learned. SVA: Maastricht.

Tonnaer, F., Cima, M., \& Arntz, A. (2015). Anger control or outbreak: the neurobiological correlates of anger provocation. XXXIVth IALMH Conference: Vienna.

Tonnaer, F., Cima, M., \& Arntz, A. (2015). Bestaat het agressieve brein? Functionele hersenactiviteit tijdens agressie provocatie bij forensische patiënten met agressie problemen. Festival Forensische Zorg: Utrecht.

Tonnaer, F., \& Cima, M. (2013). The neurocognitive correlates of reactive aggression; what does the brain tell us? 13th IAFMHS conference: Maastricht.

Tonnaer, F., Cima, M., \& Arntz, A. (2013).The neurocognitive correlates of reactive aggression; what does the brain tell us? XXXIIIrd IALMH Conference: Amsterdam.

Tonnaer, F., Cima, M., \& Arntz, A. (2012). On the search for predictors for impulsive aggression.10th Dutch Endo-Neuro-Psycho Meeting: Lunteren.

Tonnaer, F. (2011). Impulsivity as a crucial target factor for interventions in drug treatment? Modelling impulsivity and its relation to risk. NIP Sectie verslavingszorg conferentie tussen kennis en coping: Utrecht.

Tonnaer, F. (2011). Heb jij een kort Lontje? De psychologie van agressie. Jongeren Netwerk Limburg Conferentie Geweld: Roermond.

Tonnaer, F., Cima, M., \& Arntz, A. (2011). Explosive Matters. Aggression induction: what works. 4th Biennial Meeting of the Scientific Study of Psychopathy: Montreal.

Tonnaer, F., Cima, M., Doorn, N., Pepping, D. (2009). Explosive Matters. Aggression \& Executive Functioning. 19th European Association of Psychology and Law conference: Sorrento, Italy.

Tonnaer, F. \& Chakhssi, F. (2007). Incident profiling on patients characteristics. 5th EU-Violence in Clinical Psychiatry: Amsterdam. 


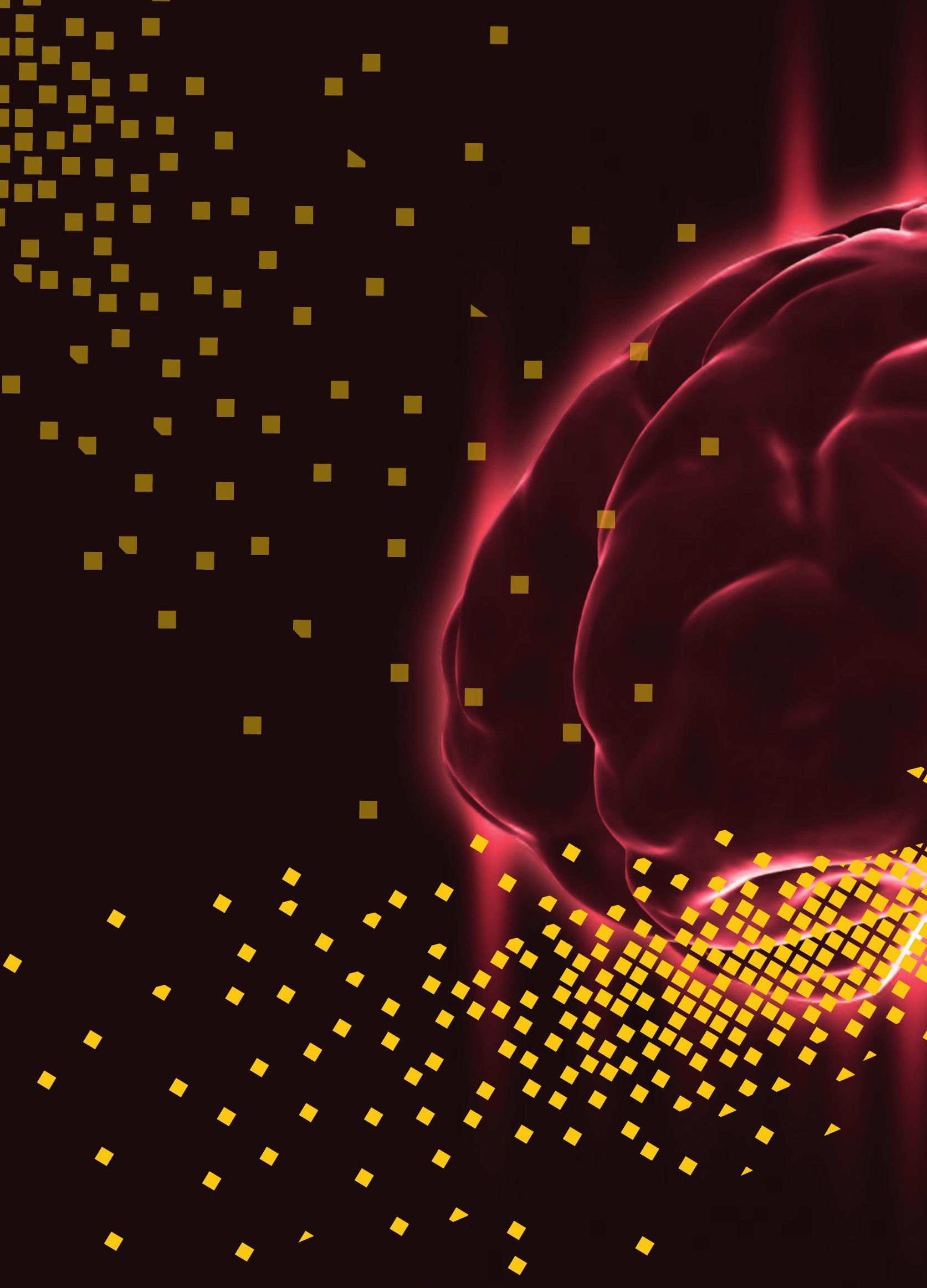

